\title{
The Scientific Way of Warfare: Order and Chaos on the Battlefields of Modernity
}

Antoine James Aimé Bousquet

Thesis submitted in fulfilment of the requirements of the PhD London School of Economics and Political Science 
UMI Number: U615652

All rights reserved

\section{INFORMATION TO ALL USERS}

The quality of this reproduction is dependent upon the quality of the copy submitted.

In the unlikely event that the author did not send a complete manuscript and there are missing pages, these will be noted. Also, if material had to be removed, a note will indicate the deletion.

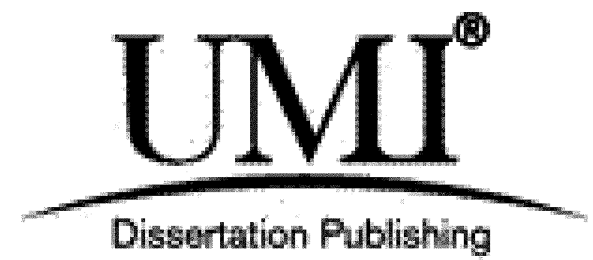

UMI U615652

Published by ProQuest LLC 2014. Copyright in the Dissertation held by the Author.

Microform Edition (c) ProQuest LLC.

All rights reserved. This work is protected against unauthorized copying under Title 17, United States Code.

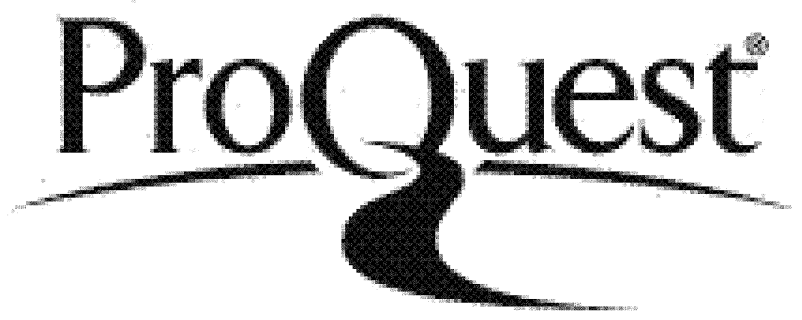

ProQuest LLC

789 East Eisenhower Parkway

P.O. Box 1346

Ann Arbor, MI 48106-1346 
I, Antoine James Aimé Bousquet, declare that the work presented in this thesis is my own.

A.ft 
Library

$$
\begin{gathered}
\text { THESES } \\
\text { F } \\
8693
\end{gathered}
$$




\begin{abstract}
The thesis of the present work is that throughout the modern era the dominant corpus of scientific ideas, as articulated around key machine technologies, has been reflected in the contemporary theories and practices of warfare in the Western world. Over the period covered by this thesis - from the ascendancy of the scientific worldview in the seventeenth and eighteenth centuries to present day - an ever more intimate symbiosis between science and warfare has established itself with the increasing reliance on the development and integration of technology within complex social assemblages of war. This extensive deployment of scientific ideas and methodologies in the military realm allows us to speak of the constitution and perpetuation of a scientific way of warfare. There are however within the scientific way of warfare significant variations in the theories and practices of warfare according to the prevalence of certain scientific ideas and technological apparatuses in given periods of the modern era. The four distinctive regimes I thereupon distinguish are those of mechanistic, thermodynamic, cybernetic, and chaoplexic warfare. Each of these regimes is characterised by a differing approach to the central question of order and chaos in war, on which hinge the related issues of centralisation and decentralisation, predictability and control.
\end{abstract}




\section{Table of Contents}

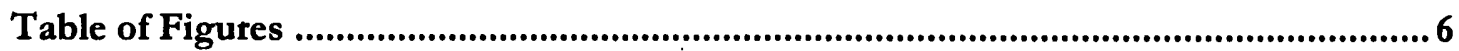

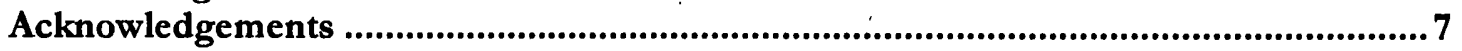

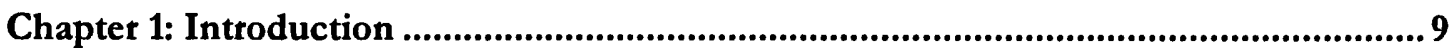

Locating the Thesis within the Historical Literature on War.............................................. 10

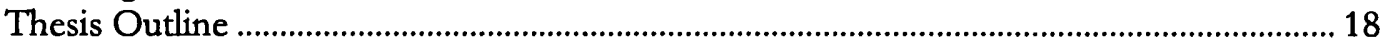

Chapter 2: Technoscientific Regimes of Order in Warfare - A

Theoretical and Methodological Framework ............................................................................ 22

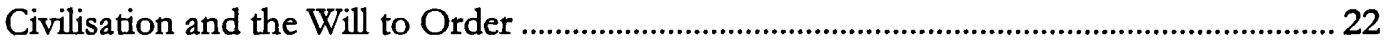

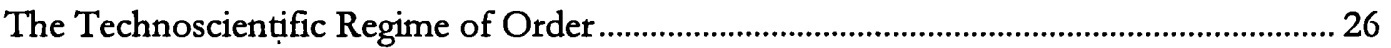

Of Discourse and Polymorphous Correlations: Science and Culture..................................... 31

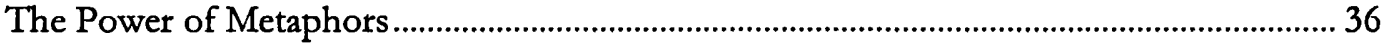

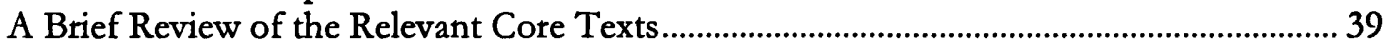

The Four Regimes of the Scientific Way of Warfare.............................................................. 43

Chapter 3: Mechanistic Warfare and the Clockwork Universe ..................................... 49

From Mechanical Clocks and Automata to Clockwork Metaphor......................................... 49

The Clockwork Universe: the Ascendancy of the Mechanistic Worldview..........................52

The Clockwork Heavens: Newtonian Mechanics and the Clockmaker God ........................ 54

The Clockwork Body and Soul: Descartes, La Mettrie and Mechanistic Physiology .......... 58

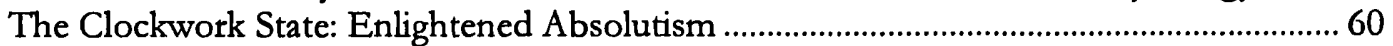

Mechanistic Warfare: Frederick the Great's Clockwork Army ................................................. 63

Chapter 4: Thermodynamic Warfare and the Science of Energy ................................... 72

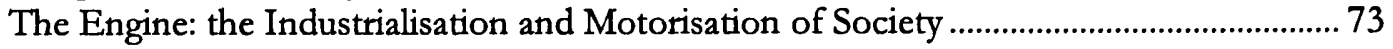

Thermodynamics: the Universe as a Heat Engine ................................................................... 75

The Human Engine: Thermodynamic Bodies and Minds ....................................................... 79

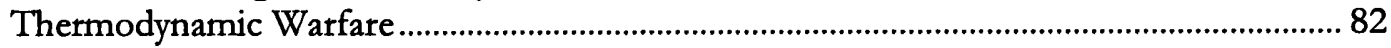

Clausewitz 'Translates' Thermodynamics ........................................................................... 90

Chapter 5: Cybernetics and the Genesis of the Computer.............................................. 96

Electromagnetic Telecommunications and War …………………………………................. 96

The Computer - Genesis and Embodiment of the Abstract Machine................................. 99

Bits and Negentropy: Information Becomes Physical........................................................... 105

Cybernetics: the Science of Control and Communications ................................................... 109

Cybernetic Organisms: From Computerised Brains to Biological Computers.....................113

Social Cybernetics ....................................................................................................................... 117

Chapter 6: Cybernetic Warfare: Computers at War...........................................................121

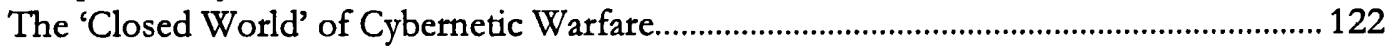

From Command to Command-and-Control ..........................................................................128

Operations Research and Systems Analysis: Solving the War Equation .............................. 136

Vietnam and the Failure of Cybernetic Warfare.................................................................... 150 
Chapter 7: A New Informational Paradigm: Chaos Theory and

Complexity Science .........................................................................................................15

The Rediscovery of Non-Linearity: Chaos Theory and Positive Feedback .........................160

Complexity and Networks of Life at the Edge-of-Chaos ...................................................... 169

Chapter 8: Towards Chaoplexic Warfare? Network-Centric Warfare and the Non-Linear Sciences

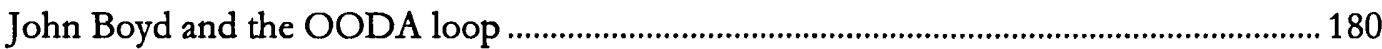

Uncertainty in War: the Non-Linear Clausewitz and the Future of Military

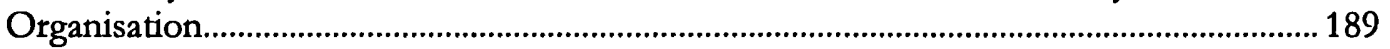

The Age of the Network..................................................................................................... 195

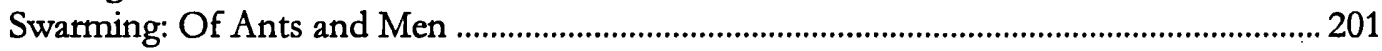

Complexity Goes To War? The Rise of Network-Centric Warfare ..................................... 206

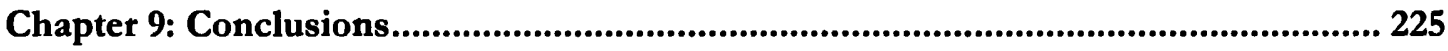

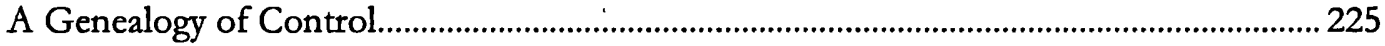

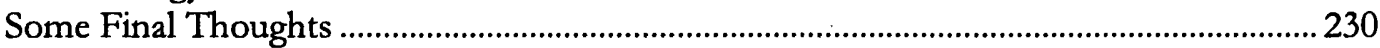

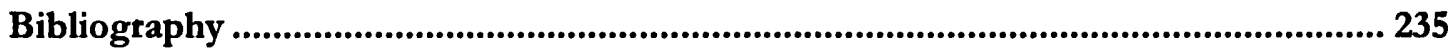




\section{Table of Figures}

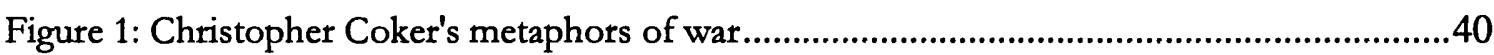

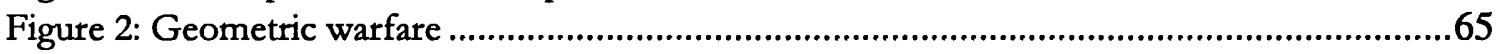

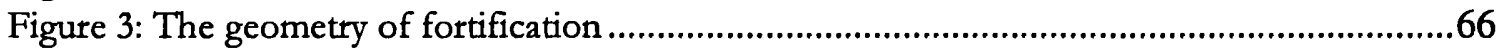

Figure 4: Diagram of the von Neumann architecture ............................................................102

Figure 5: Schematic diagram of an abstract communication machine.......................................107

Figure 6: Information feedback loop in a cybernetic system...................................................111

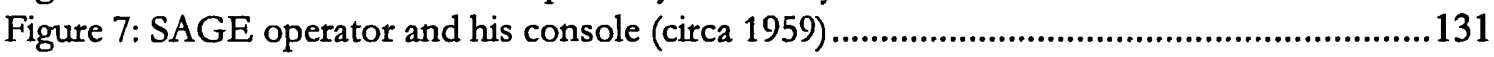

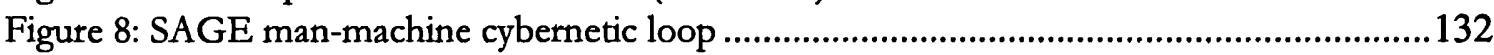

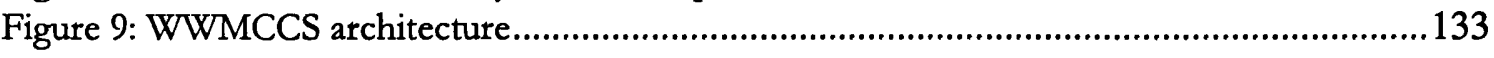

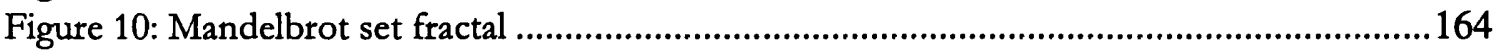

Figure 11: Self-similarity in a Mandelbrot set fractal................................................................165

Figure 12: Phase space diagram of a pendulum running down .................................................167

Figure 13: Phase space diagram of a Lorenz attractor ................................................................168

Figure 14: Bifurcation diagram of a non-linear system .............................................................172

Figure 15: Complexity is highest in between the poles of order and disorder ............................174

Figure 16: John Boyd's OODA 'loop'.........................................................................................181

Figure 17: Gell-Mann's diagram of the functional organisation of complex adaptive systems...185

Figure 18: From information to emergence ........................................................................213

Figure 19: The Information Awareness Office logo ................................................................222 


\section{Acknowledgements}

I am forever indebted to my supervisor Christopher Coker, without whom this $\mathrm{PhD}$ would certainly have never been written. I do not only want to thank him for initially agreeing to take me on as a supervisee when I first solicited him about it, for unfailingly offering stimulating and insightful comments, ideas, and readings to help me along the long and tortuous path of the $\mathrm{PhD}$, and for always keeping faith in me even when he was uncertain about the direction my work was taking, although for all of this I am eternally grateful. Indeed, I also owe him for having first opened my eyes to what the study of international relations could be when I attended his MSc course back in 19992000 and his work has been a constant inspiration to me. In many ways, the intellectual journey I have made all the way to the present conclusion of this thesis began back then.

I would also like to thank the research students at the LSE who have all contributed to making up a vibrant community in which to exchange ideas and advice or simply offer a break from the lonely labours of the $\mathrm{PhD}$ candidate. Many of the people I have met here I now count as friends and I look forward to crossing their paths again in the future. Any attempt at listing all the colleagues that have counted is a task that can only fail to be exhaustive but I would nevertheless like to particularly thank the following for having helped make the last four years such a fulfilling and enjoyable time: Andreas Antoniades, Felix Berenskoetter, Annika Bolten, Douglas Bulloch, Stephanie Carvin, Simon Curtis, Georgios Evangelopoulos, John Heathershaw, Rune Henriksen, Robert Kissack, Marjo Koivisto, Simona Manea, Serena Sharma, Colin Steinbach, Jill Stuart, Marco Vieira, and Bill Vlceck.

Special thanks are due to Neil Wells who generously gave a lot of his time to read my thesis and provide feedback and suggestions regarding my interpretation and presentation of scientific theories. Any errors contained in the present piece naturally remain entirely my own.

Finally, and most importantly, I cannot express sufficient gratitude to my parents for their unstinting love and support, both throughout my $\mathrm{PhD}$ and the rest of my life, and 
without whom none of this would have been possible. I owe them everything and it is to them that I dedicate this thesis.

AJA Bousquet, April 2007 


\title{
Chapter 1: Introduction
}

\author{
Every age bad its own kind of war, its own limiting conditions, and its \\ own peculiar preconceptions. Each period, therefore, would bave beld to \\ its own theory of war, even if the urge bad always and universally existed \\ to work things out on scientific principles. \\ Carl von Clausewitz
}

War and the threat of war have been one of the most persistent features of human societies and show little sign of setting beyond the horizon of historical experience. However, notwithstanding the endurance of the general phenomenon of war, its multiple manifestations have been shaped by the material and ideational conditions of the societies and cultures that have waged it. As we are told by Clausewitz in the above quote, every age grapples with the conduct of warfare in its own way, specific to its historical conditions and cultural baggage. Even if war's nature is invariant, as also claimed by Clausewitz, its character and form do change throughout the ages. It therefore behoves the study of war to uncover the multiple connections that bind the theory and conduct of warfare to the particular epoch and society to which they are contemporary.

The present thesis seeks to contribute to this undertaking through an enquiry into the interrelationship of Western science and warfare from the beginning of the modern era to present day. Its central claim is that these two fields of social and cultural activity criss-cross one another, their multiple points of contact and mediation particularly interwoven by the accelerated proliferation and diffusion of technology that has characterised this historical period. Science has at numerous points of juncture seen itself oriented and driven by the particular technological and operational problems raised by modern war - the Manhattan Project is only the most visible and notorious of these instances. Conversely, scientific theories and methods have been brought to bear upon the entire spectrum of warfare for the purpose of bringing greater certainty and

${ }^{1}$ Carl von Clausewitz, On War, translation by Michael Howard and Peter Paret (Princeton, NJ: Princeton University Press, 1984), p.593 
predictability to its conduct. I therefore wish to propose that we may speak of a scientific way of warfare as a set of ideas and practices, or discourse, which has gained ascendancy as a dominant approach to warfare in the Western world. While there is continuity in the appeal to technoscientific rationality, I will nonetheless distinguish between several distinct regimes of the scientific way of warfare. Each of these regimes is characterised by key ideas and practices which reflect the major evolutions in scientific worldview and technological development.

Although the thesis will draw from a wide range of sources and writings, in the final instance it is concerned with the phenomenon of war understood as acts of organised violence perpetuated by political units against each other. Its aim, in the broadest sense, is to shed light on the practice of warfare at it has developed in the Western world throughout the modern era, focusing on its scientific and technological dimensions. Therefore the thesis will not approach the question of war in terms of its causes (either general or specific), its ethical or moral justification, or the body of laws and conventions which regulate its use. As such, it is probably best viewed as part of the academic literature on the history of war, even if its approach is more theoretical than most writings in the field and the latter part of the thesis deals with present-day theory and practice (and thereby does not qualify as the history in the eyes of most professional historians). In any case, it is within this literature that I will attempt in the next few pages to locate the present work and draw out some of the crucial issues it will necessarily engage with. I will then set out the outline of the thesis according to the chapter structure along which it has been organised.

\section{Locating the Thesis within the Historical Literature on War}

War, Society, and Culture

It is unfortunate that a long-standing division of academic labour has resulted in military history and broader social history developing into distinct traditions that have all too often eschewed meaningful dialogue and potentially fruitful cross-pollination. Many strands of historical writing have thus tended to treat wars as essentially episodic bouts of organised violence interrupting the regular course of political and social life. 
Accordingly, while wars have been considered worthy of in-depth research as to their causes and their aftermath by historians of this disposition, the assumption that the conduct of wars is itself so different from ordinary social life has fuelled the notion that they have little to tell us about contemporary society as a whole. Conversely, military history has largely evolved as a distinct sphere of historical research distinct from that of the rest of the field, with a tendency among practitioners to focus on narrow areas of expertise, most frequently accounts of battles and developments on the front. All too often this literature has been reticent to engage or take on any of the findings in wider historiography and the social sciences. ${ }^{2} \mathrm{~A}$ large share of the written output has also been directed towards the lucrative but less academically rigorous popular history market, which has further devalued the field in the eyes of scholars in other fields. This prevailing compartmentalisation, although by no means absolute, has de facto constituted something of blind spot in historical research, but thankfully one that has been increasingly addressed in recent times.

This thesis rests on the conviction that the experience and practice of war has been one of the central features of the historical era spanning roughly the period from the seventeenth century to present day and commonly known as modernity. ${ }^{3}$ As such, war has influenced social and cultural developments beyond the narrow sphere of military activity per se while simultaneously being conditioned by the broader historical context in which it has been set. Dissatisfaction with the limitations of the dominant narrow approach of military history in illuminating this co-constitutive relationship has led in the past few decades to a strong growth in alternative forms of academic research into

\footnotetext{
2 Jeremy Black, Retbinking Military History (London: Routledge, 2004), p.xi

${ }^{3}$ I leave aside in this thesis any of the debates about the emergence of a new post-modern era. Much ink has been spilt over this, with authors seeking to capture a number of social, economic, and cultural changes with a plethora of different terms such as post-modernity (David Harvey, Frederic Jameson), 'late' or 'high' modemity (Anthony Giddens), 'second' or reflexive modernity (Ulrich Beck), and liquid modernity (Zygmunt Bauman). While this debate has yielded valuable insights into recent and on-going processes of societal transformation, this literature will not be directly addressed in this thesis and I will avoid adopting any of the above terminologies. Instead, I will rely on an understanding of modernity as a historical era characterised by the widespread application of technoscientific rationality to the organisation of society, and which in this sense has not been in any way overcome or superseded. The periodisation I establish within this era of modernity is therefore primarily based on evolutions in scientific theory and practice and the development of related technologies, rather than on other social, political, or cultural changes. I do not make the pretence here that my definition of modernity is any sense more proper or correct than many of the other alternatives that have been formulated, simply than it is most appropriate to the thesis I am arguing for.

David Harvey, The Condition of Postmodernity: An Enquiry into the Origins of Cultural Change (Oxford: Basil Blackwell, 1990); Frederic Jameson, Postmodermism or The Cultural Logic of Late Capitalism (London: Verso, 1991); Anthony Giddens, The Consequences of Modernity (Cambridge: Polity in association with Blackwell, 1990); Ulrich Beck, Risk Society: Towards a New Modernity (London: Sage Publications, 1992); Zygmunt Bauman, Liquid Modernity (Cambridge Polity, 2000).
} 
the history of warfare, drawing notably on concepts and preoccupations originating in the social sciences.

This development in scholarly research is partly due to significant changes in the character of war which have made the previous division of academic labour largely untenable. Indeed, distinguishing between states of war and peace has become increasingly difficult, particularly since World War II with the period of the Cold War which immediately followed and now. beyond into the present War on Terror. The intense technological and logistical requirements of modern war have demanded of states that they put themselves in a condition of permanent war readiness, able to launch offensives and respond to any aggression as swiftly as possible. ${ }^{4}$ Vast sectors of the economy, particularly in the United States but by no means exclusively, have become permanently directed towards maintaining and developing states' military capacities and readiness. ${ }^{5}$ This generalised blurring of war and peace has contributed to making increasingly evident that the study of war could be greatly enhanced by a more contextual form of historical investigation.

Thus the approach generally dubbed 'war and society' has developed a broader understanding of war, concerning itself with the personal experience and backgrounds of common soldiers, issues of gender, race, and memory, along with the relationships between war, state-building, social change, and the disciplining of bodies. ${ }^{6}$ Such work

\footnotetext{
${ }^{4}$ In effect, the principle of deterrence which structured the Cold War stalemate relied on the perpetual military mobilisation of societies on hair-trigger alert. Low-intensity violence by non-state actors such as guerrillas and terrorist groups has also served to lower the threshold of war and blur the line between policing and military operations in state responses to these actors.

5 This interconnection of industry and military is not so much a new phenomenon than an intensification of older trends. According to historian William McNeill, military-industrial complexes can be traced back to Great Britain in the late 19th century when a deliberate policy of driving technological innovation in the military and inducing firms to enter the armaments market was established. Similar military-industrial formations soon followed in France, Germany, the United States, and Japan. For van Creveld, it is after 1830 that "military-technological innovation became not only rapid but institutionalised and permanent." In any case, the phenomenon does appear to have intensified significantly after the Second World War, the conflict having itself demanded an unprecedented mobilisation of national resources.

William H. McNeill, "The Structure of Military-Technical Transformation" (USAFA Harmon Memorial

Lecture \#37, 1994) http://www.usafa.af.mil/df/dfh/docs/Harmon37.doc

Martin van Creveld, Technology and War. From 2000 B.C. to the Present (New York: Free Press, 1989), p.223

See also William H. McNeill, The Pursuit of Power. Technology, Armed Force, and Society since A.D. 1000

(Chicago: University of Chicago Press, 1982)

'John Keegan, The Face of Battle (London: Cape, 1976); John Ellis, The Social History of the Machine Gun

(Baltimore, MD: Johns Hopkins University Press, 1986); Linda Grant De Pauw, Battle Cries and Lullabies:

Women in War from Prebistory to the Present (Norman: University of Oklahoma Press, 1998); Joshua S.

Goldstein, War and Gender. How Gender Shapes the War System and Vice Versa (Cambridge: Cambridge

University Press, 2001); Sherie Mershon \& Steven Schlossman, Foxboles and Color Lines: Desegregating the

U.S. Armed Forces (Baltimore, MD: Johns Hopkins University Press, 1998); Jay M. Winter, Sites of Memory,
} 
has brought to fore the cultural and discursive dimensions of war and the military, providing insights into how culture frames, organises, and imbues with meaning the use of organised violence, along with the impact of military values and experience on the wider culture of human societies. Hence, for Keegan, war "is always an expression of culture, often a determinant of cultural forms, in some societies the culture itself."

The virtue of such studies has been to bring back culture to the centre of the picture, as opposed to being relegated to the manifestation of other social forces. As Daniel Pick points out, the ideas and representations of war prevalent in any given era should not be seen merely as the reflection of some other underlying material strata of reality:

\begin{abstract}
Writing on war is part of the material culture and economy it represents, not some subsequent straightforward effect [...] Language shapes and is shaped by social, economic, political and technological change. Representation and the pressure of symbolisation in general is never a straightforward 'reflection' of some other material 'bedrock', some supposedly non-discursive economic stratum, for instance, that can be privileged as determining in the final instance'. ${ }^{8}$
\end{abstract}

However, if this focus on cultural variables has been a welcome addition to the literature on war, it has unfortunately seen some authors substituting one pitfall for another - for example, in erecting culture in turn as the determining stratum to which all other dimensions of reality are subordinated in any explanatory account. Victor Davis Hanson has notably argued that the civic culture of the West (understood as a coherent continuum from the Ancient Greeks to present day) has granted it a superior way of war. ${ }^{9}$ There are many problems with Hanson's thesis - such as the fact that the historical record shows that the clear military superiority of the West is in reality only a recent phenomenon - but none more serious than the author's all too frequent essentialising and reifying of culture as the single explanatory level of reality.

John Lynn provided a welcome antidote with his Battle: $A$ History of Combat and Culture. ${ }^{10}$ While still focusing his analysis at the level of discourse and culture, Lynn carries out a

Sites of Mourning: The Great War in European Cultural History (Cambridge: Cambridge University Press, 1995); Eugen J. Weber, Peasants into Frenchmen: The Modernisation of Rural France, 1870-1914 (Stanford, CA: Stanford University Press, 1976); Joanna Bourke, An Intimate History of Killing: Face-to-Face Killing in Twentietb-Century Warfare (London: Granta, 2000)

${ }^{7}$ John Keegan, A History of Warfare (London: Pimlico, 2004), p.12

${ }^{8}$ Daniel Pick, War Macbine: The Rationalisation of Slaugbter in the Modern Age (New Haven, CT: Yale

University Press, 1993), p.52

9 Victor Davis Hanson, Why the West Has Won: Nine Landmark Battles in the Brutal History of Western Victory (London: Faber, 2002)

${ }^{10} \mathrm{John}$ A. Lynn, Battle: A History of Combat and Culture (Boulder, CO: Westview Press, 2003) 
broad sweep of the history of Western and non-Western warfare to make the case for understandings and practices of warfare that are culturally specific but also historically circumscribed. By appealing to a model in which discourse of wat and reality of war continually interact and co-constitute each other, Lynn allows for changes and evolutions in the discourses of war, thereby avoiding the most serious pitfalls of Hanson's work.

Accordingly, the conception of culture I will employ in this study seeks to avoid reifying or essentialising any specific characteristics of the Western practice of warfare nor to argue for any intrinsic superiority over other ways of war. The scientific way of warfare I will argue for has been historically constructed and must be always situated within the wider transformations of the modern era. Furthermore, the particular focus on the scientific features of the Western culture of warfare will be carried out alongside an analysis of the role of specific technological innovations in the process of military change, so that both ideational and material factors will be considered in conjunction. This brings us to the technological dimension of warfare, another central focus of this thesis, and for which I will now provide a brief review of the literature.

\section{War and Technology}

In contrast with the only recent sustained academic treatment of the relationship of wider culture and society to war, there exists a lengthier tradition of writings on the relationship of technology and warfare. However, it has tended to suffer from the almost exclusive focus on the impact of technology, and particularly weapon systems, on tactics and operational organisation to the detriment of developments in logistics and mobilisation. "Although it has been routinely observed that the technological development of military forces has resulted in an increase in the ratio of 'tail' (overhead resources and logistical personnel) to 'teeth' (warfighting units), focus has remained predominantly on the more glamorous technology of the latter. ${ }^{12}$

\footnotetext{
11 A detailed literature review of historical writing on military technology is available in Barton C. Hacker, "Military Institutions, Weapons, and Social Change: Toward a New History of Military Technology", Tecbnology and Culture, Vol. 35, No. 4. (Oct., 1994), pp. 768-834.

12 In its 2006 budget, the United States Department of Defense planned to spend three times as much on technology projects for the 'tail' (such as infrastructure, human resources management, and logistics) than for the 'teeth': $\$ 22.4$ billion against $\$ 7.6$ billion.
} 
Studies of this nature have tend to view technological change as an exogenous factor to military practice, frequently lapsing into technologically deterministic accounts in which the appearance of new technologies, in particular those of an offensive nature, induce fundamental transformations in the conditions of war. Changes in tactics and organisational arrangements are here viewed merely as subsequent adjustments to a new technological reality. The origins of technological innovation are rarely questioned and cultural variables are generally only treated in terms of the extent to which they facilitate or impede the adoption of inevitable changes in the practice of warfare.

While perhaps narratively satisfying, such accounts have been justifiably criticised on the grounds of their shaky philosophical and methodological foundations, as well as their reliance on an impoverished understanding of social change. ${ }^{13}$ Black wisely advises that, "instead of assuming that organisational changes [are] driven by weaponry, specifically how best to use weapons, and maybe also how to move and supply them, it is necessary to appreciate the autonomous character of organisational factors, and their close linkage with social patterns and developments." ${ }^{14}$ This is not to say that certain revolutionary weapons (such as the tank or nuclear weapons) cannot constrain and influence organisational developments, but that weaponry should not be systematically established as a first cause upon which other developments hinge.

There is a vast literature on technology and society and it would be too lengthy for me to review it in detail here. However, it is instructive to note that academic research into the relation of technological entities to their social context can be broadly classified into three different approaches. ${ }^{15}$ The first considers the way in which technology emerges and is produced and which social factors play a role. A second type of study concerns itself with the social impact of the introduction and diffusion of a technology. Finally, a last approach consists in treating both processes together and approaching technology and society as co-constitutive of each other and co-evolving together, sometimes even

Paul A. Strassman, "Taking a Bite Out of Overhead", Baseline Magazine, May 2005, p.2

http://www.strassmann.com/pubs/baseline/2005-05-a.pdf

${ }^{13}$ In addition to charges of technological determinism, many of these accounts have been accused of vehiculing a Whig interpretation of history as a narrative of teleological progress in which social actors fall into either the camp of progressive or reactionary forces in relation to the inevitable course of historical development.

${ }^{14}$ Black, Rethinking Military History, p.11

${ }^{15}$ Philip Brey, "Theorising Modernity and Technology" in Thomas J. Misa, Philip Brey \& Andrew

Feenberg (eds.), Modernity and Technology (Cambridge, MA: MTT Press, 2003), p.47 
dissolving the distinction between the two categories and preferring to speak of 'sociotechnology.' The present thesis locates itself quite clearly in the last approach, seeking to chart the multiple connections between the social and technological dimensions of war and science without establishing a primary ontological stratum of reality.

It is certainly the case that war cannot be fully understood without reference to its technological character and I can only follow van Creveld when he claims that:

\begin{abstract}
War is permeated by technology to the point that every single element is either governed by or at least linked to it. The causes that lead to wars and the goals for which they are fought; the blows with which campaigns open and the victories with which they (sometimes) end; the relationship between the armed forces and the societies they serve; planning and preparation and execution and evaluation; operations and intelligence and organisation and supply, objectives and methods and capabilities and missions; command and leadership and strategy and tactics; and even the very conceptual framework adopted by our brains in order to think about war and its conduct - all are and will be affected by technology. ${ }^{16}$
\end{abstract}

However, if we are to extend the influence of technology so widely as to include the very conceptual frameworks employed to think about war $^{17}$ while avoiding resorting to an account of the forms taken by thought which reduces them to mere reflections of material conditions, it impels us to recognise the irreducibly social and cultural character of technology. Technology affects every aspect of the social activity of war because technology is innately social and cannot be truly grasped outside of the social and cultural context in which it is produced and inserted. Technology is therefore not merely a set of tools deployed in the social realm but is itself a certain way of thinking and being in the world, "an abstract system of knowledge, an attitude towards life and a method for solving its problems." ${ }^{\text {18 }}$ Hete, the proximity of scientific conceptualisations with the dominant technologies of an era is instructive as to their combined development and constitutes one of the vital relations I will seek to map out in the following chapters.

\footnotetext{
16 Van Creveld, Technology and War, p.311

17 'Not only the conduct of war, but the very framework our brains employ in order to think about it, are partly conditioned by the technical instruments at our disposal." Van Creveld, Technology and War, p.247

${ }^{18}$ Van Creveld, Technology and War, p.312
} 
Ways of Warfare

In accordance with the above discussion, the military history that is charted in the rest of this thesis is one of the organisation of armed forces, understood as "an aspect of, and intersection and interaction with, wider social patterns and practices, leading to the social systematisation of organised violence", and which is to be at least in part accounted for by "the systematisation of knowledge, such that it is possible better to understand, and thus seek to control, the military, its activities and its interaction with the wider world."19 Hence, and this is where the present study is to be firmly located, "at one level, the study of Western warfare becomes an aspect of the history of systems as well as of power." ${ }^{20}$ Within such a history, speaking of a specifically scientific way of warfare suggests that it is possible to abstract a certain coherence or continuity in the theories and practice of warfare during the studied period, that, in other words, we can find general trends in the conduct of, and dominant modes of thinking about, war.

The notion of ways of war or warfare has previously been summoned by different authors and served as a framework for a variety of interpretations, whether it has been viewed as the product of political culture or of national character and historical experience. Basil Liddell Hart spoke of a British way in warfare in the 1930s, arguing that since the sixteenth century Britain had essentially relied on its naval might to achieve its greatest successes, primarily by distupting the trade of its enemies while financially and logistically supporting its allies, along with opportunistic littoral campaigns. ${ }^{21} \mathrm{He}$ deplored the costly and largely ineffectual use of a continental army in World War I as an abandonment of this modus operandi. Liddell Hart attributed the "British way" to the country's national culture which led it to treat war as a business-like affair in which the greatest possible economy of force should be sought. Russell Weigley's major work was concerned with an American way of war which he found to privilege wars of annihilation where the objective is the complete overthrow of the

\footnotetext{
19 Jeremy Black, War. Past, Present, and Future (Stroud : Sutton, 2000), p.29

${ }^{20}$ Black, Retbinking Military History, p.11

21 "Our historic practice, as we have seen, was based on economic pressure exercised through sea-power. The naval body has two arms; one financial, which embraced the subsidising and military provisioning of allies; the other military, which embraced seaborne expeditions against the enemy's vulnerable extremities."

David French, The British Way in Warfare 1688-2000 (London: Unwin Hayman, 1990), p.xv
} 
enemy's military power rather than more limited wars of attrition or exhaustion. ${ }^{22}$ Although the United States initially practiced the latter type of war, notably during the War of Independence, he argued that it has moved towards a strategy of annihilation as its industrial and military power has increased. As for Victor Hanson, he has sought to characterise an entire Western way of war by a common reliance on superior technology, organisation, discipline, morale, initiative, flexibility, and command which he all links to values of freedom, individualism and civic militarism. ${ }^{23}$

A way of warfare, as understood in this thesis, corresponds to an array of rationalities, techniques, frameworks of interpretation, and intellectual dispositions which characterise an approach to the use and application of socially organised violence. As in the aforementioned works on 'ways of warfare', the concern is not with the geopolitical aims or rationales behind the use of military force but with the manner in which warfare has been shaped in order to be an as reliable as possible adjunct of overall policy goals.

To summarise, therefore, the thesis of a "scientific way of warfare" as presented here rests on a broad social and cultural understanding of the role of science and technology in distributing and organising bodies, both human and artificial, on the battlefield as well as orienting thought on the practice of warfare. It is thus necessary to study in conjunction the constitution and dissemination of scientific 'truth' with the forms of social life which accompany it. Conversely, it is also vital to uncover the manner in which social and cultural context, and particularly but not exclusively the militarization of society, conditions scientific and technological development.

\section{Thesis Outline}

I will now briefly set out the thesis structure along which my argument will be developed, according to a broadly chronological sequencing.

Chapter 2 sets out the theoretical and methodological foundations of the study, expanding on the observations made above. The ideas of order and chaos are

22 Russell F. Weigley, The American Way of War: A History of the United States Military Strategy and Policy

(Bloomington, IN: Indiana University Press, 1973), p.xxii

${ }^{23}$ Hanson, Why the West Has Won 
introduced and related to the theories and practices of both warfare and science. The intimate relationship of technology and science is elaborated, notably through the notion of a unitary phenomenon of technoscience. I discuss the concepts of discourse and abstract machine and their. relevance and usefulness to the task of a combined treatment of both the material and ideational dimensions of sociocultural change. The notion of metaphor is developed as a useful conceptual lens to understand the movement of ideas and practices from one domain to another, particularly in the context of the machinic metaphors I see at play in different scientific eras. A brief review of the key texts informing this thesis follows before the chapter concludes with a summary outline of the periodisation of the scientific way of warfare developed in this thesis.

The historical study proper starts with chapter 3 and the first regime of the scientific way of warfare: mechanistic warfare. The invention and dissemination of the clock and clockwork mechanism is related to the emergence of the first major scientific body of ideas constituted by the principles of mechanism and Newtonian physics. Its ontological and epistemological implications, along with the mathematical and geometrical methodology which supports it, are discussed. I chart the manifestation of these ideas and particularly that of the clockwork metaphor in fields as diverse as cosmology, anatomy, and political theory before turning to their instantiation in the military sphere. The role of geometry and physics in the development of fortifications and ballistics is analysed here but attention is especially focused on the army of Prussia's Frederick the Great as the epitome of mechanistic warfare in which soldiers are heavily drilled and disciplined to execute pre-ordained manoeuvres on the battlefield.

The following chapter turns to the next period in the development of the scientific way of warfare, that of thermodynamic warfare. The appearance of the engine, first driven by steam and later by internal combustion and electricity, is placed in the context of the industrialisation and motorisation of Western societies. Within the new science of energy that is thermodynamics, the engine as a physical contraption and conceptual device occupies a central place. Theories of energy proliferate in the physical and biological sciences, as well as in other fields of social and cultural life. Warfare becomes thermodynamic in both the motorisation of its forces which extends their reach across space and time as never before and in its quest for ever-more powerful energy weapons, 
culminating in the atom bomb. The chapter concludes with a reading of Clausewitz's writings through the lens of thermodynamics.

Chapter 5 covers the genesis of the computer within the lineage of electromagnetic communication technologies and their applications in the military context. The emergence of the computer itself is tied to the Second World War and the momentous technological and scientific innovations which it stimulated. The sciences of information and cybernetics are presented here with attention paid to the conceptual apparatus which lays down the foundations of a new informational paradigm in the natural and social sciences. This chapter's purpose is to establish the key ideas and principles which inform the new regime of the scientific way of warfare discussed in the next chapter.

Accordingly, chapter 6 charts the ascendancy, dominance, and subsequent crisis of gybernetic warfare in Cold War America. Indissociable from the process of computerisation of the military in the wake of the Second World War, a conception of warfare resting on the notion that information is the paramount factor determining success emerges in this period, along with a belief that war can be completely managed and controlled. Its various manifestations are analysed here; from the development of "command-andcontrol" as both an operational principle and a range of sociotechnical systems to the meteoric rise to power of operations researchers and system analysts. The chapter concludes with a study of the spectacular failure of cybernetic warfare in Vietnam, drawing some preliminary lessons about the pitfalls and limitations of this approach to war.

The next phase in the development of the informational paradigm is the subject of chapter 7. Chaos theory and complexity science are presented here, with particular attention to the manner in which they develop cybernetic ideas yet also significantly break with some of their key assumptions, thereby forging a new body of ideas with a wide-ranging effect on both the natural and social sciences. Of particular importance are the concepts of non-linearity and self-organisation, imposing both limitations on predictability of systems and restoring the potential for creative transformation of those same systems. The dominant metaphor which surfaces here is that of the distributed network which eclipses the computer as centralising information processing unit. 
Chapter 8 analyses the implication of these new scientific ideas on the theories and practice of warfare and postulates the emergence of the latest regime of the scientific way of warfare: chaoplexic wa fare. I turn first to the ideas of the fighter pilot and strategist John Boyd and connect many of his insights to those of chaos and complexity science. A return to Clausewitz and the non-linear aspects of his thoughts, particularly those pertaining to the question of uncertainty, allow a further appraisal of the potential applications of the new sciences to warfare. The role of networks in contemporary warfare is then considered, first through a discussion of the operational methods of present terrorist networks, and then through an in-depth analysis of the doctrine of network-centric warfare which the United States Department of Defense has adopted.

The thesis is brought to a conclusion in the final chapter with a synthesis of the main arguments developed throughout the study and a presentation of its final findings. General ramifications and lessons to be drawn from these same findings will also be discussed, along with potential further avenues of research suggested by them. 


\section{Chapter 2: Technoscientific Regimes of Order in Warfare - A Theoretical and Methodological Framework}

This chapter will lay out the theoretical and methodological foundations on which the thesis rests, providing an exposition of my understanding of science and technology and of their social and cultural relationship to war. In particular, I will develop the idea of a will to order exerting itself through human social and intellectual life and which will set out the context for the complex interplay of chaos and order in the scientific way of warfare. I will elaborate on a number of concepts, such as those of discourse and metaphor, which will serve as useful analytical tools for the rest of the thesis. The chapter concludes with a summary presentation of the four regimes of the scientific way of warfare I will expound in the following chapters.

\section{Civilisation and the Will to Order}

The army general, the scientific inventor or the military theorist is caught up in an interminable quest to bold the internal and external forces of disruption in check.

Daniel Pick $k^{24}$

Throughout history, military leaders have sought to organise and direct their armies so that they can best preserve their order and coherence when faced with the centrifugal forces of chaos unleashed on the battlefield. Thus they have tried to avert for as long as possible the state of disorganised free-for-all into which many an army has descended into. The forces that have succeeded in remaining organised while precipitating their adversaries into a state of disarray have almost invariably prevailed in battle. Furthermore, a disorganised army means that a commander has lost any ability to exert any influence over the outcome, a loss of control which is contrary to the very principle

${ }^{24}$ Pick, War Machine, p.34 
of the instrumental application of force for political purposes. Hence, for Van Creveld, "the history of command in war consists essentially of an endless quest for certainty certainty about the state and intentions of the enemy's forces; certainty about the manifold factors that together constitute the environment in which the war is fought, from the weather and the terrain to radioactivity and the presence of chemical warfare agents, and last, not but definitely not least, certainty about the state, intentions, and activities of one's own forces. ${ }^{25}$ Likewise, John Keegan notes that the fundamental purpose of training "is to reduce the conduct of war to a set of rules and a system of procedures - and therefore to make orderly and rational what is essentially chaotic and instinctive. ${ }^{206}$ We can therefore view the practice of warfare as the attempt to impose order over chaos, to exert control where it most threatens to elude, and to find predictability in the midst of the greatest uncertainty.

States, along with other political entities, seek to employ organised violence in a manner such to attain certain political objectives. Military force is only one of the instruments of statecraft and wise governance requires that its use be always commensurate with the overall objective to which it is intended to contribute - this is the meaning of Clausewitz's oft-repeated dictum that war is the continuation of policy by other means. War pursued for its own sake or as part of a warrior lifestyle that seeks merely the perpetuation of its own existence is therefore antithetical to any raison d'état. The exercise of judgement over the appropriate means to be deployed in the pursuit of a given political end belongs to the domain commonly known as strategy. However, in order to allow for the formulation of strategy and an assessment of the role of military force within it, it is necessary for states to develop an understanding of the likely effects any course of action is likely to result in. As Colin Gray has pointedly observed, "if the essence of strategy is instrumentality, the essence of instrumentality is predictability."27 Strategic thought and behaviour is thus necessarily accompanied by a rationalisation of military force as an instrument of broader political objectives and a theorisation of the potential and limits of the use of organised violence, all in an effort to bring order and predictability to activities which would otherwise be left entirely to chance and contingency.

\footnotetext{
${ }^{25}$ Martin van Creveld, Command in War (Cambridge, MA \& London: Harvard University Press, 2003), p.264

${ }^{26}$ Keegan, The Face of Battle, pp.18-19

${ }^{27}$ Colin S. Gray, Strategy for Chaos: Revolutions in Military Affairs and the Evidence of History (London: Frank Cass, 2002), p.98
} 
Science bears a clear parallel to military organisation and the instrumental application of armed force in that its practitioners are always attempting to extract 'patterns' from 'noise', to find regularities in the fog of randomness, to uncover the 'laws' governing the behaviour of nature, to reveal the hidden order behind its apparent chaos. For the scientist Norbert Wiener, one of the pivotal characters in this thesis, the "highest destiny" of mathematics, the universal Ianguage' of science, was "the discovery of order among disorder. ${ }^{\text {"28 }}$ Alfred North Whitehead was making a very similar statement, albeit in a more poetic fashion, when he claimed that the pursuit of mathematics was "a divine madness of the human spirit, a refuge from the goading urgency of contingent happenings." ${ }^{29}$ With the discovery and formulation of regularities comes greater predictability of phenomena and an enhanced control over the natural world. Auguste Comte, the founder of positivism, explicitly made this link: "from science comes prevision; from prevision comes control. ${ }^{30}$ The scientific project is thus inextricably connected to the drive for greater control and power over the world - one only needs to refer back to the famous phrase of one of its earliest expositors, Francis Bacon: "scientia potentia est."

Engineering again appears to obey to a similar logic in that it constitutes technological devices and systems whose purposes are to be ordered and predictable by exploiting laws of physics to resist those other physical forces which would undo them. For van Creveld, it is indeed the repetitive and predictable character of physical nature which first made technology possible in primitive societies. As he further points out, technological progress from then on depended increasingly on the specialisation and integration of different tasks and tools. The coordination necessary to constitute such systems "hinges on the ability of management to predict the behaviour of each and every part of the system. Ultimately, what is involved is nothing less than an attempt to insulate the system from uncertainty by creating a perfectly controlled and perfectly stable - since change means distuption - artificial world."31

\footnotetext{
${ }^{28}$ Steve J. Heims, John Von Neumann and Norbert Wiener: From Mathematics to the Technologies of Life and Death (Cambridge, MA \& London: MIT Press, 1980), p.68

${ }^{29}$ Heims, John Von Neumann and Norbert Wiener, p.116

${ }^{30}$ Ian T. King, Social Science and Complexity: The Scientific Foundations (Huntington, NY: Nova Science

Publishers, 2000), p.20

31 Van Creveld, Technology and War, p.315
} 
In his piece entitled The Question Concerning Technology, Heidegger claims that "the essence of $\mathrm{t}$ chnology is nothing technological" but rather that, along with science, it is an expression of enframing (Ge-Stell), that is "ordering as the supposed single way of revealing." 32 The philosopher sees in enframing a will to dominate nature, to convert the whole universe into an undifferentiated "standing reserve" (Bestand) available to be put to work when needed. Heidegger seems to suggest this attitude to the world is implicit in the scientific project:

\begin{abstract}
Man's ordering attitude and behaviour display themselves first in the rise of modern physics as an exact science. Modern science's way of representing pursues and entraps nature as a calculable coherence of forces. Modern physics is not experimental physics because it applies apparatus to the questioning of nature. Rather the reverse is true. Because physics, indeed already as pure theory, sets nature up to exhibit itself as a coherence of forces calculable in advance, it therefore orders its experiments precisely for the purpose of asking whether and how nature reports itself when set up in this way. ${ }^{33}$
\end{abstract}

Science and technology are therefore the means by which the world is made to "reveal" itself in a certain way so as to order it. If Heidegger accepts that the instrumental understanding of modern technology is correct in viewing it as a means to an end, he goes further by seeming to suggest that instrumentality itself flows from the way in which technology "brings forth" or reveals the world through enframing i.e. in our way of "knowing" it.

If the ordering Heidegger is speaking of is one that corresponds to a specific technoscientific rationality, ordering as a codification of the world which seeks to abstract regularities and correlations from it and dictate ways of being within it appears to be central to all human societies, whether manifested in the form of law, religion, tradition, or morality. ${ }^{34}$ For Freud:

Order is a kind of compulsion to repeat which, when a regulation has been laid down once and for all, decides when, where and how a thing shall be done, so that in every similar circumstance one is spared hesitation and indecision. The benefits of order are incontestable. It enables men to use space and time to the best advantage, while conserving their psychical forces. ${ }^{35}$

\footnotetext{
32 Martin Heidegger, The Question Concerning Technology and Other Essays (Harper Torchbooks, 1977), p.32

${ }^{33}$ Heidegger, The Question Concerning Technology and Other Essays, p.21

${ }^{34}$ For Hedley Bull, "to say of a number of things that together they display order is, in the simplest and most general sense of the term to say that they are related to one another according to some pattern" and social order is "an arrangement of social life such that it promotes certain goals and values."

Hedley Bull, The Anarchical Society: A Study of Order in World Politics (London: Macmillan, 1977), pp.4-5

${ }^{35}$ Sigmund Freud, Civilisation and its Discontents (London: Penguin, 2004), p.40
} 
If the process of ordering does appear to be a defining characteristic of civilisation and social life, the specific forms it takes are not inconsequential, particularly with regards to the manner in which they mediate between order and chaos. What follows is an account of the specific technoscientific regime of order which emerges in the modern era, its relationship to the theories and practices of warfare, and the various ways in which the tensions between order and chaos are played out.

\section{The Technoscientific Regime of Order}

Scientific theory is a contrived foothold in the chaos of living phenomena.

Wilhelm Reich ${ }^{36}$

Behind military bardware there is hardware in general, and bebind that there is tecbnology as a certain kind of know-how, as a way of looking at the world and coping with its problems.

Martin van Creveld ${ }^{7}$

In the Western world, a particular regime of order emerged with modernity, displacing previously established mechanisms for the production of order. Indeed, order came to be increasingly justified and organised on the basis of a scientific and technical rationality. Knowledge produced through the inductive methods of scientific enquiry gained ascendancy over deductive theological and scholastic claims about the world. Both the state entities and capitalistic forms of economic organisation which emerged in this era relied on the rationalisation and systematisation of processes and social interactions to manage enlarged bureaucracies and sites of production. Efficiency considerations and cost-benefit or profit calculations increasingly supplanted tradition, custom or other grounds as the ordering principle of social organisation, thereby fuelling a systematic and continually complexifying division of labour alongside accelerating technological development. A new regime of order meant that a new way of speaking about the world and dictating social arrangements within it had acquired predominant legitimacy.

36 Wilhelm Reich, The Function of the Orgasm (1927)

${ }^{37}$ John Arquilla \& David Ronfeldt, "Cyberwar is Coming!" in John Arquilla \& David Ronfeldt (eds.), In Athena's Camp: Preparing for Conflict in the Information Age (RAND, 1997), p.25 
Foucault would here speak of a regime of truth produced by discourse and through which relations of power are established and perpetuated:

\begin{abstract}
In a society such as ours, but basically in any society, there are manifold relations of power which permeate, characterise and constitute the social body, and these relations of power cannot themselves be established, consolidated nor implemented without the production, accumulation, circulation and functioning of a discourse. There can be no possible exercise of power without a certain economy of discourse of truth which operates through and on the basis of this association. We are subjected to the production of truth through power and we cannot exercise power except through the production of truth. ${ }^{38}$
\end{abstract}

It is crucial to note that discourse in this context should not be reduced to the semantical field of spoken interaction and written text; "discourse goes beyond speech acts to refer to the entire field of signiffing or meaningful practices. these social interactions material, institutional, and linguistic - through which human knowledge is produced and reproduced. A discourse, then, is a way of knowledge, a background of assumptions and agreements about how reality is to be interpreted and expressed, supported by paradigmatic metaphors, techniques, and technologies and potentially embodied in social institutions." ${ }^{39}$ In accordance with this broad understanding of discourse as a nexus of ideas and practices which (re)produce social reality and a certain set of power relations with it, modernity is to be viewed as "a structural organisation of state, economy, society and culture; a power complex and a mode of consciousness."

With the advent of the Scientific Revolution at the dawn of the seventeenth century, a new discourse emerged with its own set of beliefs, tools and practices. A new method was established by which nature could be interrogated and its fundamental laws revealed. Its agenda was explicitly one of extending control over the physical world, as evidenced by both Descartes's invitation to seek a "practical philosophy" through which to "render ourselves the masters and possessors of nature" and Bacon's injunction to "extend the power and dominion of the human race itself over the universe." scientific discourse grew rapidly in prestige and authority as it accumulated successes to

\footnotetext{
${ }^{38}$ Michel Foucault, Powver/Knowledge (Hemel Hampstead, Herfordshire: Harvester Press, 1980), p.93

39 Paul Edwards, The Closed World: Computers and the Politics of Discourse in Cold War America (Cambridge, MA: MIT Press, 1996), p.34

40 Philip K. Lawrence, Modernity and War: The Creed of Absolute Violence (Houndmills, Basingstoke:

Macmillan, 1997), p.6

${ }^{41}$ Langdon Winner, The Whale and the Reactor. A Search for Limits in an Age of High Technology (Chicago, IL \&

London: University of Chicago Press, 1986), p.123
} 
become the dominant ordering discourse of Western civilisation. ${ }^{42}$ Some of this authority derived from its ability to make predictions about natural phenomenon but an even greater prestige was derived from its close association with technology. The synthesis that would emerge remains one of the defining characteristics of modernity.

Of course, technology had always existed as a necessary requisite of human civilisation but it previously had remained distinct from the theoretical contemplation of nature's laws. Indeed, Prigogine and Stengers claim that with Plato and Aristotle and their development of natural philosophy:

\begin{abstract}
the distinction between theoretical thinking and technological activity was established. The words we still use today - machine, mechanical, engineer - have a similar meaning. They do not refer to rational knowledge but to cunning and expediency. The idea was not to learn about natural processes in order to utilise them more effectively, but to deceive nature, to "machinate" against it - that is, to work wonders and create effects extraneous to the "natural order" of things. The field of practical manipulation and that of rational understanding of nature were thus rigidly separated. Archimedes' status is merely that of an engineer; his mathematical analysis of the equilibrium of machines is not considered to be applicable to the world of nature, at least within the framework of traditional physics. In contrast, the Newtonian synthesis expresses a systematic alliance between manipulation and theoretical understanding. ${ }^{43}$
\end{abstract}

Within this systematic alliance between science and technology, artefacts such as the clock, engine and computer were to play a key role. They allowed for the isolation and study of physical forces, the resulting new theoretical understandings of which would then feed back into the design of these and other devices. For this reason, it is more apropos to speak of the emergence of technoscience in the modern era, an ever tighter symbiotic bond between these two spheres to the point-at which any distinction is merely definitional and of limited conceptual value. Although this convergence is present at the very foundation of modern science, the proximity between science and technology from World War II onwards is such that any major technological advance has been inextricably linked to scientific knowledge. Derrida correctly signalled that

\footnotetext{
42 This is not to say that science is the only ordering discourse of modernity or that it has not been contested since its very inception. Nor could it have achieved pre-eminence without chiming with other contemporary discourses. It is also clear that mathematics and various brands of scientific endeavour also played major roles in Western and non-Western societies previous to the modern era. However this thesis is concerned with the particular forms scientific knowledge and method took on with the 'Scientific Revolution.'

${ }^{43}$ Ilya Prigogine \& Isabelle Stengers, Order out of Chaos: Man's New Dialogue with Nature (Fontana: London, 1985), p.39
} 
"one can no longer distinguish between technology on the one hand and theory, science and rationality on the other. The term techno-science has to be accepted. ${ }^{\text {nt4 }}$

We must therefore also dispense with the now widely discredited view of technology as merely applied science. Heidegger had already observed in 1954 that:

It is said that modern technology is something incomparably different from all earlier technologies because it is based on modern physics as an exact science. Meanwhile we have come to understand more clearly that the reverse holds true as well: modern physics, as experimental, is dependent upon technical apparatus and upon progress in the building of apparatus. ${ }^{45}$

There is much historical evidence that bolsters the insights of both Heidegger and Prigogine \& Stengers and affirms claims such as those according to which "thermodynamics owed much more to the steam engine than the steam engine ever owed to thermodynamics. ${ }^{246}$ Further examples of this process will be seen throughout the course of this thesis. Of course, I do not wish either to fall in the opposite conceptual trap by denying the considerable role scientific discoveries have played in the development of technology or to lapse into crude technologically deterministic forms of explanation. Rather, I will seek to demonstrate their co-constitutive interrelationship where necessary, in the knowledge that we are effectively considering a unitary phenomenon of technoscience as a way of knowing and being in the world.

Likewise, the technological and industrial development of Western societies under the conditions of modernity cannot be merely understood as the introduction and application of machinery for the purpose of increasing productive capabilities. Equally important are the forms of social organisation which allow for the implementation of specific technologies, enforcing new arrangements and combinations of individuals and machinery. Fay states:

the obvious but important truth that the exploitation of nature for the production of goods and services can only occur through the cooperative effort of men who undertake to do the work involved. This truth becomes a pre-eminent fact in a society which is devoted to a constant increase in production through the self-conscious organisation of social labour; for in these societies rational administration directed towards ensuring continuity of operation, speed, precision, and an efficient employment of men and machines leads to an

${ }^{44}$ Chris Hables Gray, Postmoder War. The Nesy Politics of Conflict (New York: The Guilford Press, 1997), p.262

${ }^{45}$ Heidegger, The Question Concerming Technology and Other Essays, p.14

${ }^{46}$ Derek J. De Solla Price, "Notes Towards a Philosophy of the Science/Technology Interaction" in Rachel Laudan (ed.), The Nature of Tecbnological Knowledge: Are Models of Scientific Cbange Relevant? (Dordrecht, Holland: D. Reidiel Publishing, 1984), p.106 
increasing division-of-labour in which men come to perform quite specialised functions, and in such a complex economy productive activity can go forward only when this activity is performed according to some highly abstract and general plan. ${ }^{47}$

What Fay says of social organisation for the production of goods and services is of course no less true for the social organisations seeking to 'produce' destructive force. Kranzberg is eager to underline that "the introduction of new analytical techniques in management forms the part of technological history just as much as it does of economic history and, now, of military history." "If a "highly abstract and general plan" is thus crucial to the organisation of modern modes of both production and destruction, we should not assume that such a plan is exogenous or secondary to the process of technological development. In Pacey's words, “technology can never be adequately understood in terms of machines and techniques alone. Machines are always used within a framework of organisation and management, and often there are organisational changes at the heart of important technological developments." ${ }^{49}$ I would go even further in claiming that those abstract organisational schemes are themselves technological in that they constitute social machines in which technical apparatuses are given function and meaning.

I follow here Deleuze and Guattari's analysis of technology:

\begin{abstract}
The principle behind all technology is to demonstrate that a technical element remains abstract, entirely undetermined, as long as one does not relate it to an assemblage it presupposes. It is the machine that is primary in relation to the technical element: not the technical machine, itself a collection of elements, but the social or collective machine, the machinic assemblage that determines what is a technical assemblage at a given moment, what is its usage, extension, comprehension, etc. ${ }^{50}$
\end{abstract}

Deleuze and Guattari develop a flat ontology, a machinic conception of society in which no domain or element is granted causal or deterministic prominence. In this conception, the machine is not primarily technical but describes any assemblage of parts which

\footnotetext{
47 King, Social Science and Complexity, p.29

${ }^{48}$ Melvin Kranzberg, "Science-Technology and Warfare: Action, Reaction, and Interaction in the PostWorld War II Era" in Monte D. Wright \& Lawrence J. Paszek (eds.), Science, Technology and Warfare: The Proceedings of the Third Military History Symposium - United Air Force Academy 8-9 May 1969, p.133 49 Arnold Pacey, Technology in World Civilization (Oxford: Basil Blackwell, 1990), p.157 50 Gilles Deleuze \& Felix Guattari, $A$ Thousand Plateaus (London \& New York: Continuum, 2003), pp.3978

Also in Deleuze's book on Foucault: "Machines are social before being technical. Or rather there is a human technology before there is a material technology. No doubt the latter develops its effects throughout the entire social field; but, for it to be possible, the tools, the material machines, must have first been selected by a diagram, taken on by an assemblage." (my translation)

Gilles Deleuze, Foucault (Paris: Les Editions de Minuit, 1986), p.47
} 
combine to work together. This allows for an understanding of social developments in which technologies, organisational arrangements, and ideas all combine to constitute mixed assemblages that allow certain actions or 'ways of being' and forbid others.

Throughout the different regimes of the scientific way of warfare that I will distinguish, I will seek to bring to the fore those abstract and general plans according to which armies have been organised and that can be found operating through technical apparatuses, social organisations, and military thinking. While embodied in all these respective forms, such plans and diagrams can also be viewed as independent from any specific stratum of reality. Foucault described the Panopticon, Jeremy Bentham's plans for the ideal prison in which all inmates could be simultaneously supervised from a single omniscient position, as "a generalisable model of functioning, [...] the diagram of a mechanism of power reduced to its ideal form [...] it is in fact a figure of political technology that may and must be detached from any specific use. ${ }^{351}$ De Landa, speaks of the formation of "abstract machines" as the point at which mechanical contraptions become "mechanism independent, that is as soon as they can be thought of independently of their physical embodiments." 52 Another way of thinking such diagrams and models would be in terms of metaphors - more on this later. For now, it is important to clarify the issues of causality and methodology raised by the above points.

\section{Of Discourse and Polymorphous Correlations: Science and Culture}

Having established the importance of the question of abstract machines and diagrams of power to the field of inquiry of this thesis, it is crucial to note the role of discourse in establishing and perpetuating them. Once again, my use of discourse as an analytical tool implies much more than speech acts or written enunciation:

\footnotetext{
51 Michel Foucault, Surveiller et Punir (Paris: Editions Gallimard, 1975), p.239

52 Manuel De Landa, War in the Age of Intelligent Machines (New York: Swerve Editions, 1991), p.142

De Landa borrows the term 'abstract machine' from Deleuze and Guattari but uses the concept in a narrower sense than its originators, in accordance with the above definition. I will mainly be following De Landa's understanding but it is useful to refer to the original formulation as it makes clear that abstract machines are to be understood as diagrams which cut across the physical and ideational realms but are not to be elevated as a. final cause since they are socially and historically produced: "an abstract machine in itself is not physical or corporeal, any more than it is semiotic; it is diagrammatic [...] [it] is neither an infrastructure that is determining in the last instance nor a transcendental idea that is determining in the supreme instance."

Deleuze \& Guattari, $A$ Thousand Plateaus, pp.141-142
} 


\begin{abstract}
Discursive practices are not purely and simply ways of producing discourse. They are embodied in technical processes, in institutions, in patterns for general behaviour, in forms for transmission and diffusion, and in pedagogical forms which, at once, impose and maintain them. ${ }^{53}$
\end{abstract}

In this sense, discourses represent a form of power in determining the arrangements of bodies, machines and materiel according to abstract organisational diagrams and formulating the conceptualisations and theorisations that support such diagrams. Science and the worldview it promotes are particularly pervasive instances of such power, and are all the more enduring due to science's ability to reformulate many of its theories while still retaining its core assumptions and method.

Thomas Kuhn's seminal work on paradigms and scientific revolutions did much to challenge the established view of a linear progression in the acquisition of scientific knowledge. ${ }^{54}$ Kuhn's historical study demonstrated that most scientific endeavour ("normal science") occurred within well-established paradigms, defined as a set of ideas and practices which determine what phenomena are to be observed and scrutinised, which kind of questions are to be asked, what constitutes a valid means of interrogation and how results are to be presented and interpreted. Periods of stability are punctuated by violent intellectual revolutions and episodes of intense controversy in which an existing paradigm is found to be no longer adequate and is replaced by a new paradigm. While Kuhn's work has been often, legitimately or not, called upon to undermine science's truth claims and positivist understandings of knowledge, it also serves to demonstrate one of the fundamental strengths of scientific discourse, that is its ability to transform its constitutive theories and frameworks while still claiming a single corpus and methodology. It is this ability to remould itself which has secured science's lasting legitimacy as an authoritative discourse in the Western world.

If some of the accounts of the development of scientific theories included here will discuss the historical role of specific scientists in their elaboration, their purpose is to set the context and chronological background of these ideas rather than to present them as a series of individual accomplishments. The romantic image of the lone and misunderstood scientist or technologist toiling in his laboratory before a sudden

\footnotetext{
${ }^{53}$ Foucault quoted in Mark C. Taylor, The Moment of Complexity: Emenging Network Culture (Chicago, IL: University of Chicago Press, 2001), p.57

${ }^{5+}$ Thomas S. Kuhn, The Structure of Scientific Revolutions - 3rd ed. (Chicago, IL: University of Chicago Press, 1996)
} 
"eureka" moment in which all suddenly becomes clear may be narratively satisfying but is a far cry from the reality of scientific endeavour. Science is always a collective enterprise conducted within a scientific community which shares and (re)produces the ideas, norms, and practices that constitute science. Ideas and theories are not produced in a vacuum but are the result of an accumulation of experiments, publications, and debates and only gain broad currency through their review by the scientific community. Hence we find the oft-observed phenomenon of multiple independent discoveries whereby similar discoveries are made by scientists working independently. ${ }^{55}$ This suggests that certain ideas or theories are ripe for formulation and diffusion at a given moment in history, as the result of both the accumulated work of previous scientists and the aptness of the cultural climate. Katherine Hayles argues in this way that the scientists behind the development of chaos theory did not act in isolation; "they rather acted like lightening rods in a thunderstorm or seed crystals in a supersaturated solution. They gave a local habitation and a name to what was in the air. It was because the cultural atmosphere surrounding them was supercharged that these ideas seemed so pressing and important." ${ }^{36}$

Indeed, science is not an activity separate from other contemporary social developments and ideational trends, much as some scientists may insist that the theories produced by the scientific method are formulated free from any of ideological constraints or subjective judgments prevalent in other forms of enquiry into the world. For Margaret Wertheim, science is necessarily always a "cultural project", in the sense that the widespread acceptance of any understanding of reality is necessarily the product of the social and linguistic negotiation of its epoch. ${ }^{57}$ In The Pearly Gates of Cyberspace, Wertheim charts the rise of the purely physicalist notion of space in the modern age to the detriment of the dualistic conception of body space and soul space prevalent in the Middle Ages. Medieval metaphysical dualism posited that reality was composed of a finite earthly realm, as well as a spiritual dimension, which contemporary art made no attempt to represent in a naturalistic manner. This worldview was increasingly challenged in the late Middle Ages and Renaissance and eventually gave way to the

55 Famous examples of multiple independent discoveries include the discovery of calculus by Newton and Leibnitz, oxygen by Lavoisier and Priestley, evolution by Darwin and Wallace, and the first law of thermodynamics by Joule, Mayer and Helmholtz.

${ }^{56}$ N. Katherine Hayles, Chaos Bound: Orderly Disorder in Contemporary Literature and Science (Ithaca \& London: Cornell University Press, 1990), p.174

${ }^{57}$ Margaret Wertheim, The Pearly Gates of Cyberspace: A History of Space from Dante to the Intermet (New York: W.W. Norton, 1999), p.133. 
desanctified vision of a single unified physical reality that now dominates Western consciousness. While the scientific theories of Kepler, Newton and Einstein underpin the elevation of a homogenised space in which the totality of reality is located, Wertheim argues that cultural developments such as the introduction of perspective and spatial integrity in painting played a key role in allowing for the psychological shift that enabled minds to accept this radically new conception of space. ${ }^{58}$

Along similar lines, the Nobel Prize physicist Edwin Schrödinger has claimed that:

\begin{abstract}
All science is bound up with human culture in general, and [...] scientific findings, even those that which at the moment appear the most advanced and esoteric and difficult to grasp, are meaningless outside their cultural context. A theoretical science unaware that those of its constructs considered relevant and momentous are destined eventually to be framed in concepts and words that have a grip on the educated community and become part and parcel of the general world picture - a theoretical science, I say, where this is forgotten, and where the initiated continue musing to each other in terms that are, at best, understood by a small group of close fellow travellers will necessarily be cut off from the rest of the cultural mankind; in the long run it is bound to atrophy and ossify however virulently esoteric chat may continue within its joyfully isolated groups of experts. ${ }^{59}$
\end{abstract}

In order for any scientific truth to gain universal or even widespread acceptance beyond its tiny communities of expertise, it therefore must necessarily be socially and culturally reproduced and validated. This entails presenting its core ideas and notions in terms that are coherent and comprehensible to the non-initiated, generally expressed through the medium of language but also eventually in a visual or experiential fashion. One crucial means by which the new can be apprehended in terms of the familiar is through metaphor.

Prigogine and Stengers question the way in which the clock became so rapidly a symbol of world order, their answer providing an insight into the methodology I will employ in this thesis:

A watch is a contrivance governed by a rationality that lies outside itself, by a plan that is blindly executed by its inner workings. The clock world is a metaphor suggestive of God the Watchmaker, the rational master of a robotlike nature. At the origin of modem science, a "resonance" appears to have been set up between theological discourse and theoretical and experimental activity - a resonance that was no doubt likely to amplify and consolidate the claim that scientists were in the process of discovering the secret of the "great machine of the universe." [...] It is not our intention to state, nor are we in any position to affirm, that religious discourse in any way determined the birth of theoretical science, or of the "world view" that happened to develop in conjunction with experimental activity. By using the term resonance - that is, mutual amplification of two discourses - we have deliberately

58 Wertheim, The Pearly Gates of Cyberspace, p.115

${ }^{59}$ Prigogine \& Stengers, Order out of Chaos, p.18 
chosen an expression that does not assume whether it was theological discourse or the "scientific myth" that came first and triggered the other." 60

The authors later note that the manner in which irreve sible time is introduced into physics in the nineteenth century with the development of thermodynamics, namely the claim to a universal "tendency towards homogeneity and death", is reminiscent of "ancient mythological and religious archetypes" which they relate to a deep anxiety originating in "the rapid transformation of the technological mode of interaction with nature [and] the constantly accelerating pace of change." ${ }^{11}$ Certainly, Crosbie Smith's masterful history of the development of the science of energy in Victorian Britain persuasively argues for the influence of the specific Protestant environment in which its formulators were immersed. ${ }^{62}$

The essential here however is Prigogine and Stenger's notion of 'resonance' between discourses and their refusal to commit to postulating the primacy of any particular discourse, preferring to opt for a more flexible contextual history which Smith also employs for his purposes in order to present "scientific work not as the product of isolated individuals but as crucially contingent upon the cultural resources of the age in which it was produced." ${ }^{33}$ For this task, Smith calls on "such seemingly diverse ingredients as industrial machines, social and institutional networks, and religious and political ideologies." ${ }^{64}$ While this thesis distinguishes itself from these aforementioned authors in specifically focusing on the 'resonances' between warfare and technoscience, I nonetheless largely share their methodological and epistemological outlooks.

One of the goals of Foucault's work was to replace the "uniform, simple notion of assigning causality" with a "whole play of dependencies" and by "by eliminating the prerogative of the endlessly accompanying cause, bring out the bundle of polymorphous correlations. ${ }^{365}$ Hence, I will not be seeking to assign strict causality to any particular substrate or domain of reality for the developments in technoscience and warfare I will be charting. Rather I will privilege an account which brings forth the resonances,

\footnotetext{
${ }^{60}$ Prigogine \& Stengers, Order out of Chaos, p.46

61 Prigogine \& Stengers, Order out of Chaos, p.116

${ }^{62}$ Crosbie Smith, The Science of Energy: $A$ Cultural History of Energy Pbysics in Victorian Britain (London:

Athlone, 1998)

${ }^{63}$ Smith, The Science of Energy, p.ix

${ }^{64}$ Smith, The Science of Energy, p.ix

${ }^{65}$ Michel Foucault (edited by Sylvère Lotringer), Foucault Live - Interviens 1961-1984 (New York, NY:

Semiotext(e), 1996), p.38
} 
tensions, and breaks of competing and complementary discourses across the sociocultural spectrum. In order to understand how different discourses can interact with one another and even co-constitute one another, it is necessary to turn to the notion of metaphors.

\section{The Power of Metaphors}

You don't see sometbing until you bave the right metaphor to let you perceive it.

Robert Stetson Shaw (chaos theory pioneer)66

Traditionally understood as mere rhetorical flourish reserved to poetry and literature and viewed as the sign of muddled thinking in philosophy, the role of the metaphor in language and human cognition has benefited from a major re-evaluation in recent times. In opposition to the view of metaphor as mere statement of similarity, paraphrase, or ornamental figure of prose ('saying one thing and meaning another'), Max Black has argued that the metaphor consists in viewing a principal conceptual domain - that is any coherent organisation of experience - through the lens of another subsidiary conceptual domain. The word 'metaphor' itself is from the Greek for 'transfer'; effectively metaphors transfer meaning from one thing to another. But, as two different things cannot by definition be the same, metaphor necessarily involves an arbitrary simplification of both objects since it must rely on illuminating certain features while obscuring others in order for the metaphor to work. Hence "the metaphor selects, emphasizes, suppresses, and organizes features of the principal subject by implying statements about it that normally apply to the subsidiary subject. ${ }^{307}$ The reverse is also true in that metaphors work both ways - the subsidiary subject comes to be seen to be more like the principal subject.

It has furthermore been argued that many literal' expressions are in fact simply 'dead' or 'frozen' metaphors that we no longer recognise as such. Obvious examples would

${ }^{66}$ James Gleick, Chaos: Making a New Science (London: Vintage, 1987), p.262

${ }^{67}$ Max Black, Models and Metaphors: Studies in Language and Philosopby (Ithaca, NY: Cornell University Press, 1962), pp.44-45 
include such expressions as the wings of a building, the branches of science, or the foot of a mountain. ${ }^{68}$ Thus, according to Schon, all language is metaphorical and the creation of metaphors is the process through which concepts are formed and displaced from old to new domains. "The metaphorical character of language [...] is due to the fact that our language, at any given time, gives us a cross-section of our processes of concept formation or discovery. The metaphors in language are to be explained as signs of concepts at various stages of displacement, just as fossils are to be explained as signs of living things in various stages of evolution." ${ }^{39}$

If conceptual thought is therefore predominantly structured by specific metaphors, it follows that many (if not all) social activities and human representations of the world around us are organised by metaphorical understandings. For Lakoff and Johnson, this implies that:

\begin{abstract}
new metaphors have the power to create a new reality. This can begin to happen when we start to comprehend our experience in terms of a metaphor, and it becomes a deeper reality when we begin to act in terms of it. If a new metaphor enters the conceptual system that we base our actions on, it will alter that conceptual system and the perceptions and actions that the system gives rise to. ${ }^{70}$
\end{abstract}

While new metaphors can modify our conceptual system, they also help us apprehend novelty. Indeed, through them we can understand the new and unfamiliar in the terms of images, objects or conceptual frameworks we are already comfortable with (we should not necessarily limit the concept of 'metaphor' to language - "metaphors can be not merely linguistic but experiential and material as well" ${ }^{71}$ ). As Richard Robbins observes:

\begin{abstract}
Metaphors give a feeling of power and control. If we have a thorough understanding of one system of relations [...] we can use it to comprehend a system of relations we only begin to grasp, and, as a result, we get a feeling of security, well-being and power. Simply by naming features of a new experience, we fix and control that experience. In every instance of the use of a known metaphor to interpret a new experience there is a transition from helplessness to power. Where something was puzzling, it suddenly becomes clear. ${ }^{72}$
\end{abstract}

\footnotetext{
${ }^{68} \mathrm{Alan}$ D. Beyerchen, "Clausewitz, Nonlinearity, and the Importance of Imagery" in David S. Alberts and Thomas J. Czerwinski (eds.), Complexity, Global Politics, and National Security (Washington, D.C.: National Defense University, 1997), p.74 
Metaphors therefore constitute an ordering mechanism by which structure and meaning can be imposed on the chaos and confusion produced by novelty. It is on the basis of the new understanding afforded by metaphor that future actions can be justified and control exerted - we are back to the will to order discussed at the beginning of this chapter.

For Black, theoretical models in science work very much like metaphors, requiring analogical transfer and revealing new relationships:

\begin{abstract}
A memorable metaphor has the power to bring two separate domains into cognitive and emotional relation by using language directly appropriate to the one as a lens for seeing the other, the implications, suggestions, and supporting values entwined with the literal use of the metaphorical expression enable us to see a new subject matter in a new way. The extended meanings that result, the relations between initially disparate realms created, can neither be antecedently predicted nor subsequently paraphrased in prose. We can comment upon the metaphor, but the metaphor itself neither needs nor invites explanation and paraphrase. Metaphorical thought is a distinctive mode of achieving insight, not to be construed as an ornamental substitute for plain thought. Much the same can be said about the role of [theoretical] models in scientific research. If the model were invoked after the work of abstract formulation had already been accomplished, it would be at best a convenience of exposition, But the memorable models of science are "speculative instruments" [...] They, too, bring about a wedding of disparate subjects, by a distinctive operation of transfer of the implications of relatively well-organised cognitive fields. And as with other weddings, their outcomes are unpredictable. Use of a particular model may amount to nothing more than a strained and artificial description of a domain sufficiently known otherwise. But it may also help us to notice what otherwise would be overlooked, to shift the relative emphasis attached to details - in short, to see new connections [original emphasis]. ${ }^{73}$
\end{abstract}

From this emerges a much more general understanding of metaphor than that allowed by its traditional literary definition since it applies to all cognitive processes by which a domain is viewed in terms of another domain. Robbins advocates an equally broad view of the metaphor, claiming that "many terms have been used to label the subsidiaries, the 'known,' that we bring to each new experience to give it meaning: 'schemata,' 'themata,' 'paradigm,' 'world vision,' 'world view,' 'model,' 'framework,' and 'theory' are just some of these labels. But, in the most rudimentary sense, all these things - schemata, theories, world visions, and the rest - are metaphors; like metaphors, we transfer theories and schemata, world visions and world views, paradigms and themata to experiential phenomena as our way of understanding the phenomena. ${ }^{.74}$

${ }^{73}$ Black, Models and Metaphors, pp.236-237

${ }^{74}$ Robbins, The Belief Macbine http://faculty.plattsburgh.edu/richard.robbins/Belief/chapter two.htm 
Nor are scientists necessarily blind to the metaphorical nature of their theoretical enterprises. To the quote of Robert Shaw given at the beginning of this section, should be added the claim of complexity theorist Brian Arthur from the Santa Fe Institute that science "is about the creation of metaphors." 75 For the English cybernetician and psychologist Gordon Pask, cybernetics was nothing else than "the art and science of manipulating defensible metaphors. ${ }^{, 76}$

In the context of this thesis, I will be discussing the four specific machinic metaphors of clockwork, engine, computer, and network that have been central to the respective technoscientific discourses of mechanism, thermodynamics, cybernetics, and chaos theory/complexity. Each metaphor has been particularly influential as it has been enmeshed within a web of theories and practices and supported by the dominant technology of the era. Within these discourses, the metaphor has both served as a point of departure for scientific speculation and as a heuristic bolstering the theories that sprang from it. ${ }^{77}$

\section{A Brief Review of the Relevant Core Texts}

In The Future of War, Christopher Coker briefly discusses paradigmatic technologies and the metaphorical frameworks through which science and war are understood. He distinguishes three machine metaphors corresponding to distinct eras in warfare with the clock, the engine and the computer (see Figure 1). This typology has served as the conceptual framework through which I pursued most of my early research and structured my thinking on this thesis.

${ }^{75} \mathrm{King}$, Social Science and Complexity, pp.13-14

${ }^{76}$ American Society for Cybernetics, "Defining 'Cybernetics"' htrp://www.asccybernetics.org/foundations/definitions.htm

7 For Michael Arbib and Mary Hesse, "scientific revolutions are in fact, metaphoric revolutions, and theoretical explanation should be seen as metaphoric redescription of the domain of the phenomena." Lily E. Kay, Who Wrote the Book of Life? A History of the Genetic Code (Stanford, CA: Stanford University Press, 2000), p.22 
- Dominant tool in society.

- Tool as metaphor for science leading to the new science of Newtonian mechanism.

- Metaphor for scientific worldview based on force.

- War as directed mechanised force.
- Dominant tool in society.

- The object of scientific study leading to the new study of thermodynamics.

- Metaphor for scientific worldview based on energy.

- War as directed energy.
- Dominant tool in society.

- Tool for science and object of scientific study leading to the new science of physics and computation.

- Metaphor for scientific worldview based on information.

- War as negative information feedback.

Figure 1: Christopher Coker's metaphors of war ${ }^{78}$

If I still share much of the analysis found in the few pages Coker dedicates to this question, my intent has been to develop the conceptual framework further and bring greater historical depth to this insight into technology as tools and metaphors connecting science and war. This has entailed delving at length into the scientific theories revolving around those technological metaphors with particular attention paid to the inter-relationships between these theories, including both the complementarities and continuities as well as the tensions and contradictions that characterise them. While a certain metaphor may appear to dominate a particular era, it does not necessarily replace wholesale previous metaphors and therefore I have avoided thinking of them in terms of paradigms because of the notions of incommensurability that Kuhn attached to them. Relative to Coker's original typology, I have also sought to go further in distinguishing between two metaphors and scientific corpuses under the informational worldview: the computer and cybernetics on one hand, and the network and chaos theory/complexity on the other. While the latter is in a sense an outgrowth of the former through its notions of systems and circular causality and the key operative concept of information, the nexus of ideas connected to each technoscientific metaphor have profoundly different implications both for the scientific Weltanschaung and military affairs.

A further crucial dimension of this present thesis is the exploration of the relationship between the ideas of order and chaos in scientific discourse, and the parallels that exist in the military sphere. In this respect, Prigogine and Stenger's Order out of Chaos and

\footnotetext{
${ }^{78}$ Reproduced from Christopher Coker, The Future of War: The Re-Enchantment of War in the Twenty-First Century (Oxford: Blackwell Publishing., 2004), p.36
} 
Katherine Hayles's Chaos Bound have been influential texts. ${ }^{79}$ Although they do not discuss warfare directly, they provide incisive commentaries on the relationship of order to chaos in science, and the manner in which this relationship has been reconceptualised through different theories. For my purposes, a central issue related to that of order and chaos has been that of the military tactics and strategies deployed to handle uncertainty and the different centralising and decentralising approaches taken by the commanders of armies. Martin van Creveld remains here probably the most brilliant commentator with his seminal study of military command through the ages, Command in War, which complemented his equally illuminating Technology and War. ${ }^{80}$ Van Creveld argues that centralisation and decentralisation of command constitute the two poles according to which military organisation has historically dealt with uncertainty (with greater success when tending towards the latter) and this view has informed my thesis in providing a lens of analysis to apply when looking at technological metaphors and scientific discourses of war. Furthermore, I also follow van Creveld in his insistence that "there does not exist, nor has there existed, a technological determinism that governs the method to be selected for coping with uncertainty" and have sought to avoid any simplistic technologically deterministic explanations in my account. ${ }^{81}$

Alongside the poles of centralisation and decentralisation can also be found two conflicting approaches to the question of predictability and control in warfare. A first approach strives for complete omniscience, driven by the belief that sufficient knowledge and data will provide a complete understanding of both the laws of war and a given military situation, thereby delivering absolute control and predictability over the practice of warfare. In other words, order must and can banish chaos. The second approach seeks to recognise the irreducible uncertainty of war and consequently views the ideal of omniscience and omnipotence in military affairs as a dangerous selfdefeating fantasy. Warfare must therefore accept and exploit this essence of unpredictability and fluidity in order for an army to prevail - here it is from chaos that order can emerge and it can necessarily only be transitory in the forms that it takes. A number of academic works have critiqued the former approach, notably in its manifestations in the American way of warfare, particularly during the Cold War. Among them are Gray's Postmodern War, Edwards's The Closed World, and Gibson's

\footnotetext{
${ }^{79}$ Hayles, Chaos Bound, Prigogine \& Stengers, Order out of Chaos

${ }^{80}$ Van Creveld, Command in War, Van Creveld, Technology and War

81 Van Creveld, Command in War, p.275
} 
account of the Vietnam War in The Perfect War - I have taken up much of their critique of technoscientific warfare in this thesis. ${ }^{82}$ However, I have also sought to analyse the second approach, afforded far less attention in secondary literature of the aforementioned type, especially when considering the development of network-centric warfare. This, I believe, allows for a nuanced and subtle reading of the scientific approach to warfare which resists the seductive but reductive view that it necessarily implies a centralising worldview, a conclusion which might be drawn on the basis of some of the aforementioned works.

Manuel De Landa's War in the Age of Intelligent Machines, published in 1991, does offer such a broad perspective, adopting van Creveld's analysis on centralisation and decentralisation and also employing a characterisation of epochs of modern warfare similar to that of Coker and which he draws from Michel Serres's writings on the history of science. ${ }^{83} \mathrm{De}$ Landa discusses three "machinic paradigms" with the clockwork, motor, and network acting as abstract machines organising military activity. His work is therefore another important point of reference for my research and this present thesis. However, while De Landa brings in notions from chaos theory and complexity to explain the entire historical development of warfare (a methodology he subsequently employed for non-military history in $A$ Thousand Years of Non-Linear History $\left.{ }^{8 \dagger}\right)$, he was writing at a time when these ideas had barely began to permeate military theory and the Cold War had only just ended. Thus, while he captured many of the crucial technoscientific trends that were developing, he could only speculate that, as a threat to centralised command and control, they would long be resisted by the military. ${ }^{85}$ While the question of whether a new technoscientific discourse has at present fully permeated military thought and practice is one that will be left open for now and addressed in the latter stages of the present piece of work, a vast military literature has certainly been produced on this theme since the early nineties. An in-depth comparison and analysis of this literature is among the original contributions I hope to make with this thesis.

\footnotetext{
${ }^{82}$ Gray, Postmodern War, Edwards, The Closed World, James Gibson, The Perfect. War. Technowar in Vietnam (Boston, MA: Atlantic Monthly Press, 1986)

${ }^{83}$ De Landa, War in the Age of Intelligent Machines, p. 62 ; Michel Serres, Hermes: Literature, Science, and Philosopby (Baltimore, MD: John Hopkins University, 1983)

${ }^{84}$ Manuel de Landa, $A$ Thousand Years of Non-Linear History (New York: Swerve Editions, 2003)

${ }^{85}$ De Landa, War in the Age of Intelligent Machines, p.130
} 


\section{The Four Regimes of the Scientific Way of Warfare}

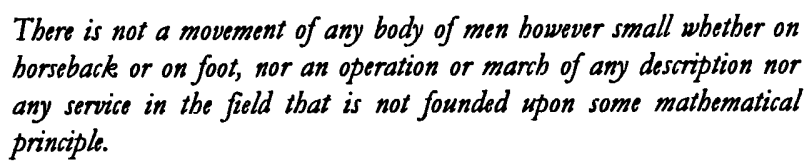

Arthur Wellesley, 1st Duke of Wellington ${ }^{86}$

All strategy is controlled by invariable scientific principles.

Henri Antoine de Jomini ${ }^{87}$

This thesis concerns itself with the development of warfare in the Western world from the advent of modernity, focusing on the role of science and technology. In an era of rapid intellectual and societal change, the practice of the application of force for military purposes was radically transformed and continues to be so. For Gray, three crucial trends emerging in the $16^{\text {th }}$ century marked the beginning of modern war:

- The application of rationality to war instead of tradition;

- The development of administrative bureaucracies;

- The systematic application of science and technology. ${ }^{88}$

While the distinctions made by Gray are useful, these three trends are closely interwoven with rationalisation underpinning the administrative reform and the scientific project. With the Enlightenment and the Scientific Revolution, reason and scientific method were recruited for the study and organisation of all fields of natural phenomenon and human activity, including a quest for the discovery of the fundamental laws governing warfare. In his Essai Général de Tactique (1770), General Guibert deplored the fact that military science was yet to match the accomplishments of the Newtons and D'Alemberts and thereby sought to determine tactics which:

would constitute a science at every period of time, in every place, and among every species of arms; that is to say, if ever by some revolution among the nature of arms which it is not possible to foresee, the order of depth should again be adapted, there would be no

\footnotetext{
${ }^{86} \mathrm{John}$ Shy, "Commentary on Westem Military Education 1700-1850" in Wright \& Paszek (eds.), Science, Technology and Warfare, p.67

${ }^{87}$ Lawrence, Modernity and War, p.22

${ }^{88}$ Gray, Postmodern War, p.111
} 
necessity in putting the same [tactics] in practice to change either manoeuvre or constitution. ${ }^{89}$

It should be noted that science had not waited for the modern world to forge a symbiosis with military affairs. Indeed the graecist John Onians has traced the origin of Greek mathematics to "the importance of absolute order in the military sphere which gave mathematics a dominant role in all Greek culture. ${ }^{290}$ Unsurprisingly, the modern era consciously modelled itself on the classical world in heralding the reaffirmation of reason as the guiding light in a new age of progress.

If it is the claim of this thesis that if a scientific way of warfare emerged with the advent of modernity and has since endured and gained in influence, there is nonetheless considerable variation in the ideas and practices advanced by it. I have organised the latter according to the machine metaphors which have dominated successive eras in the development of science and warfare (clockwork, the engine, the computer and the network) and the respective sciences they have supported (mechanism, thermodynamics, cybernetics, chaos theory/complexity). In conclusion, I will now briefly summarise the central characteristics of the four regimes of the scientific way of warfare I will distinguish, and according to which this thesis will be organised.

\section{Mechanistic Warfare and the Clock}

Mechanism constituted the first major scientific discourse and in many ways set the template for the future development of science. Under mechanism, the universe became understood as an entirely mechanical system composed wholly of matter in motion under a complete and regular set of laws of nature. The core ideas behind mechanism were the laws of motion as formulated by Newton, the concomitant notions of gravity and mass, the reversibility of time, and the belief that any whole could be understood

\footnotetext{
${ }^{89}$ Azar Gat, A History of Military Thought: From the Enlightenment to the Cold War (Oxford: Oxford University Press, 2001), p.50

${ }^{90}$ Bernhelm Booss-Bavnbek, "Mathematics and War" (Draft Essay for Hutchinson Companion Encyclopedia of Mathematics, 2001) http://mmf.ruc. dk/ hooss/mathwrar/bb mathwar.htm Erastosthenes (276 BC - $194 \mathrm{BC}$ ) claimed the main purpose for doing cube roots was to calculate settings for ballistae.

Alex Roland, "Science, Technology, and War", Technology and Culture, Vol. 36, No. 2, Supplement: Snapshots of a Discipline: Selected Proceedings from the Conference on Critical Problems and Research Frontiers in the History of Technology, Madison, Wisconsin, October 30-November 3, 1991. (Apr. 1995), p.95
} 
through the analysis of its individual parts. The metaphor of the world as a machine also begins here, to be carried on through different iterations under successive technoscientific discourses. However, the machine metaphor around which mechanism revolved was that of the clock, or more specifically the clockwork mechanism. As the philosophy and science dominating European thought throughout the seventeenth and eighteenth centuries, mechanism used the clockwork metaphor as a symbol of the order, regularity and predictability of the universe and natural bodies, with the clockwork mechanism itself serving scientific enquiry as both a tool and an object of study. By embodying a general concept of operation or model of organisation enmeshed in ascending cultural discourses, clockwork represented both the unveiled order of the physical world and a prescribed ideal in human affairs. Chaos was exorcised by the invocation of divine clockwork behind all phenomena and the promise of complete predictability and control. A clockwork universe also implied a divine watchmaker who had constructed its mechanisms and set it into motion. This vision resonated with the enlightened absolutism of the day, its faith in the rational and orderly organisation of government, and the position of the monarch as uncontested divine representative and sole seat of power. Mechanistic warfare was characterised by the same features with its armies emphasising rehearsed synchronous movements, the lack of autonomy of their parts and their unflinching obedience to the pre-determined sequence of battle decided upon by their commanders. Thus this conception of warfare attempted to maintain order and ward off chaos through a pre-programmed and centralised routine exerted against unresponsive matter. In this embodiment of the clockwork metaphor, the organisation and doctrine of Frederick the Great's Prussian army remain paradigmatic.

\section{Thermodynamic Warfare and the Engine}

With thermodynamics and the engine, science gained an understanding of the energy which drove the previously studied mechanisms of motion. From the study of heat derived from the engineering prowess behind the steam engine, nineteenth century thermodynamics proceeded to discover both the convertibility of all forms of energy and its inevitable dissipation into randomness through entropy. Time no longer appeared reversible but acquired direction, finding its arrow and leading to the inevitable heat death of the universe - from order to chaos. The thermodynamic world was one of 
instability and change in which the cultivated stability of the ancien régime was rapidly swept away by revolutionary and nationalistic fervour. But if time found its arrow, it was not always from order to chaos. Indeed, ideologies of progress also proclaimed a direction to history at the end of which lay a liberal, socialist, or national paradise - from the chaos of the age, a final and immutable order would emerge, even if more disorder would first be required in the form of war or revolution. Narratives of optimistic progress and fearful decline alternated in the cultural imagination of the nineteenth and early twentieth century European. But if there were conflicting accounts of the direction time was taking, what remained undisputed was the new impermanence of the world and the uncertainty it brought with it. As the founder of scientific socialism Karl Marx famously put it, "all that is solid melts into the air" in the foundry of the new industrial world. The engine, the device that put to work the sources of motive power and was central to industrialisation, replaced clockwork as the dominant machine metaphor and the theoretical and practical nexus for the new scientific worldview. Thermodynamic warfare saw increasing energy channelled into war, whether propelling motorised vehicles on land, sea and in the air, feeding the industrial economies mobilised for total war, both delivering and delivered by ballistic weapons, or drawing on the nationalistic ardour of conscripts and the home front. If the logistical requirements of industrial warfare brought entire economies under unprecedented centralised control, the chaos of the battlefield imposed some tactical decentralisation, notably through the German army's Auftragstaktik. Thermodynamic thought also expressed itself in the writings of the great strategist Carl von Clausewitz who recognised the essentially dynamic and irreducibly unpredictable nature of war - chaos was here understood as inherent to warfare, a constant threat to the best laid plans and which military commanders should recognise and adapt to rather than engage in futile attempts to banish it.

\section{Cybernetic Warfare and the Computer}

As the intensity and breadth of the battlefield grew along with its logistical requirements, communication technologies became necessary to achieve the required coordination of increasingly large and intricate military systems. The harnessing of electromagnetic forces for telecommunication purposes proceeded with telegraphy and telephony and stimulated growing scientific interest in the concept of information. Cybernetics 
emerged from the Second World War, offering a new science of communications and control and promising to control chaos through self-regulating mechanisms of negative information feedback. Through being defined as negative entropy (negentropy), information became conceptualised as the source of all order. The computer, also a product of the war effort, became the new dominant machine metaphor through which the world could be understood in terms of information processing. The dream of complete predictability and centralised control of mechanistic warfare was reborn with cybernetic warfare through computing and servomechanistic technologies and the analytical tools of operations research and systems analysis. The Cold War and the permanent threat of nuclear annihilation required ever greater levels of automation and centralisation of the war machine and cybernetic technology's promise of stability in the face of perturbation appeared best suited to the containment and management of a conflict of potentially apocalyptic proportions. Cybernetic warfare thus viewed military organisation purely as a top-down process, a vast techno-social machine to be integrated and directed through a strict hierarchy on the basis of the calculations of operations researchers and system analysts.

\section{Chaoplexic Warfare and the Network}

From the late 1960 s and early 1970 s onwards, this cybernetic discourse became increasingly challenged through scientific developments which grew out of the original corpus of cybernetics, military reversal in Vietnam, and geopolitical transformation. The increasing application of computers to the study of scientific problems, the rediscovery of non-linear mathematics, and an extension of the cybernetic analysis of systems to questions of self-production and self-organisation constituted novel scientific approaches which crystallised in the theories of chaos and complexity (referred to together as chaoplexity) in the 1980s. Information remains the central concept, and in this sense chaoplexity is an outgrowth of cybernetics and information theory, but the focus on change, evolution, and positive feedback breaks with the concern for stability of the cybernetic pioneers. While some of the certainties and predictability of the existing scientific theories and methodology are terminally undermined, a hidden order is discovered behind chaos which itself becomes no longer an evil to avert but the very condition of possibility of order. The key notions here are those of non-linearity, self- 
organisation, and emergence, and the central metaphor is that of the network, the distributed model of information exchange perhaps best embodied by the Internet.

As the Cold War has receded, a monolithic threat viewed through the lens of bipolarity has given way to a globalised world in which risks are diffuse and amorphous, requiring new approaches to security. Cybernetic warfare had failed spectacularly in Vietnam when faced with a diffuse and decentralised enemy, triggering a long debate on the need for reconceptualisation of military organisation. If the first incarnations of the RMA only seemed to offer further extensions of the original cybernetic paradigm, a growing influence of the ideas of chaos, complexity, and the role of networks can also be observed, leading to the adoption of the doctrine of network-centric warfare by the Pentagon in the late 1990s. Much of this doctrine draws explicitly or implicitly from the discourse and theories of complexity and self-organisation with its use of the notions of self-synchronicity and swarming. This thesis will seek to ascertain the extent to which one can now speak of chaoplexic warfare and question how significantly networkcentric warfare does in fact break with the conceptions of cybernetic warfare. 


\title{
Chapter 3: Mechanistic Warfare and the Clockwork Universe
}

\author{
The clock is the first automatic machine applied to practical purposes. \\ The whole theory of the production of regular motion was developed \\ through it.
}

Karl Marx, 1863 letter to Engels ${ }^{91}$

Mechanism, the science and philosophy dominating European thought throughout the seventeenth and eighteenth centuries and which characterised the first technoscientific regime of warfare, was crucially articulated around clockwork technology. While the clockwork mechanism itself served scientific enquiry as both a tool and an object of study, the clockwork metaphor came to represent the order, regularity, and predictability in the motion of the universe and its natural bodies. By embodying a general concept of operation or model of organisation enmeshed in ascending cultural discourses, clockwork represented both the unveiled order of the physical world and a prescribed ideal in human affairs. Emulation of the virtues of clockwork were perhaps never more obvious than in the organisation and doctrine of Frederick the Great's Prussian army. However, before broaching mechanistic warfare itself and relating the machine metaphor to its contemporary form of warfare, I will first review the genesis of clockwork technology, its interplay with scientific theory and method, and its development into a metaphorical figure of Western discourse.

\section{From Mechanical Clocks and Automata to Clockwork Metaphor}

While time-keeping devices such as the sundial and water clock had existed for centuries, their mechanical incarnation only appeared in Europe in the late thirteenth century. ${ }^{92}$ Combining the ancient Greek technology of toothed wheels and gear trains, a system of weights, and the crucial addition of an escapement mechanism allowing a

${ }^{91}$ Coker, The Future of War, p.25

92 Sundials and water clocks can be traced as far back as Ancient Egypt. However, until the mechanical clock, time keeping was imprecise and tributary to meteorological conditions (the availability of the sun or of temperatures above freezing). 
steady motion of strictly constant velocity, the clockwork mechanism brought about a revolution in horology and the design of automata.

Mechanical clocks remained expensive and bulky in the first two centuries that followed their invention but they nevertheless spread remarkably swiftly across Europe and, with an initial emphasis put on the production of tower clocks for public buildings, large numbers of individuals would have been familiar with their sight. The development of spring-based mechanisms in the late fifteenth century markedly improved the reliability and portability of clockwork devices and contributed to their further dissemination in European society. ${ }^{93}$ In 1657 , Christiaan Huygens, the discoverer of the wave behaviour of light, invented the first successful pendulum clock, markedly increasing the accuracy of timekeeping. This new precision was of huge scientific importance as without it the study of physics in the following centuries would have been greatly hampered.

The spread of the mechanical clock played a central role in reshaping social life, divorcing it from the natural cycles of day and night and imposing a division of time into constant and regular units. Clocks enabled a greater synchronisation of social activities, with punctuality elevated to a social virtue, particularly in courtly life. This new universal rhythm would play a major role in the ordering of emerging industrial societies since "the clock is not merely a means of keeping track of the hours, but of synchronising the actions of men." ${ }^{.94}$ However, the clockwork mechanism itself had an equally far-reaching cultural effect as a metaphor for the motions of celestial and natural bodies.

Indeed, as the clockmaking craft developed, timekeeping was often secondary to the display of elaborate mechanisms that attempted to mirror the different aspects of the natural world. Chief among this was the design of complex astronomical devices that indicated the motion of planetary bodies such as the famous astronomical clock of Strasbourg, first constructed in 1354 and then rebuilt in 1574. The Strasbourg clock also included a rooster automaton, imitation of life being the other chief use of clockwork mechanisms. Automated reproduction of music was also popular, effectively mimicking the actions of a human instrumentalist.

${ }^{93}$ Rodney Dale, Timekeeping (London: The British Library, 1992), p.44

${ }^{94}$ David Landes, Revolution in Time: Clocks and the Making of the Modern World (Cambridge, MA: Harvard

University Press, 1983), p.xix 
The cultural influence of automata grew as clockwork mechanisms became more complex, to the extent that automata and clocks were essentially considered as a single type of device. As Otto Mayr tells us, "in dictionaries from the sixteenth to eighteenth centuries, the automaton (a machine that moved independently on the strength of both a power supply and a plan of action, or program, of its own) was the higher, general category; the clock was merely a particular variety of automaton." ${ }^{, 95}$ We can infer from this that it was the clockwork mechanism itself, above the specific uses to which it was put, which impressed itself most on the minds of contemporaries, and particularly on those of the intellectual class that drove the Scientific Revolution which culminated in the development of Newtonian mechanics. ${ }^{96}$ Contemporary references to 'machines' evoked first and foremost clockwork as the most stunning technical achievement of the times. In effect, the clockwork denomination went from simply designating a specific object (the clock) to what de Landa has called an 'abstract machine' - a general concept of operation or model of organisation. ${ }^{97}$ This conceptual shift would allow the clockwork metaphor to blossom until it formed a central piece of the emerging philosophical and scientific worldview of mechanism.

\footnotetext{
${ }^{5}$ Otto Mayr, Authority, Liberty \& Automatic Machinery in Early Modern Eumpe (Baltimore, MD \& London: John Hopkins University Press, 1986), p.21

96 The Scientific Revolution refers to the establishment of modern scientific method (principally mathematisation, mechanisation, and empiricism) and the major theoretical developments that occurred from the discoveries of Kepler and Galileo in the late sixteenth century to the publication of Newton's Principia (1687). The boundaries of this 'revolution' are controversial, with some historians dating its beginnings to Copernicus's work on a heliocentric model of the solar system (1543) or extending it into the $18^{\text {th }}$ century, while others even question its existence, generally on the grounds that it constituted an evolution rather than revolution. Regardless of the finer points of this debate, it is clear that a powerful change in the scientific worldview occurred over this period in which the qualitative deductive Aristotelian conception of science, that had so dominated the later Middle Ages in its scholastic form, was replaced by a quantitative and empiricist inductive approach that still forms the basis of our present-day understandings of science.

${ }^{97}$ De Landa, War in the Age of Intelligent Machines, p.139
} 


\section{The Clockwork Universe: the Ascendancy of the Mechanistic Worldview}

The making of clocks $[\ldots]$ is certainly a subtle and exact work; their
wheels seem to imitate celestial orbs, and their alternating with orderly
motion, the pulse of animals.

Francis Bacon, Novum Organum (1620)

The reason that there is truth in the world is that it is a machine. Were it not to remain a machine, then the distinction between it and a dream would vanish.

Cbristian Wolff, Vernünffige Gedancken von Gott, der Welt und der Seele des Menscben (1719) 9

The clockwork 'abstract machine' is ever-present in the European scientific literature of the sixteenth to early eighteenth centuries with its metaphorical effects being felt through scientific and philosophical discourse in multiple ways. Firstly, it served as an instrument of demystification by demonstrating how apparently inexplicable motion could be accounted for by a dissimulated assemblage of cogs, weights and springs rather than by a supernatural and/or unknowable force. It also suggested that an understanding of natural phenomena could be best deduced by breaking it up into smaller parts, the study and observation of which would illuminate the entire process, a break from the holistic approach of the Aristotelian tradition. This brought to the fore the notion of cause and effect in a new and powerful way, Hobbes presenting science as nothing else than "the knowledge of consequences, and dependence of one fact upon another." ${ }^{\text {100 }}$ Crucially, the clock as a time-keeping device also served to "disassociate time from human events and helped create the belief in an independent world of mathematically measurable sequences: the special world of science." ${ }^{101}$ In this sense, clockwork was the very foundational metaphor of modern science.

${ }^{98}$ Samuel Macy, Clocks and the Cosmos: Time in Western Life and Thought (Hamden, CT: Archon Books, 1980), p.74

${ }_{99}$ Mayr, Authority, Liberty \& Automatic Macbinery in Early Modern Europe, p.74

${ }^{100} \mathrm{James}$ King, Science and Rationalism in the Government of Lowis XIV (Baltimore, MD: John Hopkins Press, 1949), p.17

${ }^{101}$ Edwards, The Closed World, p.29 
These ideas and discursive practices were all central to the development of the 'mechanistic' approach that emerged over this period. In essence, mechanism posits that the universe is best understood as a completely mechanical system composed entirely of matter in motion under a complete and regular system of laws of nature. For Karl Deutsch, the mechanistic model also:

\begin{abstract}
implied the notion of the whole which was completely equal to the sum of its parts; which could be run in reverse; and which could behave in exactly identical fashion no matter how often these parts were disassembled and put together again, and irrespective of the sequence in which the reassembly would take place. ${ }^{102}$
\end{abstract}

The parallels which can be drawn between the above properties of regularity, reversible motion, ease of disassembly and reassembly, and those of clockwork mechanisms are clear.

It is essential to understand that mechanism was as much a methodology as a set of ontological commitments. It was postulated that the best method of scientific enquiry was to break down the phenomena under scrutiny into individual parts or sequences of events which could be reliably distinguished, measured, and compared using the experimental apparatus of the day. These batches of knowledge could then be related to each other to detect regularities and formulate causal links, to extract a calculable coherence of forces expressed by the way of geometrical representations and algebraic functions. This practice of breaking down any problem into component parts which could be more effectively tackled individually before being reassembled is also common to that of the modern division of labour in which production was broken down into optimal stages in which individuals would specialise, granting greater efficiency to the overall process. We should therefore perhaps not be surprised that it is in the manufacture of clockwork, the most advanced craftsmanship of the time, that the division of labour was then applied most thoroughly. ${ }^{103}$

${ }^{102}$ Stephen David Bryen, The Application of Cybernetic Analysis to the Study of International Politics (The Hague: Martinus Nijhoff, 1971), p.5

103 The horologist Ferdinand Berthoud listed sixteen different sorts of workmen involved in producing clocks, and twenty-one making watches.

Daniel J. Boorstin, The Discoverers: A History of Man's Search to Know bis World and Himself (Hamondsworth, Middlesex: Penguin, 1986), p.66

Deleuze and Guattari tell us that "the way in which a science, or a conception of science, participates in the organisation of the social field, and in particular induces a division of labour, is part of that science itself."

Deleuze \& Guattari, $A$ Thousand Plateaus, p.368-9 
Within the mechanistic worldview which rose to prominence in the seventeenth and eighteenth centuries, the clockwork mechanism functioned as a metaphor for all physical, and by extension social, reality, articulating statements about the movement and composition of celestial and natural bodies as well as social constructs such as the state or army. English natural philosopher Robert Boyle explicitly linked clockwork to mechanist thought in 1665 :

\begin{abstract}
[The mechanist] hypothesis, supposing the whole universe (the soul of man excepted) to be but a great Automaton, or self-moving engine, wherein all things are performed by the bare motion (or rest), the size, the shape, and the situation, or texture of the parts of the universal matter it consists of [...] So that the world being but, as it were, a great piece of clockwork, the naturalist, as such, is but a mechanician; however the parts of the engine, he considers, be some of them larger, and some of them much minuter, than those of clocks or watches. ${ }^{104}$
\end{abstract}

It is to these more specific, yet interconnected, metaphors that I will now turn, starting with the revolution in astronomy which culminated in the grand Newtonian synthesis.

\title{
The Clockwork Heavens: Newtonian Mechanics and the Clockmaker God
}

In the burgeoning scientific community of the late middle ages and early modern era, the clockwork metaphor occupied a central position in the scholarly debates over the movements of the heavens. The motion and regularity of clockwork mechanisms, although highly prone to breaking down in their earlier incarnations, were from very early on compared to that of celestial bodies. Astronomical devices were among the first applications of clockwork; Cardwell even suggests that attempts to reproduce the motion of the heavens may have led to the very invention of clockwork, prior to the design of any mechanical time-keeping device. ${ }^{105}$ Certainly, as early as 1377 , Nicolas Oresme observed that "the situation is much like that of a man making a clock and letting it run and continue its motion by itself. In this manner did God allow the heavens to be moved continually [...] according to the established order." ${ }^{106}$ It thus became customary to conceive of God as the ultimate Clockmaker, the designer of a perfect mechanism that would run its divinely-appointed course until the end of time.

${ }^{104}$ Robert Boyle, The Excellency of Theology Compared with Natural Philosopby (1665) quoted in Mayr, Authority, Liberty of Automatic Macbinery in Early Modern Europe, p.56

${ }^{105}$ D.S.L. Cardwell, Turning Points in Western Technology: A Study of Technology, Science and History (New York: Neale Watson Academic Publications, 1974), p.16

106 Nicolas Oresme, Le Livre du Ciel et du Monde quoted in David Bolter, Turing's Man: Western Culture in the Computer Age (London: Duckworth, 1984), p.27 
In the first half of the sixteenth century, Copernicus greatly simplified the motion of heavenly bodies with his heliocentric theory, placing the Sun at the centre of the known universe and overturning the accepted Ptolemaic geocentric system which had Earth at its centre. There was no significant concomitant increase in the precision of astronomical predictions however, but the new system's superior aesthetic was seductive. Johannes Kepler soon added a new mathematical rigour and elegance to the theory, his avowed goal being "to show that the heavenly machine is not a kind of divine, live being, but a kind of clockwork, insofar as nearly all the manifold motions are caused by a most simple, magnetic, and material force, just as all motions of the clock are caused by a simple weight." ${ }^{\text {"107 }}$ While Galileo's telescopic observations did confirm the validity of the heliocentric hypothesis, a unifying theory of earthly and celestial motion to replace the discredited Aristotelian physics was still lacking. This crowning achievement of the Scientific Revolution was to be the work of Isaac Newton.

Newton expounded his conception of the universe and the laws governing it in his Principia Mathematica, published in 1687 and destined to become the scientific text which would set the standard for all the others that would follow. According to Newton, the natural world functioned in a completely rational and predictable way which could be described solely through the language of mathematics and geometry. The motion of all terrestrial and celestial bodies was explained by the physical attraction exerted on each other, dubbed gravitas (gravity) and whose force is a function of their respective masses and of the distance between them. Although Newton himself never explicitly used the clockwork metaphor in his work on the motion of physical bodies, his account of regular and ordered motion of planets within a single gravitational system bolstered the popular notion of a 'clockwork universe. ${ }^{108}$

Newton also found that the acceleration exerted by gravity on bodies is identical to that experienced by bodies set in motion by other forces, so that the rate of change in the momentum of an object is directly proportional to the amount of force acting upon it

\footnotetext{
${ }^{107}$ Arthur Koestler, The Sleepwalkers (London: Arkana Books, 1989), p.345

108 Pre-eminent mechanists such as Descartes did however object virulently to the principle of 'action at a distance' required by the concept of gravity, to which they preferred an explanation relying on the transmission of forces through the contact of particles and surfaces in the manner of cogwheels on one another, thereby defending a more faithful application of the clockwork metaphor.
} 
and in the direction in which the force is being applied. ${ }^{109} \mathrm{He}$ had thus seemingly uncovered the single principle behind the movements of all physical bodies and had formulated this principle into a mathematical relationship. The world thereby became understood as matter in motion according to fixed laws that could be expressed mathematically.

A further implication of Newton's findings was that, equipped with the knowledge of the fundamental laws governing it, it was possible (at least theoretically) to predict completely the future and past of all physical systems. Indeed, if a system's state at any given moment is known with precision, then the past and future of the system can be predicted with complete reliability. The mathematician and astronomer Pierre-Simon Laplace later mused about the implications when the entire universe is considered as a single system:

\begin{abstract}
We may regard the present state of the universe as the effect of the past and the cause of the future. Given for one instant an intelligence which could comprehend all the forces by which nature is animated and the respective positions of the beings which compose it, if moreover this intelligence were vast enough to submit these data to analysis, it would embrace in the same formula both the movements of the largest bodies in the universe and those of the lightest atom: to it nothing would be uncertain, and the future as the past would be present to its eyes. ${ }^{110}$
\end{abstract}

The Newtonian universe was therefore thoroughly deterministic, viewing all events as the necessary results of a sequence of causes and reducible to the transmission of a single and invariant motive force. Such processes were also necessarily reversible: the original state of any system could be restored by simply applying the reverse of any dynamic changes it had gone through.

However, it should be noted that the laws of motion were idealised in that they did not account for friction, the force which opposes the relative motion of two surfaces in contact and prevents motion from being fully transmitted from one body to the other. While not ignored by classical mechanics, friction was discounted and excluded from

109 Newton's Second Law of Gravity from the Principia Mathematica (1792 translation from Latin): "The alteration of motion is ever proportional to the motive force impressed; and is made in the direction of the right line in which that force is impressed. If a force generates a motion, a double force will generate double the motion, a triple force triple the motion, whether that force be impressed altogether and at once, or gradually and successively. And this motion (being always directed the same way with the generating force), if the body moved before, is added to or subtracted from the former motion, according as they directly conspire with or are directly contrary to each other; or obliquely joined, when they are oblique, so as to produce a new motion compounded from the determination of both." 110 Pierre Simon de Laplace, "Theorie Analytique des Probabilités", Oeueres Completes de Laplace, Volume VII (Paris: Gauthier-Villars, 1820) 
Newton's laws of motion, downgraded to a "noise" which obscured the fundamental pattern. A main reason for this was one of practicality since one of the great advantages of the laws as formulated by Newton was their linearity. In mathematical terms, linear systems are marked by proportionality (changes in system output are proportional to changes in system input) and additivity (the whole is equal to the sum of its parts). Linear functions are simple to solve as they can be broken up into individual parts which can be solved separately and their solutions added up. In contrast, non-linear systems are characterised by the absence of proportionality and/or additivity. Inclusion of the variable and non-linear phenomenon of friction would have prevented the formulation of universal and easily applicable laws of motion. Fortunately, for many practical purposes and common speeds and accelerations of motion, the effects of friction were small enough to ignore. When required, a coefficient of friction could be included in calculations but could only be experimentally determined and remained an unsightly addendum to the idealised laws of motion. It is only with the development of thermodynamics that friction and the irreversible energetic losses that result from it would take to the centre stage of the scientific worldview. ${ }^{111}$

In establishing a theory of vast explanatory power resting on a simple fundamental principle from which all related phenomena could be deduced, Newtonian mechanics became a model for all scientists seeking to create an elegant system accounting for the behaviour of the observable world. Diderot's Encyclopedie summed up best the aspirations of those seeking to emulate Newton in its article on 'system', with an exposition which relied once again on the clockwork metaphor:

System is nothing more than the disposition of the different parts of an art or a science into
a state where they all mutually support each other and where the last ones are explained
through the first. Those that account for the others are called principles, and the system is
all the more perfect as the principles are fewer in number: indeed, it is desirable that they
should be reduced to a single one. For, just as there is one main spring in a clock upon

111 It should be noted that while Newton's laws of motion are indeed linear, the systems of bodies in motion that can be constructed with them are not necessarily so. One- and two-body problems can be effectively solved as linear systems and these included all the scientific triumphs of the age, such as the calculation of the motion of celestial bodies (considered as a two-body problem in which two masses such as the Earth and the Moon exert gravitational attraction on one another) or the progress in ballistics (considered a one-body problem since the differentials in mass between a projectile and the Earth mean the former's gravitational pull on the other can be safely ignored). However, problems composed of three or more bodies pose largely insuperable difficulties as non-linear effects prevent decomposition of the system and the formulation of a general analytic solution. Henri Poincarés consideration of the threebody problem in the late nineteenth century is often seen as an early insight into what would become chaos theory (see chapter 7). While an awareness of non-linearity may have existed among some mathematicians of the seventeenth and eighteenth centuries, attention was naturally focused on the problems that could be solved with the result that the study non-linearity was largely neglected. 
which all others depend there is also in all systems one first principle to which the different parts that make it up are subordinated. ${ }^{112}$

The search for such systems has remained a constant for scientists ever since Newton's formidable achievements.

\section{The Clockwork Body and Soul: Descartes, La Mettrie and Mechanistic Physiology}

The use of the clockwork metaphor was not limited to the study of celestial bodies, it was also present in the scientific enquiry into living bodies as part of the search for universal laws governing the physical world. René Descartes, perhaps the most influential philosopher of the seventeenth century, is here a crucial figure. Descartes employed analogies between nature and clockwork frequently and extensively: "it is certain that there are no rules in Mechanics which do not hold good in Physics [...] for it is no less natural for a clock, made of the requisite number of wheels, to indicate the hours, than for a tree which has sprung from this or that seed, to produce a particular fruit." ${ }^{113}$

Descartes manifested a particular fascination for automata, even imagining some of his own (although there is no evidence any of them were realised), and he referred repeatedly to them when writing about the motion of animals. He was more reluctant to extend this analogy to human beings, presumably to avoid offending the religious sensibilities of the day and satisfy his own religious qualms, and when he did so, it was in an indirect fashion. In his Meditations, he insisted that simple observation could not disprove that humans might be mechanical automata. Statements such as that he could "see no difference between the machines built by artisans and the various bodies composed by nature alone" were also ambiguous as to whether humans were included in the natural bodies he was referring to. ${ }^{114}$

112 Mayr, Autbority, Liberty \& Automatic Machinery in Early Modern Europe, p.79

${ }^{113}$ René Descartes, Principia Philosophiae (1677) in Macy, Clocks and the Cosmos, p.80

114 René Descartes, Principia Pbilosophiae (pt. 4, chap. 203) in Mayr, Authority, Liberty é Automatic Macbinery in Early Moderm Europe, p.63. Mayr convincingly argues that the bodies in question could not be celestial ones since Cartesian cosmology was based on vortices and therefore did not allow direct comparison with machinery (and such analogies are not to be found in any of his work). Hence, he must have been referring to natural bodies. 
Ultimately, his solution was what became known as Cartesian dualism: man was distinguished from animals in being composed of both body and soul, the latter being the realm of spiritual authority and not within the remit of scientific enquiry. This allowed Descartes to describe the human body in rigorously mechanistic terms, even if he avoided direct analogies with clockwork devices. This did not prevent his works being posthumously placed on the Roman Catholic Church's Index of Prohibited Books in 1667 on the grounds of their alleged atheistic bent.

Despite this, Descartes continued to exert considerable influence after his death, even if many thinkers generally avoided too close an association with him or went through ritualistic condemnation of the philosopher. The clockwork metaphor in relation to human beings was used sparingly, although they can still be found in the writings of Blaise Pascal, Baruch Spinoza, and Robert Boyle, and this despite the strong disagreements they expressed with some of Descartes's ideas. ${ }^{115}$ Gottfried Leibniz went so far as to refer to the human soul as "a kind of spiritual automaton", specifying in a rather cryptic manner that "the operation of spiritual automata, that is of souls, is not mechanical, but it contains in the highest degree all that is beautiful in mechanism."

In the eighteenth century, French philosopher and physician Julien Offray de La Mettrie would go much further than Descartes could or dared, claiming that the soul was a physical phenomena and not an immaterial sphere separate from the body. La Mettrie used the clockwork metaphor extensively in his major work L'Homme Machine, arguing that "the human body is a watch." However, his most provocative statement was undoubtedly that:

\begin{abstract}
Since all the faculties of the soul depend to such a degree on the proper organisation of the brain and of the whole body, that apparently they are but this organisation itself, the soul is clearly an enlightened machine. For finally, even if man alone had received a share of natural law, would he be any less a machine for that? A few more wheels, a few more springs than in the most perfect animals, the brain proportionally nearer the heart and for this very reason receiving more blood - any one of a number of unknown causes might always produce this delicate conscience so easily wounded, this remorse which is no more foreign to matter than to thought, and in a word all the differences that are supposed to exist here. Could the organism then suffice for everything? Once more, yes; since thought visibly develops with our organs, why should not the matter of which they are composed
\end{abstract}

115 Mayr, Authority, Liberty of Automatic Machinery in Early Modern Europe, pp.67-68

116 G.W. Leibniz, Theodicy (1710) in Mayr, Authority, Liberty of Automatic Machiney in Early Modern Europe, p.72 and p.224 
be susceptible of remorse also, when once it has acquired, with time, the faculty of feeling? ${ }^{117}$

In that single paragraph, La Mettrie postulated the primacy of mechanistic physical embodiment over the immortal soul while also implying that what ultimately separated humans from animals were merely modest biological differences. Unsurprisingly, his defence that "I do not mean to call in question the existence of a supreme being; on the contrary it seems to me that the greatest degree of probability is in favour of this belief' did little to stave off accusations of atheistic materialism. The condemnation of the Church forced him to leave France and then Holland to live in Berlin under the protection of Frederick the Great, the man who would best exemplify the ideals of the clockwork state and army.

\section{The Clockwork State: Enlightened Absolutism}

The clockwork metaphor suggested a world of harmony, order, and predictability with motion originating from a single impulse and transmitted perfectly by all the 'wheels' and 'gears' of the underlying mechanism. This worldview naturally resonated most strongly with the aspirations of the emerging doctrine of enlightened absolutism: that of a rational and ordered system of government in which an all-powerful monarch determined the impulses to be given to the machinery of state.

Thomas Hobbes, the most prominent theorist of absolutism, is primarily known for comparing the state to the human body but given the popularity of the clockwork metaphor in relation to natural bodies, we should not be surprised to find both analogies conflated in the opening paragraph of Leviathan:

Nature (the art whereby God hath made and governs the world) is by the art of man, as in many other things, so in this also imitated, that it can make an artificial animal. For seeing life is but a motion of limbs, the beginning whereof is in some principal part within, why may we not say that all automata (engines that move themselves by springs and wheels as doth a watch) have an artificial life? For what is the heart, but a spring; and the nerves, but so many strings; and the joints, but so many wheels, giving motion to the whole body, such as was intended by the Artificer? Art goes yet further, imitating that rational and most excellent work of Nature, Man. For by art is created that great Leviathan called a CommonWealth, or State (in Latin, Civitas), which is but an artificial man, though of greater stature

117 Julien Offray de La Mettrie, LHomme Macbine (1748) http://cscs.umich.edu/ crshalizi/LaMettrie/Machine 
and strength than the natural, for whose protection and defence it was intended; and in which the sovereignty is an artificial soul, as giving life and motion to the whole body. ${ }^{118}$

Louis XIV was arguably the paragon of absolutism, and is commonly attributed the perhaps apocryphal phrase: "l'état, c'est moi" (Frederick II would make the more modest claim of being the "servant of the state"). The designated virtues of order and regularity were actively sought within the French government with reform achieved primarily through the instruments of law and règlements. Statistical and social surveys became an institutionalised practice of government, efforts were made to harmonise legislation across the territories, and the state bureaucracy was expanded and reformed to weaken traditional allegiances other than that to the king and to centralise power. ${ }^{119}$ This vision of the state endured beyond the lifetime of Louis XIV; the general and member of the French academy, Jacques-Antoine-Hippolyte de Guibert writing in 1772 that "discipline must be made national. The state I depict will have simple, reliable easily controlled administration. It will resemble these huge machines which by quite uncomplicated means produce great effects." ${ }^{\text {"120 }}$ For some Enlightenment thinkers (but certainly not all), the esprit de systéme and esprit géometrique were instruments of despotism, notably illustrated by the fact that Maréchal Vauban, responsible for the some of the most notable innovations in the application of geometry to the design of fortifications, was also behind plans for the equal taxation of the produce of all land in France. ${ }^{121}$

Louis XIV's court life was notoriously regimented with his days following rigid timetables and etiquette, and with punctuality elevated to the noblest of virtues. The King's fondness for order and a linear aesthetic was also reflected in the pure geometric forms of the palace garden in Versailles. He viewed French excellence in philosophy and science as a symbol of prestige in Europe, establishing national academies and patronage for its promotion, but was personally of a limited intellectual disposition and quick to censor any work that appeared incompatible with absolute monarchy. So while Louis XIV was a fine representative of absolutism, his desire for order and stability echoing the clockwork metaphor, the title of enlightened monarch is most appropriate for Frederick II of Prussia, the Philosopher King.

\footnotetext{
${ }^{118}$ Thomas Hobbes, Leviathan (1651) http://www.gutenberg.org/dirs/etext02/lvthn10.txt

${ }^{119} \mathrm{King}$, Science and Rationalism in the Government of Louis XIV, pp.312-313

${ }^{120}$ Foucault, Surveiller et Punir, p.198

The term used by Guibert in French for 'means' is 'ressorts' which is also the word for 'springs.'

${ }^{121}$ David D. Bien, "Military Education in $18^{\text {th }}$ Century France; Technical and Non-Technical

Determinants" in Wright \& Paszek (eds.), Science, Technology and Warfare, p.57
} 
Aside from the aforementioned La Mettrie, to which he granted patronage when he was forced in exile and for which he even composed the official eulogy, Frederick the Great surrounded himself with many of the leading rationalist and mechanistically inclined philosophers of his time, such as D'Alembert, Voltaire, Euler, Maupertuis and Algarotti. Upon accession to the throne in 1740, he even recalled Christian Wolff, exiled by his father Frederick I in 1723 after it was suggested that his deterministic teachings implied that soldiers were automata and that punishment for desertion was therefore pointless. ${ }^{122}$ Frederick II undoubtedly shared many of the mechanistic ideas of these illustrious contemporaries and prided himself for his philosophical leanings.

Writing on the role of laws in the state in 1750, Frederick's mechanist beliefs are in clear evidence in his vision of the ideal state:

\begin{abstract}
A body of perfect laws should be the crowning achievement of the human spirit as regards the politics of government: one would observe there a unity of design and of rules so exact and so well proportioned that a state conducted by such laws would resemble a watch all of whose springs have been made for the same purpose; [...] everything would be anticipated, everything would be coordinated, and nothing would be subject to mishap. ${ }^{123}$
\end{abstract}

Johann Heinrich Gottlieb von Justi, the Prussian Kameralist, expressed best the role of the sovereign within mechanised government: "a well-constituted state must perfectly resemble a machine where all the wheels and gears fit each other with the utmost precision; and the ruler must be the engineer, the first driving spring or the soul $[\ldots]$ that sets everything in motion."124

In both the reigns of Louis XIV and Frederick II, as well as to a lesser extent those of Joseph II of Austria and Catherine II of Russia, far-reaching rationalisation and centralisation of the state were carried out, accompanied by an expanding bureaucracy, the "wheels and gears" of government. This mechanising trend would perhaps be nowhere clearer than in the changes brought about in warfare, a social activity in which order and discipline were most naturally valued. It is with Frederick II's army, the last great war machine before the advent of the French imperial Grande Armée, that the clockwork model can be observed most clearly in military affairs.

\footnotetext{
122 Mayr, Autbority, Liberty \& Automatic Machinery in Early Modern Europe, pp.76 \& 107 ${ }_{123}$ Mayr, Authority, Liberty of Automatic Machinery in Early Modern Europe, p.108 ${ }^{124}$ Mayr, Authority, Liberty \& Automatic Macbinery in Early Modern Europe, p.111
} 


\section{Mechanistic Warfare:Frederiick the Great's Clockwork Army}

In the seventeenth andeighteenth centuries, the conduct of war increasingly came under scientific scrutiny, a trond that has only intensified ever since. In some cases, practical problems which arose $\mathrm{n}$ war stimulated scientific discoveries; in other cases, it was the successes of the phyical sciences which inspired the quest for the discovery of equivalent universal lavs. As Giat notes on the period which concerns us, "the ideal of Newtonian science excted the imilitary thinkers of the Enlightenment and gave rise to an ever-present yearnirg to infuse the study of war with the maximum mathematical precision and certainty ?ossible.?" 125

Bombardment and forification became less empirical as they were increasingly guided by geometrical principles and the developing science of ballistics. Ballistic knowledge (and notably of the prabolic trajectory of projectiles) was greatly enhanced through Galileo's discovery of the principle of inertia, the law of freely falling bodies, and the principle of the composition of velocities, which he came to partly through his study of military problems and participated in the erection of classical physics. ${ }^{126}$ Virilio explicitly connects the subsequent progress made in ballistics to that of the astronomical sciences, as a well as to a whole range of mathematical innovations from Descartes' analytical geometry to Poncelet's projective geometry and Euler's method for calculating ballistic trajectories. ${ }^{127}$ In response to the destructive power of the cannon and the advantage it provided armies besieging cities, geometry was applied to the purpose of optimising increasingly complex polygonal fortification designs such that "safety was achieved less by tangible masses of masonry than by abstract geometrical patterns of line of fire"128 (see Figure 3). Thus the British military theorist Henry Lloyd could say in 1766 that fortifications were "purely geometrical" and artillery "nothing but geometry."129

125 Gat, $A$ History of Military Thorght, p.30

${ }^{126}$ De Landa, War in the Age of Ittelligent Machines, p.40

Mathematician and military empineer Benjamin Robins subsequently improved markedly on Galileo's calculations in the 1740s, adding a crucial understanding of air resistance. According to Steele, Robins's analysis of muzzle velocities of projectiles fired from muskets - assisted by a 'ballistics pendulum' of his own invention - marked an eary thermodynamic understanding of an internal combustion engine which may have played a role in the furure development of the science of energy.

Brett D. Steele, "Muskets and Psndulums: Benjamin Robins, Leonhard Euler, and the Ballistics

Revolution", Tecbnology and Culture, Vol. 35, No. 2. (Apr. 1994), pp. 348-382.

127 Paul Virilio, The Lost Dimension (NewYork: Semiotext(e), 1991), p. 46

128 Thomas P. Hughes, "Commentary" in Wright \& Paszek (eds.), Science, Technology and Warfare, p.71

${ }^{129}$ Gat, $A$ History of Military Thought, p.72 
Nor was the belief that mechanistic conceptions could be applied to military affairs solely limited to ballistics and fortification. Indeed, Louis Pierre de Chastenet, the Count of Puységur, made the claim that military tactics "is easily reduced to sure rules, because it is entirely geometrical like fortifications." ${ }^{130}$ According to Lynn, it was Diderot's epochal Encyclopédie which "enshrined the conviction that geometry linked fortress design, siege warfare, and battle tactics" when it listed military architecture and tactics as a form of "Elementary Geometry" under the entry on "Science of Nature." 131 The aforementioned Henry Lloyd was also clearly drawing from Newtonian mechanics when he asserted that mathematical principles extended to battle formations since "the impulse that bodies, animate or inanimate, make on each other $[. .$.$] is in proportion to$ mass and velocity."132

${ }^{130}$ Lynn, Battle, p.126

${ }^{131}$ Lynn, Battle, pp.120-121

See also John A. Lynn, "The Treatment of Military Subjects in Diderot's Encyclopédie", The Journal of Military History, Vol. 65, No. 1. (Jan., 2001), pp. 131-165

Lynn also points to Pierre Lenfant's painting of 1761 commemorating the French victory at the battle of Fontenoy in 1744 as the embodiment of the ideals of 'inear warfare' in its depiction of the battle as elegantly ordered with the arrangement of troops obeying perfect geometrical regularity even in the heat of combat. (Battle, p.114)

132 Gat, $A$ History of Military Thought, p. 72 


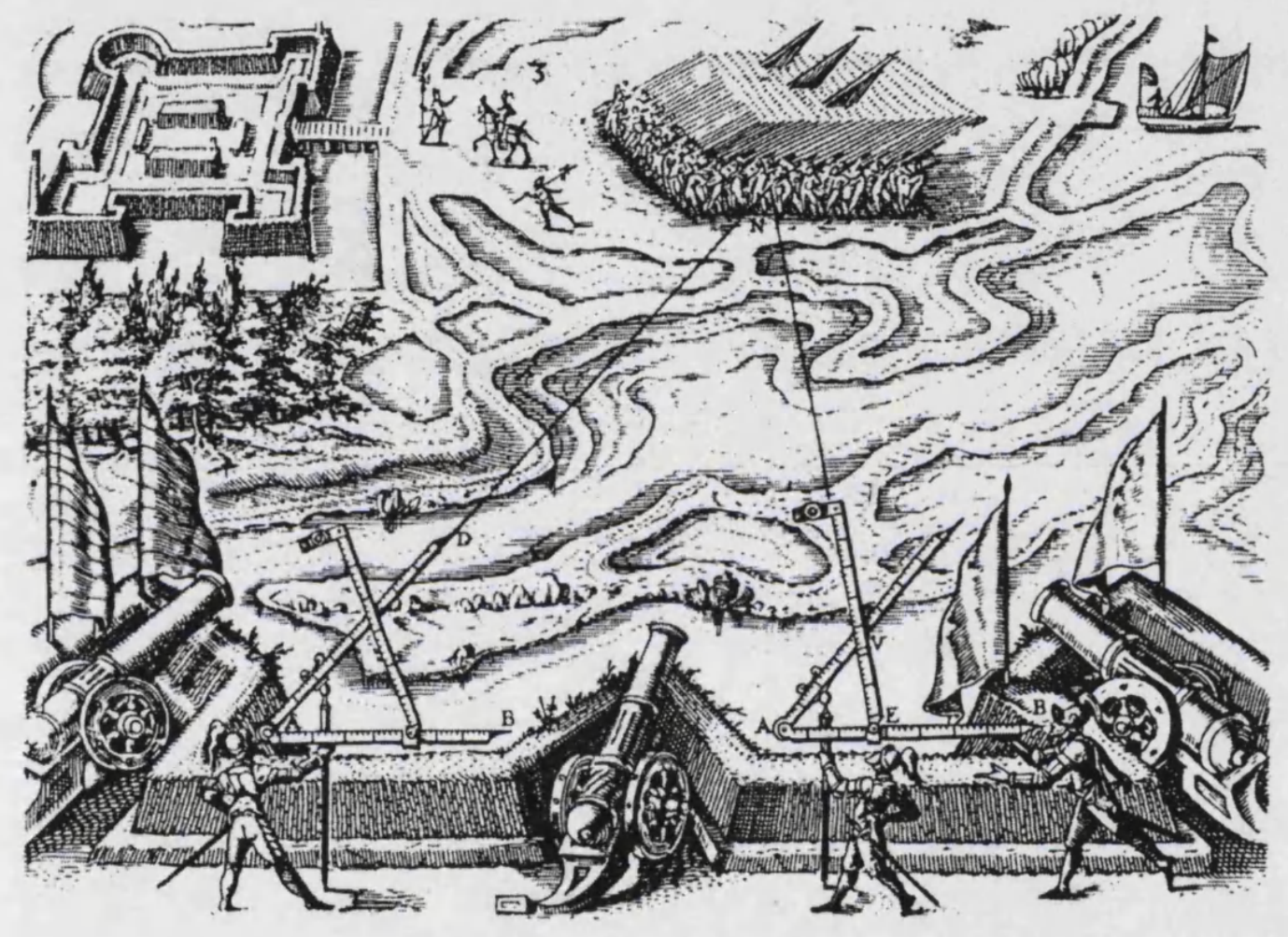

Figure 2: Geometric warfare ${ }^{133}$

${ }^{133}$ Benjamin Bramer, Bericbt zu M. Jobsten Burgi Seligen Geometrischen Triangular Instruments (Kassel, 1648) http://www.mhs.ox.ac.ulk/geometry/ figrosm.htm 

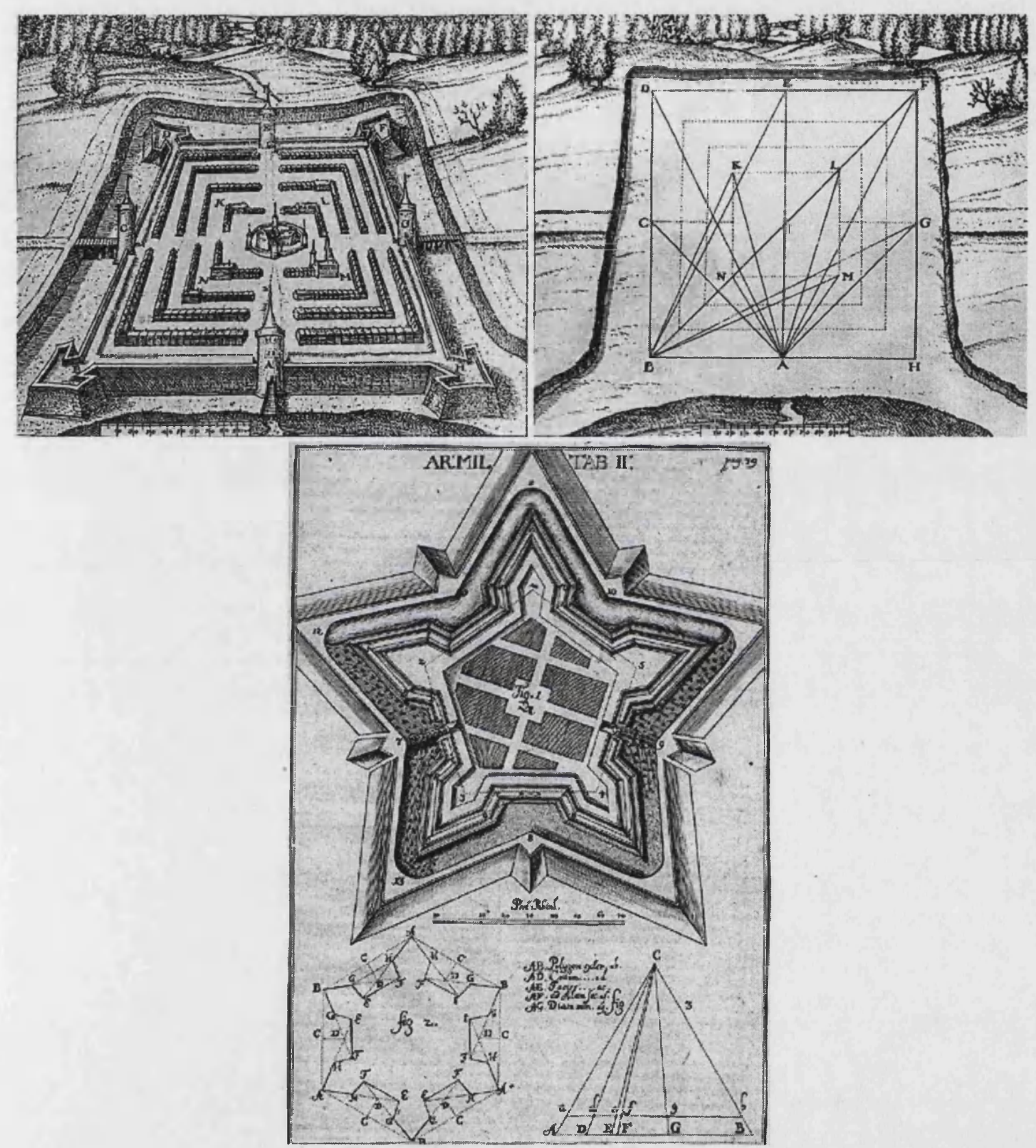

Figure 3: The geometry of fortification ${ }^{134}$

${ }^{134}$ Leonhard Zubler, Fabrica et Usus Instrumenti Chorographici (Basel, 1607)

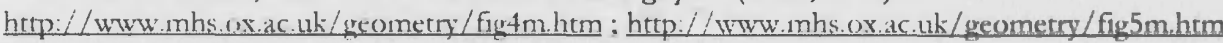
Johann Christoph Sturm, Mathesis Compendiaria (Coburg, 1714) hrtp:/ / www mhs ox.ac.uk/ greometry/figl $103 \mathrm{~m}$.htm 
The question of formations and tactics was perhaps made all the more urgent by the considerable transformations in the composition of armies which occurred in this period. Improvements in firearm technologies made musket-equipped infantry the core unit of any army, with mobile artillery providing support. With the adoption of the bayonet at the end of the seventeenth century, pikemen were rendered largely dispensable. As for the cavalry, its medieval glory days long gone, it remained as the bastion of the aristocracy but its influence on the battlefield was in terminal decline. With chivalty now an archaic concept to which only the odd lip service was paid, eighteenth century armies were predominantly composed of mercenaries and professional soldiers and desertion was an ever-present risk for them. Combined with the limited command and control technologies of the age in increasingly noisy and smoke-filled battlefields and involving growing numbers of troops, this imposed severe limits on potential tactical flexibility.

Frederick the Great's solution to this problem was to reduce individual initiative to a minimum, insisting in his own writings that military effectiveness "depended on strict discipline, unconditional obedience, prompt execution of orders", and that the common soldier should fear his officer more than the enemy. ${ }^{135}$ Van Creveld observes that "Frederick II was among the first modern commanders to try to command all of his army all of the time, but this could only be achieved by turning it into a mindless, lifeless machine. ${ }^{\prime 136}$ It was a clear attempt to model an army on the regularity and predictability of clockwork with every cog playing a pre-determined role fixed by the original conveyer of motion. While such an army would be unable to respond dynamically to events on the battlefield, this would nonetheless allow Frederick to experiment with a number of complex, although rigid, tactical deployments. The result was a formidable machine superior to anything rival states could field at the time and it became a model army which contemporaries sought to emulate, even to the point of replicating the Prussian uniform in some cases. However, notwithstanding Frederick's own input, in many ways it was also the end-product of a lengthy process of military transformation undergone across Europe over the two previous centuries and which had seen the establishment of professional standing armies, the introduction of the systematic drill,

135 Dennis Showalter, The Wars of the Frederick the Great (London \& New York: Addison Wesley Longman, 1997), p.330

${ }^{136}$ Van Creveld, Command in War, p.45 
and the development of gunpowder and firearms. Hence "its training, its discipline, and its tactics were refinements rather than innovations."137

The introduction of systematic drills can be dated to Maurice of Nassau, Prince of Orange (1567-1625), covering the handling of firearms, basic body positions and marching in ranks. Intensive drilling of troops meant that "the individual movements of soldiers when firing and marching as well as the movements of battalion actoss the battlefield could be controlled and predicted as never before." 138 Over the course of the following 150 years, the practice of drilling spread throughout European armies, reaching its acme under Frederick the Great. Cadenced marching, the synchronisation of the step of all the men marching together, had been lost since Roman times and was introduced to the Prussian drill by Frederick William I in the 1730s. However it was his son that "systematically utilised for tactical purposes the Prussian army's ability to march in step." ${ }^{\text {"139 }}$ By the end of the monarch's reign, 75 steps per minute, a reasonably fast pace, had become the standard employed for movement at drill, on the march, in the field, off duty and even when carrying loads. French military officers Toulongeon and Hullin, visiting Prussia in 1786, remarked that "the measure of this pace is imprinted in the soldier's brain, and his legs have been so accustomed to working at this speed that they seem to act by clockwork.",140

Despite the poor quality of Prussian muskets, Frederick's army delivered fire faster than any other did in its age, thanks to its superior discipline. The introduction of firearms meant that the importance of individual physical prowess declined to the benefit of trained professional skill and, at a time where firearm technology did not allow any precision targeting, their effective use required both speed and regularity. Military commanders thus "broke down the motions needed to load and fire a gun into a cycle of elementary operations, and began to drill their men day in and day out, until these operations had become automatic. By orchestrating this cycle so that as one rank loaded the other one shot, they were able to create tactical formations capable of delivering almost continuous volleys of fire." ${ }^{\text {141 }}$ The coordination of such volleys allowed for the

\footnotetext{
${ }^{137}$ Showalter, The Wars of the Frederick the Great, p.355

${ }^{138}$ McNeill, Pursuit of Power, p.130

${ }^{139}$ Showalter, The Wars of the Frederick the Great, pp.109-110

${ }^{140}$ Christopher Duffy, The Army of Frederick the Great (Vancouver: David \& Charles, 1974), p.83

${ }^{141}$ De Landa, War in the Age of Intelligent Macbines, p.58
} 
maximisation of the shock effect on enemy ranks, greatly improving the efficiency of firearms relative to other weapons.

Frederick was known to check the performance of firing exercises with his watch, with elite troops able to fire as many as seven blank rounds a minute (although battle conditions would see this drop to three live rounds at the most). This emphasis on speed may however have been counter-productive at times, the Prussian officer von Gaudi complaining that "with this damned 'minute fire' the men become exhausted and incapable of doing anything more after loosing off a few of these over-hasty salvoes. You could push them over with your little finger." ${ }^{142}$ Dennis Showalter has also commented that, in the latter part of Frederick's reign, "drill movements, always precise and demanding, became exacting to the point of impossibility even for experienced men." Regardless of its excesses, the Prussian obsession with drilling produced highly trained and obedient troops which could perform on the battlefield with the regularity and precision of automatons and played no small part in the repeated military successes of Frederick the Great. The frequency of drilling exercises also had the advantage of reducing the idleness of troops whose time was mostly spent in anticipation of encounters with the enemy rather than in battle, enforcing discipline and contributing to an esprit de corps.

The Prussian soldier was 'mechanised' in the process of drilling, his movements systematically dictated and rehearsed until they became instinctive. Maurice of Nassau had discovered over a century earlier that by breakin down the process of loading and firing matchlock muskets into a sequence of individual moves, soldiers could be taught to carry them out in a synchronised fashion in response to shouted commands. ${ }^{1+3}$ In the Prussian army of the eighteenth century, this practice was further refined and extended: "the regulations of 1743 laid down six stages to bring down the weapon to one's foot, four to extend it, thirteen to raise it to the shoulder, etc." ${ }^{144}$ Each of these stages, analogous to individual cogs in the operation of a mechanical process, could be isolated and improved upon in terms of speed and efficiency to contribute to the overall performance of the process. Michel Foucault notes that "the celebrated automata [...] were not only a way of illustrating an organism, they were also political puppets; small-

\footnotetext{
142 Duffy, The Army of Frederick the Great, p.89

${ }^{143}$ Pacey, Technology in World Civilization, pp.98-99

144 Michel Foucault, Discipline and Punish (London: Penguin Books, 1991), p.154
} 
scale models of power: Frederick II, the meticulous king of small machines, well-trained regiments and long exercises, was obsessed with them."145

Frederick's army was akin to a giant clockwork mechanism in which bodies and technologies were combined to produce a 'war machine' that embodied all the virtues of its model: precision, predictability and order. While military exercises were designed with the end of increasing battlefield effectiveness, they also served a symbolic and ritualistic function, embodying Frederick's vision of army and state. The clockwork appearance of the Prussian army, most observable in the controlled conditions of the biannual military reviews Frederick was so fond of, and in which up to 40,000 troops could be present, was not lost on contemporary commentators. On his only visit to Berlin in 1778, Goethe wrote that "from the huge clockwork that unrolls before you, from the movement of the troops, you can deduce the hidden wheels, especially that big old [program] drum, signed F[redericus] R[ex], with its thousand pins which generate these tunes, one after another."146

Naturally, actual combat conditions saw the war machine operating with much less order than its model, sometimes even prone to breaking down spectacularly, but the considerable military successes achieved by Frederick the Great during his reign are clear evidence of its effectiveness and resilience. While tactical adjustments were practically impossible once battle had been initiated, uncertainty was minimised by automating the actions of soldiers according to a centralised predetermined plan. Mechanistic warfare's solution to the threat of chaos on the battlefield was thus to preordain the actions of every soldier in accordance with an overarching organisational plan which shaped the army, at least in theory, into an extension of the sovereign's will seen as the impulsion setting in motion an idealised clockwork mechanism.

\section{Conclusion}

Organised around the figure of clockwork, mechanism constituted the first cohesive body of scientific ideas and practices in the modern world. Its cultural resonance was far-reaching, impacting multiple areas of knowledge and social activity and offering the

${ }^{145}$ Foucault, Discipline and Punish, p.136

${ }^{146}$ Mayr, Authority, Liberty \& Automatic Macbinery in Early Modern Europe, p.109 
promise of an enlightened and permanently ordered world. Mechanistic warfare briefly appeared to provide a superior answer to the perennial uncertainties of battle and limitations to the exertion of the commander's will. However, the carefully cultivated order of the ancien régime was about to be swept away in the birth pangs of a new world matked by industrial and political upheaval. Along with it came new technologies and sciences, chief among which were the engine and thermodynamics, the science of energy. 


\title{
Chapter 4: Thermodynamic Warfare and the Science of Energy
}

For classical mechanics the symbol of nature was the clock; for the
Industrial Age, it became a reservoir of energy that is always threatened
with exbaustion. The world is burning like a furnace; energy, although
being conserved, also is being dissipated.

Ilya Prigogine and Isabelle Stengers ${ }^{147}$

The thermodynamic world was one of instability and motion, a period of rapid and turbulent socio-cultural transformation whose paradigmatic technology was undoubtedly the engine. For Sadi Carnot, the forefather of thermodynamics, writing in 1824 , the engine seemed "destined to produce a great revolution in the civilised world":

\begin{abstract}
Already the steam-engine works our mines, impels our ships, excavates our ports and our rivers, forges iron, fashions wood, grinds grain, spins and weaves our cloths, transports the heaviest burdens, etc. It appears that it must some day serve as a universal motor, and be substituted for animal power, water-falls, and air currents. ${ }^{148}$
\end{abstract}

For Carnot and others, such a revolutionary technology impelled science to uncover the physical laws governing it and this was achieved in the course of the nineteenth century, transforming the entire scientific worldview in the process. In 1908, Joseph Larmor, who held the Lucasian Chair Mathematics at Cambridge once occupied by Newton could proclaim that thermodynamics "has not only furnished a standard of industrial values which has enabled mechanical power [...] to be measured with scientific precision as a commercial asset; it has also in its other aspect of the continual dissipation of mechanical energy, created the doctrine of inorganic evolution and changed our conception of the material universe."119

Following on the previous chapter's structure, I will first discuss the development of the engine as technological artefact before analysing its metaphorical and heuristic role in thermodynamics and finally turning to the corresponding regime of the scientific way of

${ }_{147}$ Prigogine \& Stengers, Order out of Chaos, p.111

148 Sadi Carnot, Reflections on the Motive Power of Fire and on Macbines Fitted to Develop that Power (1824)

http://www.historg.rochester.edu/steam/camot/1943/Section2.htm

${ }^{149}$ Smith, The Science of Energy, p.14 
warfare. Motorisation and industrialisation transformed the practice of warfare but as early as the writings of Clausewitz we can see thermodynamic notions infusing military thought.

\section{The Engine: the Industrialisation and Motorisation of Society}

While clockwork mechanisms could transmit motion steadily and efficiently, they still relied on an external source of power: energy generated by the force of gravity (as with the weight-driven clock), the muscular power of man and animal (be it directly transferred or stored as with the spring), or by the natural elements of wind and running water. The eighteenth century would see the early development of a dynamic technology that could drive itself by unlocking and harnessing intimate sources of power.

Steam-powered devices were built as early as the turn of the Christian era and even perhaps as far back as Ancient Egypt, but were little more than experimental or ornamental objects until the end of the seventeenth century. Building on von Guericke's scientific research on atmospheric pressure, Thomas Savery patented in 1698 the first steam-powered machine to pump water out of coal mines. A partnership with Thomas Newcomen led to a commercially viable machine in 1712 with the addition of piston and cylinder. It is estimated that over a thousand of those "atmospheric steam engines" were built by the end of the century but their cost-efficiency was very poor and they were not employed outside the mining industry where coal, the engine's fuel, was abundant. Realising in 1765 that the Newcomen steam engine was wasting nearly threequarters of the steam energy in heating the piston and chamber, James Watt significantly improved its design over the following years, thereby rendering it much more efficient and economical. ${ }^{150}$

By the beginning of the nineteenth century, the steam engine had become a vital technology in industrialising Britain, converting energy into mechanical work and no longer limited to pumping water out of mines to extract coal but also driving mills and powering the burgeoning factories. However, the steam engine was not only employed in a revolution in the means of production; it would also herald an equally momentous

${ }^{150}$ Robert Thurston, A History of the Growth of the Steam-Engine (New York: Appleton, 1878) http://www.history.rochester.edu/steam/thurston/1878/Chapter3.html 
revolution in transportation with the first application of its motive power to maritime transport in 17.88 and the construction of the first railway in 1825. The rapid spread of railroads provided an expanding transport infrastructure which further stimulated economic development and social transformation. The steam-powered locomotive was as potent a symbol of the thrust of modernisation as any, annihilating distances, transporting goods, bodies, and ideas over great distances and was undoubtedly an impressive sight for those unfamiliar with it. States enthusiastically embraced railways, to the extent that some countries, such as Spain, were so enraptured with their 'railway dream' that they neglected the development of the industries that would provide the freight for the railroads to carry. ${ }^{151}$

Marked by a dramatic transformation in the modes of economic production, demographic explosion, rapid urbanisation, and the emergence of a new proletarian class, the nineteenth century was a time of great socio-economic upheaval in the rapidly industrialising world. By removing human dependency on wind and water streams as sources of energy, the engine enabled the widespread automation of processes previously executed by hand. Through division of labour and the assembly line, labour was deployed in such a manner as to allow the smoothest possible operation of machines. As a result, the work rate was now imposed by mechanical devices onto the worker, reversing the relationship of the labourer to his tools. This new organisation of production was rationalised in the 'scientific management' of Taylorism at the turn of the twentieth century and its productive capacity further increased with the motorisation of the assembly line introduced by Ford in 1913.

Although primitive devices existed as early as 1807 , it was not until the second half of nineteenth century that practical internal combustion engines appeared, in no small part due to the theoretical advances of thermodynamics discussed below. In 1859, JeanJoseph Lenoir first demonstrated an electric spark internal combustion engine using a combination of compressed air and coal gas as its energy source, applying it to sea and land transport in the following decade. By 1883, Daimler and Maybach had a successful combustion engine using liquid fuel running, followed by the construction of the first automobiles by Daimler and Benz within a few years. Over the next fifty years, combustion engines were widely applied to land, air and sea transport as well as

151 Pacey, Technology in World Civilization, p.141 
industry, signalling a shift from coal to petroleum fossil fuels as the main energy source. The electric motor was born when Michael Faraday discovered electromagnetism in 1821. Subsequent development of large-scale electricity generating systems in the latenineteenth and early-twentieth centuries led to numerous practical domestic and industrial applications for electric motors.

Despite their growing importance by the 1820 s, the Watt steam engine and its successive incarnations had been the product of only an approximate understanding of atmospheric phenomena and decades of experimentation. A comprehensive scientific understanding of the physical processes involved was still lacking. The first breakthrough would be found in the work of French military engineer Sadi Carnot, giving birth to the science of energy known as thermodynamics.

\section{Thermodynamics: the Universe as a Heat Engine}

While clockwork mechanisms merely transmit motion along a preordained path, heat engines generate their own energy and therefore motion - "the mechanical work produced must be seen as the result of a true process of transformation and not only as transmission of movement." ${ }^{\text {.152 }}$ This distinction is central and would impact minds in a powerful manner. Scientific enquiry naturally turned to the study of these processes of transformation, leading to the discovery of the fundamental natural laws of energy, thereby establishing the science of thermodynamics and revolutionising all aspects of the scientific worldview. By 1875, the new science had gained such a prominent status that the Britannica entry for 'energy' could proclaim that "a complete account of our knowledge of energy and its transformations would require and exhaustive treatise on every branch of physical science, for natural philosophy [physics] is simply the science of energy."153

In 1824, the engineer Sadi Carnot published his famous treatise, Reflections on the Motive Power of Fire and on Machines Fitted to Develop that Power, in which he set out the physical principles behind the operation of the heat engine. Carnot had sought answer the muchdebated question of "whether the motive power of heat is unbounded, whether the

152 Prigogine \& Stengers, Order out of Chaos, p.106

${ }^{153}$ Smith, The Science of Energy, p.2 
possible improvements in steam-engines have an assignable limit - a limit which the nature of things will not allow to be passed by any means whatever - or whether, on the contrary, these improvements may be carried on indefinitely." ${ }^{\text {"154 }} \mathrm{He}$ discovered in the process that heat flowed from warmer to cooler areas - from the hot boiler to the cool condenser in the steam engine. Carnot thus showed that the efficiency of an engine is proportional to the temperature difference between the input and output. Therefore total efficiency would require an infinite difference, a physical and theoretical impossibility that implied that there would necessarily always be a heat waste. ${ }^{155}$

Carnot's work would permit the mathematical calculation of the maximum amount of work that any given engine could produce but the wider implications of his theory were much more profound. His discovery of the physical laws upon which the operation of the steam engine relied required its conceptualisation as an abstract machine. Carnot insisted, in what can be seen as the founding statement of the science of thermodynamics, that:

\begin{abstract}
In order to consider in the most general way the principle of the production of motion by heat, it must be considered independently of any mechanism or any particular agent. It is necessary to establish principles applicable not only to steam engines but to all imaginable heat engines, whatever the working substance and whatever the method by which it is operated. ${ }^{156}$
\end{abstract}

Through this formulation, Carnot allowed for the engine to be understood as an abstract mechanism, a diagrammatic organisation detached from any single material embodiment and now ripe for conceptual and metaphorical migration. In 1854, scientist William Rankine was following in these footsteps in defining a "thermo-dynamic engine" as "any body, or assemblage of bodies, which produces mechanical power from heat." ${ }^{\text {157 }}$ For De Landa, the abstract mechanism of the engine can be seen to consist of three separate components: "a reservoir (of steam, for example), a form of exploitable difference (the heat/cold difference) and a diagram or program for the efficient

154 Carnot, Reflections on the Motive Power of Fire http://www.history.rochester.edu/steam/carnot/1943/Section2.htm

155 Sadi's father, the French revolutionary general Lazare Carnot, had previously studied the efficiency of machines and some of his son's later ideas can be traced back to those original insights. In his 1783 Essai sur les Macbines en Général, Lazare had concluded that there was always a necessary loss of "movement of activity" (i.e. of useful work) in any mechanical transmission of motion.

Lazare Carnot, Essai sur les Machines en Général (1786)

hitp://math-doc, uif-grenoble.fr/cgi-bin/oeitem?id=OE CARNOT 1 R5 0

156 Hans Christian von Baeyer, Information: The New Language of Science (London: Weidenfeld \& Nicolson, 2003), p.153

157 Smith, The Science of Energy, p.155 
exploitation of (thermal) differences." ${ }^{158}$ While in a steam engine the differences in pressure of the air according to its temperature are used to set a piston in motion, electric engines exploit the differences in polarity in the electromagnetic field to convert electrical energy from a battery (or other electrical reservoir) into mechanical energy.

Carnot's ideas gave birth to a new scientific worldview which he began to theorise:

It is to heat that we must attribute the great and striking movements on the earth. It causes atmospheric turbulence, the rise of clouds, rain and other forms of precipitation, the great oceanic currents [...] lastly it causes earthquakes and volcanic eruptions. From an immense natural reservoir we can draw the motive power we need [...] To develop that power, to appropriate it to our own use is the purpose of fire-engines. ${ }^{159}$

Along with thermodynamics came a conception of the world very different from the ordered and precise universe conveyed by the clockwork metaphor; one in which disruption and instability were not incidental, or the product of dysfunction, but intrinsic to its very nature.

James Joule discovered in the 1840s that energy could be converted from one form to another, heat being only one of them. From this was postulated the first law of thermodynamics: that of the conservation of energy. It stated that the total amount of energy in the universe was a constant; it simply took different forms. However, Clausius and Kelvin confirmed in the 1850s what had been hinted at in Carnot's writings: within a closed system, the amount of useable energy decreases as it is employed (the second law of thermodynamics). Entropy is the measure of this phenomenon, namely that of the level of disorder (i.e. unusable energy lost to dissipation or friction) within a system. Another way of formulating it is to say that energy naturally flows only from being concentrated in one place to becoming diffused or dispersed i.e. from hot to cold and never the reverse. Hence the exploitable differences which could be converted into work within a closed system will be eventually irredeemably lost.

The ultimate implications of the second law could not be more dramatic: if the universe can be said to constitute a closed system, then it must necessarily be experiencing increasing and irreversible entropy. In other words, the universe is winding down, slowly cooling until its 'heat death' when it will be but a lifeless and motionless void. The second law of thermodynamics became known as 'time's arrow' as it stated a clear

${ }^{158}$ De Landa, War in the Age of Intelligent Machines, p.141

${ }^{159}$ Bolter, Turing's Man, p.32 
direction to physical processes: from order to disorder. This was a huge blow to the stable, reversible clockwork universe of perpetual motion that the mechanist worldview supported. The dissipation of energy implied non-reversible processes, in contrast with all previously established physical laws. It suggested direction, degradation and end to all the phenomena of the physical universe.

In the place of the stable and linear motion of clockwork, steam and fire also brought to the fore the notions of randomness and unpredictability. ${ }^{160}$ In the science of the day, this manifested itself by a shift from a world of mathematical regularity and precision expressed through geometry to a stochastic world in which the mathematics of probability played a growing role. In the second half of the nineteenth century, Ludwig Boltzmann related the probabilistic behaviour of material particles such as molecules with the phenomenon of rising entropy in closed systems, formulating for the first time a physical law in statistical terms and founding the hugely influential disciplines of statistical physics. ${ }^{161}$

Michel Serres sees in the painting of Joseph Turner, the precursor of Impressionism, the 'translation' of Carnot, that is, the influence of thermodynamic notions. Contrasting with the use of "lines, points and circles" in the technique of George Garrard (the development of geometry having permitted the discovery of classical perspective projection in art), Serres points at the randomness and fragmentation of shape in scenes dominated by clouds, fire, smoke and fog: "the perception of the stochastic replaces the drawing of form." 162 Turner is most famous for his dramatic portrayals of the turbulence and power of nature, but, like many contemporaries, he was also fascinated by the wrenching transformation of the Industrial Revolution. He painted the railroad in Rain, Steam, and Speed, ironworking in Dudley, textile mills in Leeds, and coal production in Keelmen Heaving in Coals by Night, seeking to reproduce motion and randomness in his art rather than the immaculate stillness of classical painting.

\footnotetext{
${ }^{160}$ Steam engines tended to be unstable, requiring a careful balance of pressure to maintain a constant speed (and, more critically, to avoid an explosion). This led to the invention of the centrifugal Watt governor, the first feedback control mechanism, allowing the automatic regulation of engine speed. The founders of the science of cybernetics would later hail the Watt governor as one of the finest embodiments of the early self-regulating servomechanism (see next chapter).

${ }^{161}$ According to Boltzmann's theories, the state of maximum entropy or disorder postulated by the second law of thermodynamics is only the probabilistic outcome of the motion of particles in a closed system. It is theoretically possible for total entropy in such a system to decrease but the probability of such an event is vanishingly small.

162 Michel Serres, Hermes III: La Traduction (Paris: Les Editions de Minuit, 1974), p.237
} 
In the 1860s, William Thomson (the future Lord Kelvin) and Peter Guthrie Tait published a highly influential treatise whose intention was to provide an overarching view of the state of understanding of the physical sciences in view of the different advances made by thermodynamics. The resulting Treatise on Natural Pbilosopby received the following review in the Scotsman newspaper in 1868:

\footnotetext{
The world of which they give the Natural Philosophy is not the abstract world of Cambridge examination papers - in which matter is perfectly homogenous, pulleys perfectly smooth, strings perfectly elastic, liquids perfectly incompressible - but it is the concrete world of the senses, which approximates to, but always falls short alike of the ideal of the mathematical as of the poetic imagination [...] Nowhere is there actual rest; nowhere is there perfect smoothness; nowhere motion without friction. ${ }^{163}$
}

Energy dissipation and entropy undermined the eighteenth century vision of frictionless and reversible mechanisms and its promise of absolute control and predictability. As Prigogine and Stengers observe, "unlike dynamic objects, thermodynamic objects can only be partially controlled. Occasionally they 'break loose' into spontaneous change."164

With the ascendancy of the engine, mechanical processes certainly did not become irrelevant but, in the industrial age, the focus shifted towards the laws of energy that drove those mechanisms. Force was replaced by energy as the dominant currency of the new scientific paradigm, and this shift is clearly observable in the contemporary ideas about body and mind.

\section{The Human Engine: Thermodynamic Bodies and Minds}

Whereas the clockwork metaphor had promulgated an understanding of the human body as a cold, clean and quiet machine, animated as if by levers, springs and cogs, thermodynamics would inspire a very different vision. The body was still a machine but now it was a hot, noisy, and dirty energy-consuming one; emphasis was put on respiration, blood circulation, and the consumption of nutrients that provided the energy for it. Writing in 1887, the physiologist Auguste Chauveau claimed that "what we can state as far as the engines of the physical world are concerned can necessarily and

163 Smith, The Science of Energy, p.192

164 Prigogine \& Stengers, Order out of Chaos, p.120 
completely be applied to organised machines, and [...] to the human machine, which we can study most easily and scientifically.",165

Analogies between heat engines and the human body can already be found in the work of Antoine Lavoisier, often referred to as the father of modern chemistry. Following experiments conducted on guinea pigs, he wrote in 1780 that:

\begin{abstract}
Respiration is thus a very slow combustion phenomenon, very similar to that of coal; it is conducted inside the lungs, not giving off light, since the fire matter is absorbed by the humidity of the organs of the lungs. Heat developed by this combustion goes into the blood vessels which pass through the lungs and which subsequently flow into the entire animal body. Thus, air that we breathe is used to conserve our bodies in two fashions: it removes from the blood fixed air, which can be very harmful when abundant; and heat which enters our lungs from this phenomenon replaces the heat lost in the atmosphere and from surrounding bodies. ${ }^{166}$
\end{abstract}

Bodies were thus modelled like engines with a circulation diagram in which oxygen (a gas named by Lavoisier himself) acted as a fuel for the production of heat, replacing that which was lost from the body's activity. Further experiments enabled Lavoisier to establish that increases in oxygen consumption, pulse rate, and respiratory rate could be observed when the body was exerted, linking mechanical work to heat production. These ideas continued to gain credence throughout the scientific community in the nineteenth century.

Medical practitioners also came to an awareness of the importance of heat production to biological organisms, although nearly a century after Lavoisier's discoveries. Daniel Fahrenheit had invented the mercury thermometer in 1714, along with the temperature scale that carries his name, thereby creating a much-needed universal standard of heat measurement. However, clinical thermometry did not become an accepted part of medical diagnostics until the 1860s and the publication of Carl Wunderlich's research. The German physician took over a million readings from 25,000 patients, establishing a range of normal body temperature from 36.3 to $37.5^{\circ} \mathrm{C}$. Since deviation from this could be indicative of disease and a malfunction of the human heat engine, thermometers thereupon become central instruments of medical diagnostic.

\footnotetext{
${ }^{165}$ Auguste Chauveau, La Thermodynamique et le Travail Chez les Etres Vivants (Revue Scientifique, 1887), p.678 quoted in Jacques Gleyse \& al., "Physical Education as a Subject in France (Shool Curriculum, Policies and Discourse): The Body and the Metaphors of the Engine - Elements Used in the Analysis of a Power and Control System during the Second Industrial Revolution", Sport, Education and Society 1, vol. 7 (2002), pp.5-23 http://recherche.univ-montp3.fr/cerfee/article php3?id_article $=191$

166 Frank Katch, "Antoine Laurent Lavoisier (1743-1794)" (Sportscience, 1998)

htp://www.sportsci.org/news/history/lavoisier/lavoisier.html
} 
The nineteenth century and early twentieth century also yielded a greater understanding of the human metabolism and the respective roles of proteins, carbohydrates, and lipids in providing energy for the operation of the human body. Metabolism (from the Greek word for 'change') refers to the manner in which the body consumes food and converts it into energy, measured in Calories that are 'burnt' through the exercise of the body. The nutritional term of Calorie is directly borrowed from the equivalent term in physics, defined as the amount of heat necessary to raise the temperature of 1 gram of water by 1 degree Celsius. Following on from the first law of thermodynamics, the Calorie unit allows for the quantitative measurement and convertibility of all forms of energy.

The evolution of gymnastics as part of the school curriculum in France is another instructive case study that reflects the shift towards an energetic paradigm. Until the 1880s, gymnastics were essentially mechanistic with a focus on ground-based and segmented movements similar to the previously discussed drilling of the Prussian army - an unsurprising fact given that teachers generally received their training during military service. Physiologists and chronophotographers Etienne-Jules Marey and Georges Demenÿ began to push, among others, for a new approach, emphasising the similarities between heat engine and body:

Our blood contains hydrocarbons similar to the oil burnt in our lamps, the coal burnt in our fires. It also contains oxygen which, as it combines with the former elements, causes their combustion, providing a source of heat and energy. Muscular contraction and movement are the result of this physiological process. Will power provokes movement just as an electric spark will provoke an explosion in an unstable volatile matter. ${ }^{167}$

Subsequently, movement in gymnastics (soon renamed physical education), while not abandoning completely mechanistic conceptions, paid much greater attention to the energetic notions of input and output, with a view to optimising those processes and avoiding 'overheating.' The military aspects of gymnastics were largely expurgated from training manuals while the dynamic exercise of sports and games played a greater role. ${ }^{168}$

Freud was also clearly influenced by thermodynamics for the elaboration of his theory of the mind, referring in 1895 to "psychical energy as bound (order) and unbound

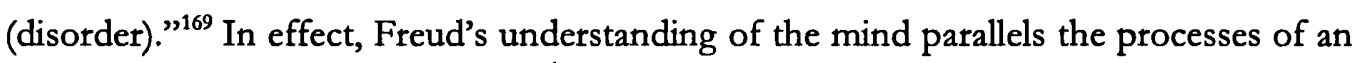

${ }^{167}$ Georges Demenÿ, Les Bases Scientifiques de l'Education Physique (Paris: Alcan, 1902), p.12

168 Gleyse \& al., "The Body and the Metaphors of the Engine"

${ }^{169}$ John Lechte, Key Contemporary Concepts: From Abjection to Zeno's Paradox (London: Sage, 2003), p.207 
engine with a circulation diagram between conscious and unconscious. A decrease in the energy of one area results in an equivalent increase in the energy of the other (the first law of thermodynamics) with a tendency for psychic energy to flow from the 'hotter' area to the 'cooler' area as in the resurgence of repressed urges (the second law). The notion of impulses as bursts of psychic energy also suggests a disruptive and unstable force much more akin to the worldview expounded by thermodynamics than that presented by mechanism. The concept of entropy can also be seen in the death drive's urge for complete satisfaction, effectively a total dissipation of psychic energy as a form of final equilibrium. ${ }^{170}$

\section{Thermodynamic Warfare}

The artillery of our division are excellent shots, the first impact arriving on the dot. The bowling approach of the iron blocks grows increasingly dense and polyphomic, simply for the purpose of drowning the other side in a steadily swelling tide of vicious, raging and numbing sounds. Landmines draw their beaded arss of sparks above us and shatter in volcanic explosions. White signal rockets flood the twinkling clouds of smoke, gases and dust, which simmer with a glaring light, like a boiling lake over the fields. Multicoloured rockets bang over the trenches, bursting into little stars and suddenly expiring like the coloured signals in a giant marshalling yard. All machine guns in the second and third lines are bighly active. The hiss of their countless blurred shots forms the grim background, which fills the minute gaps in the sound of the beayy guns. ${ }^{171}$

Ernst Jünger, Der Kampf als inneres Erlebnis (1922)

We bave finally made the engine that can smash all engines, the power that can destroy all power.

John Schaar on nuclear weapong ${ }^{172}$

In the thermodynamic age, conflict rapidly grew in scope and intensity with states committing all their military, industrial and moral energies into war. The harnessing of industrial might resulted in increasing centralisation of production and a trend towards command economies. Nationalist and revolutionary ideals galvanised entire societies

\footnotetext{
${ }^{170}$ Lechte, Key Contemporary Concopts, p.207.

171 Translated from Emst Jünger, Der Kampf als Inneres Erlebnis (1922), p.31

http://mitglied.lycos.de/nordolf/Ernst $\% 20 J \%$ fcnger $\% 20$ -

\%20Der $\% 20 \mathrm{Kampf} \% 20$ als $\% 20$ inneres $\% 20$ Etlebnis.doc

172 Lawrence, Modernity and War, p.88
} 
into bloody conflicts. War took on a powerful metaphysical role, an engine for a history which had discovered a teleological direction towards the promised lands of nationhood, empire, and socialism. The application of the motor to warfare also had momentous implications, introducing unprecedented vectors of speed and movement into war and leading to wide-ranging tactical and strategic experimentation.

Conceptually, the engine promulgated a different mode of operation and worldview from that of clockwork. De Landa sees in Napoleon's armies the manifestation of an 'abstract motor':

\begin{abstract}
Napoleon himself did not incorporate the motor as a technical object into his wars [...], but the abstract motor did affect the mode of assemblage of the Napoleonic armies: 'motorised' armies were the first to make use of a reservoir of loyal human bodies, to insert these bodies into a flexible calculus (non-linear tactics), and to exploit the friend/foe difference to take warfare from clockwork dynastic duels to massive confrontation between nations. ${ }^{173}$
\end{abstract}

The Revolutionary and Napoleonic wars were not marked by rapid technological change but organisational and ideological transformations nevertheless altered the practice of warfare, as well as the meaning ascribed to it.

The successes of Napoleon can be partly explained by the fruition of tactical innovations introduced in the French army following disastrous defeats at the hands of Frederick the Great's armies during the Seven Years War. Comte Jacques de Guibert notably developed a more dynamic and mobile conception of deployment on the battlefield, moving away from geometric conceptions of manoeuvre and granting battalions greater autonomy. ${ }^{174}$ For Gat, he was the author of revolutionary ideas with a lasting influence on the development of the French army on the eve of the Revolution. Guibert advocated "mobility, rapidity, and boldness in the conduct of operations [...]; movement in independent formations [...]; and flexible manoeuvring in open columns before deploying into the firing-line, instead of the highly complex and rigid manoeuvring of the linear formation that had been employed and perfected by the Prussians." ${ }^{175}$ In contrast with Frederick's attempts to control his entire army, Napoleon was to grant high levels of autonomy to individual corps, allowing for the deployment of forces over a wider area and greater flexibility and interchangeability in the position

\footnotetext{
${ }^{173}$ De Landa, War in the Age of Intelligent Machines, p.141

174 Lawrence, Modernity and War, p.16

175 Gat, $A$ History of Military Thought, p.54
} 
and role of respective corps. According to van Creveld, "whereas Napoleon's opponents sought to maintain. control and minimise uncertainty by keeping their forces closely concentrated, Napoleon chose the opposite way, reorganising and decentralising his army in such a way as to enable its parts to operate independently for a limited period of time and consequently tolerate a higher degree of uncertainty."1776

Historian Richard Riehn argues that Napoleon's scientific education is reflected in his particularly dynamic conception and practice of warfare:

\begin{abstract}
Trained in the artillery sciences, [Napoleon] had a keen grasp of the principles of physics and the concepts of energy and force. No one understood better than he the relationships of mass, time, and the distance that went into the creation of energy. This much is emerges from his methods of conducting a campaign or battle [...] Once his plan developed, Napoleon's understanding of the concepts of energy and force would erupt again. Massive batteries, massive infantry columns and on occasion, massive cavalry columns could break a wall by the concentration of great energy and create rapid concentrations of force at this chosen point of attack, achieving local superiority even if he did nor enjoy the overall advantages in numbers. ${ }^{17}$
\end{abstract}

Key to this ability to concentrate force and direct energies was the introduction of the Levée en masse. Conscription allowed military campaigns on an unprecedented scale by calling on all able-bodied men to fight for universalistic and/or nationalistic ideals, providing the Emperor with a fresh flow of loyal and fervent recruits.

Witnessing Napoleon riding past after his victory in Jena in 1806, Hegel saw in the Emperor the "world-spirit", the embodied march of History. From conflicts serving the ambitions of an aristocratic class, wars became understood as the 'engines' of history, crucial junctures at which nations revealed their true nature and purpose, fulfilling their historical destiny. ${ }^{178}$ Despite all the attempts by Metternich and the representatives of the Old Regime to turn back the 'clock' in 1815, the forces unleashed by the Napoleonic wars had definitively set the world on a new trajectory. From the second half of the nineteenth century, war was increasingly rationalised with the aid of evolutionary, theory, a dynamic understanding of biology that had replaced the taxonomy of eighteenth

\footnotetext{
176 Van Creveld, Command in War, p.61

177 Steele, "Muskets and Pendulums", Technology and Culture, p.372

178 Trotsky later proclaimed that war was the "locomotive of history", combining the notion of motorised acceleration with that of a teleological set of 'rails' leading to a final destination, namely communism.
} 
century natural science. ${ }^{179}$ In the last pages of The Origin of Species, Charles Darwin claimed that:

From the war of nature, from famine and death, the most exalted object which we are capable of conceiving, namely the production of higher animals, directly follows. There is grandeur in this view of life, with its several powers, having been originally breathed into a few forms or into one; and that, whilst this planet has gone cycling on according to the fixed law of gravity, from so simple a beginning endless forms most beautiful and most wonderful have been, and are being, evolved. ${ }^{180}$

Thus, war and conflict were elevated to a fundamental physical law as universal and uncontested as Newton's theory of gravity but which substituted the immutable cyclicality of the latter for a diachronic theory of change. Being in accordance with the very laws of nature, warfare was therefore considered a progressive and virtuous endeavour, the truest expression of the nation-state's vitality and historical destiny.

Entire nations would soon be pitted against each other, with each successive war announcing a new and unprecedented level in the mobilisation of human, economic and industrial resources. As well as extending over regions, countries and continents rather than specific locations, battles would increasingly last days, weeks or even months. ${ }^{181}$ The industrialisation of the means of destruction created huge problems in terms of logistics, not least for the supply of ammunitions, spare parts and fuel. While in 1870-1 over nine-tenths of the supplies consumed by the German army were food and fodder, in 1916 two-thirds of all the supplies for a British division were made of ammunition, engineering materials and other kinds of equipment. ${ }^{182}$

The first direct application of motor power to warfare can be seen in the use of railways, enabling both a rapid deployment of troops across great distances and reliable supply lines that would sustain large armies. Previously, armies would essentially depend on the resources they could find in the territory they were occupying; increasingly, they could

179 While thermodynamics pointed to a movement from the ordered to the chaotic and the differentiated to the homogenous with the dissipation of useable energy, the theory of evolution provided an account of increasing differentiation and complexity in the living world. This is not necessarily the contradiction it may at first appear to be since thermodynamics allows for pockets of decreasing entropy within an overall picture of rising entropy. Crucially, however, both theories provided a direction to physical processes, an arrow to time. Furthermore, Michel Serres sees in Darwin's theories the manifestation of the 'abstract motor' with a reservoir of populations generating dynamic evolution through the exploitation of differences in survival fitness, following a mechanism of circulation of naturally selected species.

De Landa, War in the Age of Intelligent Machines, p.141

${ }^{180}$ Pick, War Machine, pp.85-6

181 Van Creveld, Technology and War, p.122

182 Van Creveld, Command in War, p.185 
be supported by agriculture and industries located hundreds of kilometres away. As early as 1842 , Prussia made plans for the construction of a network of strategic railways in preparation for the eventuality of a simultaneous war against France and Russia. It went on to make increasing use of railways in its spectacularly successful campaigns in Schleswig Holstein, Austria and France between 1864 and 1870. Combined with industrial production and the early electromagnetic telecommunication technologies (more of which in the next chapter), railways participated in the constitution of the huge static war fronts of World War I, capable of sustaining enormous costs, both in lives and material.

Firearm technology also improved greatly in the nineteenth century and first half of the twentieth century, both in terms of power and accuracy. Ballistics was complemented by a new understanding of the chemistry of explosives and the physical laws of heat, with focus shifting from the reversible phenomenon of 'trajectory' to the irreversible process of 'explosion.' ${ }^{183}$ If up to the mid-nineteenth century, the rifle could only be used with any significant effectiveness when employed in mass, new firearms now allowed precision targeting along with an exponential rise in the rate of fire. Accompanied by the development of ever more powerful artillery, this increasingly made tight formations of advancing men unsustainable although the military establishment was slow to recognise this. This tactical inertia led to disaster in World War I where the machine gun rendered charges across open ground all but suicidal.

Most of World War I was thus characterised by a tactical and strategic stalemate during which European nations focused all the firepower and industrial might they could muster in very concentrated areas. The resulting casualties were horrendous: 260,000 men died and a further 450,000 were injured during the Battle of Verdun alone. As World War I veteran Ernst Jünger put it, the soldier was thus reduced to fuel for the war machine, "just like charcoal, which is hurled under the glowing cauldron of war so as to keep the work going. 'The troops are burnt to cinders in the fire' is the elegant formula found in the manuals of the military art." ${ }^{\text {"184 }}$ Jünger's words remarkably echo those of Clausewitz in his letter to Fichte in 1809, in which he insisted on the need for

${ }^{183}$ De Landa, War in the Age of Intelligent Machines, p.242.

Van Creveld notes that a gun can be simply understood as an internal combustion engine acting in one direction instead of two.

Van Creveld, Technology and War, p.82

184 Jünger, Der Kampf als Inneres Erlebnis, p.33 
"mobilising the energies of every soldier to the greatest possible extent and in infusing him with the warlike feelings, so that the fire of war spreads to every component of the army instead of leaving numerous dead coals in the mass." ${ }^{\text {185 }}$

But for Jünger, men were not only consumed by the Great War; some were also recast it in its fire. With machines of fire and metal now dominating the battlefield, survival required that men take on their attributes:

\begin{abstract}
The spirit of this Materialschlacht ('battle of materials') and war of the trenches, which had been fought more ruthlessly, more wildly and more brutally than any other, produced men which the world had not seen before. It was a new race, embodying energy and charged with the greatest strength. Sleek, lean and sinewy bodies with striking facial features, beneath the helmets were eyes petrified by a thousand frights. They were vanquishers, Stablnaturen ('natures of steel'), tuned in with the struggle in its most abominable form. Their approach over splintered landscapes meant the last triumph of a fantastic horror. Whenever their bold troops closed in on battered positions, where pale creatures with mad eyes stared at them, unforeseen energies were set free. As jugglers of death, masters of explosives and the flame, and as glorious predators, they moved through the trenches. ${ }^{186}$
\end{abstract}

Like many young men of his generation, Jünger was profoundly affected by what he saw and experienced during World War I. While the unspeakable horror of the industrial battlefield had broken many men, among others such as Jünger it was a revelatory experience, fuelling futurist fantasies which would resonate in the post-war politics of traumatised European societies. Alongside the exaltation of wat, fascism embraced the cult of the machine, the relentless advance of modernisation, and the perceptible increase in speed that touched all aspects of social life but were above all embodied by motorisation. ${ }^{187}$ Hitler wrote in Mein Kampf of "the universal motorisation of the world, which in the next war will be overwhelmingly decisive in the struggle." ${ }^{\text {188 }}$ For Mussolini, movement was the word which summed up best the new century: "movement towards the icy solitude of the poles and towards the virgin peaks of the mountains, movement towards the stars and towards the depths of the seas... movement everywhere and acceleration in the rhythm of our lives." 189

In his book Fire and Movement, Enst Jünger identified motorisation of movement as the very means to overcome the deadlock created by projected energy weapons in WWI: "It

185 Pick, War Machine, p.36

${ }^{186}$ Jünger, Der Kampf als Inneres Erlebnis, p.14

${ }^{187}$ For Paul Virilio, speed is inherently fascistic. If such a blanket statement is perhaps overly reductionist, he is correct is identifying an affinity which accounts for the enthusiasm of fascism for motorisation.

Paul Virilio, Speed and Politics: An Essay on Dromology (New York: Semiotext(e), 1986)

188 Gat, $A$ History of Military Thought, p.620

${ }^{189} \mathrm{Gat}, A$ History of Military Thought, p.581 
appears absurd to us today that the warring Will nearly exclusively uses the technical apparatus at its disposition to increase firepower, whereas movement in combat is still essentially limited to primitive energy, that of the muscular strength of man and horse." 190 If the tank had arrived too late to prove decisive in World War I, it had nevertheless heralded the application of the combustion engine to armoured ground vehicles - "it was the tank that regrouped all of the operations in the speed vector and recreated a smooth space for movement by uprooting men and arms." ${ }^{191}$ If most military practitioners were initially unsure about the value of this new weapon system, Colonel J. F. C. Fuller had no doubts about its revolutionary impact:

\begin{abstract}
As the tank can use its weapons and carry its own protection when in movement, it will enable the present static fighting to be replaced by dynamic fighting; that is to say, the soldier, whether infantryman or gunner, will not have to halt in order to deliver blows, but will do so whilst in movement. This possibility must sooner or later lead to a radical recasting of tactical organization, as radical as that which followed the introduction of gunpowder. ${ }^{192}$
\end{abstract}

Indeed, motorisation of movement on the battlefield proceeded apace with the development of armoured ground and airborne vehicles propelled by combustion engines.

As Fuller had foreseen, radical tactical experimentation followed, most notably in the Wehrmacht's use of Blitzkrieg in the first part of World War II. Blitzkrieg relied on the combination of aerial bombardment with motorised ground forces to achieve a high degree of surprise through mobility and speed. The Wehrmacht privileged decentralised operations (Auftragstaktik, also known as mission-oriented tactics) with commanders providing overall objectives and troops granted a great level of initiative to adapt to the fluidity of the battlefield. Van Creveld observes that "like Napoleon, but in charge of forces whose mobility was far superior and which consequently spread over much larger spaces, the World War II panzer leader was forced to decentralise the chain of command and rely on intelligent initiative at every rank, beginning with the lowest in order to seize every opportunity and exploit it to the hilt." already experimented with similar tactics in the later stages of the First World War with

\footnotetext{
190 Ernst Jünger, Feuer und Bewegung in Ernst Jünger, Sämtliche Werke, vol. I-IX (Stuttgart, 1980) V, p.118

${ }^{191}$ Deleuze \& Guattari, $A$ Thousand Plateaus, p.397

192 J. F. C. Fuller, The Foundations of the Science of War (1926)

http://cgsc.leavenworth.army. mil/carl/resources/csi/fuller2/fuller2.asp

193 Van Creveld, Command in War, p.191

We will see in the next chapter the role electromagnetic telecommunication technologies played in maintaining coherence within such a decentralised organisation of troops.
} 
the use of Sturmtruppen, elite shock troops that would infiltrate allied defences and use surprise to capture or destroy headquarters or strongpoints. Such battalions, of which Jünger was a distinguished member, employed flexible chains of command and although their successes were insufficient to win the war, it foreshadowed the organisational innovations that would follow.

Finally, the new increase in mobility brought on by motorisation also resulted in the disappearance of the front as strategic bombing brought lethality to entire nations. Civilian populations were soon explicitly targeted as war became total. Science and technology were directed to the development of ever more destructive energy weapons, culminating in the atom bomb. When nuclear weapons were dropped on Hiroshima and Nagasaki, the spectacular closing chapter to the most destructive and costly war in history, few could doubt anymore the prescience of the prediction made by the electrical engineer and scientist Nikola Tesla in 1900 concerning the evolution of "the war apparatus toward the greatest possible speed and maximum rate of energy-delivery."104 The final increase in the destructiveness of war which Hiroshima and Nagasaki heralded and which was pursed ad absurdum with the rapid development of nuclear weaponry appeared to bring to a close the era of total war. Indeed, George Kennan would observe in 1961 that:

\begin{abstract}
The atom has simply served to make unavoidably clear what has been true all along since the day of the introduction of the machine gun and the internal combustion engine into the techniques of warfare [...] that modern warfare in the grand manner, pursued by all available means and aimed at the total destruction of the enemy's capacity to resist, is [...] of such general destructiveness that it ceases to be useful as an instrument of any coherent political purpose. ${ }^{195}$
\end{abstract}

The application of the computer and electromagnetic telecommunication technologies to strategic and military affairs during the Cold War would largely preoccupy itself with trying to reconcile war with the existence of such terrible weapons, whether in preparation for a nuclear exchange or in managing conflict so that this threshold would never be passed.

Before we can move on to this next era however, I will conclude this chapter with a discussion of Clausewitz and the relation of the ideas he developed in $O n W a r$ to the

\footnotetext{
${ }^{194}$ H. Bruce Franklin, War Stars: The Superveapon and the American Imagination (New York: Oxford University Press, 1988), p.205

195 Gray, Postmodern War, p.138
} 
thermodynamic world whose birth he was witnessing and to the later scientific developments he appeared to anticipate.

\section{Clausewitz 'Translates' Thermodynamics}

While Azar Gat has made a persuasive case for the influence of romanticism and its anti-rationalistic stance on the writings of Carl von Clausewitz, ${ }^{196}$ it is nevertheless also possible to relate the Prussian officer's ideas to the thermodynamic developments in science. Indeed, whereas Clausewitz neglected the growing importance of new energy technologies, writing as he was at a time in which technological change in military affairs was still relatively slow, he was scientifically literate, reading mathematical treatises and attending physics lectures at a time where science was turning to the study of energy and advances in the theories of probability were being made. Despite his professed dislike of metaphors in military theory, Clausewitz employed a broad range of them, many of which echo thermodynamic notions. Writing in an epoch on the cusp of the science of energy, Clausewitz naturally inherited some terms that originated from the vocabulary of mechanism (centre of gravity, friction, etc.) but many of the ideas he developed broke significantly with mechanistic approaches to warfare.

Notwithstanding his emphasis on genius and moral factors, those qualities most celebrated by the romantics, it would be misleading to view Clausewitz as anti-science or anti-reason. His major work $O n W a r$ work still sought to provide a reasoned understanding of war but one which recognised the inherent limits of reason when grappling with such a dynamic and complex phenomenon, in the same way that thermodynamicists had to trade the mechanistic claims of complete predictability for a more stochastic understanding of the natural world.

Clausewitz's approach must be contrasted with many of the popular contemporary military theorists, most prominently Jomini and von Bülow, who still sought to discover the eternal laws of war that had conferred victory throughout the ages. This led to the elaboration of a number of fixed rules, algebraic formulas, and geometric principles which remained very much in the spirit of mechanist conceptions of warfare in

196 Gat, $A$ History of Military Thought

John Lynn has subsequently adopted and expanded on much of this analysis - Lynn, Battle, p.190-210 
assuming proportionality, linearity, and thus predictability. While Jomini, drawing on his experience of Napoleonic warfare, did advocate mobility, initiative, and aggressive conduct in military operations, his work remained heavily premised on the existence of optimal geometric lines of operation which if properly followed would ensure victory at all times and places. This attitude was even more marked in Bülow with Newtonian physics weighing heavily on his theory of military force, his use of language and arithmetic mirroring that of the law of gravitation:

\begin{abstract}
The agency of military energies, like other effects or nature, becomes weaker [...] in an inverse ratio of the squares of the distance; that is to say, in this particular, of the length of the line of operations. Why should not this law, which governs all natural effects, be applicable to war, which now consists of little more than the impulsion and repulsion of physical masses? If, which I do not doubt, it is admissible in the theory of the line of operations, we may in the future easily calculate the utmost extent to which military success may be carried. ${ }^{197}$
\end{abstract}

Clausewitz rejected the mechanistic approach, indicting it for only paying "regard to activity on one side, whilst war is a constant state of reciprocal action, the effects of which are mutual." ${ }^{198}$ It is useful to remind ourselves of the original audience he was addressing in $O n W a r$, namely the Prussian military elite which had suffered humiliating defeats at the hand of Napoleon and longed for a return to its glory days. It would therefore be natural for Clausewitz to emphasise those elements of the Prussian tradition which he considered harmful, namely the drive for "an army made like an automaton by its rigid formations and orders of battle, which, movable only by the word of command is intended to unwind its activities like a piece of clockwork." ${ }^{199}$ For Clausewitz, such an approach came to the detriment of an understanding of war as a dynamic process: "the shock of two hostile bodies in collision, not the action of a living power upon an inanimate mass."200

While the feedback process of the 'reciprocal actions' by the two opposing forces would theoretically tend to the 'extreme' and the 'absolute', the escalation to pure unlimited war is impossible because conflict is necessarily circumscribed by its historical context and hence always by policy and its instrumental calculations. ${ }^{201}$ Clausewitz concludes that "if the extreme is no longer to be apprehended, and no longer to be sought for, it is

197 Gat, $A$ History of Military Thought, p.85

${ }^{198}$ Carl von Clausewitz, On War (Hertfordshire: Wordsworth, 1997), p.86

199 Pick, War Machine, p.37

${ }^{200}$ Clausewitz, On War, p.8

${ }^{201}$ Clausewitz, On War, pp.9-10 
left to the judgement to determine the limits for the efforts to be made in place of it, and this can only be done on the data furnished by the facts of the real world by the lans of probability." 202 The Prussian major-general proceeds:

The absolute, the mathematical as it is called, nowhere finds any sure basis in the calculations in the art of war; [...] from the outset there is a play of possibilities, probabilities, good and bad luck, which spreads about with all the coarse and fine threads of its web, and makes war of all branches of human activity the most like a gambling game. ${ }^{203}$

The role of chance and the 'fog of war' necessarily deny the military commander the complete predictability and control of operations that mechanistic warfare promised therefore "war must always set itself free from the strict law of logical necessity, and seek aid from the calculation of probabilities." ${ }^{204}$ Clausewitz's emphasis on chance is to be contrasted with eighteenth century general Maurice de Saxe's belief that "war can be made without leaving anything to chance. And this is the highest point of perfection and skill in a general."205

War is therefore for Clausewitz a phenomenon marked by uncertainty and capable of erupting with the suddenness of "a perfect explosion." 206 Clausewitz returns several times to this conception of war as an indeterminate release of energy: "a pulsation of violent force more or less vehement, consequently making its discharges and exhausting its powers more or less quickly. ${ }^{207}$ Acting as a brake on the tendency of war towards the extreme, policy is "interwoven with the whole action of war, and must exercise a continuous influence on it" but only "as far as the nature of the forces liberated by it will permit. ${ }^{3208}$ Reason, in the form of policy, is crucial in order to exert some control over the use of armed conflict and de facto prevents its escalation to the absolute, but this control is still nonetheless limited in the face of the energies released by war.

\footnotetext{
${ }^{202}$ Clausewitz, On War, p.12

${ }^{203}$ Clausewitz, On War, pp.19-20

${ }^{204}$ Clausewitz, On War, p.27

${ }^{205}$ Lynn, Battle, p.129

206 Clausewitz, On War, p.13

${ }^{207}$ Clausewitz, On War, p.21

This notion of war as an indeterminate release of energy that eventually exhausts itself manifests itself also in his notion of the "culminating point of the attack" according to which any offensive diminishes in strength as it continues to advance until the point at which it can be reversed with ease by the opposition. The task of the commander therefore becomes the identification of this point, and which cannot be objectively calculated or determined and is therefore the province of intuition and genius.

${ }^{208}$ Clausewitz, On War, p.21
} 
We can also see thermodynamic notions at play in the famous concept of friction, the innate tendency for the accumulation of small setbacks that can result in severe breakdowns in the operation of the military machine. It might seem at first sight that the metaphorical term refers back to a mechanistic understanding of war but closer analysis does not allow for such a straight-forward reading:

\begin{abstract}
Everything is very simple in war, but the simplest thing is difficult. These difficulties accumulate and produce a friction which no man can imagine exactly who has not seen war. [...] The military machine, the army and all belonging to it, is in fact simple, and appears on this account easy to manage. But let us reflect that no part of it is in one piece, that it is composed entirely of individuals, each of which keeps its own friction in all directions. Theoretically all sounds very well: the commander of a battalion is responsible for the execution of the order given; and as the battalion by its discipline is glued together into one piece, and the chief must be a man of acknowledged zeal, the beam turns on an iron pin with little friction. But it is not so in reality, and all that is exaggerated and false in such a conception manifests itself in war. The battalion always remains composed of a number of men, of whom, if chance so wills, the most insignificant is able to occasion delay and even irregularity. ${ }^{209}$
\end{abstract}

Clausewitz rejects here the linear notions of additivity and assembly of the clockwork metaphor, arguing that the military machine cannot be reduced to parts any larger than its most basic constitutive elements, human bodies. Hence, friction "is not concentrated, as in mechanics, at a few points" but rather "is everywhere brought into contact with chance, and thus incidents take place upon which it was impossible to calculate, their chief origin being chance. ${ }^{2210}$ Recall that the non-linear phenomenon of friction had been excluded from Newton's laws of motion on the grounds that its effects were so marginal for most cases that they could be safely ignored in any calculations. However, for Clausewitz friction is everywhere in war and can accumulate with disastrous consequences. Therefore, friction cannot be dismissed as an unimportant deviation from the ideal mechanism; rather it is a fundamental and irreducible property of war. Clausewitz's use of the term 'friction' is hence much closer to the understanding of thermodynamics than that of mechanism since unpredictability and chance are endogenous to the system. ${ }^{211}$

Clausewitz's greatest insights were slow to be recognised by the military establishment. Indeed, Jomini was the more popular theorist for at least fifty years after the publication

\footnotetext{
${ }^{209}$ Clausewitz, On War, pp.66-67

210 Clausewitz, On War, p.67

211 U.S. Air Force Colonel John Boyd explicitly connected Clausewitzian friction with the second law of thermodynamics in his work on the warfighting decision cycle in the 1980s. The concepts of entropy and information are very closely linked, as we shall see in the next chapter.

Barry D. Watts, "Clausewitzian Friction and Future War" (McNair Paper Number 52, October 1996) http://www.ndu.edu/inss/McNair/menair52/m52c11.htmal
} 
of On War. Even after he gained pre-eminence, Clausewitz's indeterminacy has often been mistaken for a lack of clarity rather than an integral part of his philosophy. Frequently, military students of his work have made the "implicit and even explicit claim that, if Clausewitz were only less confused and understood his own concepts better, he would sound like Jomini." ${ }^{212}$ As a result, emphasis was recurrently put on those elements of his work which appeared to provide eternal rules for victory, such as the targeting of the enemy's 'centre of gravity', and the maximum concentration of force and mass, those linear Newtonian concepts.

Unsurprisingly, it is among the German military establishment that his ideas would be best appreciated and understood, notably by Helmut von Moltke the Elder:

No plan of action can look with any certainty beyond the first meeting with the major forces of the enemy [...] The commander is compelled during the whole campaign to reach decisions on the basis of situations than cannot be predicted. All consecutive acts of war are, therefore, not executions of a premeditated plan, but spontaneous action, directed by military tact. ${ }^{213}$

Auftragstaktik would be a logical response to a Clausewitzian understanding of war, distributing uncertainty, adjusting to contingency and navigating the inherent chaos of warfare.

\section{Conclusion}

If the harnessing of intimate sources of energy powered the rapid industrial development of Western societies and dreams of unlimited progress, it also brought with it instability and the recurring fear of their exhaustion. The linear certainties of mechanism appeared undermined by the discovery of an ineluctable and irreversible drive towards physical disorder. Thermodynamic warfare was marked by an increasing intensity and breadth of conflicts with the liberated energies and passions consuming continents until their eventual dissipation through the complete material and moral enervation of the societies engaged in them. An awareness of the irreducible uncertainty of warfare and of the consequent futility of mechanistic warfare's previous attempts to impose order through a static predetermined battle plan permeated the thought of the

${ }^{212}$ Alan D. Beyerchen, "Clausewitz, Nonlinearity and the Unpredictability of War", International Security, 17:3 Winter, 1992) http:/ www.clausewitz.com/CWZHOME/Beyerchen/CWZandNonlinearity.hton ${ }^{213}$ Lynn, Battle, p.212 
more astute of military observers. Notwithstanding, the quest for order was to continue. Indeed, the next milestone in technoscientific development would revolve around the concept of information and its potential for managing thermodynamic uncertainty. Communication and control now took centre stage through electromagnetic technologies and particularly the computer. 


\section{Chapter 5: Cybernetics and the Genesis of the Computer}

The two previous chapters have each treated of a separate regime of the scientific way of warfare, combining a discussion of both the respective key technologies and scientific principles along with an analysis of their relationship to the forms of warfare contemporary to them. However the next two regimes will be covered over the course of two chapters each, a first one setting out the central technological and scientific concepts and a second dedicated to their military embodiments. This is partly due to the need for a longer exposition of the scientific ideas which gain in complexity as we will progress but is above all demanded by the necessity of a lengthier analysis of military theory and practice. Indeed, from the Second World War onwards, the mantle of the scientific way of warfare clearly passes on to the United States and its conduct of war will remain the central focus of the remaining study. With the particularly technologically-intensive American approach to warfare, reliance on science to think and practice warfare reaches a new apex and hence requires particular consideration.

I will provide here an account of the genesis of the computer in the context of the lineage of electromagnetic technologies. Particular attention will be paid to military applications and the specific role which the Second World War played in the development of the computer and its related sciences. This will be followed by a discussion of the scientific concept of information, the principles underpinning the cybernetic science of control and communications, and the latter's diffusion in fields as diverse as engineering, biology, human cognition, and the social sciences. The widespread military applications of cybernetics and computers will be left to the next chapter.

\section{Electromagnetic Telecommunications and War}

Whereas the clock harnessed the laws of motion (as subsequently theorised by classical mechanics) and the engine put to work the intimate sources of energy of inert matter by 
exploiting heat differentials (leading to the science of thermodynamics), the technologies of telecommunications and computing involved the mastering of the electromagnetic field. Electricity was a phenomenon that had been observed for millennia but a real understanding of its nature and its relation to magnetism had to wait for the nineteenth century and the work of such luminaries as Ampère, Faraday, and Maxwell. The application of electricity and radio waves to communications would allow information to travel as fast as the physical limits of the known universe, namely the speed of light.

The electric telegraph heralded the start of a telecommunications revolution that would lead to present-day computer networks. ${ }^{214}$ Previous to it, the speed of communication over large distances was broadly limited to that of the fastest existing means of transport. Beacons, smoke signals, or other visual signs could be relayed across vast expanses but weather and geography were a major hindrance to the performance and reliability of these systems. Furthermore, the complexity of messages that could be transmitted was very limited; the semaphore network used by Napoleon could only transmit two words a minute and the cost of sending a message was roughly thirty times as high as for the electric telegraphs which would follow. Aside from being considerably more cost-effective, the latter could also transmit forty to fifty words a minute with the introduction of the Morse code in $1844 .{ }^{215}$ The telecommunications device was an instant success with telegraphs accompanying the construction of railroads, providing invaluable help in managing the expanding rail networks. By 1866, the first transatlantic telegraph cable had been completed, a formidable annihilation of distance. The telegraph also allowed for the precise synchronous setting of clocks and the establishment of standardised time, often called 'railway-time' because of its initial purpose in coordinating railroad timetables. We have here an example of the complementarities of different technologies when they are combined in complex technosocial assemblages, the mutual dependencies of clock, telegraph and railways promoting and reinforcing their potential for organising social life.

Armies relied on telegraphy from the very beginning, both as early warning systems of the movements of any foreign army and to manage the huge logistical challenges of

${ }^{214}$ Telegraphy refers to the long distance transmission of written messages without physical transport. By this definition this would include non-electromagnetic telecommunication technologies such as smoke signals or other visual signs, as well as modern technologies such as email or fax. However, I will be using the term telegraph here to describe only the electric telegraph that employed Morse code.

${ }^{215}$ Pacey, Tecbnology in World Civilization, p.138 
industrialised war. Because of their reliance on fixed stations and cables, both the telegraph and the telephone were best suited to defence than offence. The difficulty of extending a communications network in the field essentially limited their tactical application to siege warfare, an increasingly peripheral activity of war. ${ }^{216}$ World War I saw the extensive use of the telephone for communication between military headquarters and the front, but the lines stopped at the latter. Beyond the trenches, command relied on traditional means, namely optical and acoustic signals that were increasingly drowned out by the noise and smoke of the industrial battlefield.

Wireless telegraphy, the transmission of text through radio waves, was pioneered in the last decade of the nineteenth century. Its early uses were primarily naval, enabling ships to send Morse code between themselves as well as with land. Voice was added to radio communications at the turn of the century. It was not until the inter-war period however, that the technology was made reliable, mobile, and simple to use, accompanied by a broadening of the frequency spectrum, thereby reducing the problem of mutual interference that had plagued its tentative use in the trenches of the First World War. ${ }^{217}$ The Germany military was the first to apply wireless telecommunications in a systematic manner: in World War II, most of its tanks and planes were equipped with two-way radio communication for contact with other vehicles and headquarters. This enabled the high degree of coordination and tactical flexibility that Blitzkrieg required, as discussed in the previous chapter. As with virtually all major technological innovations, the successful use of radio by the German army had as much to do with the quality and quantity of the device as with its integration within a new organisational and tactical scheme that could take full advantage of it.

Electromagnetic communications continued to grow in importance after the Second World War as miniaturisation proceeded, transmission of video was added to that of audio, and orbiting satellites layered a telecommunications network across the entire globe. However, this period was also characterised by the increasing convergence of those technologies with that of the computer, and so we must now turn to the latter's genesis.

216 Van Creveld, Command in War, p.107

217 Van Creveld, Command in War, p.191 


\section{The Computer - Genesis and Embodiment of the Abstract Machine}

The computer's Anglo-Saxon name betrays its specific original function, that of a complex calculator. ${ }^{218}$ In fact, computers initially referred to individuals, often women, employed to do arithmetic calculations, whether assisted or not by mechanical aids. One of the first applications of this 'primitive' computing power was the calculation of ballistics firing tables for artillery. Electronic computers were born as a technology designed for the automation of these calculations; in that sense they are part of the lineage of the slide rule and abacus. But the computer is first and foremost a conceptual machine that was imagined and theorised before its current embodiment was ever produced. This is in contrast to the clock and engine which only became abstract machines after the technologies reached a certain level of refinement through the trialand-error work of countless artisans.

The principles of operation of the computer rest on logic. Computing is essentially the repeated application of a fixed and finite set of rules to incoming data. As a purely conceptual machine, a computer could therefore exist in any number of forms: from the simple use of pen and paper to a complex set of cogs and gears or its more familiar electronic embodiment. In the 1830s, building on his work on gear-based calculators, mathematician Charles Babbage imagined the first programmable computer, the Analytical Engine. His design involved 'programs' using loops of punched cards, ${ }^{219}$ a 'memory' which could store the results of intermediary calculations, a control unit and an output mechanism, all crucial features of modern electronic computers. Unable to secure the necessary government funding, Babbage was never able to build his Analytical Engine. ${ }^{220}$

The abstract computer would resurface in 1937 as part of Alan Turing's elaborate demonstration in the field of symbolic logic. In order to prove his point, Turing conceived of what became known as a 'Turing Machine'. The theoretical machine would

218 The different names given to the computer in various languages are instructive in that they reveal specific understandings of the technology's purpose or nature. The French refer to it as the 'ordinateur' a machine that puts things in order. In Finnish, it is a 'tietokone', which means 'knowledge machine.' In Chinese, the computer is called 'dian nao' or 'electric brain.' Finally, the Icelandic language has a particularly poetic formulation with 'tölva', the 'number prophetess.'

219 The use of punched cards as an early form of software can be traced back to Jacquard's loom, which used cards to modify sewing designs at the turn of the nineteenth century.

${ }^{220}$ In 1991, a team from the London Science Museum eventually built a working Analytical Engine, demonstrating the correctness of Babbage's design. 
be able to read, write and erase data, and employed a memory, a central processing unit, and a program controlling the machine's operations through a finite series of mathematical instructions known as algorithms. Although Turing had only conceived of his machine for theoretical purposes, it would soon find a physical embodiment thanks to the progress made in the harnessing of electromagnetic forces. The physical computer would have no doubt emerged sooner or later but it was the technological impulse of the Second World War that was crucial to the circumstances of its genesis. The brute calculating power of the computer became necessary for two technoscientific projects of the war: cryptanalysis and nuclear physics.

Cryptography, the secret coding of messages, had developed greatly in order to protect electromagnetic telecommunications from interception and impersonation. Throughout World War II, the Allies expended great effort in breaking the Enigma code used by the German military for its telecommunications. Doing so required a phenomenal computing power for its day and which could only be achieved through an unprecedented efficiency in the automation of calculations. The technological breakthrough was so formidable that the German military, utterly convinced of the inviolability of the Enigma cipher, refused until the end to accept that it had been broken despite obvious indications that the Allies were receiving advance warning of their plans. Alan Turing was closely involved in the successful program in which Colossus, one of the first digital, programmable, and electronic computers, played a central role. Though not strictly speaking a Turing machine, it was nevertheless one of several significant milestones in the development of the modern computer. ${ }^{221}$

The development of the nuclear bomb was an unprecedented industrial, technoscientific and military undertaking that mobilised up to one percent of the United States federal budget. Recent advances in theoretical physics had made a nuclear bomb a tangible perspective but there remained major obstacles to its realisation. Incredibly complex calculations were necessary to strengthen the basic understanding of nuclear fission and harness it into a practical device. The Manhattan Project began by relying on mechanical calculators operated by some of the wives of the scientists but it soon became apparent

221 The title of first electronic computer is fiercely disputed with other candidates including the Z3 and ENIAC computers. The intricacies of the arguments are less important than the fact that they simply illustrate that the development of the general purpose computer (i.e. Turing-complete) was complex, piecemeal, and contingent on the applications to which the device was put to and on the availability and cost of other technologies, in contrast to its theoretical and abstract model. 
that greater computing power would be required. Under the impulsion of the mathematician John von Neumann, modified IBM punched-card machines were introduced and allowed the completion of the project before the end of the war. ${ }^{222}$

Von Neumann played an important role in the development of the computer as both a conceptual and physical machine. If Turing had already imagined a machine that would fulfil all the functions of the modern computer, it was von Neumann who provided the crucial bridge between the abstract mechanism and the material work electrical engineers were pursuing. According to Herman Goldstine, a mathematician and army officer who brought him in as a consultant at the University of Pennsylvania in 1944 to work on the design of high-speed digital computers contracted by the Army, von Neumann was the first person "who understood explicitly that a computer essentially performed logical functions, and that the electrical aspects were ancillary." 223 By reducing all computing operation to logical functions, von Neumann was able to design a method whereby problems could be broken down into a sequence of discrete logical steps that could be programmed into a computer, establishing the approach of serial computing. He also gave his name to a computer architecture which distinguished itself from previous mechanical embodiments in that it used a single storage structure (memory) to contain both instructions and data. In this way, computers could be systematically reprogrammed for each new task rather than being purpose-built for a particular operation.

A diagram of the von Neumann architecture can be seen in Figure 4. The arithmetic logic unit (ALU) performs all the arithmetic computations according to instructions transmitted by the control unit (in practice, modern computers integrate these two elements in their central processing unit, the CPU). The memory unit serves as temporary storage for all the program instructions and data that are being executed by the computer. Intermediate results can be stored in the memory and recalled when necessary during the computation of a problem with several discrete logical steps. Input and output connect the computer to its environment, allowing for the introduction of

\footnotetext{
222 In contrast to other scientists such as Robert Oppenheimer who became uncomfortable about the consequences of their work on the Manhattan project, von Neumann remained closely involved in the development of nuclear weapons until his death in 1957. A fervent proponent of nuclear build-up and even of a pre-emptive strike on the Soviet Union, he participated in the development of the hydrogen bomb and was appointed Commissioner of the Atomic Energy Commission in 1955.

223 Heims, Jobn von Neumann and Norbert Wiener, p.182
} 
new programs and data and the communication of computation results. Of course, the output can also serve as a new input for the computer, constituting a closed processing loop in which the computer responds to the stimulus of its own output. This point is particularly relevant to the below discussion of cybernetics.

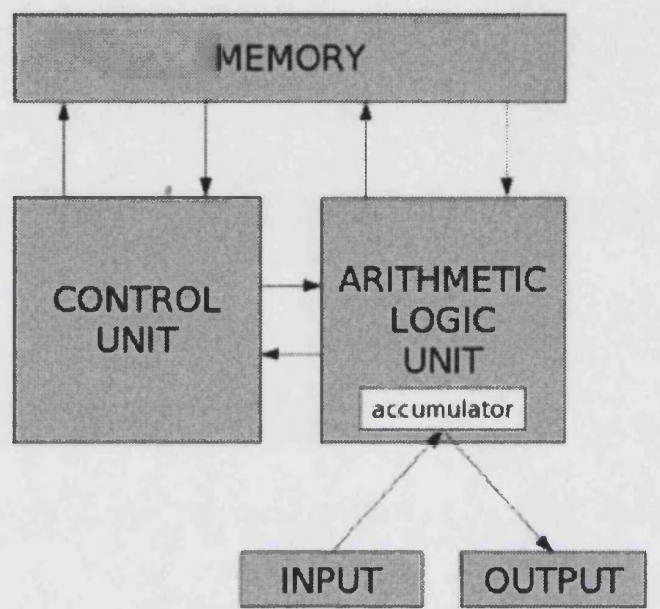

Figure 4: Diagram of the von Neumann architecture 224

Following their initial genesis for the purposes of code-breaking and the completion of the Manhattan project, computers subsequently continued to play a central role in the post-war military, involving the development of thermonuclear devices based on nuclear fusion and numerous military programs to be discussed in the following chapter. The electromagnetic computer was thus born and evolved as a military technology - "for two decades, from the early 1940s until the early 1960s, the armed forces of the United States were the single most important driver of digital computer development..225

The formidable computational power and the exponential increase that has been observed since (based on empirical observation, Moore's law states that computing power roughly doubles every 18 months) was made possible by the harnessing of electromagnetic forces and more specifically the understanding of the behaviour of electrons provided by quantum mechanics. ${ }^{226}$ The development of the transistor, a semi-

224 http://upload wikimedia.org/wikipedia/commons/1/1c/Von Neumann architecture.png

${ }_{225}$ Paul N. Edwards, "Why Build Computers?" in Merritt Roe Smith \& Gregory K. Clancey (eds.), Major Problems in the History of American Technology: Documents and Essays (Boston: Houghton Mifflin, 1998), p.454462

226 Quantum mechanics conform to thermodynamics but violate the linearity of Newtonian mechanics. At atomic or sub-atomic levels, the behaviour of matter no longer conforms to Newton's predictions. This 
conductor device which can serve as the building-block for logic gates in computer architecture (binary bifurcations for any step of a logical sequence) allowed both greater reliability and miniaturisation than the previous technology of vacuum tubes.

Whereas clockwork involves the transmission, storing and amplification of mechanical force and the engine amounts to the conversion of an energetic release from inert matter into mechanical work, the electronic computer's 'motion' is not at the level of any of its components but rather occurs at that of electrons whose patterns express logical and mathematical relationships. As Paul Edwards points out, "computers do not perform physical work [...] they can only control other machines that do, such as lathes, printers, or industrial robots. To do this, they transform information - programs, specifications, input from sensors - into control signals."227

It is the computer's ability to apply conditional branching and run programs that can respond to their own results as much as to external inputs that make it an ideal control mechanism. Thus a computer can be used to regulate and modify the behaviour of other machines via feedback loops. As we shall see in the next section and Norbert Wiener's work on servomechanisms, this was not a feature unique to the computer but the latter allowed a far greater complexity, precision and ubiquity of such control mechanisms. The development of the computer interface - an interface being defined as "where two or more information sources come face-to-face" 228 - has enabled progressively greater real-time control by the human user.

But to focus exclusively on its ability to execute logical programs and its application as a control device would mean neglecting another essential feature of the computer, namely its capacity to manipulate any form of symbolic information and thus simulate any electronic symbol-producing machine. This includes all media technologies of video and audio recording, processing and reproduction. For a long time, these technologies remained quite distinct from the computer but their relatively recent digitalisation is

implies that Newtonian physics are only an approximation of physical processes and that apply only at a macro level. The probabilistic behaviour of quantum particles revealed by measurement suggests the world might be fundamentally indeterminate and stochastic. This discovery delivered another blow to the totalising claims of mechanism, at least at the micro-level of reality, requiring the further extension of probabilistic mathematical instruments to apprehend natural phenomena. Chaos theory would later show that linear assumptions of mechanism blinded it to many physical processes at the macro-level, including those of a deterministic nature. (see chapter 7 ).

${ }_{227}$ Edwards, The Closed World, p.28

${ }^{228}$ Michael Heim, The Metapbysics of Virtual Reality (New York : Oxford University Press, 1993), p.77 
erasing any fundamental distinction between the computer and the specific technologies of the television, camera or radio. We may distinguish devices by the type of media content they produce or transmit or by the interface with which we interact with them, but ultimately they are all in a more or less advanced process of cannibalisation by digital computer technology. This is seen in the current collapsing of devices: emails can be sent through a television, photographs taken with a telephone, films viewed on a personal digital organiser. The computer therefore constitutes an abstract machine that encompasses all electronic technology of symbolic representation.

Lastly, the conjunction of computing and telecommunication technologies has enabled computers to network together and share information and processing power, with the Internet as perhaps the most spectacular product of this tele-interaction of computing devices). This has enabled the convergence observed today in electronic devices while also greatly extending the distances across which a computer can act as a control mechanism, whether automated or under human operation.

To summarise then, the contemporary networked computer can be understood as a single device capable of four distinct yet interlocked functions:

1. a logic machine applying finite rules to data;

2. a control mechanism using information feedback (i.e. a servomechanism see below);

3. a semiotic machine handling any symbolic information including numbers, characters and images;

4. an electromagnetic telecommunications device.

None of these functions are exclusive to the computer and conversely many modern computing devices only fulfil one or a few of these functions, depending on the purpose for which they were designed. However, the computer finds itself at the point of convergence of several techno-scientific developments whose conjunction has amplified and transformed their respective capabilities and potentialities. ${ }^{229}$ The computer's ability to imitate any symbol-producing machine has enabled it to 'cannibalise' all such

\footnotetext{
${ }^{229}$ A similar convergence was already observed when Alexander Graham Bell and others combined electric sound reproduction with telegraphy to give birth to the telephone in the last quarter of the nineteenth century.
} 
machines and integrate them under a single digital architecture. What unites all these separate technologies in a single device or abstract machine is the notion of information. Indeed, narrowed down to its barest definition, the computer is first and foremost an information-processing device. In the theories of Norbert Wiener and Claude Shannon, the three functions of calculation, communication and control were already being linked in the 1940s before they were combined in any single machine. The concept which united these functions was that of information. If force was the core concept of Newtonian mechanics and energy that of thermodynamics, it is information which would fulfil a similar organising function for the science of cybernetics.

\section{Bits and Negentropy: Information Becomes Physical}

\footnotetext{
Information is information, not matter or energy. No materialism which does not admit this can survive at the present day.
}

Norbert Wiener ${ }^{230}$

Before scientists began paying attention to it in the years preceding World War II, information was traditionally understood as the communication of human knowledge. However, the scientific concept of information which emerged in this period is quite distinct. The problem with the established definition of information as necessarily connected to meaning, and therefore context, was that it made scientific quantification and general theorisation extremely complicated. Engineers seeking to improve the efficiency of telecommunication technology therefore sought to detach the meaning of information from the process of transmission. Ralph Harltey, responsible for some of the foundations of information theory, wrote in 1928 of the need "to eliminate the psychological factors involved and to establish a measure of information in terms of purely physical quantities."231

Such a measure emerged from Claude Shannon's war research on fire-control systems and cryptography at the AT\&T Bell labs. As an engineer, Shannon was concerned with

\footnotetext{
${ }^{230}$ Norbert Wiener, Cybernetics or Control and Communications in the Animal and the Macbine (New York: Wiley, 1949), p.155

231 Rafael Capurro, The Concept of Information (2003) http://www.capurrode/infoconcept.html
} 
the practical issue of the reliability of the transmission of a message, not its meaning. Communication and information were thus to be understood as a process between a sender and a receiver of communication that is distinct from the meaning being transmitted. Shannon's colleague Warren Weaver emphasised this distinction:

\begin{abstract}
The word information, in this theory, is used in a special sense that must not be confused , with its ordinary usage. In particular, information must not be confused with meaning [...] The word information in communication theory relates not so much to what you do say, as to what you could say. That is, information is a measure of one's freedom of choice when one selects a message [...] The concept of information applies not to the individual messages (as the concept of meaning would) but rather to the situation as a whole. ${ }^{232}$
\end{abstract}

For Katherine Hayles, this 'meaninglessness' allowed information to become disembodied and "to be conceptualised as if it were an entity that can flow unchanged between different material substrates." 233 Information becomes "a pattern, not a presence. ${ }^{.234}$ Information could thus be theorised and mathematically expressed as an abstract value detached from its specific embodiments in a similar way to matter and energy. Concomitantly, the process of communication was analogously abstracted from physical embodiment into a general diagram of operation. This understanding of information and communication would be central to the constitution of cybernetics as a science of control and communications within and between systems, be they organic, mechanical or social.

Indeed, for Shannon, the aim was to "consider certain general problems involving communication systems" which required the representation of "the various elements involved as mathematical entities, suitably idealized from their physical counterparts."235 In other words, to conceptualise an abstract communication machine. The abstract machine presented by Shannon consisted of five different components: an information source which produced the message to be communicated, a transmitter which operates on the message in order to produce a signal suitable for transmission, a channel which provided the medium for the signal be transmitted, a receiver which reconstructs the message from the signal, and a destination to which the message was intended. In addition, Shannon considered a noise source which would introduce a stochastic interference to the signal

\footnotetext{
232 Tom Siegfried, The Bit and the Pendulum: From Quantum Computing to $M$ Theory - The New Pbysics of Information (New York: John Wiley \& Sons), p.167

${ }^{233}$ N. Katherine Hayles, How We Became Postbuman: Virtual Bodies in Cybernetics, Literature, and Informatics

(Chicago \& London: University of Chicago Press, 1999), p.54

${ }^{234}$ Hayles, How We Became Posthuman, p.18

${ }^{235}$ Claude E. Shannon, "A Mathematical Theory of Communication", Bell System Tecbnical Journal, Vol. 27, 1948, pp.3-4 ht巾://cm.bell-labs.com/cm/ms/what/shannonday /shannon1948.pdf
} 
and impede communication; the question then becomes the level of redundancy necessary to avoid the pattern of the message being drowned out by the noise - how to preserve order from chaos.

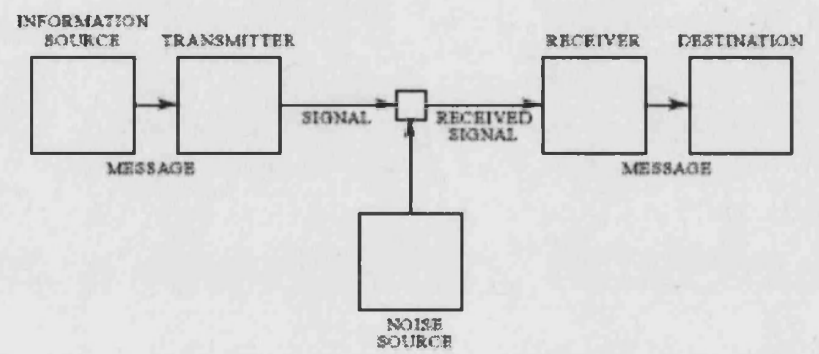

Figure 5: Schematic diagram of an abstract communication machine ${ }^{236}$

The basic unit of information would be the bit (binary digit) with one bit representing the choice between two mutually exclusive choices e.g. the true or false of logic, the zero or one of the digital computer. Since Shannon had demonstrated that binary choices were the least expensive way to handle information, the transmission of any information could therefore be broken down into a sequence of optimal (i.e. more or less equally probable) binary choices that would identify the correct message from the range of possible messages. ${ }^{237}$

Shannon's probabilistic approach to information meant that the greater the uncertainty about a situation - in other words, the wider the range of equally probable alternative states that could be communicated - the larger the physical quantity of information necessary. Similarly, an improbable message would contain more information than a highly probable one. Shannon equated the mathematical measure of information with Boltzmann's formula for thermodynamic entropy (the measure of unusable energy or disorder within a closed system) because of the similarity in the probability distribution. $^{238}$

\footnotetext{
236 Shannon, "A Mathematical Theory of Communication", p.3

${ }^{237}$ Von Baeyer, Information, pp.30-31

${ }^{238}$ Shannon's discovery was made outside of the realm of the physical sciences but the immediately apparent overlap between the measurement of information and that of entropy and the explanatory power it seemed to offer soon led scientists to make the connection into a meaningful physical one, thereby initiating a momentous transformation in the scientific worldview. According to Henri Atlan, "a real kinship between quantity of information and entropy means that not only does this notion of information have practical relevance for the statistical treatment of some communication problems but that it also expresses a universal physical reality in relation to other measurable physical magnitudes such as energy, temperature, etc... and that it thus fully enters the domain of the natural sciences."
} 
However, Norbert Wiener, the founder of cybernetics, along with the physicist Leon Brillouin, effected a crucial change in sign to Shannon's equation. Information became defined as the opposite of entropy - negative entropy or negentropy:

The notion of the amount of information attaches itself very naturally to a classical notion in statistical mechanics: that of entropy. Just as the amount of information in a system is a measure of its degree of organisation, so the entropy of a system is a measure of its degree of disorganisation; and the one is simply the negative of the other. ${ }^{239}$

Information therefore became a measure of order and opposed to entropy as that of disorder and randomness. Anthropologist and cyberneticist Gregory Bateson further expanded on this new understanding of information:

\begin{abstract}
The technical term "information" may be succinctly defined as any difference which makes a difference in some later event. This definition is fundamental for all analysis of cybernetic systems and organisations. The definition links such analysis to the rest of science, where the causes of events are commonly not differences but forces, impacts, and the like. The link is classically exemplified by the heat engine, where available energy (i.e. negative entropy) is a function of a difference between two temperatures. In this classical instance, "information" and "negative entropy" overlap. ${ }^{240}$
\end{abstract}

Thus the function of cybernetic systems driven by information feedback, that is systems endowed with the ability to adjust future conduct by past performance, is "to control the mechanical tendency towards organisation; in other words, to produce a temporary and local reversal of the normal direction of entropy."241 The general tendency towards increasing entropy remains but, on the background of this rising chaos and indeterminacy (which Wiener designated as 'evil', the diabolical arch-enemy of the scientist in search of the order governing the universe), ${ }^{242}$ information allows for the constitution of pockets of decreasing entropy and growing complexity, and which Wiener explicitly links to progress.

Henri Atlan, L'Organisation Biologique et la Theorie de l'Information (Paris: Editions du Seuil, 2006), p.174 See chapter 4 for a discussion of entropy and thermodynamics.

${ }^{239}$ Wiener, Cybernetics, p.18

The term of negentropy was first introduced by Erwin Schrödinger in his 1944 text What is Life. Erwin Schrödinger, What is Life? And Other Scientific Essays (Garden City, NY: Doubleday Anchor, 1956) ${ }^{240} \mathrm{John}$ Arquilla \& David Ronfeldt, "Information, Power, and Grand Strategy: In Athena's Camp" in Stuart J.D. Schwartzstein (ed.), The Information Revolution and National Security (Washington, DC: The Center for Strategic and Intemational Studies, 1996), p.137

${ }^{241}$ Norbert Wiener, The Human Use of Human Beings: Cybernetics and Society (London: Eyre and Spottiswoode, 1954), pp.24-25

${ }^{242}$ Wiener's view of evil here is that which St Augustine characterises as incompleteness (negative evil) rather than the malicious type of the Manicheans (positive evil). Wiener, The Human Use of Human Beings, p.11 \& pp.34-35 
As Hayles points out, Shannon's original theory "defines information as a probability function with no dimensions, no materiality, and no necessary connection with meaning. It is a pattern, not a presence." ${ }^{243}$ This shift was pursued further in cybernetics, reinforcing a conception of information which severed it from notions of meaning and the individual contexts in which it is found to become a universal pattern common to all forms of organisation - a scientific concept as crucial as those of matter or energy. Later theories have posited that matter and energy are but the mere expression of information, thereby elevating the latter to the sole metaphysical building-block of the universe. Summing up this worldview, social theorist Kenneth Boulding described matter and energy as "mostly significant as encoders and transmitters of information."2244

The dominance of the scientific concept of information appears today complete, having gained pre-eminence over those notions previously taken to be the core constituent of our reality. But such a momentous ontological shift in the scientific view of nature began with considerably more limited preoccupations centred around engineering problems and in the context of the rapid technological transformations wrought by World War II. The science of cybernetics that would emerge from this technoscientific endeavour would be the major contributor to the elaboration and the subsequent dissemination of the informational paradigm.

\section{Cybernetics: the Science of Control and Communications}

The thought of every age is reflected in its technique. Norbert Wiener ${ }^{245}$

Although it drew on older ideas and research, cybernetics, just like the computer, was born from the imperatives of war. Indeed, Norbert Wiener's wartime research played a major role in the elaboration of the central postulates of cybernetics. Wiener worked on one of the most urgent technological problems of the Second World War, namely the

243 Hayles, How We Became Posthuman, p.18

244 Arquilla \& Ronfeldt, "Information, Power, and Grand Strategy" in Schwartzstein (ed.), The Information

Revolution and National Security, p.139

245 Wiener, Cybernetics, p. 55 
improvement of antiaircraft defences. With the increase in the speed and altitude of bomber aeroplanes, antiaircraft gunners could no longer simply visually target the plane since it would have moved out of position in the short time necessary for the projectile to reach it. Antiaircraft defences were thus notoriously inefficient and successful hits resulted more from chance than the gunner's accuracy. Whereas the traditional problem of ballistics required the production of lengthy tables detailing the appropriate artillery elevation according to type of gun, shell, and range to a fixed target, fire control against a rapidly mobile target was a real-time computational problem. Wiener therefore focused on first developing a mathematical theory for making a statistical prediction of the future course of a plane given available information on its position and motion. Real-time application of the theory required the processing of information provided by radar (another product of the discoveries of electromagnetism) into adjustments in the aiming of the gun. A missed shot would be followed by an adjustment of the aim, a new shot and further adjustment if necessary. This led Wiener to think of this process as a feedback loop in which information gathering and processing precedes an action that results in a changed state and new flow of information.

The etymology of cybernetics refers to the Greek for steersman or governor and reflected Wiener's belief that a steersman and his rudder formed a feedback loop. The antiaircraft unit, whether fully automated or incorporating a human controller, thus formed a self-steering device guided by an information feedback loop. ${ }^{246}$ Wiener designated all self-steering devices relying on negative information feedback as servomechanisms:

\begin{abstract}
The machines of which we are now speaking are not the dream of the sensationalist, nor the hope of some future time. They already exist as thermostats, automatic gyro-compass ship-steering systems, self-propelled missiles - especially such as seek their target - anti aircraft fire-control systems, automatically controlled oil-cracking stills, ultra-rapid computing machines, and the like. They had begun to be used long before the war indeed, the very old steam-engine governor belongs among them - but the great mechanization of the Second World War brought them into their own, and the need of handling the extremely dangerous energy of the atom will probably bring them to a still higher point of development. [...] the present age is as truly the age of the servo-mecbanisms as the nineteenth century was the age of the steam engine or the eighteenth century the age of the clock [my emphasis]. ${ }^{247}$
\end{abstract}

\footnotetext{
${ }^{246}$ It is necessary here to distinguish between negative and positive feedback loops. Negative feedback refers to a system that responds to changed inputs with a stabilising adjustment. Positive feedback loops respond to inputs by amplifying the change in the variable and further moving the system from its point of origin. Wiener's work was essentially preoccupied with the first form of feedback. Positive feedbacks came to play a central role in the subsequent theories of chaos and complexity, as we shall see in chapter 7.

${ }^{247}$ Wiener, Cybernetics, p.55
} 
A cybernetic system, or servomechanism, is characterised by three distinct components: (a) receptors or sensors that can absorb informational input from its environment, (b) a processing unit which can record and process this input, compare it with the desired state of the input, and issue the necessary instructions onwards to (c) an output mechanism which can impact the environment in the required way. New outputs result in a new flow of input thereby closing the feedback loop. This continuous loop is enabled by the flow of information that links all the components together and allows the system to respond to changes in the perceived environment and adjust its behaviour accordingly (see Figure 6). This contrasts markedly with clockwork mechanisms which can only follow the pre-programmed path built into them and have no ability for selfregulation.

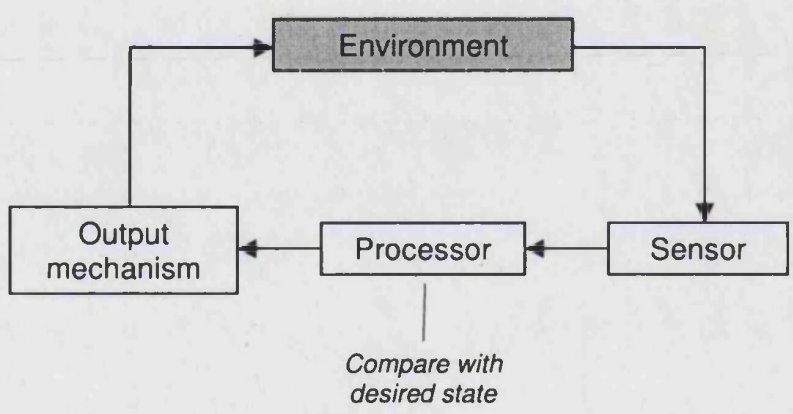

Figure 6: Information feedback loop in a cybernetic system

The servomechanism also distinguishes itself in that it substitutes the chain of causality ( $A$ is the cause of effect B) suggested by clockwork and characteristic of traditional scientific theories with the notion of circular causality ( $A$ is the cause of effect B which is cause of A). Consequently, reductionist atomistic frameworks of interpretations give way to systemic holistic understandings of any object of study. Mechanism had sought to understand any whole by an analytical treatment of all of its individual components and of the sequential and linear causal relation of one component to the next. A clockwork mechanism could be perfectly theorised and subsequently perfected in this manner. In contrast, cybernetics and the affiliated methodologies focus on a holistic understanding of a system in which the components enter into relations of causal circularity. Thus in cybernetics the whole is superior to the sum of its parts. 
In his engineering work during the war Wiener had dealt with the probabilistic problem of predicting the future path of an airplane. Also reflected in his earlier work on statistical mechanics and quantum physics, Wiener's view of the world was fundamentally probabilistic and his mathematical work revolved around the means to grasp stochastic processes and exert predictability and control over them. Wiener had a predilection for mathematical problems which "involved finding predictability through chaos or signal through noise"248 and likened the discovery of laws of nature to the identification of repetitive patterns involved in breaking a secret communications cipher. ${ }^{2+9}$ Cybernetic mechanisms therefore naturally appeared as the means by which order could be imposed over chaos. Nor would such mechanisms be limited to solving engineering problems; Wiener would find cybernetic processes at work everywhere among living organisms. In this way the behaviour of animal and machine could be brought under a single theory since the identification of patterns of communication and control could be substituted for the study of specific physical embodiments.

Homeostasis was a term coined in the 1930s to describe the process by which living organisms adjust their internal environment to maintain a stable state. Examples would include the regulation of body temperature and cardiac rhythm or the concentration of nutrients and waste products within the tolerable limits of the organism. Wiener adopted the term and applied it more generally to all systems whose behaviour relies on negative feedback to stave off entropy. Homeostasis was thus the means by which a system could maintain its goal - survival in the case of a biological life form ("the process by which we living beings resist the general stream of corruption and decay"259), the continued regulation of a mechanical process within defined boundaries for a servomechanism - in a changing environment which could never be predicted with complete certainty. The pursuit of such a goal via negative feedback loops is what Wiener understood as the teleology of a system. This is quite distinct from teleology as generally defined in the context of political and historical 'grand narratives' since there is no finality of development, only the persistent effort to maintain a stable state.

\footnotetext{
${ }^{248}$ Heims, John Von Neumann and Norbert Wiener, pp.146-147

${ }^{249}$ Wiener, The Human Use of Human Beings, p.124

${ }^{250}$ Wiener, The Human Use of Human Beings, p.95
} 
It should be noted that if another cybernetic system was put in the place of the environment in Figure 6, we would have two cybernetic systems interacting with one another as each tries to impose its own desired state on the other. If the respective goals are incompatible, the systems will be in a state of conflict or competition; if the goals can be conciliated, a mutually satisfactory equilibrium may be reached. A control relationship is established when one system can dominate another system and impose its preferences over it. In cybernetics, control and communication are inextricably linked since control "is nothing but the sending of messages which effectively change the behaviour of the recipient."251

Complex control systems are thus composed of a hierarchy of nested cybernetic systems, each with its own goal but subservient to the goal of the system above it. For example, a machine or organism whose overall goal is survival might have a set of subsidiary goals that serve this purpose: a regular supply of energy, the evasion of a threat, or any other behaviour that addresses a disturbance that takes the system away from its overarching desired state. The more complex the environment and the greater the variety of possible perturbations, the more control loops will be required to attain and sustain the system's goal. These nested hierarchies constitute a top-down architecture of control which cyberneticists see as explanatory of the "increasing complexity which characterises such fundamental developments as the origin of life, multicellular organisms, the nervous system, learning, and human culture." 252 Bureaucratic organisations and their top-down command layers offer another obvious example in human societies.

\title{
Cybernetic Organisms: From Computerised Brains to Biological Computers
}

\begin{abstract}
We believe that men and other animals are like machines from the scientific standpoint because we believe that the only fruitful method for the study of buman and animal bebaviour are the methods applicable to the behaviour of mechanical objects as well [...] as objects of scientific enquiry; humans do not differ from machines.
\end{abstract}

${ }^{251}$ Wiener, The Human Use of Human Beings, p.8

${ }^{252}$ Francis Heylighen \& Cliff Joslyn, "Cybernetics and Second-Order Cybernetics" in R.A. Meyers (ed.), Encyclopedia of Physical Science \& Technology - 3rd ed. (New York: Academic Press, 2001) http://pespmc1.rub.ac.be/Papers/Cybernetics-EPST.pdf p.18 
While the clock and engine metaphors allowed frequent comparisons between machines and humans, the computer metaphor blurred even more drastically their borders since it theorised and enabled their combination under a single system linked by information feedback, as with the integration of the human operator in an anti-aircraft unit. Consequently, human and machine came to be described and analysed in the same terms. For Kenneth Craik, a British psychologist working on the problem of radar tracking during the war, "the human operator [of tracking devices] behaves basically as an intermittent correction servo" and both could be described by the same equations. ${ }^{254}$

Cybernetics was concerned from the very beginning with describing the universal mechanisms behind biological and mechanical systems and therefore naturally also the interface between them. This produced a discourse that combined the anthropomorphising of machines and mechanisation of biology and which quickly moved from the explicitly metaphorical to the literal. Neurophysiologist Ralph Gerard made this last observation at the seventh Macy conference (the inter-disciplinary conferences during which cybernetics were founded in the post-war period):

We started our discussion in the 'as if spirit. Everyone was delighted to express any idea that came to his mind, whether it seemed silly or certain or merely a stimulating guess that would affect someone else. We explored possibilities for all sorts of 'ifs.' Then, rather sharply it seemed to me, we began to talk in an 'is' idiom. We were saying much the same things, but now saying them as if they were so..$^{255}$

Wiener showed great interest in prosthetics, viewing improvements in the condition of the invalid as one the most immediate promises of cybernetics, especially given the postwar concerns he expressed about the military applications of cybernetics. But there is only one step from rehabilitation to enhancement and the term of cyborg (cybernetic organism) was later coined during research into cybernetic technologies that would enable humans to operate in hostile extraterrestrial environments (the battlefield is of course one of the most hostile terrestrial environments).

\footnotetext{
${ }^{253}$ Norbert Wiener \& Arturo Rosenbluth, "Purposeful and Non-Purposeful Behaviour", Philosopby of Science 17 , Oct 1950, p.326

${ }^{254}$ Edwards, The Closed World, p.182

${ }^{255}$ Slava Gerovitch, From Newspeak to Cyberspeak: A History of Soviet Cybernetics (Cambridge, MA \& London: MIT Press, 2002), p.90
} 
Research into the brain and nervous system was greatly influenced by the development of computers and played a central role in cybernetic discourse. Wiener insisted that:

The ultra-rapid computing machine, depending as it does on consecutive switching devices, must represent an almost ideal model for the problems arising in the nervous system. The all-or-none character of the discharge of the neurones is precisely analogous to the single choice made in determining a digit on the binary scale, which more than one of us had already contemplated as the most satisfactory basis of computing machine design. ${ }^{256}$

It was known that neurons were connected to each other via synapses through which electrical and chemical signals are transmitted. The input from other neurons determine whether an individual neuron will 'fire', that is send out a signal to those neurons connected to its output. A neuron can therefore be thought of as in being in one of two states: 'firing' or 'not firing'; this binary choice naturally appeared analogous to the 0 or 1 states of computing logic gates.

Von Neumann's theoretical elaboration of the computer was developed in parallel with an analogous theory of the human mind such that both coevolved together and "it is difficult to know which came first." ${ }^{257}$ Hence the discipline of artificial intelligence emerged at the same time as modern computing and the general assumption was that computer science was uncovering the mechanisms of human thought. Consequently, in Capra's words:

The computer model of mental activity became the prevalent view of cognitive science and dominated all brain research for the next thirty years. The basic idea was that human intelligence resembles that of a computer to such an extent that cognition - the process of knowing - can be defined as information processing i.e. as manipulation of symbols based on a set of rules. ${ }^{258}$

Arthur Burks, a collaborator of von Neumann notes that the mathematician thought of computers in two way: one as a "general-purpose computational device" and the other as a "general theory of automata, natural and artificial." 259

Lily Kay has provided a detailed account of the manner in which cybernetics and information theory impacted research into biochemistry and genetics after the war, shifting the scientific discourse from one based on notions of chemical and biological

256 Wiener, Cybernetics, p.22

${ }^{257}$ Fritjof Capra, The Web of Life: $A$ New Synthesis of Mind and Matter (London: Flamingo, 1997), p.66

${ }^{258}$ Capra, The Web of Life, p.66

${ }^{259}$ M. Mitchell Waldrop, Complexity: The Emerging Science at the Edge of Order and Chaos (London: Viking, 1992), p.161-2 
specificity to one articulated around informational conceptions. ${ }^{260}$ Nucleic acids became eventually designated as the carriers of informational content, bearers of a genetic 'code' to be broken by molecular biologists. The 1950 s saw the discovery of the structure of DNA, the nucleic acid believed to carry the genetic instructions for the development of all cellular life forms. Composed of only four different types of chemical bases (abbreviated as $A, T, G$, and $C$ ) that connect the two strands of the famous double helix, DNA is seemingly able to account for the enormous differentiation and specialisation of life-forms. Sequences of those elementary building blocks have been compared to the computer code which provides instructions to a computer. Small sequences of three bases (e.g. ACT, CAG, TTT) translate into 'instructions' for specific amino acids which then form proteins (amino acid sequences) according to a set of 'rules.'

Kay has persuasively related this informational discourse to the rise of cybernetics and information theory and the military contexts in which they emerged so that within molecular biology "the genetic code became the site of life's command and control."261 Indeed, for the geneticist and Nobel Prize winner Jacques Monod, the organism was nothing but "a cybernetic system governing and controlling the chemical activity at numerous points" and gene-enzyme regulations constituted a system "comparable to those employed in electronic automation circuitry, where the very slight energy consumed by a relay can trigger a large-scale operation, such as, for example, the firing of a ballistic missile. ${ }^{262}$

Even as the structure of DNA was being discovered, Wiener was putting forward a view of life as a pattern of organisation determined by its informational content and whose physical embodiment was both sustained and renewed by homeostasis. "Our tissues change as we live: the food we eat and the air we breathe become flesh and bone of our body, and the momentary elements of our flesh and bone pass out of our body every day with our excreta. We are but whirlpools in a river of ever-flowing water. We are not stuff that abides, but patterns that perpetuate themselves. ${ }^{203}$ For Wiener, therefore, the organism is the message. However, in the final instance, life remains nothing but a local

${ }^{260}$ Kay, Who Wrote the Book of Life?

${ }^{261}$ Kay, Who Wrote the Book of Life?, p.5

${ }^{262}$ Kay, Who Wrote the Book of Life?, p.17

${ }^{263}$ Wiener, The Human Use of Human Beings, p.96 
and temporary reversal of entropy in a universe in which overall randomness and chaos is necessarily increasing - "life is an island here and now in a dying world."264

\title{
Social Cybernetics
}

In the 1950s, cybernetics appeared to offer a whole new interdisciplinary theory and methodology with anthropologists, linguists, physiologists, sociologists, philosophers, engineers and computer scientists all applying cybernetic principles to their field. Cybernetics was not so much a traditional scientific discipline than a convergence of engineering techniques, scientific theories and philosophical concepts under a common discourse that allowed the discussion and analysis of artificial machines, biological organisms, and social organisation as equivalent systems of control and communication operating under a single set of principles. Upon opening the Third Congress of the International Association of Cybernetics in 1961, its president Georges Boulanger announced that cybernetics:

\begin{abstract}
intends to investigate freely in the domain of the mind. It wants to define intelligence and to measure it. It will attempt to explain the functioning of the brain and to build thinking machines. It will assist the biologist and the doctor, and also the engineer. Educational practice, sociology, economics, law, and philosophy will become tributary to it. And it can be said that there is not a sector of human activity that can remain foreign to it. ${ }^{265}$
\end{abstract}

Initially, Wiener's already ambitious goal for cybernetics was a theory of "control and communications in the animal and the machine" 260 but the definition was soon expanded to the understanding of the behaviour of all complex systems, including social. ${ }^{267}$ After the first Macy conference in 1946, Wiener had proposed that fields as diverse as statistical mechanics, communication engineering, the theory of control mechanisms in machines, biology, psychology and social science could all be understood through an emphasis on the role of communication:

The neuromuscular mechanism of an animal or of man is certainly a communication instrument, as are the sense organs which receive external impulses. Fundamentally the social sciences are the study of the means of communication between man and man, or,

264 Wiener, The Human Use of Human Beings, p.95

${ }^{265}$ Céline Lafontaine, LEmpire Cybernétique - Des Machines à Penser à la Pensée Machine (Paris: Editions du Seuil, 2004), p.25

${ }^{266}$ Heims, John Von Neumann and Norbert Wiener, p.184

${ }^{267}$ Charles R. Dechert, "The Development of Cybernetics" in Charles R. Dechert, The Social Impact of Cybernetics (Notre Dame, ID: University of Notre Dame, 1966), p.20 
more generally, in a community of any sort of being. The unifying idea of these disciplines is the MESSAGE, and not any special apparatus acting on messages. ${ }^{268}$

He further claimed in 1948 that "it is certainly true that the social system is an organisation like the individual, that is bound together by a system of communication, and that it has a dynamics in which circular processes of a feedback nature play an important role." ${ }^{269}$ Several social scientists would later develop these ideas and apply many of the principles of cybernetics and systems analysis to their fields of study. Chief among them, Karl Deutsch explicitly drew from cybernetics to introduce notions of information feedback to the understanding of social systems and the 'steering' of government in his seminal Nerves of Government while David Easton formulated a theory of the political system defined as "a means whereby certain inputs are converted into outputs" and where the properties of feedback allow it "to regulate stress by modifying or redirecting its own behaviour." ${ }^{270}$

But while Norbert Wiener did see the potential applications of his theory to social organisation, he was reluctant to grant this interpretation the same scientific credibility as to the study of machines and organisms. A liberal humanist at heart, Wiener was particularly concerned about the implications for the liberal subject of a cybernetic management of society:

\begin{abstract}
I have spoken of machines, but not only of machines having brains of brass and thews of iron. When human atoms are knit into an organization in which they are used, not in their full right as responsible human beings, but as cogs and levers and rods, it matters little that their raw material is flesh and blood. What is used as an element in a machine, is in fact an element in the machine. Whether we entrust our decisions to machines of metal, or to those machines of flesh and blood which are bureaus, and vast laboratories and armies and corporations, we shall never receive the right answers to our questions unless we ask the right questions. ${ }^{271}$
\end{abstract}

If Wiener was uneasy about 'social machines', his own language contributed to this logical extension of the cybernetic conceptual apparatus. It is also quite obvious that no social machine treats individuals as "cogs and levers and rods" so completely than the military (an institution with which Wiener refused any association after the war, in contrast to von Neumann). Wiener tended to see a democratic potential in cybernetics

\footnotetext{
${ }^{268}$ Steve J. Heims, The Cybernetics Group (Cambridge, MA: MIT Press, 1991), p.22

${ }^{269}$ Quoted in Capra, The Web of Life, p.62

${ }^{270}$ David Easton, $A$ Framework for Political Analysis (Chicago, IL \& London: University of Chicago Press, 1979), p.112 \& p.128; David Easton, A Systems Analysis of Political Life (New York, NY: John Wiley \& Sons, 1965); Karl Deutsch, The Nerves of Government (New York, NY: The Free Press, 1963)

271 Wiener, The Human Use of Human Beings, p.185-186.
} 
with its promise of feedback and reciprocal influence. However cybernetics could just as well serve a hierarchical organisation in which subservient systems fulfilled individual homeostatic roles set by the overarching system.

\section{Conclusion}

As Slava Gerovitch points out, the scope of the ambition of cybernetics entailed the development of a new language that would be common to all the scientists and social scientists studying systems of control and communications across all disciplines. ${ }^{272}$ However, the promise of a new unified natural philosophy was never realised as cybernetics became a victim of both its own success and the overambitious goals it had set itself. Wildly popular in the fifties and sixties, it attracted a lot of research funding for many projects that yielded disappointing results and lead to an inevitable fall from grace. Furthermore, the constitution of something as broad as a science of systems could only be sustained across such a broad range of disciplines and subject areas by diluting the conceptual and explanatory apparatus to the point at which its usefulness and incisiveness were severely impaired. The term itself fell out of favour in the 1970s and 1980s and few scientists or academics would refer to themselves as cyberneticists today.

However, rather than disappearing altogether, cybernetics dispersed itself into all the fields it had touched and thus much of its ontology and core concepts - namely those of information, circularity, and feedback - continued to play a major role in many disciplines. In a 1994 interview, Heinz von Foerster, one of the founding fathers of the cybernetics movement, stated that "cybernetics melted, as a field, into many notions of people who are thinking and working in a variety of other fields."273 In some ways, the influence of cybernetic ideas is now more pervasive than when it was identified as a single discipline. The servomechanism would indeed become the defining technology of its age, rarely referred to as such but subsumed as one of the functions of the ubiquitous information-processing computer. The work of the early cyberneticists would later feed into the development of the theories of chaos and complexity in the 1970s and 1980s,

272 Gerovitch, From Newspeak to Cyberspeak

273 Stefano Franchi, Güven Güzeldere, \& Eric Minch, "Interview with Heinz von Foerster", Stanford Humanities Review, Volume 4, Issue 2, 1995 http://www.stanford.edu/group/SHR/4-

$2 /$ text/interviewvonf.hrml 
marking a crucial transformation in the informational paradigm and with major ramifications for this thesis, the discussion of which will have to wait until chapter 7 . Indeed, it is necessary to first turn to the profound effects of cybernetics and the computer on American military theory and practice during the Cold War. 


\title{
Chapter 6: Cybernetic Warfare: Computers at War
}

\begin{abstract}
The most important single outcome of technological progress during the decades since World War II bas been that, on the modern battlefield, a blizzard of electromagnetic blips is increasingly being superimposed on and to some extent substituted for - the storm of steel in which war used to take place.
\end{abstract}

Martin van Creveld ${ }^{27+}$

This chapter concerns itself generally with the cyberneticisation and computerisation of the American military in the wake of the Second World War along with the centralising trend that dominated it throughout the Cold War. ${ }^{275}$ The Cold War was characterised not only by a transformation in the structure of world politics with the advent of bipolarity but also by momentous changes in the practice and theories of warfare. If the role of technology has been greatly studied, particularly in relation to nuclear weapons, the influence of the scientific ideas which accompanied technological development has been afforded far less attention. Cybernetic concepts and technologies bolstered an understanding of war which strove to frame the use of military force into an activity totally amenable to scientific analysis, to the detriment of other forms of thought.

The computer is naturally a central figure of this chapter. Gene Rochlin lists five main roles fulfilled by computers in the military after World War II:

- embedded means of fire control for artillery and anti-aircraft guns;

- solvers of long, complex technical and engineering problems;

- elements of advanced command and control;

- basic tools for strategic analysis and war gaming;

274 Van Creveld, Tecbnology and War, p. 282

275 The focus on the United States is a choice determined by two factors. Firstly, the U.S. was the most enthusiastic adopter of the computer and its related sciences, making it the truest heir of the scientific way of warfare. Secondly, although interesting parallels can no doubt be found in the Soviet Union, limits on the available literature and the greater secrecy of that society constitute an important obstacle to an indepth discussion of the role of the computer in its military. Nonetheless, it is hoped that further research in this area will be conducted and made available in the English-speaking world. 
- embedded and programmed controllers for self-guided weapons. ${ }^{276}$

All these aspects will be considered in this chapter but the treatment of the computer as a tool will be secondary to an analysis of its metaphorical function within the nexus of ideas and practices that make up a third regime of the scientific way of warfare: cybernetic warfare.

I shall first discuss in general terms the 'closed world', following Paul Edward's term, constituted by cybernetic warfare and in which cybernetic technologies proliferate alongside a conceptual and methodological apparatus which emphasises the controllable and predictable nature of war. In the subsequent sections, I turn more specifically to its central features: the shift from traditional notions of command to that of 'commandand-control', the reduction of war to a set of mathematical functions and cost-benefit calculations susceptible to optimisation through operations research and systems analysis, and the increasing modelling and simulation of conflict. The chapter concludes with the Vietnam War, a conflict in which the aforementioned ideas and practices were truly put to the test and incurred spectacular reversals, thereby revealing many of the flawed assumptions of cybernetic warfare.

\section{The 'Closed World' of Cybernetic Warfare}

In The Closed World, Paul Edwards relates the rapid computerisation of the military to the constitution of a 'closed world' discourse conveying "a radically bounded scene of conflict, an inescapably self-referential space where every thought, word, and action is ultimately directed towards a central struggle."277 Framed by the permanent threat of nuclear devastation, the Cold War opposing the West and the East became the exclusive geopolitical framework through which all policies, events and rhetoric were interpreted and considered in relation to the goal of, if not winning, at least maintaining the status quo and surviving. Within this discourse, computers acted as powerful tools and metaphors promising "total oversight, exacting standards of control, and technicalrational solutions to a myriad of complex problems."278

\footnotetext{
276 Gene I. Rochlin, Trapped in the Net: The Unanticipated Consequences of Computerization (Princeton, NJ:

Princeton University Press, 1997), p.138

277 Edwards, The Closed World, p.12

${ }^{278}$ Edwards, The Closed World, p.15
} 
In analysing this 'closed world' discourse, Edwards identifies several central features. Engineering and mathematical techniques which allow for the creation of models of aspects of the world as closed systems combine with technologies such as the computer which enable large scale simulation, systems analysis and central control. A language of systems, gaming, communication and information is erected, privileging abstract formalisms over "experiential and situated knowledge." Visions of omnipotence through air power and nuclear weapons assisted by "centralised, instantaneous, automated command and control" are summoned in response to fears of an expansionist Soviet Empire. ${ }^{279}$

Within this conceptual framework, uncertainty and unpredictability - chaos in other words - are understood as information deficiencies and thus susceptible to be overcome by the appropriate deployment of negentropic information/communication technologies and computerised simulations of conflict.

Edwards does indeed explicitly connect the 'closed world' discourse to the development of cybernetics and computerisation. Computers are seen as participating in the creation and sustaining of this worldview in two ways. "First, they allowed the practical construction of central real-time military control systems on a gigantic scale. Second, they facilitated the metaphorical understanding of world politics as a sort of system subject to technological management. ${ }^{\text {280 }}$ Hence the closed world is not simply the proliferation and imposition of the discursive framework of superpower confrontation on all international and domestic politics but also an understanding of the world that defines the latter as finite, manageable and computable.

The 1980s 'Star Wars' project (Reagan's Strategic Defense Initiative) and its ambition for a defensive shield capable of rendering nuclear weapons ineffective is frequently seen as the epitome of this worldview and Fred Reed also points to the computer metaphor in this context:

It consists in believing that the world is like the inside of a computer. In programming a computer, all things are clean and certain. Each instruction does one thing, precisely described in the manual, with only one possible result, which can be easily ascertained. As

${ }^{279}$ Edwards, The Closed World, p.15

${ }^{280}$ Edwards, The Closed World, p.7 
long as a program is quite small, it will run to a foreseeable end with no surprises, click, click, click. This is a world of godlike certainty. ${ }^{281}$

Edwards convincingly connects cybernetics and computer sciences to an overarching set of "tools, techniques, practices and languages which embody an approach to the world as composed of interlocking systems amenable to formal mathematical analysis." 282 This forms the basis on which a cybernetic understanding of war and its "systems of organised complexity" is constructed. In his earlier work, Edwards was already charting this conceptual apparatus and speaking of an "AI mentality - an approach to inherently vague, ill-defined, constantly changing problems [whose] central belief is that by circumscribing a specific problem domain and formalising its features, problem-solving algorithms and heuristic logics can be created to find solutions automatically."283

As direct experience of total war receded and new inconceivably destructive weapons were developed, mathematical and logical models and simulations of warfare became fetishised for their promises of predictability and control. Defence intellectuals were perhaps their keenest practitioners and most outspoken proponents, wielding these instruments to the very highest spheres of executive power. Convinced with often nearreligious fervour of the superiority of their method, they were determined to apply scientific rationalism to the entire spectrum of war. Sharon Ghamari-Tabrizi has noted that the quantitative studies they conducted and promulgated "often aimed toward an ideal of omniscient information management." ${ }^{\text {284 }}$

Founded on a Weltanschauung that drew its conviction from the practical engineering successes of the informational sciences, cybernetic warfare strove to shape military affairs into a perfectly modelled and controlled closed world. By importing this methodological and conceptual baggage, military thinkers internalised many of their assumptions. If, as "engineering approaches designed to solve real-world problems, systems theories tend in practice to assume the closure of the system they analyse,"

281 Gray, Postmodern War, p.73

282 Paul N. Edwards, "The Closed World: Systems Discourse, Military Policy and Post-World War II US Historical Consciousness" in Les Levidow \& Kevin Robins (eds.), Cybory Worlds: The Military Information Society (London: Free Association Books, 1989), pp.138-139

${ }^{283}$ Gray, Postmodern War, p.72

${ }^{284}$ Sharon Ghamari-Tabrizi, The Worlds of Herman Kabn: The Intuitive Science of Thermonuclear War (Cambridge, MA: Harvard University Press, 2005), p.128 
military problems framed within the same conceptual and methodological framework naturally $\mathrm{t}$ nded to be also perceived in terms of closed systems. ${ }^{285}$

Such closed systems lend themselves perfectly to modelling and simulation, the ability to run and re-run scenarios in the belief that all factors have been incorporated and appropriately weighted. Whatever the true usefulness of such models (and cases of models being 'validated' by real events are scant), they have come to exert a powerful influence on military leaders and policymakers, all looking for certainty and mastery over events, however illusory. Bill Nichols points to the role of cybernetic systems in:

\begin{abstract}
creating a world of simulacra amenable to total control [...] cybernetic simulation renders experience, and the real itself, 'problematic'. It draws us into a realm, a design for living, that fosters a fetishised relationship with the simulation as a new reality all its own, based on the capacity to control, within the domain of the simulation, what had once eluded control beyond it. ${ }^{286}$
\end{abstract}

It might be easy to dismiss all this as academic hyperbole if it wasn't for senior military commanders and policy-makers frequently preaching from the same holy book. In 1969, General William Westmoreland, Commander-in-Chief of U.S. forces in Vietnam, famously prophesised the imminent arrival of the fully cyberneticised and frictionless battlefield:

\begin{abstract}
On the battlefield of the future, enemy forces will be located, tracked, and targeted almost instantaneously through the use of data links, computer assisted intelligence evaluation, and automated fire control. With first round kill probabilities approaching certainty, and with surveillance devices that can continually track the enemy, the need for large forces to fix the opponent becomes less important. I see battlefields that are under 24-hour real or near-real time surveillance of all types. I see battlefields on which we can destroy anything we can locate through instant communications and almost instantaneous application of highly lethal firepower. [...] In summary, I see an Army built into and around an integrated area control system that exploits the advanced technology of communications, sensors, fire direction, and the required automatic data processing. 287
\end{abstract}

As we shall see, such a drive for certainty and predictability was common among those who put faith in computerised systems and the analytical techniques of operations research and systems analysis in the 1950s and 1960s. For Edwards, Westmoreland's

\footnotetext{
${ }^{285}$ Edwards, "The Closed World" in Levidow \& Robins (eds.), Cyborg Worlds, pp.138-139

${ }^{286}$ Les Levidow \& Kevin Robins, "Towards a Military Information Society?" in Levidow \& Robins (eds.), Cyborg Worlds, p.173

${ }^{287}$ William Westmoreland, Address to the Association of the U.S. Army, October 14, 1969 http://216.239.59.104/search?q=cache:Kw2tmkrW5lgJ:www.stanford.edu/group/mmdd/SiliconValley/ Westmoreland/westmoreland.rtf
} 
speech epitomises the "vision of a closed world, a chaotic and dangerous space rendered orderly and controllable by the powers of rationality and technology.,"288

More recently, the debate on the Revolution in Military Affairs (RMA), fuelled by the spectacular and virtually casualty-free success of the first Gulf War, has seen similar sentiments expressed. In 1997, former Air Force Chief of Staff Ronald Fogleman told Congress that "in the first quarter of the $21^{\text {st }}$ century you will be able to find, fix or track, and target - in near real-time - anything of consequence that moves upon or is located on the face of the Earth." 289 Since the mid-nineties, Admiral William Owens has been calling for the establishment of a 'system of systems' combining digital computing power, new communications technology and space-based systems to finally lift the Clausewitzian 'fog of war. ${ }^{290}$

The appeal of such certainty to an institution in which the training of troops is designed "to reduce the conduct of war to a set of rules and a system of procedures - and thereby to make orderly and rational what is essentially chaotic and instinctive" is obvious. ${ }^{291}$ It is therefore not surprising that the military has embraced computers as the panacea to the eternal problem of uncertainty and unpredictability in war. Van Creveld facetiously sums up the attraction of computers to the military machine:

\footnotetext{
Computers with their binary on-off logic seem to appeal to the military mind. This is because the military, in order to counter the inherent confusion and danger of war, is forever seeking ways to make communications as terse and unambiguous as humanly possible. Computers by their very nature do just that. Had they only been able to stand at attention and salute, in many ways they would have made ideal soldiers. ${ }^{292}$
}

There are, however, specific cultural factors which made the United States military a particularly fertile ground for computerisation and a technoscientific approach to warfare even before World War II. Indeed the American experience and culture of war is one in which engineering, logistics, and technology have long played a central role. As the first modern industrial war, the American Civil War had required the extensive uses of railways and the North eventually prevailed due in large part to its industrial and

${ }^{288}$ Edwards, "Why Build Computers?" in Smith \& Clancey (eds.), Major Problems in the History of American Tecbnology, pp.454-462

${ }^{289}$ Michael O'Hanlon, Technological Change and the Future of Warfare (Washington, DC: Brookings Institution Press, 2000), p.13

${ }^{290}$ William A. Owens \& Edward Offley, Lifting the Fog of War (Baltimore, MD: John Hopkins University

Press, 2000)

291 Gray, Postmodem War, p.95

${ }^{292}$ Van Creveld, Technology and War, p. 239 
economic superiority. Later, the entry of the U.S. into the First World War in April 1917 had also necessitated a rapid mobilisation and the solving of numerous logistical problems in transporting troops and material across the Atlantic. Nor can the weight of the West Point military academy in the training of the country's military elite be discounted. Following its founding in 1802 on the model of the French Ecole Polytechnique, West Point emphasised civil engineering as the foundation of its curriculum and many of its graduates were responsible for the construction of the American transport infrastructure in the 19th century. If the curriculum has since been broadened, engineering and military science remain an important part of it and contribute to fostering a conception of warfare as a problem to be solved through scientific rationality.

It is also possible to relate the longing for information omniscience and "godlike certainty" in military affairs to the increasingly instrumentalist understanding of war that has developed in the West, and particularly the United States. As the existential and metaphysical dimensions of war recede, war defined as "a rational instrument employed by states in a controlled manner for purposes that are either economic or political" by $\mathrm{Coker}^{293}$ finds in technoscience the tools of such policy. Cybernetic thought provides a comforting lens through which to view the use of force as it reduces military strategy to "a one-factor question about technical forces; success or failure is measured quantitatively $[\ldots]$ machine-system meets machine-system and the largest, fastest, most technologically advanced system will win. Any other outcome becomes unthinkable."294 This tendency to think of armies as 'machine-systems' is a product of the scientific and technological way of warfare and the increasing reliance on an industrial base to sustain war efforts.

Military commanders have always sought to maintain order in the face of chaos of the battlefield and the constant threat of a breakdown in the cohesion of their armies. Different epochs have responded in different manners to this challenge. Mechanistic warfare was an attempt to maintain order over the chaos of the battlefield by reducing the behaviour of soldiers to that of pre-programmed clockwork automats. With thermodynamic warfare, the increasingly powerful releases of energy made communication of orders on the battlefield extremely difficult but the industrialisation

${ }^{293}$ Coker, The Future of War, p.6

294 Gibson, The Perfect War, p.23 
of warfare implied a development of telecommunications, logistics, and production processes over which a great degree of centralising control could be achieved. The ability to marshal resources appropriately became the paramount factor determining military and strategic victory in those wars of attrition. As van Creveld points out:

The technological revolution that opened with the telegtaph and the railway very largely turned war itself into a question of managing complex systems. Time after time some new tactic or technological device seemed to offer a way out, but in each case the end result was more integration, not less. Integration permitted greater and greater forces to be mobilised, husbanded, focused, and finally hurled at the enemy. To this extent, it is understandable that victory in World War II did not go to the side whose soldiers had fought the hardest, or that came up with the most brilliant operational schemes. Rather, those belligerents gained the upper hand whose administrators, scientists, and managers developed the means by which to set up gigantic technological systems and run them as efficiently as possible. ${ }^{295}$

The integration and operation of these increasingly complex systems would only be made possible by the development and extension of information and telecommunication technologies, leading to the establishment of centralised commandand-control structures, to which I shall now turn.

\section{From Command to Command-and-Control}

Command-and-control has become the common term employed by the military brass to describe its function. The addition of the term 'control' to what previously had simply been called 'command' is revealing in itself. Command suggests the mere transmission of orders while control suggests a process that involves a feedback mechanism allowing the controller to obtain new information from the system, adjust its orders accordingly and thus direct far more accurately its subordinates. As Rochlin puts it:

Command was historically an open cycle process: the commander set up the battle, gave instructions, provided for whatever contingencies could be planned for, and then issued the command to execute. After that, the ability to intervene was minimal. In contrast, control is a closed cycle process with feedback, analysis, and iteration; it was not possible even to consider the transition from command to command-and-control until modern technical means for intelligence and communications became available. ${ }^{296}$

\footnotetext{
295 Van Creveld, Technology and War, p.161

${ }^{296}$ Rochlin, Trapped in the Net, p.204
} 
Military strategist John Boyd contrasted command as directing, ordering, or compelling and control as regulating, restraining, or holding to a certain standard. ${ }^{297}$ Command and control infrastructures thus brought with them the hope that the inherent disorder of the battlefield could be overcome through information flows in the same way cybernetic systems stave off entropy. In 1995, Lt. Gen. Carl O’Berry spoke of Horizon, an effort to ensure compatibility among all information systems in the U.S. military, in the following terms: "[Horizon] brings order out of something that until new has been an atmosphere of entropy. For the first time we have taken interoperability to the domain of science instead of emotion. I'm taking the guesswork out of $C^{4} I$ systems architecture."2988

The shift from command to command-and-control is indicative of new expectations about the role and capabilities of the hierarchy in directing the operations of the military machine. That this evolution is directly related to information is clearly illustrated by the litany of acronyms that have since followed: $\mathrm{C}^{3} \mathrm{I}$ (Command, Control, Communications, and Information - or Intelligence), $C^{4} \mathrm{I}^{2}$ ( $\mathrm{C}^{3} \mathrm{I}$ plus Computers and Inter-operability), $C^{3} I S R\left(C^{3} I\right.$ plus Surveillance and Reconnaissance), $C^{3} I S R T$ (C ${ }^{3}$ ISR plus Targeting), etc.

Integration of armed forces into a coherent system maintained by information and communication technologies (ICTs) amenable to centralised control has been an observable trend in all modern industrial armies. As the range and specialisation of military personnel and equipment increase along with the concomitant logistical challenges characteristic of industrial warfare, reliable channels of communication become essential. Furthermore, information demands tend to increase exponentially since, "as the number of specialties grows, the amount of information needed to coordinate their performance grows not arithmetically but geometrically, everybody (or groups of every kind) having to be coordinated with everybody else. ${ }^{3299}$ The limitations of early ICTs in terms of their availability and the volume of information that could be processed and transmitted made centralisation all the more appealing since it reduced the number of potential channels of communication. For the major part of their existence, computers were too bulky and unwieldy to be brought onto the battlefield

\footnotetext{
297 Gregory A. Roman, "The Command or Control Dilemma: When Technology and Organizational Orientation Collide" (Research Paper Presented To Air Force 2025, April 1996), p.4 http://csat.au.af.mil/2025/volume1/vol1ch04.pdf

${ }^{298}$ Arquilla \& Ronfeldt, "Information, Power, and Grand Strategy" in Schwartzstein (ed.), The Information Revolution and National Security, p.146

${ }^{299}$ Van Creveld, Command in War, p.235
} 
and computer scientists privileged centralised processing of information to maximise the limited processing power available.

However, there were also specific geopolitical conditions which combined with the new technology of nuclear weapons to particularly drive centralisation of the military in the post-war era. Indeed, concerns over the eventuality of nuclear war, be it intentional or accidental, were omnipresent in the 1950s and continued, somewhat abated, throughout the Cold War. Due to the incredible destructive power of nuclear weapons and the rapidity of the delivery systems (first bombers then intercontinental ballistic missiles), it became crucial to ensure a very tight control over their use, as well as develop effective early warning mechanisms for a credible nuclear deterrent.

With the development of jet-powered aircraft, the time available in the window of opportunity for detection and interception of bombers potentially carrying nuclear weapons shrunk and existing command-and-control systems were no longer adequate. Computers presented a clear technological solution to the problem of effective and rapid processing and transmission of both incoming information (provided by radar and observation posts) and outgoing information (sent to anti-aircraft defences such as interceptor fighter planes or land-based weapons). As an article in the Air University Quarterly Review of Winter 1956-57 put it, "the speed with which these weapons could react, each to the other, seems to indicate that only a machine with vast memory and instant response could be expected to indicate a successful counter strategy in sufficient time to be useful. ${ }^{300}$

Within a year of this article, the Air Force announced SAGE (Semi Automated Ground Environment), the first computer-based command, control and communications system for the purpose of constituting a centralised air defence network. Based on information from radar echoes, the calculation of precise positions and speeds of multiple planes required massive computing power while the efficient and prompt transmission of this data to anti-aircraft weapon systems necessitated a reliable communications network. Target information collected and processed by SAGE would be transmitted to air defences, namely interceptor aircraft or missile systems.

\footnotetext{
${ }^{300}$ Sharon Ghamari-Tabrizi, "U.S. Wargaming Grows Up: A Short History of the Diffusion of Wargaming in the Armed Forces and Industry in the Postwar Period up to 1964", StrategyPage.Com http://www.strategypage.com/articles/default.aspitarget $=$ Wgappen.htm
} 
SAGE broke significantly with existing computer technology because of its requirement for real-time processing and responses to user inputs. Until then, the norm was batch processing, the execution of series of non-interactive jobs all at one time. Users programmed the computer, entered the data to be processed, and waited for its output to be generated and displayed via print-outs. Expanding on Whirlwind (MIT's research project into a military flight simulator), SAGE resulted in several crucial developments in computer technology. Real-time processing required a revolutionary user interface, so SAGE was able to present data to a hundred operator stations via a cathode ray tube the screen technology familiar to millions of computer users today - and responded to requests for additional information from operators handling light guns directed at the screen (see Figure 7). The resulting decrease in the delay between inputs and outputs created a close cybernetic loop between computer and user which has only gained in complexity and intimacy since (see Figure 8). The use of telephone lines to transfer computer data was also pioneered by SAGE, an early premise of the technology that would lead to the development of the Internet.

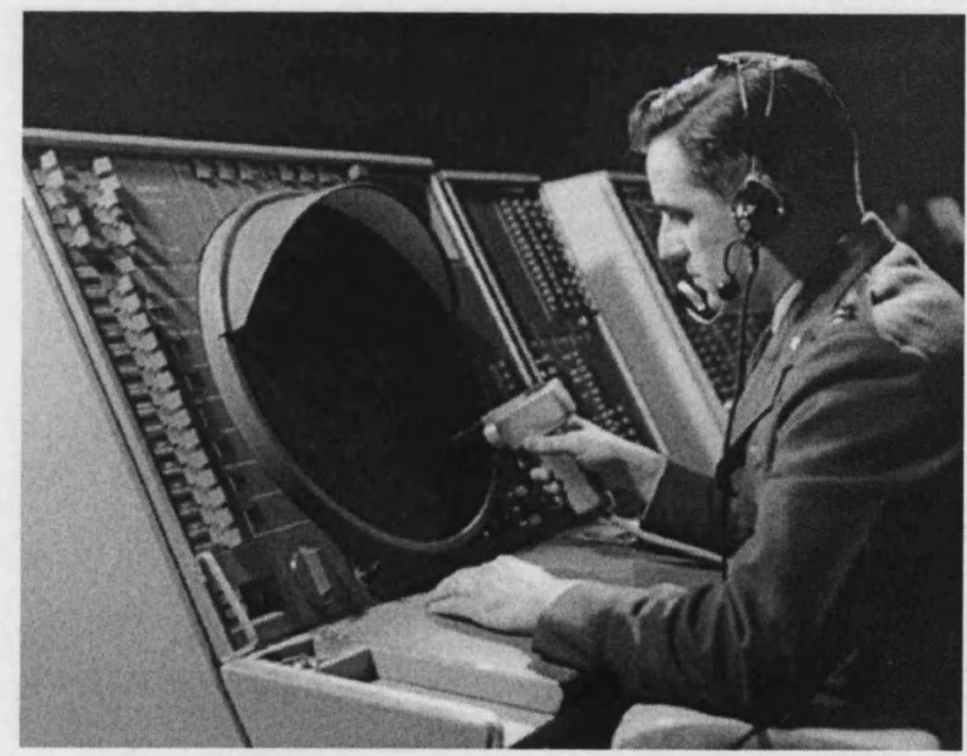

Figure 7: SAGE operator and his console (circa 1959) ${ }^{301}$

301 htop:/www. nitre.org/about/photo archives/sage photo.html 


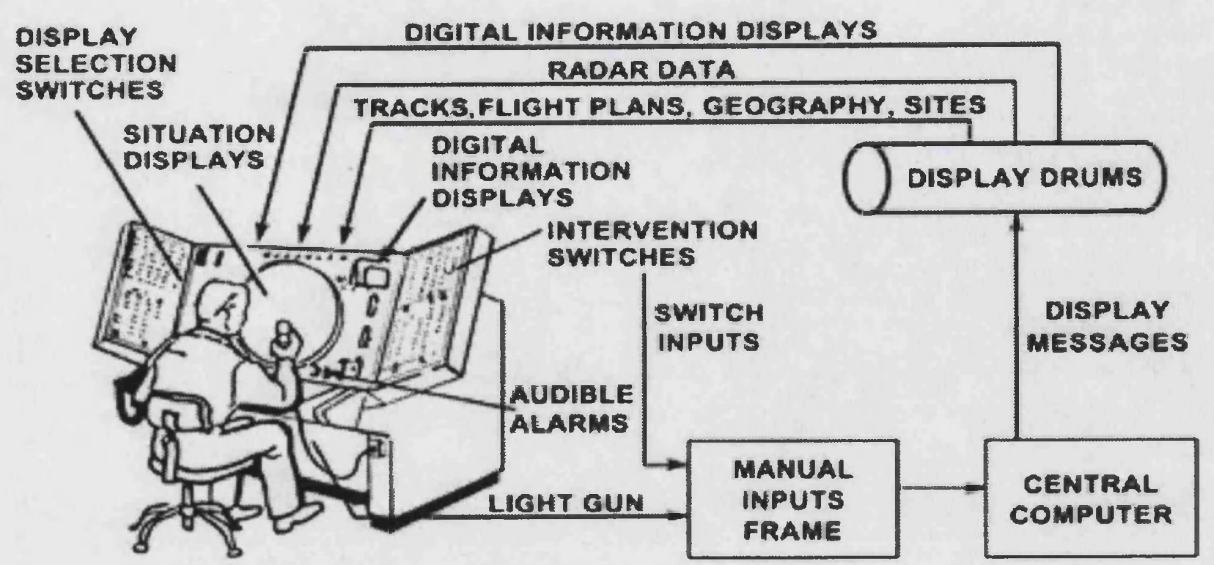

Figure 8: SAGE man-machine cybernetic loop ${ }^{302}$

Although obsolete by the time of its completion in 1963 (the deployment of ICBMs by the Soviet Union having rendered anti-aircraft defences largely irrelevant) and critically flawed in certain aspects, the system drove the development of crucial information technologies as well as the adoption of certain organisational principles. As such, "SAGE was less important as an actual defence system than as a symbol of things to come $[\ldots]$ it is the idea of automated control and information processes - the concept itself - that has shaped, more than any technology, the contemporary U.S. armed forces." ${ }^{303}$ In total, between 8 and 12 billion dollars were spend on developing and implementing SAGE, a higher level of expenditure than had been dedicated to the Manhattan Project.

SAGE was followed by numerous related projects, most notably the World Wide Military Command and Control System (WWMCCS) in 1962 (see Figure 9). Progressively extended from Strategic Air Command to the rest of the military, WWMCSS allowed for centralised global command-and-control of American troops through a broad spectrum of telecommunication systems including military satellites. In 1996, WWMCCS was deactivated and replaced by the Global Command and Control System (GCCS). Both projects have in common the extension and operation of

\footnotetext{
$302 \mathrm{http} / /$ /www mitre.org/about/photo archives/photos/low res/sage f4946.jpg

${ }^{303}$ Edwards, "The Closed World" in Levidow \& Robins (eds.), Cyborg Worlds, p.143

Also see chapter 3 of Edwards, The Closed World for a detailed account of the development of SAGE.
} 
command-and-control structures across the globe, establishing cybernetic system closure over the entire planet. ${ }^{304}$

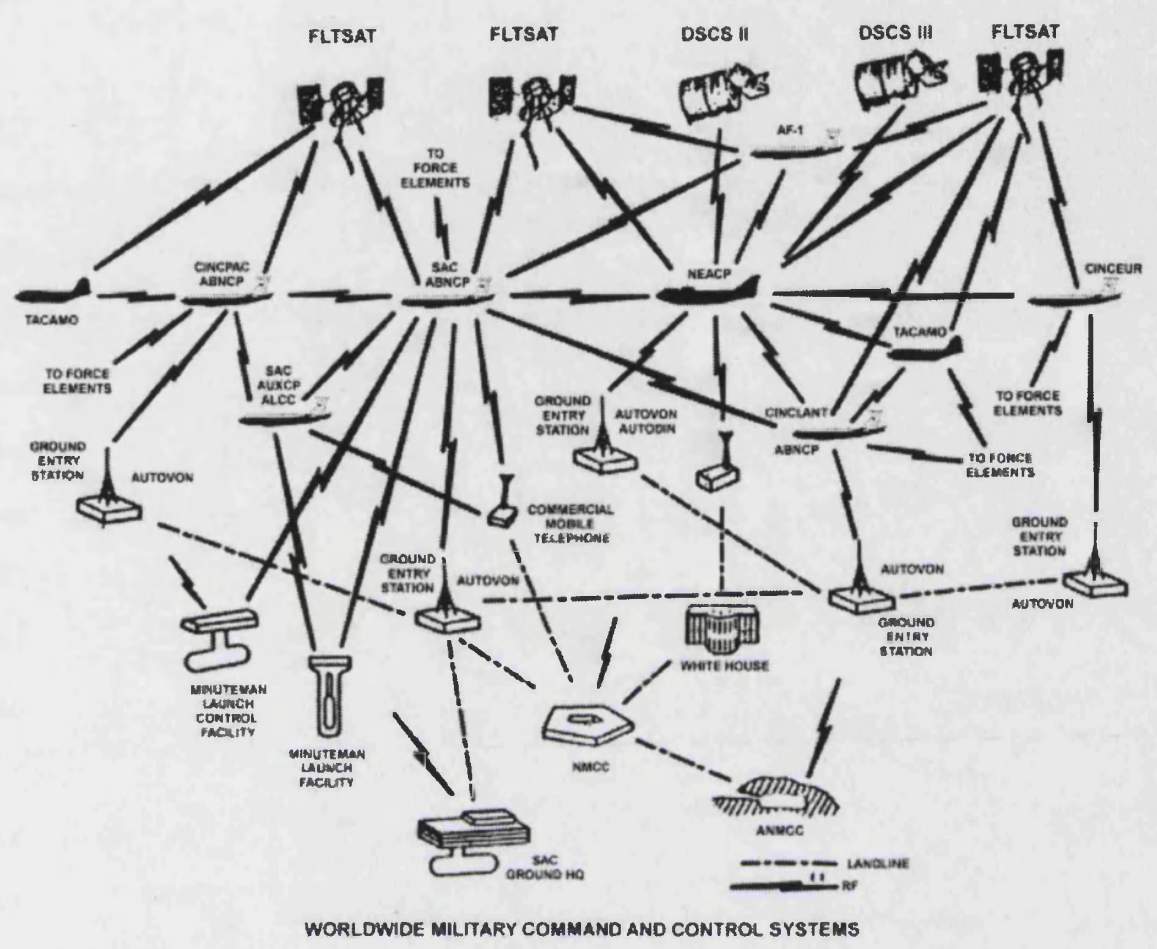

Figure 9: WWMCCS architecture ${ }^{305}$

Such global ambitions require the availability of reliable telecommunications anywhere in the world. No technology has been more crucial in this respect than the artificial satellites now orbiting the earth in their thousands, our communication relays and eyes in the sky. The enclosure of the world within global command-and-control architectures required the militarisation of space and its occupation by human artefacts. ${ }^{306}$ The space race between the U.S. and U.S.S.R. triggered by the launch of Sputnik was therefore not merely a matter of prestige and propaganda for both nations; the balance of power in space had immediate practical implications for security and warfare back down on Earth. As early as 1946, the RAND project (more on which below) published its first study entitled Preliminary Design of an Experimental World-Cirling Spaceship in which it was

${ }^{304}$ There were also civilian applications of the technology such as air-traffic control systems and SABRE, the airline reservation system in operation since 1964.

305 The Federation of American Scientists http://www fas.org/nuke/guide/usa/c3i/wuwmecs.htm

306 While satellite technology was initially exclusively reserved for scientific and military purposes, it is notable that a majority of operational satellites are today in the civilian field and providing commercial services from meterology to telecommunications. 
claimed that "a satellite vehicle with appropriate instrumentation can be expected to be one of the most potent scientific tools of the twentieth century" and that its achievement "would produce repercussions comparable to the explosion of the atomic bomb. "307

Encircling the globe in a mesh of geocentric orbits would not only allow for the final abolishing of distance by enabling instantaneous communications from any location on the planet, it would also permit the precise coordinates of individuals or objects to be known and transmitted. The first satellite navigation system, NAVSAT, was made operational in 1964, initially for ballistic missile submarines: With an accuracy of about two hundred metres provided by ten orbiting satellites, it was sufficient for the guidance of nuclear missiles. 1967 saw the Russians launch their own satellite navigation system called Tsyklon. Research on a system.providing greater precision and coverage was iniated by the United States in 1973 and eventually led to the NAVSTAR Global Position System (commonly known as GPS) through a network of 24 satellites made fully operational in 1995 . While 40,000 U.S. troops were using GPS devices by 2002 , the service was also made commercially available resulting in sales of several million receivers, soon to become a standard function of mobile phones. ${ }^{308}$ Concerned with its potential use by the military of enemy states, the U.S. has retained the right and means to degrade its reliability through a feature named "Selective Availability" that reduces accuracy from 15 to 100 metres. This dependency on America, along with the appeal of significant commercial benefits, has prompted the European Union to launch its own satellite navigation system, Galileo, which will function with an accuracy of five metres when it is operational around 2012. The expressed hostility of the U.S. to this project underlines the importance attached to positioning systems and the military and strategic value of the information provided by them.

The Strategic Defense Initiative or 'Star Wars' project, whether under Reagan or its revised form under the Bush administration, is a clear descendent of SAGE as a computer-controlled and centrally-commanded scheme, and epitomises the militarisation of space and its potential impact on earth-bound warfare. An air defence system designed to intercept ballistic missiles fired at the United States through a

\footnotetext{
${ }^{307}$ Project RAND, "Preliminary Design of an Experimental World-Circling Spaceship" (1946), pp.13-14 htp://www.rand.org/pubs/special memoranda/2006/SM11827part1.pdf

308 David Hambling, Weapons Grade (London: Constable \& Robinson, 2005), p.43
} 
complex network of sensors and precision-guided missiles (some located on earth, others space-based), SDI was founded on a profoundly held faith in the potential for information technology to grant omniscience and omnipotence by providing an infallible shield against attack. However, the technological feats required for the effective operation of such a system remain enormous, then and now, with many experts casting doubts over their feasibility. Edwards goes as far as to say that the 1.980s project was "almost entirely imaginary and ideological" and with a minimal military potential. ${ }^{309}$

Missile defence projects came out of research initiated in World War II as a response to the emerging jet engine aircraft since the speed and altitude at which these planes operated rendered gun-based systems largely obsolete. Under its Ajax and Hercules iterations, Project Nike saw the development of missile defence systems located in the proximity of major industrial and urban centres. Aside from an improvement in speed and range over gun defences, Nike missiles could be guided from the ground so as to home in on their target. Radar stations would track the radar signature of the missile and target aircraft, feeding this data to a computer which would calculate the missile's optimal course for achieving interception, adjusting its flight as new information came in. At the point of closest approach, the computer would send a 'burst command' that would cause the missile to detonate. A clear cybernetic loop is here in evidence: the radar acting as a sensor, the computer as the processor, and the missile's behaviour as the output.

Edwards sees these cybernetic principles as applied throughout the military with machines, bodies, and organisations constituting:

\begin{abstract}
command-control-communications systems [which] operated as a nested hierarchy of cybernetic devices. Airplanes, communications systems, computers, and anti-aircraft guns occupied the micro levels of this hierarchy. Higher-level 'devices', each of which could be considered a cyborg or cybernetic system, included aircraft carriers, the WWMCCS, and NORAD early warning systems. At a still higher level stood military units such as battalions and the Army, Navy, and Air Force themselves. Each was conceptualised as an integrated combination of human and electronic components, operating according to formalised rules of action. Each level followed directives taken from the next highest unit and returned information on its performance to that unit. Each carried out its own functions with relative autonomy, issuing its own commands to systems under its control and evaluating the results using feedback from them. ${ }^{310}$
\end{abstract}

${ }^{309}$ Paul N. Edwards, "From 'Impact' to Social Process: Computers in Society and Culture" in Sheila Jasanoff et al. (eds.), Handbook of Science and Technology Studies (Beverly Hills, CA: Sage Publications, 1994) htp://www.si.umich.edu/ pne/PDF/impact.pdf, p.11

310 Edwards, The Closed World, p.206 
This understanding of military operations as interlocked systems obeying formalised rules invited, and indeed required, their analytical treatment through the lenses of mathematics and logic. In order to determine the formalised rules of action according to which each level of the hierarchy of cybernetic devices should operate on the basis of incoming information, it was necessary to identify the parameters and signals upon which to act. Exhaustive models of the behaviour of both the U.S. military and that of its potential enemies were thus developed, thereby reducing war to a complex equation to be resolved by a technoscientific priesthood.

\title{
Operations Research and Systems Analysis: Solving the War Equation
}

\author{
Modern war has become too complex to be entrusted to the intuition of \\ even the most experienced military commander. Only our giant brains \\ can calculate all the possibilities. \\ Jobn Kemeny, RAND Consultant and co-creator \\ of the BASIC computer language, $1961^{31 "}$
}

"The representation and analysis of real world processes using logic, mathematics and computer science," operations research (OR) and its offspring systems analysis (SA) transformed the manner in which war was prepared for, planned and imagined. ${ }^{312}$ Despite initial resistance by officers, statistical control, OR and SA gained a rapidly growing influence over planning and operations in the post-war era. By 1962, this approach had become so popular and ubiquitous since its early applications in World War II that OR could proclaim itself to be "the attack of modern science on complex problems arising in the direction and management of large systems of men, machines, material and money in industry, business, government and defence." ${ }^{313}$ Systems analysis likewise "served as the methodological basis for social policy planning and analysis across such disparate areas as urban decay, poverty, health care, education, and the

\footnotetext{
${ }^{311}$ Ghamari-Tabrizi, The Worlds of Herman Kabn, p.149

312 Department of the Army Pamphlet 600-3-49, "Operations Research/Systems Analysis" (Washington, DC: Department of the Army, 1987) http://www.army.mil/usapa/epubs/pdf/p600 3 49.pdf

${ }^{313}$ Nigel Cummings, "How the World of OR Societies Began" (The OR Society) http://www.orsoc.org.uk/orshop/(awagdrfkrmznlwneegwigdqi)/orcontent.aspx?inc=article news orclu b.htm
} 
efficient operation of municipal services such as police protection and fire fighting."314 However, as De Landa has observed, most of these techniques were pioneered in the military and the broad application of this management science effectively marked the transfer of "command and control structures of military logistics to the rest of society and the economy." ${ }^{315}$

Operations research seeks to improve operations by studying an entire system rather than exclusively concentrating on specific elements. In the context of the transfer of operations research to business in 1950s-60s but equally applicable to military affairs, Gene Rochlin tells us that "the new agenda differed from the old in a major expansion of the scope of analysis; instead of treating the firm as a series of isolated, interacting operations to be integrated from the top, it was now visualised as single, complex, interrelated pattern of activities, to be analysed, coordinated and optimised as a whole. ${ }^{.316}$

In this sense OR and SA are very much in the cybernetic mould in their belief in a whole that is superior to the sum of its parts and their assumptions about the closure of the systems being modeled. Stafford Beer is probably the most pre-eminent academic and consultant to have explicitly connected cybernetics to operations research and management, publishing the influential Cybernetics and Management in $1959 .{ }^{317} \mathrm{He}$ was later entrusted with a project to develop a national real-time computerised system to run the entire Chilean economy under the Allende government from 1970 to 1973 . For Beer, cybernetics is nothing less than "the science of which operational research is the method":

\footnotetext{
Operational research comprises a body of methods which cohere to provide a powerful tool of investigation. Cybernetics is a corpus of knowledge which might reasonably claim the status of a science. My contention is that the two are methodologically complementary; that the first is the natural technique in research of the second, and the second the natural embodiment in science of the first. By definition, each is concerned to treat a complex and interconnected system or process as an organic whole. By methodology, each is concerned
}

314 The RAND Corporation, "A Brief History of RAND” http://www.rand.org/about/history/ For a detailed account of the applications of cybernetics, systems analysis, and computer simulations to urban planning and management in the US, notably by former defence intellectuals, see Jennifer S. Light, From Warfare to Welfare: Defense Intellectuals and Urban Problems in Cold War America (Baltimore, MD \& London: John Hopkins University Press, 2003)

${ }^{315}$ De Landa, War in the Age of Intelligent Macbines, p.5

316 Rochlin, Trapped in the Net, p.59

${ }^{317}$ Stafford Beer, Cybernetics and Management - 2nd edition (London: English Universities Press, 1967) 
with models and analogies from every source. By science, neither is departmental. By philosophy, each attests to the indivisible unity of knowledge. ${ }^{318}$

Another source draws out further the similarities:

One major characteristic of cybernetics is its preoccupation with the construction of models and here it overlaps operational research. Cybernetic models are usually distinguished by being hierarchical, adaptive and making permanent use of feedback loops. Cybernetics in some ways is like the science of organisation, with special emphasis on the dynamic nature of the system being organised. ${ }^{319}$

The computer is here again central since the optimisation of the mathematical models constructed by operations researchers and systems analysts is achieved through the use of computer-based algorithms which calculate changes in the system's behaviour resulting from any changes in the multiple variables that constitute the models. Without the computer, the widespread application of OR and SA and the increasing complexity of the models developed would have been impossible. In this sense, these analytical techniques are inseparable from the technologies that support them. The viability of the models is dependent on their ability to be translated into computer code, that is into a program that can convert quantifiable inputs into quantifiable outputs. As system analysts James Martin and Adrian Norman put it, "a model without numbers cannot be manipulated so measurement and quantification is a fundamental part of the description resulting from analysis, and the basis of the evaluation of systems design." 320 Consequently, that which cannot be assigned a number or expressed in terms of logical relationships is necessarily excluded. ${ }^{321}$

The following section will offer a brief history of OR and SA, focusing on their rapid, although not uncontroversial, rise within the American defense establishment, culminating in the nomination of Robert McNamara to the position of Secretary of Defense. Information on the use of operations research and systems analysis in the

${ }^{318}$ Stafford Beer, "What Has Cybernetics to Do with Operational Research?”, Operational Research Quarterly, Vol. 10, No. 1, 1959)

${ }^{319}$ F.H. George, "What is Cybernetics" hrtp://wrw.des.st-

and.ac.uk/ mkw/IC Group/What is Cybernetics.html

${ }^{320}$ James Martin \& Adrian R.D. Norman, The Computerised Society (Harmondsworth, Middlesex: Penguin Books, 1973), p.569

321 Operations researchers do occasionally pursue qualitative research such as conducting interviews and open-ended surveys. However, these exercises are clearly secondary to the manipulation of quantitative data and not the basis on which OR and its extended family of management sciences have asserted their institutional authority to analyse and determine organisational and operational structures. Therefore I will only consider these analytical techniques as being defined by their use of logic, mathematics and computer science. 
Soviet Union is harder to come by given the society's highly secretive character. ${ }^{322}$ There is however no doubt that it found widespread applications and it is instructive to note that much of what is called OR and SA in the West was known in the Soviet Union as cybernetics, a discipline which, after at first being denounced as bourgeois 'philosphical obscurantism', was hailed at the 1961 Party Congress as a vital factor in the Soviet 'revolution of the military system. ${ }^{323}$

\section{From the RAND Corporation to Robert McNamara: the Rise of the System Analyst}

Operations research was pioneered by the British in the late 1930s and was enthusiastically embraced by the U.S. military during the Second World War. OR Air Force studies multiplied exponentially in this period: "offensive ones dealing with bombing accuracy, weapons effectiveness, and target damage [...] defensive ones dealing with defensive formations of bombers, battle damage and losses of our aircraft, and air defence of our bases [...] studies of cruise control procedures, maintenance facilities and procedures, accidents, in-flight feeding and comfort of crews, possibility of growing vegetables on South Pacific islands, and a host of others. ${ }^{\text {.324 }}$

Van Creveld accounts for the initial success of this mathematical approach with the particular nature of strategic bombing and the defensive measures deployed against it. ${ }^{325}$ The development of air defences necessitated the establishment of socio-technical systems of a greater complexity than had ever been previously constructed. The integration of radar required the creation of an extended coverage of the airspace through individual radar stations (with particular attention paid to reducing overlap and mutual interference) along with a communications network that could transmit the relevant information to a centralised headquarters for processing and then onwards to air defense units such as anti-aircraft guns or fighter planes. Faced with such heavy defensive systems, it became necessary for bombers to fly at altitudes that were frequently too high for the crews to directly observe their targets. Consequently,

322 One notable exception is Slava Gerovitch's fascinating work, From Newspeak to Cyberspeak: A History of Soviet Cybernetics

${ }^{323}$ Andrew Wilson, The Bomb and the Computer (London: Barrie \& Rockliff, 1968), p.49

324 Clayton J. Thomas \& Robert S. Sheldon, "Air Force Operations Analysis" in Carl Harris \& Saul Gass (eds.), Engyclopaedia of Operations Research and Management Science (Kluwer Academic Publishers, 2000) http://www.mors.org/history/af oa.pdf

325 Van Creveld, Technology and War, pp.191-194 
operations had to be planned days ahead, as well as coordinated and integrated with ground facilities, air support and a host of anti-radar measures. "Thus strategic bombing not only found itself opposed by a technological system but itself assumed all the

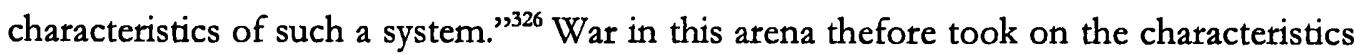
of a battle of attrition between two competing technological systems. This configuration naturally lent itself to being run by centralised statistically-based forms of management.

Naval warfare, particularly anti-submarine activities, was the other field in which operations research obtained impressive results during World War II. When British antisubmarine aircrafts reduced the depth at which depth charges were to detonate on the recommendation of operations researchers, the increase in successful attacks was so great that the German military became convinced the British were using a new type of explosive. OR was also able to reduce the loss rate of naval convoys when analysts realised that larger convoys suffered lower percentage losses than small convoys.

The greater simplicity and homogeneity of the aerial and marine environments certainly played a crucial factor in the success of OR since warfare in those milieus was easier to model mathematically than land operations. More generally, modern war involved "more repetitive operations susceptible to analysis" in that "a men-plus-machines operation can be studied statistically, experimented with, analysed, and predicted by the use of known scientific techniques just as a machine operation can be. ${ }^{3327}$ Scientists felt that they were ideally trained to grapple with the problems of modern war with their ability "to get down to the fundamentals of a question - to seek out broad underlying principles through a mass of sometimes conflicting and irrelevant data [...] with the result that they were often able to discredit what the military regarded as 'commonsense' solutions."

After the war, operations research - the optimizing of existing systems - soon morphed into systems analysis - the design of the most effective system for the accomplishment of a defined objective - granting analysts planning powers. After 1945, procurement cycles increased in terms of the time necessary for the research and development, production, and deployment of any new technology. Furthermore, closer cybernetic

326 Van Creveld, Technology and War, p.194

${ }^{327}$ Clayton J. Thomas \& Robert S. Sheldon, "Military Operations Research" in Harris \& Gass (eds.), Encyclopaedia of Operations Research and Management Science http://www.mors,org/history/mor.pdf

${ }^{328}$ Wilson, The Bomb and the Computer, p.43 
integration of vehicles, projectiles, communications, radar, and electronic countermeasures created weapon systems whose components could not be designed separately in order for integration into a functioning whole to be successful. This naturally empowered those analysts that proposed a scientific methodology according to which technological and budgetary decisions could be determined. Systems analysis was perfectly suited to this task since its microeconomic logic and optimisation routines enabled planners to determine the best allocation of resources given a limited supply of resources. Reviewed through a range of possible future security and military environments, alternative systems could be compared and judged in terms of efficiency and cost.

This approach promoted a worldview of warfare which reduced it to a mathematical problem with a number of variables that could be manipulated and a production model that could be scientifically managed along Taylorist ideals. ${ }^{329}$ RAND, the think-tank created by the U.S. Air Force, became the home of systems analysis, often to the detriment of any other forms of thinking about national security. As Kaplan puts it, "for an organisation dominated by mathematicians, systems analysis appeared to be the way to get the scientific - the right - answer. Projects that involved no systems analysis, such as most of the work produced by the social science division, were looked down upon, considered interesting in a speculative way at best." ${ }^{\text {330 }}$

Models grew to astonishing levels of complexity, fuelled by the desire to create an accurate simulation of conflict, a scientific understanding of a quite literal war machine. The father of systems analysis, RAND researcher Ed Paxson, was symptomatic of this with the minutiae of his obsession in planning for World War III:

His dream was to quantify every single factor of a strategic bombing campaign - the cost, weight, and payload of each bomber, its distance from the target, how it should fly in

\footnotetext{
${ }^{329}$ Fortun and Schweber have drawn out the similarities between Taylorism's 'scientific management' and operations research in their efforts to improve system efficiency, but also underlining that the central difference between them is that whereas the former used exclusively deterministic models in which "the effect of a given action was assumed to result in a well-defined and well-determined effect" (in other words, along the lines of the clockwork model of science), OR dealt principally with "stochastic processes and with probabilistic models that explicitly recognised uncertainty as an intrinsic feature of the processes being modelled." Here, OR rejoins cybernetics again in that the science of communications and control sought to grapple with problems of a stochastic nature, such as the future positions of an enemy airplane that an anti-aircraft system was trying to track.

M. Fortun \& SS. Schweber, "Scientists and the Legacy of World War II: The Case of Operations

Research (OR)", Social Studies of Science, Vol. 23, 1993, p.624

${ }^{330}$ Fred Kaplan, The Wizards of Armageddon (New York: Simon \& Schuster, 1984), p.87
} 
formation with other bombers and their fighting escorts, their exact routing patterns, the refueling procedures, the rate of attrition, the probability that something might go wrong in each step along the way, the weight and inaccuracy of the bomb, the vulnerability of the target, the bomb's 'kill probability,' the routing of the planes back to their bases, the fuel consumed, and all extraneous phenomena such as the weather - and put them all into a single mathematic equation. 331

Planning for the use of nuclear weapons in a bombing campaign was a particularly urgent task during the Cold War and required continuous reviewing since the technology and availability of bombs and missiles were subject to rapid change. The explosive power of individual devices - first triggered by nuclear fission in atomic bombs, then nuclear fusion for hydrogen bombs - escalated vertigineously with 1952 witnessing the American test of a 10.4 megaton bomb, nearly 700 times more powerful than the bomb dropped on Hiroshima and superior to the combined total explosive ordnance employed in the two world wars. ${ }^{332}$ Launching systems gained in range and accuracy; with the evolution from the medium-range bomber B-29 in 1945 to the intercontinental ballistic missile (ICBM) in 1957, full-blown nuclear war could be initiatied within a few hours of the executive decision. Further shortened by the unavoidable delay in the detection of such an attack from either of the Cold War protagonists, this window might be the only one available to policy-makers in which to respond in kind before being ravaged.

There was to be no rehearsal or practice run for nuclear war, and perhaps no second chance. Consequently, a 'hot' World War III had to be planned for by being analysed, quantified, systematised, and simulated. Systems analysis, game theory and the whole range of available mathematical and statistical instruments were the only means to rationalise armageddon and "think the unthinkable." ${ }^{3333}$ The expected levels of casualties and destruction of a full-blown nuclear war were such that they threatened to render meaningless any notion of strategy as the rational use of force for political aims, in accordance with Clauswitz's dictum. Perhaps even more terrifyingly, analysts believed that it might become rational for any one of the adversaries to initiate nuclear war if it either believed that an attack against it was imminent or that it might be possible to survive retaliation after a first strike.

331 Kaplan, The Wizards of Armageddon, p.87

332 In a game of one-upmanship typical of the Cold War, the Soyiet Union detonated a completely impractical bomb of 50 megatons baptised Tsar Bomba (the 'Emperor Bomb') in 1961. This remains the most powerful nuclear device ever detonated, even though the same bomb design could have been used for a 100 megaton explosion.

333 Thinking about the Untbinkable was the title of notorious nuclear strategist Herman Kahn's second book that followed On Thermonuclear War in 1962. 
Faced with such a chilling prospect, defense intellectuals saw it as their duty to salvage strategic thinking and bring the nuclear face-off under rational and scientific management, viewing it as the only means by which to prevent or limit nuclear war. The priority of the analysts therefore became to preserve the "delicate balance of terror"334 over and above any notion of winning the face-off, to ensure that the 'cold war system' could return to homeostatic equilibrium and ward off the possibility of it exceeding the bounds beyond which it would self-destruct in an apocalyptic spasm dubbed "wargasm" by the nuclear strategist Herman Kahn. Initially, the focus of systems analysts was to ensure that the United States could incur a Soviet first strike and still retain enough nuclear weapons to ravage the Soviet Union under a policy of 'massive retaliation'; thus, it would never be rational to initiate a first strike. ${ }^{335}$ On the recommendation of senior analysts, reinforced missile silos and airbases were constructed and a system whereby fleets of bombers carrying nuclear payloads were permanently in flight and others were ready to launch at short notice was established. Subsequently, some defence intellectuals such as Kahn sought to chart a path between the either/or of complete restraint and full-blown armageddon by conceiving of a rationalised limited use of nuclear weapons. Under such a scheme, a graduated use of nuclear weapons was imagined according to which a form of tit-for-tat bargaining with the enemy could proceed and avert automatic escalation to complete annihilation.

In the absence of any battlefield experience of nuclear weapons, systematic mathematical calculation of the theoretical damage they would inflict on urban areas and troops was the only means by which to assess offensive and defensive requirements. Consequently, nuclear payloads, delivery systems, military and civilian defensive measures along with the strategies and tactics within which these would be inserted were

\footnotetext{
334 Albert Wohlstetter, "The Delicate Balance of Terror" (1958) http://www.rand.org/publications/classics/wohlstetter/P1472/P1472.html

335 Kubrick's film Dr. Strangelove or How I Learned to Stop Worrying and Love the Bomb pushed the logic of mutually assured destruction (MAD) to its absurd conclusion with the Doomsday Machine. Actually first imagined by Hermann $\mathrm{Kahn}$, the device is constituted of a computer hooked up to a huge stock of thermonuclear bombs that will be automatically detonated and shroud the earth in radiation upon detection of a nuclear attack by the adversary. In taking the human out of the loop, deterrence could be made more effective since the adversary could not be tempted to gamble on a failure of nerve. As the eponymous Dr Strangelove puts it: "deterrence is the art of producing in the mind of the enemy... the fear to attack. And so, because of the automated and irrevocable decision making process which rules out human meddling, the doomsday machine is terrifying. It's simple to understand. And completely credible, and convincing."

Stanley Kubrick (director), Dr. Strangelove or How I Learned to Stop Worrying and Love the Bomb (Columbia Pictures, 1964)
} 
also given the system analysis treatment. Nor was systems analysis limited to nuclear aspects of warfare, the entire spectrum of conventional military operations were subject to its scrutiny. As RAND's first vice-president Alan Henderson declared in 1949, "systems analysis seeks to cover the full range of possible future weapons characteristics and simultaneously analyse each set of possible characteristics in all possible tactics and strategies of employment." ${ }^{336}$

However, while the consideration of the relative merits of two bombers with ten variables as possible during World War II yielded already over 1,000 combinations, raising the number of systems being considered by only four resulted in over a million combinations for evaluation. ${ }^{337}$ Furthermore, the rapidly evolving characteristics of the weapons required a constant revision of their potential and impact on existing tactical and strategic war plans. This exponential increase in possible permutations made this task perfectly suited to, and only achievable by, the computer. Thanks to its formidable processing power - that is its ability to conduct logical tasks at gxeat speed - the computer allowed for the creation of complex models with multiple variables, providing a rapid calculation of any changes in their values.

The same modelling techniques were also employed for a vast range of wargames which simulated an array of operations from the tactical to the operational to the strategic, from individual battalions to anti-aircraft defenses to global geopolitical exercises. While wargaming had long been practiced - the Germans had been keen enthusiasts of Kriegsspiel from the nineteenth century onwards - the new generation of wargames and simulations were an extension of OR and SA since they relied on the same methodology for their models. COW, one of the earliest games played at RAND in the early 1950s, involved 20 states interacting through a mathematical modelling of international relations. The Army's STAG Directory listing deemed that "despite grossly unrealistic features, it demonstrated the possibility, in principle, of applying scientific modeling methodology to a field as vague as the political arena. ${ }^{2338}$

Ghamari-Tabrizi points to the manner in which these wargames constituted their own closed worlds:

${ }^{336}$ Ghamari-Tabrizi, The Worlds of Herman Kabn, p.138

${ }^{337}$ I.B. Holley Jr., "The Evolution of Operations Research and the Impact on the Military Establishment; The Air Force Experience" in Wright \& Paszek (eds.), Science, Tecbnology and Warfare, p.101

${ }^{338}$ Ghamari-Tabrizi, "U.S. Wargaming Grows Up" 
Following the thread of systems thinking, the gamers tried to shoehorn everything of importance into game design and play. Since a major war would batter every department of life, they were tempted to expand their model into infinitely complex details in the simulation of reality. But at the same time, they were determined to set upper and lower boundaries, limits and constraints of every kind onto that surging impluse towards the Weltbild. In other words, in war game design, one makes out a wish to catch a richly furnished world, but one sealed off like a terrarium or a tableau in a paperweight. This snug little world, in which the totality could be grasped all at once, encompasses the universe of miniature life. ${ }^{339}$

Computers became increasingly employed in wargames, first to calculate the outcome of any decision by the players by processing it through complex models of warfare and international relations (thereby avoiding lengthy calculations on paper and references to rulebooks), and secondly as an interface for the players. With the aim of providing greater realism, the environments of decision-makers were often reproduced painstakedly. Mediated through computerised displays and interfaces, real wartime situations and simulations would be largely indistinguishable. Wargamers at RAND would eventually grant computers an even greater role by making them fully-fledged players. Faced with human players that would persistently refuse to cross the nuclear threshold in simulated excercies, the simulationists developed artificial intelligences that could play the role of the Soviet Union or United States, creating a variety of iterations characterised by different personalities and willingnesses to resort to force. ${ }^{340}$ Computers were effectively the ideal wargamers: cold, logical, purely instrumental and devoid of the messy cultural, social and historical attributes that plagued human players and could not be mathematically modelled. Fully computerised wargames allowed for the rapid testing of an entire range of weapon system characteristics, logistics, tactics, and strategies for the purpose of identifying the optimal combination. ${ }^{3+1}$

But the use of wargames was not restricted to testing models; they could also provide their own facts and statistics for interpretation and inclusion in the models. As one wargamer observed: "as we recede from such sources of empirical data as World War II and Korea, an ability to generate synthetic battlefield facts becomes increasingly

339 Ghamari-Tabrizi, The Worlds of Herman Kabn, p.166

${ }^{340}$ DeLanda, War in the Age of Intelligent Machines, p.103

${ }^{341}$ In the 1983 film Wargames, the U.S. military entrusts the launching of nuclear weapons to a computer called WOPR (War Operations Plan and Response) in a bid to eliminate the potential for human error and failure of nerve. A teenage hacker, convinced he is playing the latest computer game, inadvertently triggers a countdown to thermonuclear war. At the climax of the film, the hero succeeds in convincing the computer to play out all the simulated scenarios and strategies for a full-blown nuclear exchange with the Soviet Union, resulting in the artificial intelligence's realisation that these all lead to mutual annihilation and that therefore the only manner to win this particular 'game' is not to play.

John Badham (director), Wargames (MGM, 1983) 
important." ${ }^{342}$ These synthetic facts drawn from the experiences of simulated conflict could then be fed back into further models of war - simulation begetting simulation in a hyperreal feedback loop increasingly removed from situated experience of combat in the 'real world'.

If institutional resistance from the Air Force - RAND's main sponsor - to studies that attempted to model warfare in its entirety forced the organisation into publicly downgrading the ambition in the scope of their research projects, in practice, the systemic interelationship of areas of study and the commonly-held belief of analysts in the superiority of their methodology made such restrictions difficult to maintain. Alain Enthoven, Deputy Assistant Secretary for Systems Analysis under McNamara, once pointed out to a General that "I have fought as many nuclear wars as you have." In fact, given his time at RAND modelling them and playing war games, Enthoven may well have believed that he had actually fought more nuclear wars, albeit simulated. Enthoven's quip was symptomatic of the attitude of RAND analysts towards the military brass, convinced as they were that "in order to approach nuclear war properly, one had to become a perfect amnesiac, stripped of the intuitions, judgements, and habits cultivated over a lifetime of active duty."343 Combat experience and traditional common wisdom of the military were thus devalued in favour of the cool rational calculations of the defence intellectual. In 1961, this latter vision appeared to have triumphed over the generals as Robert McNamara was made Secretary of Defense and proceeded to apply the paraphernalia of systems analysis across the military more systematically than ever before.

Robert Strange McNamara had first risen to prominence during the Second World War, distinguishing himself as one of the most brilliant analysts in the Statistical Control Office, where he conducted operations research on the Air Force operations using human computers and IBM counting machines. He was notably involved in the strategic bombing campaign of Japan, recommending the switch to firebombing and lower altitude bombing which the notorious Air Force General Curtis LeMay (later head of Strategic Air Command during the Cold War) adopted with devastating results for Japanese cities. After the war, he left the armed forces to join the Ford Corporation in

${ }^{3+2}$ Ghamari-Tabrizi, The Worlds of Herman Kabn, p.169

${ }^{343}$ Ghamari-Tabrizi, The Worlds of Herman Kabn, p.48

Kahn echoed Enthoven's sentiment when he asked officers who were critical of his approach, "how many thermonuclear wars have you fought recently?" 
1946, applying the same principles of scientific management with great success, before being offered the role of Secretary of Defense by President Kennedy. Surrounding himself with a team of ex-RAND analysts that shared his worldview, McNamara set out to extend these principles to all branches of the military. A controversial figure, particularly unpopular with certain sections of the military over which he asserted previously unseen levels of civilian control, McNamara was once referred to as a "'human IBM machine' who cares more for computerised statistical logic than for human judgments."3+4

McNamara instigated the Planning, Programming and Budgeting System (PPBS) in 1962, perhaps his most lasting legacy, by institutionalising systems analysis in the decision-making process of military planning and procurement. With PPBS, cost-benefit and cost-effectiveness analysis were applied across all branches of the military so that various military programs from different services could be evaluated, compared, and granted funding accordingly. ${ }^{345}$ Department of Defense Comptroller Charles Hitch (exRAND) was responsible for the implementation of PPBS, defining the system analysis approach that was being applied as:

\footnotetext{
economic analysis applied to the public sector. Economic analysis is concerned with the allocation of resources. Its maxim is: maximise the value of objectives achieved minus the value of resources used. In business this reduces itself to maximising profits. In Defence $[\ldots]$ we lack a common valuation for objectives and resources and therefore have to use one of two weaker maxims - maximise our objectives for given resources, or minimise our resources for given objectives. ${ }^{346}$
}

PPBS was subsequently extended across the federal bureaucratic structure, in particular the social welfare agencies of the Departments of Health, Education and Welfare and Office of Economic Opportunity. Hitch insisted that systems analysis acted merely as an instrument assisting decision-makers rather than being the decisive factor in determining spending plans. Gregory Palmer agrees that PPBS was often more of a heuristic or ideal, but that "in its pristine form, PPBS was a closed system, rationally ordered to produce carefully defined outputs. ${ }^{3477}$ As such, critics claimed its influence was pervasive and dangerously misleading if applied uncritically. I will now turn to some of the criticisms directed towards operations research and systems analysis.

${ }^{344}$ U.S. Department of Defense, "Biography of Robert S. McNamara"

http://www.defenselink.mil/specials/secdef histories/bios/mcnamara.htm

${ }^{345}$ Kaplan, The Wizards of Armageddon, p.254

${ }^{346}$ Wilson, The Bomb and the Computer, p.49

${ }^{347}$ Edwards, The Closed World, p.5 


\section{Criticisms of Operations Research and Systems Analysis}

In his Farewell Address to the people on January 17, 1961, President Eisenhower famously warned against "the acquisition of unwarranted influence, whether sought or unsought, by the military-industrial complex." Less often quoted are his words about the "danger that public policy could itself become the captive of a scientifictechnological elite." 348 A military man, Eisenhower was most likely at least in part thinking of the operations researchers and system analysts which rose to prominence during his presidency and were about to take control of the Pentagon, equipped with instruments they believed could be used to tackle all social problems. "The military effect of cybernetics and computers did more than bring about changes in administration, logistics, communications, intelligence and even operations," van Creveld tells us, "they also helped a new set of people to take charge, people who thought about war - and hence planned, prepared, waged, and evaluated it - with the aid of fresh criteria and from a fresh point of view." ${ }^{349}$

Because of the scientific and mathematical methodology upon which this new point of view relied, analysts systematically privileged the quantifiable aspects of warfare:

With computers acting as the stimulus, the theory of war was assimilated into that of microeconomics [..] Instead of evaluating military operations by their product - that is, victory - calculations were cast in terms of input-output and cost effectiveness. Since intuition was replaced by calculation, and since the latter was to be carried out with the aid of computers, it was necessary that all the phenomena of war be reduced to quantitative form. Consequently everything that could be quantified was, while everything that could not be tended to be thrown onto the garbage heap. ${ }^{350}$

Under the impulse of computer modelling and systems analysis, the understanding of war which emerged during the Cold War was therefore frequently biased towards those elements which could be quantified.

But even that which could be quantified could not necessarily be precisely measured or estimated and would frequently only be the product of more or less inspired guesswork. For Solly Zuckerman:

\footnotetext{
348 President Dwight Eisenhower, Farewell Address to the People, January 17, 1961

${ }^{349}$ Van Creveld, Technology and War, p.246

350 Van Creveld, Technology and War, p.246
} 


\begin{abstract}
Operational analysis implies a kind of scientific natural history. It is a search for exact information as a foundation for extrapolation and prediction. It is not so much a science in the sense of a corpus of exact knowledge, as it is the attempted application of rigorous methods of scientific method and action to new and apparently unique situations. The less exact the information available for analysis, the less it is founded on experience, the more imprecise are its conclusions, however sophisticated and glamorous the mathematics with which the analysis is done. ${ }^{351}$
\end{abstract}

Thus, for all their scientific rigour, systems analysis and wargames relied heavily on intuitive and speculative guesses about numerous factors for which there was limited available information. As such, the outcome of systems analysis studies or war games was heavily dependent on the assumptions underpinning their models, some acknowledged by the analysts, others largely concealed or unquestioned. ${ }^{352}$ Driven by their desire for predictability, analysts constrained uncertainty by either setting the possible variations of factors within clearly delineated numerical ranges and probability sets or by simply discounting all those elements that could not be treated in this bounded way. Princeton academic Klaus Knorr noted some of the uncertainties frequently neglected by SA:

\begin{abstract}
Costs may be uncertain, technology may be uncertain, the properties of military conflict situations may be uncertain, and the reactions and capabilites of the potential enemy nations are apt to be uncertain. The last uncertainty is of particular import; it is imperative that military choices be examined within a framework of interaction. An opponent's responses to our choices may, after all, curtail ot altogether nullify the advantage we seek. Nor is it enough to recognise the conflict aspects of the problem. The possibilities of tacit or formal co-operation may be equally significant. 353
\end{abstract}

In fairness, senior system analysts recognised some of the limitations of their studies and it would be erroneous to claim that policy was solely dictated by them. As Alain Enthoven himself put it, operations research and systems analysis "cannot be 'objective' in the sense of being independent of values [...] value judgments are an integral part of the analysis: and it is the role of the analyst to bring to light for the policymaker exactly how and where value judgments enter so that the latter can make his own value judgments in the light of as much relevant information as possible." ${ }^{354}$ Nevertheless, government policies increasingly required some form of scientific costing and analysis

351 Perry, "Commentary" in Wright \& Paszek (eds.), Science, Technology and Warfare, p.117

352 Perhaps more so than any of his colleagues, Herman Kahn was particularly forthright about the speculative nature of much of his work and how much of it relied on crucial assumptions that had little if any empirical foundation. This frankness did not make Kahn's work any less controversial, both pilloried and applauded for provocatively broaching the taboo subject of full-out nuclear war and envisaging a post-war world in On Thermonuclear War (1961).

353 Wilson, The Bomb and the Computer, p.114

354 Perry, "Commentary" in Wright \& Paszek (eds.), Science, Technology and Warfare, p.117 
for their justification, even if other motives drove their promotion and adoption. The cybernetic model of warfare erected by the system analysts was one that was frictionless, a perfectly oiled machine resting on elegant mathematical constructs. The leeway for intuition and guesstimates opened up these models to manipulation for political and institutional motives. As Fred Kaplan narrates, McNamara frequently used systems analysis models to placate the insatiable demands of the air force for more nukes, insisting on 'scientific' justification for such expenditure. The services soon caught on to this new way of determining procurement needs and created their own systems analysis departments that would produce reports that endorsed their own preferences. As senior RAND analyst Albert Wohlstetter bemoaned it, "the problem with the use of numbers was that you've bequeathed them to people of bad faith and to people of good faith as well. ${ }^{3355}$

McNamara himself came to be disillusioned with the approach he had championed, recognising the impossibility of making war. into a fully rational and predictable instrument of policy: "war is so complex, it's beyond the ability of the human mind to comprehend all the variables. Our judgement, our understanding, are not adequate. ${ }^{2356}$ McNamara was to learn this lesson during his tenure as Secretary of Defense between 1961 and 1967, during which the United States got progressively sucked into a Vietnam War it could not win, despite (or perhaps because of) its army of system analysts in the Pentagon. Hindsight is a precious commodity but Vice Admiral Rickover summed up what had long been military wisdom during a 1966 subcommittee hearing of the House Committee on Appropriations in which he attacked the cost-effectiveness studies of the Department of Defense:

\begin{abstract}
All wars and military development should have taught us that [...] a war, small or large, does not follow a prescribed 'scenario' laid out in advance. If we could predict the sequence of events more accurately, we could probably avoid war in the first place. ${ }^{357}$
\end{abstract}

\title{
Vietnam and the Failure of Cybernetic Warfare
}

The limits of the centralising cybernetic model became clear in Vietnam, although its large role in the U.S. defeat has often been disregarded. ${ }^{358}$ James Gibson has perhaps

${ }^{355}$ Gregg Herken, Counsels of War (New York, NY: Alfred A. Knopf, 1985), p.230

${ }^{356}$ Errol Morris (director), Fog of War (Sony Pictures, 2004)

357 Wilson, The Bomb and the Computer, p.110 
done the most to document the dramatic failure of 'technowar', "a production system that can be rationally managed and warfare as a kind of activity that can be scientifically determined by constructing computer models." ${ }^{\text {359 }}$ Since the development of computers allowed for the gathering and processing of vast amounts of data, it was inferred that it would be possible to gain a far superior understanding and control of military operations.

The principles of OR and SA were systematically applied to provide analysis of the conflict and guidance to the policymakers while cybernetic command-and-control technologies were widely deployed. Van Creveld concedes that because of the ebb and flow of the conflict, the absence of a clear front, and the guerilla tactics of the Vietcong, it was extremely difficult to gain any insight into the conflict without statistical means. ${ }^{360}$ Nevertheless, what developed in Vietnam can be appropriately described as an information pathology', an obsession with statistical evaluations and directing the war from the top, perceived as the point of omniscience when in practice soldiers on the ground often understood far better than their superiors how badly the war was going. Beside masking the reality of the conflict, the informational demands of this approach eventually overwhelmed the military infrastructure:

\begin{abstract}
Extreme specialisation of personnel and units, coupled with adherence to the traditional triangular chain of command, meant that headquarters was piled upon headquarters and that coordination between them could only be achieved, if at all, by means of inordinate information flows. A tendency towards centralisation, the pooling of resources, and the running of the war by remote control - especially evident in the field of logistics and in the air war against North Vietnam - further augmented the demand for information. Though the signals network that the U.S. army established in South Vietnam was the most extensive, expensive and sophisticated in history, it proved in the end incapable of dealing with this "bottomless pit", as General Abrams once put it. ${ }^{361}$
\end{abstract}

Gibson submits that technowar not only altered the conduct of war but even the likelihood of the use of force: "by adopting microeconomics, game theory, systems

358 Of course, the reasons for American defeat in Vietnam are multi-faceted and certainly cannot be reduced to the way in which military operations were pursued there. Furthermore, the military was not in any conventional sense of the word defeated by the Vietcong but the latter did succeed in convincing the American public and political class that the war could not be won either. While the war was therefore ultimately lost on the political battlefield, I would argue that it was a misplaced faith in the technoscientific approach to war which gave the war planners an illusory sense of what could be achieved through only military means and caused them to pay insufficient attention both their own political strategy and that of the North Vietnamese. Arguably, some of these mistakes were repeated in the Iraq war of 2003.

359 Gibson, The Perfect War, p.156

360 Van Creveld, Command in War, p.253

${ }^{361}$ Van Creveld, Command in War, p.258 
analysis, and other managerial techniques, the Kennedy asministration advanced 'limited' war to greater specificity, making it seem much more controllable, manageable, and therefore desirable as foreign policy. ${ }^{362}$ Henry Kissinger illustrated this very point and the dangerous bubris which resulted from it when he claimed in 1968 that "a scientific revolution has, for all practical purposes, removed technical limits from the exercise of power in foreign policy."363

The U.S.'s bombing campaign in Vietnam obeyed a gradation in the use of force through which signals could be sent to the North Vietnamese. This amounted to a communicative theory of war where the level of violence can be alternatively ratcheted up or alleviated according to the message to be sent. In this manner, the government wished to convince the North Vietnamese that they could not win, thereby forcing them to negotiate and steering them towards the desired behaviour. In Kissinger's words once again, "in a limited war, the problem is to apply graduated amounts of destruction for limited objectives and also to permit the necessary breathing spaces for political contacts. ${ }^{2364}$ This thinking emerged from attempts by defence intellectuals, frustrated by the paradoxical powerlessness of nuclear weapons so destructive they could not be used, to theorise and rationalise their limited use against the Soviet Union as bargaining chips in an eventual showdown. This strategy was ultimately abandoned because of the impossibility to guarantee that nuclear war would not rapidly escalate into an apocalyptic war of extermination but resurfaced in the context of the Vietnam War.

By applying bargaining models based on game theory which assumed a common utilitymaximising rationality and cost-benefit framework of analysis on all sides, strategists erected an understanding of the enemy that was a mere reflection of the their own worldview. This perception was further bolstered by the military and civilian leadership's conception of war as determined principally by the management of complex industrial systems:

Limited war fought as a war of attrition means that only information about technologicalproduction systems will count as valid knowledge about the enemy. For the military as well as civilian, the enemy becomes a mirror image of ourselves, only "less" so. ${ }^{365}$

${ }^{362}$ Gibson, The Perfect War, p.80

${ }^{363}$ Henry Kissinger, "Central Issues of American Foreign Policy" in Henry Kissinger, Agenda for a Nation

(Washington, D.C.: The Brookings Institution, 1968)

364 Gibson, The Perfect War, p.22

365 Gibson, The Perfect War, p.23 
Since military effectiveness could only be measured by the yardstick of 'technologicalproduction systems,' the North Vietnamese were necessarily inferior and victory was the only conceivable outcome for the American war machine.

If technowar's closed self-referentiality was a major factor in bringing about its defeat in Vietnam, blinded as its proponents were to the successful asymmetric strategy deployed by the Vietcong, its principles could still prove formidably effective against the right opponent. In the Gulf War of 1991, Saddam Hussein opposed the hierarchical system of the U.S. army with his own inferior centralised and rigid system and was comprehensively defeated. Centralised command-and-control is suited to high-intensity wars of attrition in homogeneous environments such as was presented by Saddam's attempt to fight a modern industrial war in the Iraqi deserts. However, when faced with low-intensity conflicts where a dispersed enemy merges into a complex environment (such as the Vietcong in the jungles of Vietnam), the productivist logic of technowar is susceptible to spectacular inefficiency and failure. Attempts to simplify the battlespace through the practice of deforestation and the use of Agent Orange made little difference against an opponent that played to its strengths and understood its enemy far better than the Americans did. Witness North Vietnamese General Vo Nguyen Giap's piercing observation:

\footnotetext{
The United States has a strategy based on arithmetic. They question the computers, add and subtract, extract square roots, and then go into action. But arithmetical strategy doesn't work here. If it did, they would already have exterminated us with their airplanes. ${ }^{366}$
}

The American reliance on information technologies to direct the war brought its own problems. For one, whatever the improvements in information technologies, it is quite easy for the volumes of information to escalate so fast that saturation and bottlenecks result, especially when command-and-control is highly centralised. Intelligence on Vietcong positions and movements frequently arrived too late to be actionable, delayed in an information-processing infrastructure unable to treat all the data it was fed. And this despite the creation of an unprecedented telecommunications network in a field of operations, with electronic communications gear accounting for a third of all major items of equipment brought into the country and the first use of satellite 
communications for military purposes in $1965 .{ }^{367}$ As Arquilla and Ronfeldt recognise, "informational overload and bottlenecking has long been a vulnerability of centralised, hierarchical structures for command and control., ${ }^{368}$

Central to this was the fact that the measure of information gathering was frequently one of quantity over quality. The pressure on infantry units to produce detailed reports of their operations and particularly to match their 'production' targets in terms of enemy casualties led to wildly inaccurate and overblown estimates that masked the extent to which the U.S. strategy was failing. Gibson points to a related problem in the intelligence field where operations were gauged primarily on data volumes:

\begin{abstract}
Collection departments received most agency budgets and collection departments represented their progress in terms of how many 'bits' of information they collected, or how many hours of radio messages were recorded. Since their work was so tangible and measurable, collection departments got the most. As one senior staff member of the National Security Council said, "95 percent of the U.S. intelligence effort has been on collection, and only 5 percent on analysis and production [intepretation]."369
\end{abstract}

The paradox of this informational approach to warfare is noted by van Creveld: "designed to produce accuracy and certainty, the pressure exercised at the top for more and more quantitative information ended up by producing inaccuracy and uncertainty." ${ }^{370}$ It had been widely assumed that the development of informationgathering and processing technologies would allow a far greater understanding and control of military operations. In practice, the collection and production of information for its own sake created at best greater uncertainty and confusion and at worst a fictional account of the conflict based on a misplaced sense of omniscience and from which erroneous decisions would be made. As Pentagon systems analyst Alain Enthoven was himself to recognise, "you assume that there is an information system that will tell you what you want to know. But that just isn't so. There are huge amounts of misinformation and wrong information." ${ }^{371}$ Thus, far from eliminating the Clausewitzian 'fog of war', information-processing techno-social assemblages generate themselves " $a$

${ }^{367}$ Van Creveld, Command in War, p.239

Van Creveld also tells us that there was one radio set for every 4.5 soldiers in Vietnam compared to one for every 38.6 soldiers during World War II

${ }^{368}$ Arquilla \& Ronfeldt, "Cyberwar is Coming!" in Arquilla \& Ronfeldt (eds.), In Athena's Camp, p.45

${ }^{369}$ Gibson, The Perfect War, p.367

370 Van Creveld, Command in War, p.259

371 Herken, Counsels of War, p.220 
kind of twilight, which, like fog or moonlight, often tends to makes things seem grotesque and larger than they really are.,372

Between 1967 and 1972, the Air Force ran Operation Igloo White at the cost of nearly $\$ 1$ billion a year. Through an array of sensors designed to record sound, heat, vibrations, and even the smell of urine, feeding information to a control center in Thailand which sent on the resulting targeting information to patrolling jet aircraft (even the release of bombs could be controlled remotely), this vast cybernetic mechanism was designed to disrupt the Ho Chi Minh Trail, a network of roads and trails providing logistical support to the North Vietnamese. At the time, extravagant claims were made about the performance of the system with the reported number of destroyed trucks in 1970 exceeding the total number of truck believed to be in all of North Vietnam. ${ }^{373}$ In reality, far fewer truck remains were ever identified, there were probably many false positives in target identification, and the North Vietnamese and their Laotian allies became adept at fooling the sensors. In spite of all this, the official statistics still trumpeted a $90 \%$ success rate in destroying equipment travelling down the Ho Chi Minh Trail, an assertion difficult to sustain given that the North Vietnamese conducted major tank and artillery operations in South Vietnam in 1972. Edwards incisively observes that "Operation Igloo White's centralised, computerised, automated, power-at-a-distance method of 'interdiction' resembled a microcosmic version of the whole U.S. approach to Vietnam." 374

It might be objected that specific mistakes were made in Vietnam and that subsequently the Pentagon and military addressed some of these operational and technological failings in future operations. Regular improvements in sensors and information processing and distributing technologies are also frequently touted as the panacea that can resolve past difficulties. Nevertheless, the inherent difficulty of measuring quality of information as opposed to its quantity, along with the natural tendency for subordinates to provide the data that their superiors want to see and according to which their careers

\footnotetext{
372 Clausewitz, On War, p.90

373 Paul N. Edwards, "Cyberpunks in Cyberspace: The Politics of Subjectivity in the Computer Age" in Susan Leigh Star, ed., Cultures of Computing (Keele, UK: Sociological Review and Monograph Series, 1995), pp. 69-84 http://www.si.umich.edu/ pne/cyberpunks.htm 374 Edwards, "Cyberpunks in Cyberspace"
} 
will be advanced, means that information-gathering always remains vulnerable to distortion, deception, and manipulation.

Lastly, an informational approach to war and a reliance on computers has the inevitable consequence that those elements which can be quantitatively measured are privileged over those that cannot. Intuition, courage, and willpower - attributes that have been considered central to war for centuries - become devalued. John Lewis Gaddis explicitly criticises a tendency in American strategic thought in postwar era "to equate the importance of information with the ease of measuring it - an approach better suited to physics than to intemational relations. ${ }^{3775}$ The mindset thus produced is perhaps best summed up by McNamara's response to a White House aide's assertion that the Vietnam War was doomed to failure: "Where is your data? Give me something I can put in the computer. Don't give me your poetry."376

Not only were the statistical indicators pointing to U.S. success in the Vietnam frequently erroneous and misleading, the models on which the war managers relied were equally faulty. Trapped in a mindset which treated the war as a purely technical problem to be solved through overwhelming application of materiel according to a scientific methodology, these officials failed to grasp the sheer determination of their opponents and the extent of the success of their political strategy. Colonel Harry Summers relates an anecdote whose absurdity aptly captures the disjuncture between the statistical assessment of the war and its reality:

\begin{abstract}
When the Nixon Administration took over in 1969 all the data on North Vietnam and the United States was fed into a Pentagon computer - populations, gross national product, manufacturing capability, number of tanks, ships, and aircraft, size of the armed forces, and the like. The computer was then asked, 'When will we win?' It took only moments to give the answer: 'You won in 1964|'377
\end{abstract}

\title{
Conclusion
}

Defeat in Vietnam exposed the shortcomings of cybernetic warfare and revealed the inherent limitations of any attempts to make war into an entirely controllable and

${ }^{375}$ John Lewis Gaddis, Strategies of Containment: A Critical Appraisal of Postwar American National Security Poligy

(Oxford: Oxford University Press, 1982), p.84

${ }^{376}$ Edwards, The Closed World, pp.127-128

377 Beatrice Heuser, Reading Clausewritz (London: Pimlico, 2002), p.170 
predictable activity. The cybernetic model of warfare erected by the system analysts was one that was frictionless, a perfectly oiled machine resting on elegant mathematical constructs. Rather than eternal attributes of the battlefield, uncertainty and unpredictability became understood merely as a lack of information which could be overcome through the deployment of the proper information and communication technologies and elaboration of appropriate models of conflict.

The formidable technological impulse of World War II, marked in particular by the development of nuclear weaponry and information and communication technologies, empowered those individuals which mastered the language and methodology of the sciences that accompanied this technology. This was to the detriment of established traditions of military thought and practice of warfare. Via an "organised scientific discourse' through multiple, but centralising relationships among high-bureaucratic positions, technobureaucratic or production logic in the structure of its propositions, and the conventional educated prose style," cybernetic warfare excluded accounts of the war which did not conform to the exigencies of technoscientific discourse. For Gibson, this amounted to a neglect of 'warrior knowledge' which he describes in terms of Foucault's notion of 'subjected knowledge, ${ }^{378}$ that is knowledge "disqualified as inadequate to their task or insufficiently elaborated: naïve knowledges, located low down on the hierarchy, beneath the required level of cognition or scientificity."379

If the debacle of Vietnam provoked some serious soul-searching among American strategists and military men, it did not result in an immediate or widespread abandonment of the worldview epitomised by cybernetic warfare or a significant revaluation of other forms of thought on war. Throughout the rest of the Cold War and beyond, information technology has continued to be embraced as the panacea to the chaos and indeterminacy of war. The Strategic Defense Initiative promised an invulnerable shield against nuclear attack through a combination of computers and space weapons while revolutions in military affairs in the mould of Westmoreland's vision have been repeatedly heralded. However, the miniaturisation and diffusion of computers and telecommunication devices, accompanied by developments in the informational paradigm through the new scientific theories of chaos and complexity, has

${ }^{378}$ Gibson, The Perfect War, p.467

${ }^{379}$ Foucault, Power/Knowledge, p.82 
led to a new understanding of warfare revolving around the notion of the network and which holds the promise of decisively breaking with cybernetic warfare. 


\section{Chapter 7: A New Informational Paradigm: Chaos Theory and Complexity Science}

The focus of the original cyberneticists on control mechanisms as a means of overcoming disorder (or entropy) has in recent decades progressively given way to a consideration of the distributed emergence of 'complexity.' While information has remained the core concept of this new approach, the new sciences of chaos and complexity have reconceptualised disorder as a deterministic process and a necessary condition of order as opposed to an unruliness to be warded off. As with cybernetics, chaos and complexity have constituted broad fields of interdisciplinary enquiry that have left practically no area untouched and appear as part of a broader cultural moment. This evolution is reflected in developments in military operations with a move away from computerised hierarchical centralisation towards decentralised self-synchronising networks, as we shall see in chapter 8 .

For now, the present chapter will focus on presenting the conceptual framework of the new scientific theories of chaos and complexity (dubbed 'chaoplexity' by some commentators because of their theoretical proximity and overlap ${ }^{389}$. Attention will be paid in particular to the mànner in which they challenge many of the most fundamental assumptions about the possibilities for complete predictability and control of systems as well as to the nature of the processes underlying change and the very essence of life. Central to this challenge are the non-linear dynamics and positive feedback processes underpinning 'chaotic' phenomena and the distributed networks around which the emergence and self-organisation of complex systems occurs.

${ }^{380}$ John Horgan, The End of Science: Facing the Limits of Knowledge in the Twilight of the Scientific Age (London: Abacus, 2002), pp.191-192 


\title{
The Rediscovery of Non-Linearity: Chaos Theory and Positive Feedback
}

Early cybernetic thought mainly focused on how systems use information and control mechanisms to steer towards and maintain their goals while counteracting various disturbances. Drawn from a study of engineering problems, the systems that were considered were viewed as closed and with overarching goals that were determined exogenously. Control hierarchies maintained a pre-designated behaviour through negative information feedback, with the explicit goal being homeostasis of the system. Furthermore, early cybernetics was primarily preoccupied with linear phenomena since engineers traditionally strove to keep their systems linear, as it made them simpler to build and to predict. As we saw in the previous chapter, this approach dominated the technoscientific outlook of the military for most of the Cold War since the integration of technological systems naturally predisposed planners to think in engineering terms.

However, cyberneticists and system theorists eventually began to broaden their field of enquiry to question how systems reproduced themselves and even emerged in the first place. While the earlier approach had been suited to dealing with engineering problems and the practical issues of machine design, it soon appeared limited for the consideration of physical and biological phenomena. It was through their study of biology that Humberto Maturana and Francisco Varela formulated the concept of autopoeisis ('self-creation') in the early 1970s:

\begin{abstract}
An autopoietic machine is a machine organized (defined as a unity) as a network of processes of production (transformation and destruction) of components which: (i) through their interactions and transformations continuously regenerate and realize the network of processes (relations) that produced them; and (ii) constitute it (the machine) as a concrete unity in space in which they (the components) exist by specifying the topological domain of its realization as such a network. ${ }^{381}$
\end{abstract}

As in the 'machines' of first wave cybernetics, these were defined by sets of relations between parts but here these relations not only accounted for their operation but also for their continual reproduction - "the living organisation is a circular organisation which secures the production or maintenance of the components that specify it in such a manner that the product of their functioning is the very same organisation that

\footnotetext{
${ }^{381}$ Humberto Maturana \& Francisco Varela, "Autopoiesis and Cognition: the Realization of the Living" in Robert S. Cohen \& Marx W. Wartofsky (eds.), Boston Studies in the Pbilosopby of Science 42 (Dordecht: D.

Reidel Publishing Co, 1980), p.78
} 
produces them." ${ }^{382}$ The living organism is thus primarily conceived of as a selfperpetuating process by which its constitutive components and its pattern of organisation mutually sustain and reproduce one other in a closed causal loop.

Along with self-production, interest in the notion of self-organisation grew in the 1970s in order to explain the dynamic emergence of systems and here the departure from early cybernetics is particularly significant. ${ }^{383}$ The inquiry into self-organisation led to an exploration of the phenomenon of positive information feedback, which had previously been essentially seen as a disruptive process since it took systems away from their desired equilibrium. In theories of self-organisation, positive feedback accounts for the emergence of complexity in systems in which outputs feed back into them as inputs, allowing for runaway processes of change. The study of non-linear relationships in which outputs are not proportional to inputs allowed for the formulation of exponential processes of change central to the scientific theories of chaos and complexity. "While negative feedback is the essential condition for stability, positive feedbacks are responsible for growth, self-organisation, and the amplification of weak signals." ${ }^{\text {"384 }}$

Ilya Prigogine related positive feedback to self-organisation in his Nobel Prize winning work on dissipative structures:

\begin{abstract}
The initial step in the development of self-organizing systems, in Prigogine's analysis, occurs when energy flowing into a system increases and generates chaotic, or random, behaviour. Such behaviour arises through 'positive feedback', in which an initial change in the value of any parameter or value of the system results in an amplification of change elsewhere in the system. As a result, the system's components grow increasingly random and chaotic, and threaten to destroy the system altogether. If certain conditions are present, however, the system undergoes a radical transformation; at some point, the energy is channelled into new forms of behaviour, and the elements of the system interact in a uniform way, and what had been, or might have become, uncontrolled random behaviour is now channelled into highly structured interactions. ${ }^{385}$
\end{abstract}

\footnotetext{
382 Humberto Mathurana quoted in Hayles, How We Became Posthuman, p.138

${ }^{383}$ It would be inaccurate to say that the notion of self-organisation was absent from early cybernetics since scientists like Ross Ashby and Heinz von Foerster developed the concept in their respective studies of the nervous system and biological systems. However, as Capra points out, the difference with latter understandings of self-organisation is that these allowed for the creation of new structures and new modes of behaviour, in contrast with the models of the early cyberneticists. "For Ashby all possible structural changes take place within a given 'variety pool' of structures, and the survival chances of the system depend on the tichness, or 'requisite variety' of that pool. There is no creativity, no development, no evolution." Capra, The Web of Life, p.85

384 Heylighen \& Joslyn, "Cybernetics and Second-Order Cybernetics"

http://pespmc1, vub.ac.be/Papers/Cybernetics-EPST.pdf p.12

${ }^{385}$ R A. Jenner, "Dissipative Enterprises, Chaos, and the Principles of Lean Organizations", Omega: The

International Journal of Management Science, Vol. 26, No. 4, December, 1998
} 
The study of positive feedback systems and non-linear functions in a variety of fields encompassing meteorology, fluid dynamics, chemistry, and population biology led to the emergence of a new interdisciplinary scientific corpus: chaos theory. The common thread to all these studies was the use of mathematics to model physical systems and explore the behaviour and patterns of non-linear functions. Mechanistic science had focused its attention on linear phenomena since the mathematical functions by which they could be expressed were easy to understand and solve. In contrast, non-linear equations have very complex behaviours, can have multiple solutions for any given value, and are largely impervious to analytical techniques (non-additivity means these equations cannot be broken up into smaller parts that are individually solved before being recombined, as is possible with their linear counterparts). While the privileging of linear equations by scientists was essentially due to their greater ease of manipulation and study, this methodological constraint came to be interpreted as reflecting the nature of reality. As mathematician Ian Stewart has observed, "classical mathematics concentrated on linear equations for a sound pragmatic reason: it could not solve anything else $[\ldots]$ so docile are linear equations that the classical mathematicians were willing to compromise their physics to get them.. ${ }^{386}$ In other words, scientists came to view phenomena as essentially linear with non-linearity an aberration or deviation from the linear norm.

In fact, it is now held that the reverse is true: both mathematically and physically, linear equations are the exception, not the norm. ${ }^{387}$ Nature is fundamentally non-linear. While the behaviour of all linear systems is consistent in the sense that they tend towards a fixed equilibrium, non-linear systems display a broad range of behaviours dependent on their mathematical properties. Some tend towards fixed equilibrium in the same way as linear systems, others may enter a pattern of regular oscillation between different points. Yet others revealed an unexpected behaviour that became the foundation of chaos theory. Indeed, certain non-linear functions produce incredibly intricate patterns and non-periodic behaviour which seem completely random and disorderly. The great discovery of chaos was that "simple deterministic models could produce what looked like random behaviour. The behaviour had an exquisite fine structure, yet any piece

\footnotetext{
386 Beyerchen, "Clausewitz, Nonlinearity and the Unpredictability of War"

${ }^{387}$ David Campbell, Jim Crutchfield, Doyne Farmer, \& Erica Jen, "Experimental Mathematics: The Role of Computation in Nonlinear Studies", Communications of $A C M$ 28(4), 1985, pp.374-384

htp://www.santafe.edu/ idf/papers/experimentalmathematics.pdf
} 
seemed indistinguishable from noise. ${ }^{n 388}$ Thus, it became possible to identify a structure and order to phenomena which previously appeared to have none. In this sense, chaos theory is a misnomer; the phenomena it models are not random, probabilistic, or truly chaotic since they obey deterministic laws. Disorder finds in chaos theory its own hidden order.

It was the computer that provided the tool for the exploration of non-linear functions, its processing power allowing for the iteration of calculations that uncovered the hidden patterns produced by these functions/systems. These patterns could be represented graphically as with the case of Benoit Mandelbrot's work on fractals, those infinitely detailed geometric objects produced by the repeated application of simple mathematical rules (see Figure 10). Fractals usually display the property of self-similarity across scales, defined as a geometrical resemblance or physical correspondence between the parts of a system and the system as a whole. Indeed, similar or identical patterns can be observed at different levels of magnification of a given structure - increased detail never results in a decrease in the complexity of the patterns (see Figure 11). This phenomenon is a result of the iteration of simple rules governing the constitution of complex forms. Far from being limited to mathematical oddities, Mandelbrot's work uncovered fractal structures in fern leaves, clouds, bronchia, rock formations, and even stock market prices. ${ }^{389}$ In his book The Fractal Geometry of Nature, Mandelbrot insisted on both the novelty of his work relative to traditional geometry and its replication in the observable world: "many patterns in Nature are so irregular and fragmented, that, compared with Euclid [...] Nature exhibits not only a higher degree but an altogether different level of complexity." 390

\footnotetext{
388 Gleick, Chaos, p.79

389 For the latter, see Benoit B. Mandelbrot \& Richard L Hudson, The (Mis)Behaviour of Markets: A Fractal

View of Risk, Ruin and Reward (London: Profile Books, 2004)

${ }^{390}$ Quoted in Hayles, Chaos Bound, p.164
} 


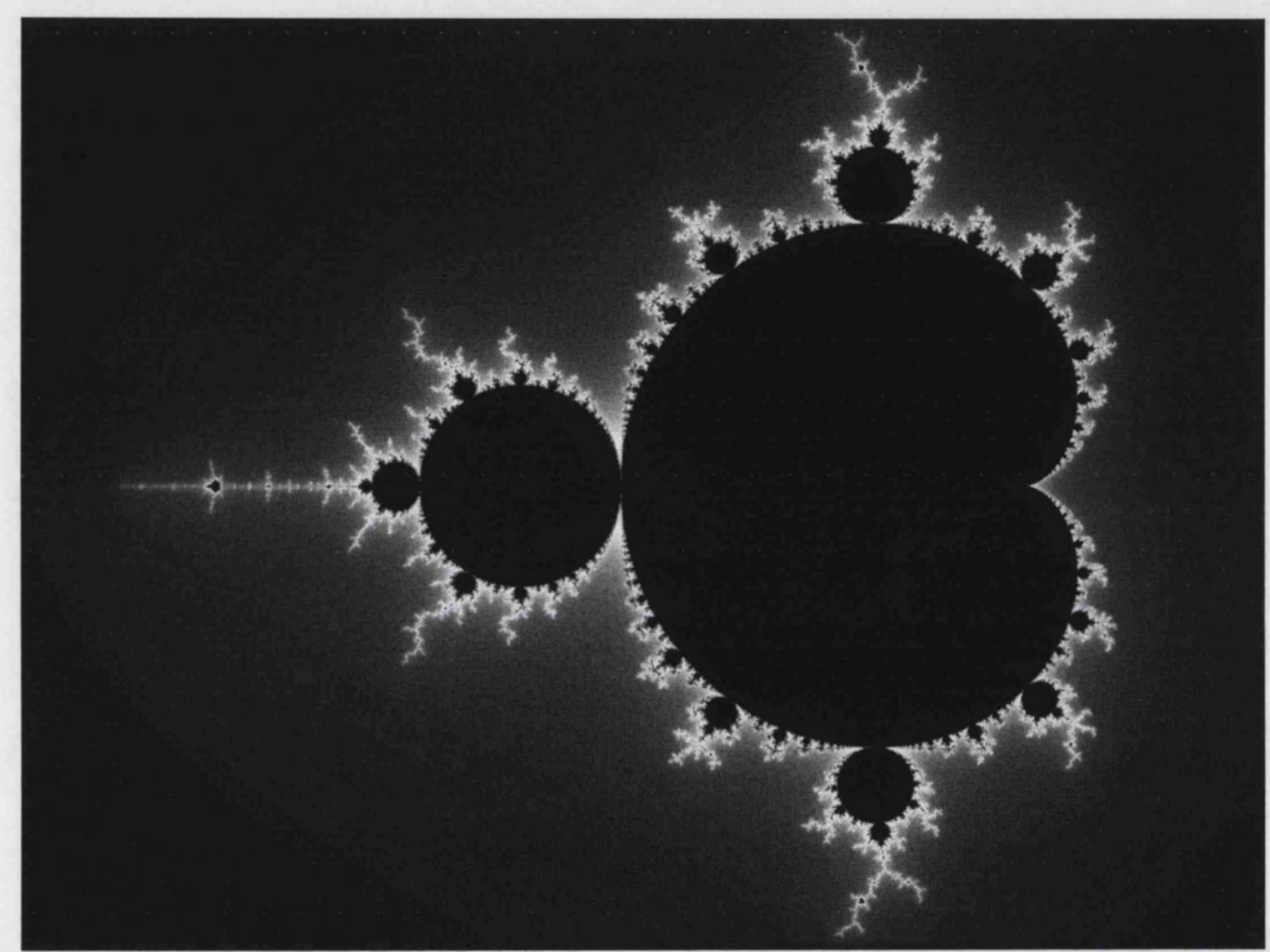

Figure 10: Mandelbrot set fractal ${ }^{391}$

391 htup://upload.wikimedia.org/wikipedia/commons/2/21/Mandel zoom ou mandelbrot set.jp: 


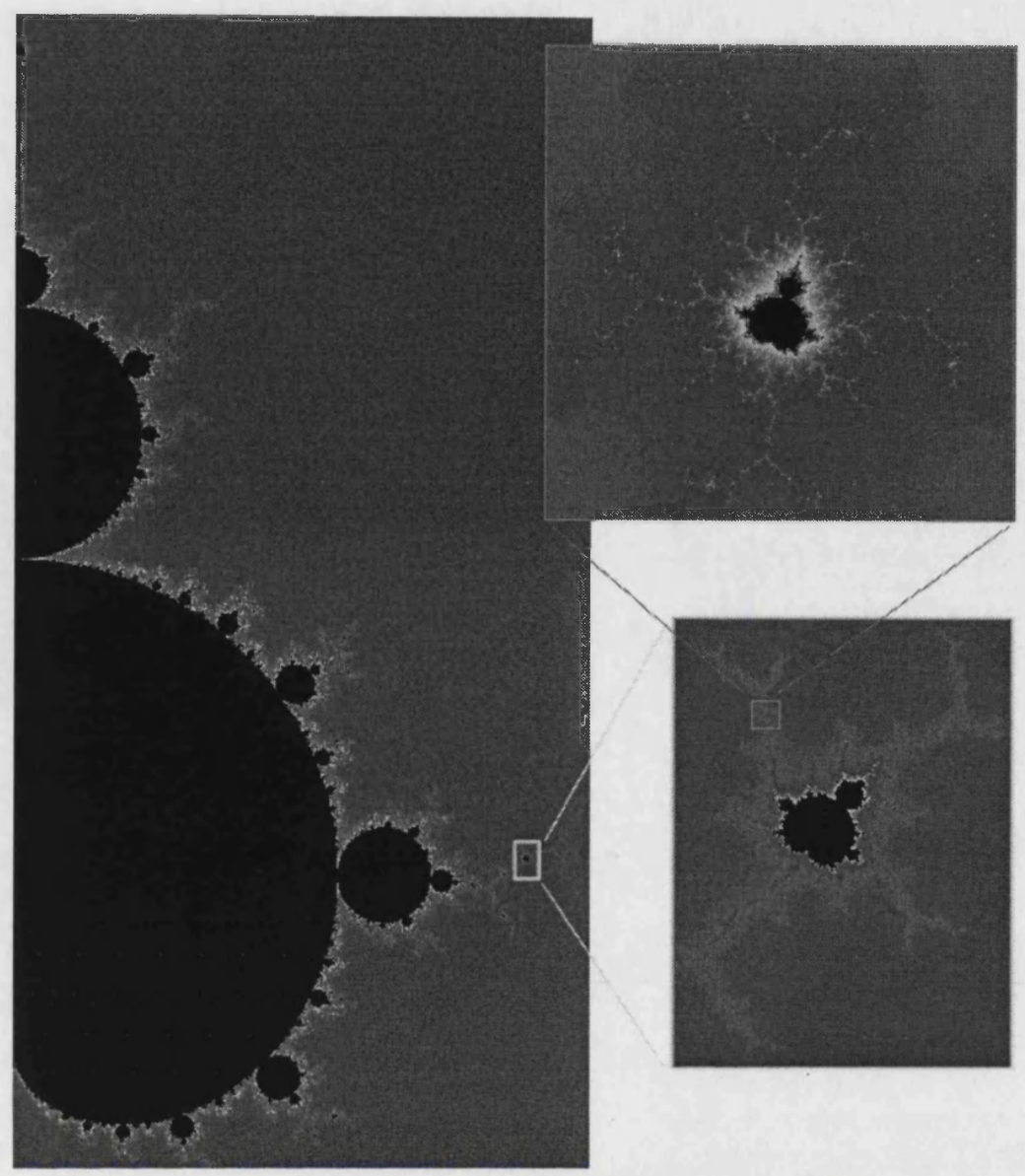

Figure 11: Self-similarity in a Mandelbrot set fractal ${ }^{392}$

Such discoveries constituted unexpected scientific developments that emerged from the use of computers. It had been originally thought that computers might provide the processing power to perfectly reveal the past and predict the future of physical systems, given a full understanding of the natural laws governing them. Recall Laplace's invocation of a theoretical intelligence which could "comprehend all the forces by which nature is animated" and for which consequently "nothing would be uncertain and the future as the past, would be present to its eyes." ${ }^{393}$ But such a claim relied on a Newtonian conception of the world which was to be terminally undermined by chaos theory. Indeed, the presumption of classical physics on which the Laplacian dream rested was that "very small influences can be neglected [...] there is a convergence in the way things work, and arbitrarily small influences don't blow up to have arbitrarily large

${ }^{392} \frac{\mathrm{htcp} / \text { / astronony. swin.edu.au/ pbourke/fractals/selfsimilar/ }}{\text { Laplace, "Théorie Analytique des Probabilités" }}$ 
effects. ${ }^{3394}$ What the study of non-linear equations revealed was their sensitive dependence on initial conditions, that is the non-proportionality of cause to effect or input to output: In other words, minute variations in the initial conditions of a dynamical system can produce large variations in the long term behaviour of the system. The popular metaphor employed to illustrate this phenomenon is the 'butterfly effect', the notion that a butterfly flapping its wings in Tokyo could cause a tornado in California. The implications of sensitivity to initial conditions is that any finite model of such a dynamic system is necessarily limited in its predictive capacity as there will always be unavoidable imprecision in our measurement of initial conditions (due to both limitations in measurement instruments and the practical need to round off figures at some decimal point). Beyond a certain number of iterations, precise predictions become virtually useless. For example, this characteristic of non-linear systems is evoked to explain the persistent inability of meteorology to make any reliable forecasts beyond about a week.

It should be noted that the late-nineteenth century mathematician Henri Poincare had anticipated much of chaos theory by distinguishing chance as statistical randomness from chance as a deterministic process that could not be predicted due to sensitivity to initial conditions:

\begin{abstract}
A very slight cause, which escapes us, determines a considerable effect which we can not help seeing, and then we say this effect is due to chance. If we could know exactly the laws of nature and the situation of the universe at the initial instant, we should be able to predict exactly the situation of this same universe at a subsequent instant. But even when the natural laws should have no further secret for us, we could know the initial situation only approximately. If that permits us to foresee the subsequent situation with the same degree of approximation, this is all we require, [and] we say the phenomenon has been predicted, that is ruled by laws. But this is not always the case; it may happen that slight differences in the initial conditions produce very great differences in the final phenomenon; a slight error in the former would make an enormous error in the latter. Prediction becomes impossible and we have the fortuitous phenomenon. ${ }^{395}$
\end{abstract}

Of course, Poincare did not have at hand the computational instruments to demonstrate his powerful intuition and this remarkable insight could not seriously challenge the dominant linear paradigm of the physical sciences and remained neglected for nearly another century.

Although chaos theory has imposed a limitation on the long-term predictability of nonlinear systems, it has simultaneously revealed an inherent order in phenomena that had

394 Gleick, Chaos, p.15

395 Beyerchen, Clausewitz, "Nonlinearity and the Unpredictability of War" 
previously appeared completely disordered, thereby allowing for a short-term predictability where there was none before. Furthermore, if precise long-term predictability as classically understood is now found to be impossible, a qualitative understanding of the behaviour of a system may in certain circumstances replace a now foreclosed quantitative one. The exact future state of a non-linear system may be impossible to predict but it is often possible to identify and model its overall behaviour, notably through the identification of its attractor.

An attractor is a set behaviour towards which a dynamical system evolves to in the long term. Such attractors come in different shapes, depending on the type of system and its behaviour within its phase space. In the fields of mathematics and physics, the phase space is the space in which all possible states of a system are represented, with each possible state of the system corresponding to one unique point in the phase space. Each parameter (or degree of freedom) of a given system constitutes an axis in a multidimensional space; thus, each possible state of the system can be represented by one point and one point only. A succession of plotted points allows for the representation of the system's behaviour over time in a phase space diagram. In the case of a simple mechanical system like a swinging pendulum, the phase space can be constituted by two axes, one for position, the other for momentum. With friction, the pendulum will sway from side to side, progressively slowing down until it reaches its resting position (momentum and position 0 ). The attractor in this case is a fixed point to which the system converges to in what manifests itself as a spiral in the phase space diagram (see Figure 12).

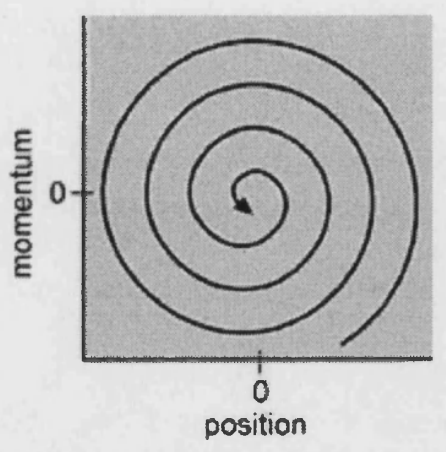

Figure 12: Phase space diagram of a pendulum running down ${ }^{396}$

${ }^{396}$ http://wnw physicscentral.com/action/images/04/action-04-08-3.gif 
A system that settles into a periodic and cyclical behaviour is said to have a limit cycle attractor (physical examples include clock pendulums and heartbeats at rest). In the case of a clock pendulum, the system would be represented in a phase space diagram as a circle. However, the type of attractor of real interest to chaos theorists is that known as strange attractors.

The Lorenz attractor was the first strange attractor to be discovered as part of meteorologist Edward Lorenz's attempts in the early sixties to model the weather using non-linear equations within a computer simulation. A strange attractor represents a system whose long-term behaviour is non-periodic (i.e. whose trajectories never merge) and is sensitive to initial conditions. And yet, as in the case of the Lorenz attractor, the phase space diagram displays an intricate but clearly recognisable pattern which sheds light on the system's long-term behaviour (see Figure 13).

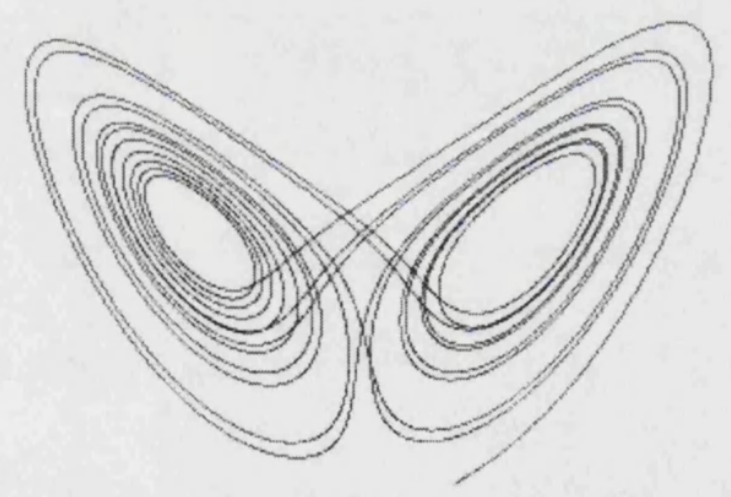

Figure 13: Phase space diagram of a Lorenz attractor

As a system organised around a strange attractor cannot pass twice by the same point in its phase space (if it did so it would mean that the system had entered a periodic cycle), the structure of a strange attractor is therefore fractal, displaying the same infinite level of complexity at all scales as Mandelbrot's geometrical constructs.

Prediction thus shifts from quantitative analysis (calculating where a point will be at a particular moment) to qualitative analysis (understanding the general behaviour of the 
system). Not only is prediction of chaotic systems therefore not completely impossible, but even a certain degree of control appears within reach. By identifying unstable periodic orbits (general areas of the phase space which the system returns to - by definition, it cannot return to a same point), some systems can be nudged back into those orbits. ${ }^{397}$ While chaos control is still largely at an experimental stage, it demonstrates that chaos theory does not stand against or outside the technoscientific project of control but rather recasts it so that order is not so much imposed on chaos as made to emerge from disorder by utilising the latter's properties. The next stage in the development of the nonlinear sciences would suggest further such ways to mould reality since it would seek to uncover the processes behind the very spontaneity and malleability of life.

\section{Complexity and Networks of Life at the Edge-of-Chaos}

Despite the sizeable contributions of chaos theory, there was a sense among certain scientists that the theory didn't go far enough. It explained how certain simple rules of behaviour could give rise to astonishingly complicated dynamics but it did not sufficiently address the apparently inexorable growth of order and structure in the universe, particularly in the context of biological evolution and social organisation. Further research in this area gave birth to another interdisciplinary science known as complexity whose focus was on the behaviour of complex systems - systems composed of many parts which are coupled in a non-linear fashion. The notion of network is essential here to describe the patterns of interaction which are constituted by the interplay of entities in a complex system:

\footnotetext{
The first and most obvious property of any network is its non-linearity - it goes in all directions. Thus the relationships in a network pattern are non-linear relationships. In particular, an influence, or message, may travel along a cyclical path, which may become a feedback loop. The concept of feedback is intimately connected with the network pattern. ${ }^{398}$
}

A central related concept is that of emergence, the process by which complex structures form on the basis of simple rules. As scientist Stephen Wolfram put it:

\footnotetext{
${ }^{397}$ One of the earliest papers on chaos control was Edward Ott, Celso Grebogi, \& James A. Yorke, "Controlling Chaos", Physical Revien Letters 64, 1990, pp.1196-1199. Research is ongoing into chaos control in optical and electronic systems as well as cardiac dynamics.

${ }^{398}$ Capra, The Web of Life, p. 82
} 


\begin{abstract}
Whenever you look at very complicated systems in physics or in biology, you generally find that the basic components and the basic laws are quite simple; the complexity arises because you have a great many of these simple components interacting simultaneously. The complexity is actually in the organisation - the myriad possible ways that the components can interact. ${ }^{399}$
\end{abstract}

This view is in opposition to reductionist approaches such as mechanism which view properties of the system as the mere aggregation of those of their constituent parts. Emergent properties, however, are properties of the whole that cannot be deduced from the properties of the individual parts making it up.

Complexity turns out to an exceedingly difficult term to define in a precise and definite manner and disagreements abound on the criteria which should determine whether an object of study should be considered complex or not. The nebulous characteristic of the term reflects in part the fact that it covers a broad field of enquiry into non-linear dynamic systems rather than denoting a clearly defined scientific theory. For Murray Gell-Mann, the appropriateness of the word refers back to its etymology - plexus means braided or entwined, from which is derived complexus, meaning braided together. ${ }^{400}$ Hence complexity suggests the "intricate intertwining or interconnectivity of elements within a system, and between a system and its environment." ${ }^{\text {401 }}$

Complex adaptive systems constitute a special case of complex systems that are capable of changing and learning from experience. Complexity theorist John Holland defines a complex adaptive system as a dynamic network of many agents acting in parallel, constantly acting and reacting to what the other agents are doing. The control of a complex adaptive system tends to be highly dispersed and decentralized; any coherent behaviour in the system arises from competition and cooperation among the agents themselves. It is the accumulation of all the individual decisions taken by the multitude of agents which produces the overall behaviour of the system, which can thus be said to be emergent. ${ }^{402}$

Complex adaptive systems include living organisms, insect colonies, bird flocks, ecosystems, businesses, stock markets, and other forms of social and cultural

\footnotetext{
${ }^{399}$ Waldrop, Complexity, p.86

${ }^{400}$ Murray Gell-Mann, "Let's Call It Plectics", Complexity Journal, Vol. 1/ No. 5 (1995/96)

http://www.santafe.edu/ mgm/plectics.pdf

401 James Moffat, Complexity and Network-Centric Warfare (CCRP Publications, 2003), p.68

http://www.dodccrp.org/publications/pdf/Moffat Complexity.pdf

402 Waldrop, Complexity, pp.145-146
} 
organisation with the constituent agents being cells, species, individuals, firms, or nations. According to Holland, there are common characteristics which characterise all these systems and that complexity science can reveal, thereby offering the promise of resolving many of the world's problems:

\begin{abstract}
Many of our most troubling long-range problems - trade imbalances, sustainability, AIDS, genetic defects, mental health, computer viruses - centre on certain systems of extraordinary complexity. The systems that host these problems - economies, ecologies, immune systems, embryos, nervous systems, computer networks - appear to be as diverse as the problems. Despite appearances, however, the systems do share significant characteristics, so much so that we group them under a single classification at the Santa Fe Institute, calling them complex adaptive systems (CAS). This is more than terminology. It signals out intuition that there are general principles that govern all CAS behaviour, principles that point to the way of solving the attendant problems. Much of our work is aimed at turning this intuition into fact. 403
\end{abstract}

We see here that the explanatory scope attributed to complexity theory by its proponents is no less ambitious than that of the original cyberneticists.

The exploration of non-linear functions with computers also revealed the phenomenon of bifurcation in the study of dynamical systems. The discovery was made that a small change made to the parameter or control values of a system could cause a sudden qualitative change in the system's long-run dynamical behaviour. The notion of bifurcation was to become key in explaining the transformation and evolution of systems - "systems reach points of bifurcation when their behaviour and future pathways become unpredictable and new higher order, more differentiated, structures may emerge." ${ }^{204}$ For certain control values, the system will respond to all perturbations by settling back down to an established stable state. When the control values are such that the system reaches its first point of bifurcation, the system will develop two alternative stable states either of which it will settle in, depending on the perturbations applied to it. As the parameters values continue to change, each stable will further bifurcate, multiplying the number of possible states. Beyond certain parameter values, the system will shift to chaotic behaviour, following a strange attractor. It is just before the onset of this behaviour, where bifurcations are greatest but stable states still exist, that system adaptability is maximised, at the 'edge of chaos' (see Figure 14: Bifurcation diagram of a non-linear system).

\footnotetext{
${ }^{403}$ Horgan, The End of Science, pp.195-196

${ }^{404}$ John Urry, Global Complexity (Cambridge: Polity, 2003), p.28
} 


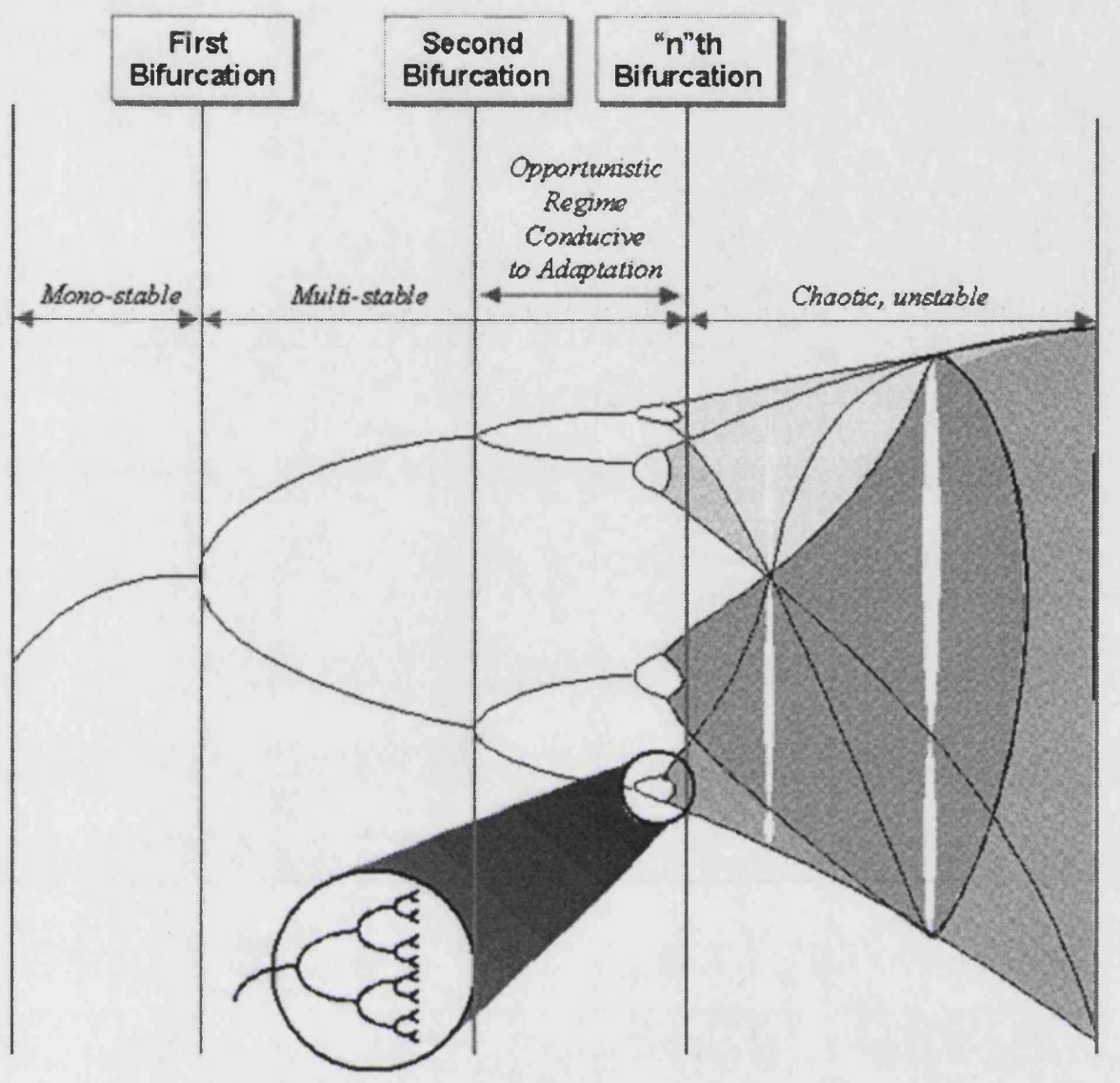

Figure 14: Bifurcation diagram of a non-linear system ${ }^{405}$

Complexity thus redefines 'life' as a balance between forces of order and forces of disorder, between fixed rigid structures and chaotic motion. As Waldrop puts it:

Right in between the two extremes [of order and chaos], at a kind of abstract phase transition called 'the edge of chaos', you also find complexity: a class of behaviours in which the components of the system never quite lock into place, yet never quite dissolve into turbulence, either. These are the systems that are both stable enough to store information, and yet evanescent enough to transmit it. These are the systems that can be organised to perform complex computations, to react to the world, to be spontaneous, adaptive, and alive. ${ }^{406}$

\footnotetext{
${ }^{405}$ Linda P. Beckerman, "The Non-Linear Dynamics of War", Science Applications International Corporation, 1999

hetp: / / www belisarius.com/modern business strategy/beckerman/nom linear.htm

406 Waldrop, Complexity, p.293
} 
Building on the discoveries of chaos theory, complexity theorists found that it is at frontier of the phenomena of chaos, the "narrow domain between frozen constancy and chaotic turbulence," that the most complex and adaptive structures can be found. ${ }^{407}$

It is through mechanisms of information processing, distribution and exchange that complex adaptive systems can emerge and evolve. According to Nobel Prize physicist Murray Gell-Mann:

\begin{abstract}
A complex adaptive system acquires information about its environment and its own interaction with that environment, identifying regularities in that information, condensing those regularities into a kind of 'schema' or model, and acting in the real world on the basis of that schema. In each case, there are various competing schemata, and the results of the action in the real world feed back to influence competition among these schemata. ${ }^{408}$
\end{abstract}

It is via these schemata, by identifying patterns and correlations, that complex adaptive systems separate regularities from randomness in the raw data flow that traverses them. On this basis, the complex adaptive system can constitute a description of an observed system, predict events, or create prescriptions for its own behaviour. Through a process of continuous learning, these schemata are always being adjusted and rebuilt as the complex adaptive system interacts with its environment and other systems, and new information is absorbed.

Gell-Mann proposes that the length of description of schemata be used as a measure of complexity. Descriptions of systems showing completely regular, highly ordered, patterns of behaviour would be low in informational content (since the pattern could be expressed in very few terms) while descriptions of completely random behaviour would have no informational content at all (since no pattern at all can be discerned). Hence informational content and complexity are maximised in between these two extremities, at "the edge of chaos" (see Figure 15).

${ }^{407}$ Francis Heylighen, “Complex Adaptive Systems” (Principia Cybernetica Web, 1996) http://pespmc1.rub.ac.be/CAS.html ${ }_{408}$ Murray Gell-Mann, The Quark and the Jaguar. Adventures in the Simple and the Complex (London: Little Brown \& Company, 1994), p.17 


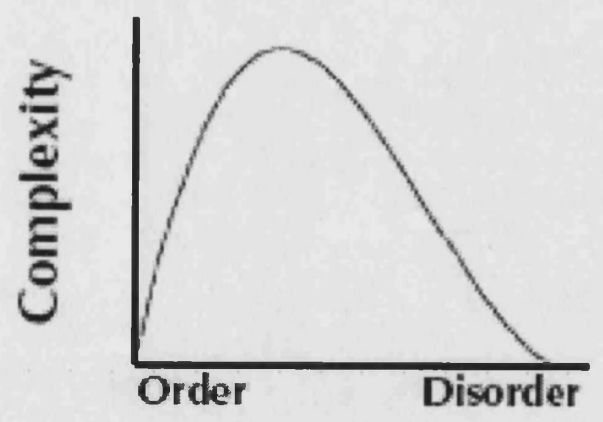

Figure 15: Complexity is highest in between the poles of order and disorder

It should be noted that the sense in which complex systems are adaptive is quite distinct from traditional scientific understandings of the adaptation and optimisation of systems in that it allows for radical transformation by virtue of which new types of behaviours and goals can emerge. Whereas servomechanisms seek to regulate behaviour within the confines of an existing structure and a pre-determined goal via negative feedback, complex systems can modify their internal structure and redefine their objectives through positive feedback. As John Holland puts it, "adaptation, whatever its context, involves a progressive modification to some structure or structures." ${ }^{309}$ Prigogine and Stengers make a similar distinction here:

It is obvious that the management of human society as well as the action of selective pressures tend to optimise some aspects of the behaviour or modes of connection, but to consider optimisation as the key to understanding how populations and individuals survive is to risk confusing causes with effects. Optimisation models thus ignore both the possibility of radical transformations - that is, transformations that change the definition of a problem and thus the kind of solution sought - and the inertial constraints that may eventually force a system into a disastrous way of functioning. Like doctrines such as Adam Smith's invisible hand or other definitions of progress in terms of maximisation and minimisation criteria, this gives a reassuring representation of nature as an all-powerful and rational calculator, and of a coherent history characterised by global progress. To restore both the inertia and the possibility of unanticipated events - that is, restore the open character of history - we must accept its fundamental uncertainty. ${ }^{+10}$

If the major contribution of chaos theory, complexity and self-organisation was to uncover the vital role of decentralised co-ordination and positive feedback mechanisms, it would be misleading to assume from this that hierarchical control and negative

409 John H. Holland, Adaptation in Natural and Artificial Systems (Cambridge, MA: MIT Press, 1995), p.3 410 Prigogine \& Stengers, Order out of Chaos, p.207

In the $19^{\text {th }}$ century, Nietzsche had already criticised contemporary physiological and biological thought for only understanding organisms in terms of adaptation (in the sense of optimisation): "it fails to appreciate the paramount superiority enjoyed by those plastic forces of spontaneity, aggression, and encroachment with their new interpretations and tendencies, to the operation of which adaptation is only a natural corollary."

Friedrich Nietzsche, The Genealogy of Morals, II 12 (Dover Publications, 2003), p.52 
feedback were now viewed as irrelevant. Rather, the new scientific consensus viewed opposing processes as complementary, balancing change and stability. Complexity theorist Doyne Farmer points out that

evolution thrives in systems with a bottom-up organisation, which gives rises to flexibility. But at the same time, evolution has to channel the bottom-up approach in a way that doesn't destroy the organisation. There has to be a hierarchy of control - with information flowing from the bottom up as well as from the top down. ${ }^{411}$

Likewise, both forms of feedback can generally be observed in complex systems as negative feedback serves to constrain the growth of positive feedback. Without the former, the latter would simply extinguish itself when it runs out of resources to fuel its process of expansion (as in the case of a virus epidemic or the chemical process of combustion) or risk dissolution when run-away processes become too strong to preserve the fine balance between "frozen constancy and chaotic turbulence." Nonetheless, chaos and complexity affirm the primacy of positive feedback and decentralised emergence since they are the prerequisites for creation and change and that it is only through them that mechanisms for negative feedback and hierarchical control can then appear. In other words, an emergent structure may subsequently exert some downward causation on the parts whose interaction produced it in the first place but this is a secondary effect of bottom-up self-organisation.

The worldview postulated by the sciences of complexity is thus a seismic shift away from the dominant paradigm: "nature is to be viewed as a dynamical shifting web, not a mechanical, hierarchical pyramid. ${ }^{, 412}$ No longer is order a product of a natural tendency towards equilibrium; on the contrary, it is with non-equilibrium that order emerges from chaos, at the point where instability and creative mutation allow for the genesis of new forms and actions. ${ }^{413}$ Consequently, the systems produced through these processes of self-organisation have distinct emergent features which cannot be understood solely through an analysis of their atomistic components since it is their patterns of interaction which constitute their complexity. In the field of genetics, this has lead to break from an understanding of strands of genes in DNA as a biochemical computer executing a genetic program in favour of the view that the genome, the complete set of genes in an organism, "forms a vast interconnected network, rich in feedback loops, in which genes

\footnotetext{
411 Waldrop, Complexity, p.294

412 King, Social Science and Complexity, p.48

413 Prigogine \& Stengers, Order out of Chaos, p.287
} 
directly indirectly regulate each other's activities." ${ }^{\text {414 }}$ Hence, according to Francesco Varela, "the genome is not a linear array of independent genes (manifesting as traits) but a highly interwoven network of multiple reciprocal effects mediated through repressors and depressors, exons and introns, jumping genes, and even structural proteins." ${ }^{215}$ Nevertheless, complexity remains within the informational paradigm since these nonlinear interactions "do not have to be physical, they can also be thought of as the transference of information."

Complex systems also tend to be open systems in their interactions with their environment, as such their borders may not always be easy to ascertain. Consequently, these characteristics pose many analytical challenges and have major implications for the approach of any model or simulation of a complex system:

\begin{abstract}
Rather than trying to figure out all the chains of causality, the [non-linear] modeller looks for nodes where feedback loops join and tries to capture as many of the important loops as possible in the system's 'picture.' Rather than shaping the model to make a forecast about future events or to exercise some central control, the non-linear modeller is content to perturb the model, trying out different variables in order to learn about the system's critical points and its homeostasis (resistance to change). The modeller is not seeking to control the complex system by quantifying it and mastering its causality; (s)he wants to increase his/her 'intuitions' about how the system works so $s($ he) can interact with it more harmoniously. ${ }^{417}$
\end{abstract}

As with chaos theory, the traditional goal of attaining complete and precise quantitative knowledge of a system, and with that the possibility for gaining full control of it, gives way to a more limited and qualitative understanding which relies more on a certain 'intuition', perhaps the same continuous learning process described by the theory of complex adaptive systems. Indeed, Gell-Mann sees schemata and adaptive learning at the heart of all cognitive processes.

Decentralised self-organising systems are also better equipped than centralised systems to deal with limited predictability and contingency. According to Langton, "since it's effectively impossible to cover every conceivable situation, top-down systems are forever running into combinations of events they don't know how to handle. They tend to be touchy and fragile, and they all too often grind to a halt in a dither of

\footnotetext{
${ }^{414}$ Capra, The Web of Life, p.199

${ }^{415}$ Capra, The Web of Life, p.199

${ }^{416} \mathrm{King}$, Social Science and Complexity, pp.76-77

$417 \mathrm{King}$, Social Science and Complexity, p.54
} 
indecision. ${ }^{, 418}$ In contrast, decentralised systems of quasi-autonomous units can operate. more effectively and with a greater degree of adaptability on the basis of local calculations of networked agents within it.

\section{Conclusion}

Whereas early cybernetics had focused primarily on self-regulating and stabilising systems, the sciences of complexity and chaos which followed have studied selforganising systems which develop emergent properties through positive feedback mechanisms. While the former were interested in stable systems maintaining themselves and converging towards a determined goal (homeostasis), the latter have turned to the decentralised mechanisms by which complex adaptive systems emerge, change, and reproduce themselves (autopoiesis).

These two approaches are not contradictory per se; rather the sciences of selforganisation see the systems studied by early cyberneticists as only special cases within a broader study of systems. There is continuity in that systems remain the focus of analysis with the whole privileged over the parts, and in that information remains the core metaphorical concept. Circularity is also central to both approaches but these differ with regard to the circular processes which are emphasised. Early cybernetics saw positive feedback as essentially undesirable since it took systems away from their equilibrium and could even threaten their dissolution (as in a run-away engine accelerating till it falls apart or explodes): order giving way to disorder (i.e. entropy). Complexity and chaos theorists, on the other hand, have turned to positive feedback in order to explain systemic change and seemingly unpredictable yet deterministic forms of behaviour - here apparent disorder finds its own order.

In summary, chaos and complexity (or chaoplexity) can be condensed into three main points:

- non-linearity and sensitivity to initial conditions as observed in chaotic systems impose severe limits on attempts to predict the behaviour of such systems.

${ }^{418}$ Waldrop, Complexity, p.279 
Precise quantitative analysis must yield to a more qualitative understanding via the identification of system attractors;

- decentralised and distributed network relations and positive feedback allow for the bottom up emergence and evolution of complex systems;

- complexity and adaptability are greatest at the 'edge-of-chaos' where systemic structure can be retained but is also at its most flexible and creative. Such systems are best suited to responding to contingency and unpredictability.

In the next chapter, we will see how these ideas have permeated military thought and become the basis for the new theories and practices of chaoplexic warfare. 


\section{Chapter 8: Towards Chaoplexic Warfare? Network-Centric Warfare and the Non-Linear Sciences}

If mechanism and clockwork, thermodynamics and the engine, and cybernetics and the computer can all be related to specific contemporary approaches to the conduct of war, does the emergence of sciences of chaos and complexity alongside the figure of the network herald the appearance of a new chaoplexic way of warfare? On one level, there is ample evidence of the impact the non-linear sciences are having on the development of technologies with potential military applications. Indeed, they have ramifications for the development of virtually all technologies deemed high priority by the military, including but not limited to semiconductor materials, microelectronics circuits, software engineering, high-performance computing, machine intelligence and robotics, simulation and modeling, radar, sensors, signal and image processing, and biotechnology. ${ }^{419}$ However, this chapter will not be concerning itself with these direct applications of chaos and complexity theories to technological development but rather with the manner in which their concepts and principles can be seen working through present theories and practices of warfare. I will argue that the non-linear sciences have clearly permeated a sizeable portion of military literature in the United States, particularly the highlyinfluential one on network-centric warfare, now the official doctrine of the U.S. Department of Defense. However, since we still stand at the threshold between cybernetic and chaoplexic warfare, serious questions remain as to whether networkcentric warfare really represents a full engagement with the principles and implications of the non-linear sciences or simply a re-branding of established cybernetic approaches.

The first section of the chapter will turn to the influential ideas of John Boyd, in particular his famous OODA loop, as they represent a first strain of military theory to

419 Glenn E. James, "Chaos Theory: The Essentials for Military Applications" (Naval War College, Newport, Rhode Island, Center for Naval Warfare Studies, Newport Paper Number Ten, October 1996), p.4 http://www.nwc.navy.mil/press/npapers/np10/np10.pdf

Panel on Mathematics (Nonlinear Science and the Navy), Naval Studies Board, Commission on Physical Sciences, Mathematics, and Applications, National Research Council, "Nonlinear Science" (Washington DC: National Academy Press, 1997) 
draw from scientific conceptions to move beyond the limitations of the cybernetic understanding of warfare. Restoring contingency and unpredictability to military affairs and an understanding of the decision cycle akin to a complex adaptive system, Boyd made creative change central to success in war. The second section turns more specifically to the role of uncertainty in war with a rereading of Clausewitz through the lens of the non-linear sciences and further considers the implications for the organisation and tactics of armed forces, a discussion that is carried on through to the two following sections on networks and swarming. Finally, the chapter concludes with a study of the doctrine of network-centric warfare in the light of earlier sections and determines whether it does indeed break decisively with cybernetic warfare and mark the emergence of a new regime the scientific way of warfare.

\section{John Boyd and the OODA loop}

John Boyd is a crucial and pivotal figure in the emergence of scientifically inspired military thought which, in the aftermath of the Vietnam War, began to challenge many of the entrenched principles of cybernetic warfare. One of the most successful fighter pilots in the history of the U.S. Air Force (he was known as "Forty-Second Boyd" for his ability to defeat any opponent in aerial combat in less than forty seconds), Boyd developed a theory of aerial combat and was closely involved with the development of the F-15 and F-16 fighter planes. If Boyd is increasingly considered to be one of the greatest military strategists of recent times, he never wrote a key text, preferring instead a few short articles and numerous briefings to a both military and civilian audience. While Boyd was something of an iconoclast whose uncompromising stance and unconventional ideas generated hostility from the Air Force hierarchy, his ideas have gained widespread exposure within the U.S. military. The first organisation to adopt his ideas, and which remains probably the one that has stayed closest to their original spirit, is the Marine Corps. Boyd was closely involved in the elaboration of the Corps's 1989 military manual, Warfighting (subsequently updated in 1997), which will be called upon in the next section. 
His most enduring contribution was the elaboration of the OODA 'loop' (see Figure 16), a theory of the decision-making process of the fighter pilot which subsequently became extended to all aspects of warfare, including the strategic dimension.

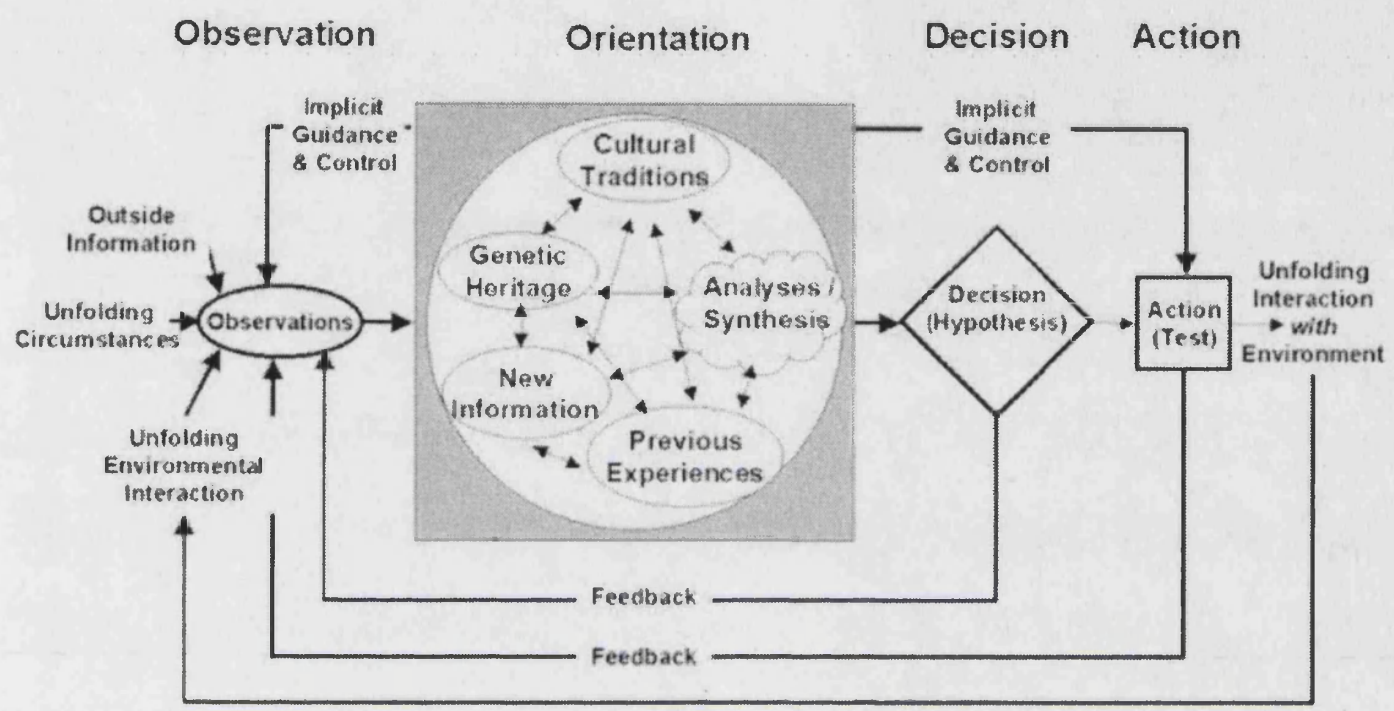

Figure 16: John Boyd's OODA 'loop'420

OODA stands for Observe-Orient-Decide-Act and seeks to model the decision-making process a combatant goes through when engaged in the warfighting environment. It is effectively a cognitive theory that can be applied to any situation, which accounts for its current enthusiastic adoption in business management literature. In the observation phase, the actor (or system) absorbs information from his environment, his situation within it, and the actions of his adversary. In the orientation phase, the actor interprets this information through an existing framework of analysis which creates meaning, discerns existing opportunities and threats, and provides a range of responses to initiate. The decision phase sees the actor commit to a course of action which is subsequently carried out in the following phase. Not only does the actor then return to the observation phase on the basis of the new information following from the action phase and consequent unfolding interaction with the environment, but feedback loops are operating between all stages in the cycle and the observation phase as the actor continually absorbs new information in order to adjust his frameworks and behaviour accordingly. For Boyd, the

${ }^{420}$ Beckerman, "The Non-Linear Dynamics of War" 
OODA 'oop' was applicable across all levels of warfighting from the individual combatant to command and control structures: "the process of observation-orientationdecision-action represents what takes place during the command and control process which means that the OODA loop' can be thought of as being the C\&C loop. ${ }^{3421}$ Since OODA 'oops' operate at all levels according to the same principles, the OODA 'loop' can be thought of as fractal in its self-similarity across scales. ${ }^{422}$

While at first glance the OODA 'loop' resembles a typical cybernetic loop whereby a system adjusts its behaviour to incoming information from its interaction with the environment in order to meet a desired objective, the crucial difference is the stage Boyd described as the most important: orientation. A closer look at the above diagram reveals that orientation actually exerts "implicit guidance and control" over the observation and action phases as well as shaping the decision phase. Furthermore, "the entire 'loop' (not just orientation) is an ongoing many-sided implicit cross-referencing process of projection, empathy, correlation, and rejection" in which all elements of the 'oop' are simultaneous active. ${ }^{423}$ In this sense, the OODA 'oop' is not truly a cycle and is presented sequentially only for convenience of exposition (hence the scare quotes around 'loop').

With the orientation phase, Boyd allows for the analytical framework itself to be modified through the comparison of observations of the external world with the system's internal framework, and thus for the system to act in new, unforeseen, ways. He distinguishes between two different processes that occur during orientation: "analysis (understanding the observations in the context of pre-existing patterns of knowledge) and synthesis (creating new patterns of knowledge when existing patterns do not permit the understanding needed to cope with novel circumstances). ${ }^{324}$ Boyd lists a number of elements which come into play in determining new frameworks (cultural traditions, genetic heritage, previous experiences, new information) but these are less important than the very principle that such frameworks can and must change.

${ }^{421}$ John R. Boyd, “Organic Design for Command and Control” (Briefing - May 1987) http://www.d-ni.net/boyd/ndf/c\&c.pdf

422 David Nicholls \& Todor Tagarev, "What Does Chaos Theory Mean for Warfare?", Aerospace Powver Journal, Fall 1994 http://www.airpower.maxwell.af.mil/airchronicles/apj/apj94/nichols.homl

Nicholls and Tagarev also argue Sun Tzu was recognising the fractal nature of war when he wrote that "generally, management of many is the same as management of few."

${ }^{423}$ John R. Boyd, "The Essence of Winning and Losing" (Briefing, January 1996)

424 Chuck C. Spinney, “Genghis John”, Proceedings, U. S. Naval Institute, July 1997, pp. $42-47$

http://www.d-n-i.net/fcs/comments/c199.htm 
Cybernetic warfare conceptualised as a negative feedback system necessitates a complete modelling of war in which all factors and parameters have to be accounted for. Indeed for a negative feedback system to adjust to changes in the environment, it must be designed so that all eventualities have been foreseen and/or all parameters to be monitored have been designated; otherwise, it will be enable to initiate the required selfcorrecting behaviour. This fuels attempts to effect a systemic closure of our understanding of the phenomenon of war that characterise the drive of operations research and systems analysis to perfectly model and simulate war. However, Boyd explicitly rejects the possibility of such a final and total understanding of war and points to the irreducibly incomplete and evanescent character of any theoretical framework seeking to encapsulate reality.

Indeed, Boyd repeatedly insists that regular overhauls of such frameworks are both necessary and unavoidable. Invoking the second law of thermodynamics, Boyd postulates that, as closed systems, internal frameworks are unavoidably subject to rising entropy as the mismatch between a changing environment and model increases. ${ }^{425}$ For Boyd, entropy here designates "the potential for doing work, the capacity for taking action, or the degree of confusion and disorder associated with any physical or information activity. ${ }^{\text {"426 }}$ Tinkering with the inner structure of the framework in order to preserve it is a self-defeating effort: "any inward-oriented and continued effort to improve the match-up of concept with observed reality will only increase the degree of mismatch." ${ }^{427}$ Rigidly adhering to the same closed model of reality leads to chaos (entropy) and eventually death. In order to counter this, Boyd advocates taking apart existing frameworks and reconstructing new ones through a perpetually ongoing process of "destruction and creation":

People using theories or systems evolved from a variety of information will find it increasingly difficult and ultimately impossible to interact with and comprehend phenomena or systems that move increasingly beyond and away from that variety - that is, they will become more and more isolated from that which they are trying to observe or deal

\footnotetext{
425 Boyd also draws on Heisenberg's quantum uncertainty principle (it is impossible to simultaneously fix or determine precisely the velocity and position of a particle or body at the quantum level) and Gödel's incompleteness theorem (no logical or mathematical system can be complete in the sense that there are necessarily propositions that cannot be either proven or disproven from the axioms or postulates of the system) to argue for the impossibility of ever achieving a perfectly consistent and stable system. ${ }^{426}$ John R. Boyd, "Destruction and Creation" (1976) http://www.belisarius.com/modem business strategy/boyd/destruction/destruction and creation.htm ${ }^{427}$ Boyd, "Destruction and Creation"
} 
with, unless they exploit the new variety to modify their theories/systems or create new theories/systems. ${ }^{428}$

Akin to chaos and complexity theorists, Boyd reinvents entropy as the condition through which creation and novelty can emerge: "an entropy increase permits both the destruction or unstructuring of a closed system and the creation of a new system to nullify the march toward randomness and death. ${ }^{.429}$ The essence of Boyd's theory can be summed up by the following formula: "a changing and expanding universe of mental concepts matched to a changing and expanding universe of observed reality. ${ }^{430}$

The similarities between the OODA loop and Murray Gell-Mann's theory of schemata in complex adaptive systems are striking: "a complex adaptive system acquires information about its environment and its own interaction with that environment, identifying regularities in that information, condensing those regularities into a kind of 'schema' or model, and acting in the real world on the basis of that schema. ${ }^{9+31}$ GellMann's own diagram of the operational process of complex adaptive systems mirrors that of the OODA Ioop' (see Figure 17). While Gell-Mann's cycle differs from Boyd's OODA loop' in that in that it is truly sequential and lacks the latter's complex feedback loops and "implicit guidance and control" which prevent it from being a straightforward cycle, ${ }^{432}$ the essential remains that both theories postulate the need for ever-changing conceptual frameworks to cope with novelty. Indeed, Gell-Mann insists on the perpetually evolving nature of schemata when faced with new information. In Mark Taylor's words:

When there are too many discrepancies between the theory and the data of experience, new ideas must be explored and concepts formulated. If the input of the so-called real world cannot be effectively processed, the schema either adapts or becomes obsolete..$^{433}$

\footnotetext{
${ }^{428}$ John R. Boyd, "The Conceptual Spiral" (unpublished briefing) http://www.d-n-i.net/boyd/pdf/intro.pdf p.18

429 Boyd, "Destruction and Creation"

430 Boyd, "Destruction and Creation"

${ }^{431}$ Gell-Mann, The Quark and the Jaguar, p.17

One could also note similarities between Boyd's process of synthesis of new frameworks and the ideas of Thomas Kuhn concerning the emergence and collapse of scientific paradigms.

432 I owe this insight to Chet Richards, one of Boyd's close associates.

${ }^{433}$ Mark C. Taylor, The Moment of Complexity, p.206
} 


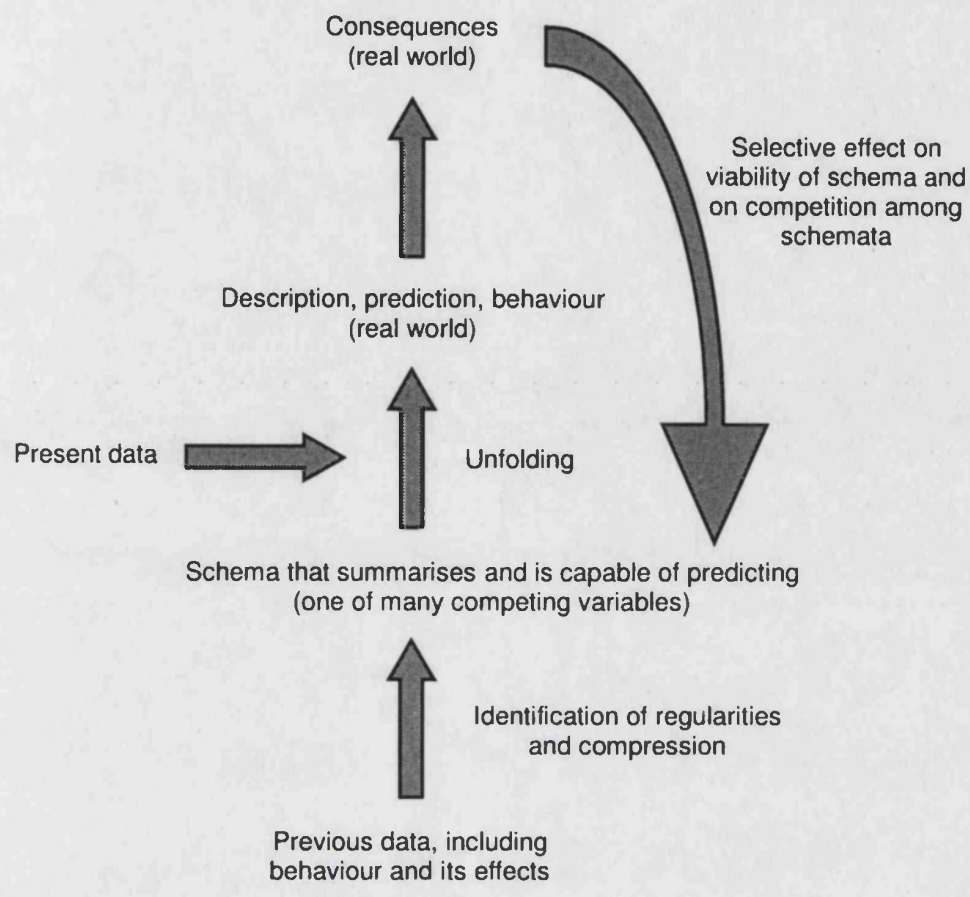

Figure 17: Gell-Mann's diagram of the functional organisation of complex adaptive systems ${ }^{434}$

Certainly, Boyd's theory became no less ambitious in the scope of phenomena it eventually strove to explain. According to Grant Hammond, the OODA 'loop' is nothing less than a theory of life since the "process of seeking harmony with one's environment, growing, interacting with others, adapting, isolating oneself when necessary, winning, siring offspring, losing, contributing what one can, learning, and ultimately dying - is for Boyd reducible to a series of OODA 'loops."”+35

For Chuck Spinney, a close collaborator of Boyd, the connections between the OODA 'loop' and developments in the field of complexity and evolutionary biology are clear:

Each of us bases decisions and actions on observations of the outside world that are filtered through mental models that orient us to the opportunities and threats posed by these observations. As Konrad Lorenz and others have shown, these mental models, sometimes called paradigms, shape and are shaped by the evolving relationship between the individual organism and its external environment [...] Evolutionary biologists, ethologists, and cyberneticists will immediately recognize that the words 'shape' and 'shaped by' tell us the OODA loop is the product of a co-evolutionary interaction. Since all co-evolutionary processes embody positive as well as negative feedback loops, the OODA loop is necessarily a non-linear system and will exhibit unpredictable emergent behaviour. ${ }^{436}$

${ }^{434}$ Reproduced from Gell-Mann, The Quark and the Jaguar, p. 25

435 Grant T. Hammond, "The Essential Boyd"

http://www.belisarius.com/modern business strategy/hammond/essential boyd.htm

${ }^{436}$ Chuck Spinney, "Asleep at the Switch in Versailles... or ... Why Nonlinear Realities Overwhelm Linear Visions ... or ... Why did Slobo Cave?” (Defense and the National Interest, September 6, 1999)

http://www.d-n-i.net/fcs/comments/c317.htom 
This notion of unpredictability is crucial since Boyd believes in a perpetually renewed world that is "uncertain, everchanging, unpredictable"437 and thus requires continually revising, adapting, destroying and recreating our theories and systems to deal with it. Our understanding of the world is always playing catch-up with reality and our systems must consequently remain open to structural and behavioural change. Such a stance is in perfect accordance with the ideas of complexity theory: "since the system has to cope with unpredictable change in the environment, the development of the structure cannot be contained in a rigid [deterministic] programme that controls the behaviour of the system. ${ }^{3438}$ Therefore our conceptual frameworks must stay open to change on the basis of the new information from the external world and avoid at all cost closing on themselves, interpreting all new information through the prism of rigid and untouchable schemata - "the greatest danger is to get captured by your own thought processes rather than remaining sensitive to the changing environment and your opponent. ${ }^{3439} \mathrm{Or}$ in other words, "the most dangerous internal state of an OODA loop' occurs when the orientation process becomes so powerful that it force fits the organism's observations into fitting a preconceived template, even when those observations threaten the relevance of that template.

Boyd therefore moves from the traditional view of uncertainty as a threat that must be overcome to an irreducible characteristic of being and the very condition of possibility of change and creativity:

Ambiguity is central to Boyd's vision. It is not something to be feared but something that is a given. Being creative organisms, we should welcome it and make use of it. The world is ambiguous. [...] We never have complete and perfect information. [...] Our decisions and actions are hypotheses to be tested against this ambiguous environment. The best way to succeed in it is to revel in ambiguity. ${ }^{+11}$

\footnotetext{
${ }^{437}$ Boyd, "The Conceptual Spiral" http://www.d-n-i.net/boyd/pdf/intro.pdf p.37

${ }^{438} \mathrm{King}$, Social Science and Complexity, p.79

${ }^{439}$ Hammond, "The Essential Boyd".

440 Chuck Spinney, "Is America Inside Its Own OODA Loop?" (Defense and the National Interest, January 26, 2005) http://www.d-n-i.net/fcs/comments/c536.htm

441 Hammond, "The Essential Boyd"

For all the benefits of this condition of permanent ambiguity, there are also risks which Spinney discusses with reference to notions from chaos and complexity theory:
}

Boyd showed that an OODA Loop (the decision cycle of an individual or any collection of individuals) is an open, far-from-equilibrium process. This is a crucial finding: students of chaos theory, systems control theory, or the theory of evolution will immediately recognize the implications of such a construction: the OODA Loop is capable of expansion and 
Not only are ambiguity and unpredictability the conditions of true creativity but they are also ass ts to be exploited against opponents. Indeed, predictable patterns of military behaviour hand a crucial advantage to the opponent and exposes one to defeat. Conversely, making one's actions unpredictable unsettles the opponent's own OODA 'loop' as he strives to discern a pattern amidst the 'noise' created by unpredicted actions. Since war pits opposing OODA 'loops', the most effective and evolutive loop' will prevail: "you can either go through the OODA 'oop' cycle faster than your opponent or you can vary your tempos and rhythms so your opponent cannot keep up with you. ${ }^{n+42}$ The more overwhelmed the opponent is, the more likely he is likely to fold back on his existing schemata, desperately trying to match existing frameworks that are becoming increasingly isolated from reality until his final collapse. This is very much in accordance with a Clausewitzian understanding of war as a 'clash of wills' in which the primary target is the adversary's will and ability to resist rather than his physical capabilities. The idea that "to win, you need to get inside the adversary's OODA loop" ${ }^{\text {443 }}$ has become common-place in contemporary military literature, particularly in the network-centric variety, to the point that it has become an incantation that is not always based on a consistent and faithful understanding of Boyd's ideas, as we shall later see. For now, it is important to note that when Boyd talks about a "quicker OODA loop"', he does not simply mean cycling through the sequence of observationorientation-decision-action faster but rather is referring to all the cross-referencing connections that make the OODA into a complex adaptive system. Hence, in order to confound and defeat an opponent, the OODA loop' must be "more subtle, more indistinct, more irregular, and quicker - yet appear otherwise. ${ }^{\text {}}{ }^{444}$ Initiative, surprise and deception are thus key; merely increasing the speed at which one acts by responding to stimulus from pre-establised templates (i.e. without truly orienting) is not a quickening of the OODA 'loop', a point missed by many subsequent theorists.

A crucial distinction between Boyd's ideas and those governing cybernetic warfare, and one that parallels the development of chaos and complexity theories, is his focus on the

growth, but it is also inherently unpredictable and its pathway can lead also to chaos, because it incorporates positive as well as negative feedback control loops.

Spinney, "Is America Inside Its Own OODA Loop?"

412 Hammond, "The Essential Boyd"

${ }^{443}$ Hammond, "The Essential Boyd"

444 John R. Boyd, "Patterns of Conflict" (Presentation, December 1986)

http://www.d-n-i.net/boyd/patterns.ppt 
conditions of emergence and transformation of systems through information rather than merely the manner in which information is processed by a fixed organisational schema. Arquilla and Ronfeldt seem to be making a similar argument when they seek to distinguish the notion of information as process from that of structure. For them, the notion of information processing, which they attribute to Shannon, Wiener and the cyberneticists, useful as it may be, tends to overemphasise the importance of technological infrastructure to the detriment of organisational arrangements. ${ }^{45}$ They remind us that:

\begin{abstract}
All structures contain embedded information. Where there is structure - or pattern or organisation - there is information. Somehow the amount of structure and the amount of information go together. Embedded information is what enables a structure - be it physical, biological, or social - to hold its form, to remain coherent, even to evolve and adapt. All forms of organisation thus depend on embedded information; they do not have shape, and cannot retain their shape, without it. ${ }^{446}$
\end{abstract}

Arquilla and Ronfeldt contrast information as merely processed by a system with information as the codification of the structure of the system itself. One recognises here again the shift from the regulation of a system through information which concerned early cybernetics to the question of the self-production and self-organisation of systems in chaoplexity. By interpreting information as the pattern that constitutes form and organisation, Arquilla and Ronfeldt come to a new understanding of war as an informational process that goes beyond theories of communication:

Warfare has long revolved around who can hurl the most mass - as in the aptly named levée en masse of the Napoleonic era, or the human wave assaults on the western front in World War I and the eastern front in World War II. In the nuclear age, the emphasis shifted to hurling energy, as exemplified by the shock waves and radiation released by the splitting or fusing of atoms in bombs. Victory depended not only on directing mass or energy to deplete an enemy's war-fighting stocks, but also on keeping that enemy from hurling mass and energy at oneself, and on being able to absorb and recover from whatever mass and energy it did hurl. If information is a physical property, then in the information age winning wars may depend on being able to hurl the most information at the enemy while safeguarding against retaliation. The notion would affect how we think about all manner of weapons systems. Compare, for example, a round shot fired from an eighteenth-century smoothbore cannon, to a shell fired from a modern rifled artillery barrel, to a new wire-guided antitank missile. How do they rate, relatively, in terms of mass, energy, and information? The mass of each may be about the same, but the energy each represents differs greatly. More to the point, each consists of different materials organised in dissimilar ways. Each sums up a very different set of sciences and technologies. Thus, each represents a radically different embodiment of not only mass and energy but also information to hurl at an enemy. The one that represents the most information - the missile - is the most effective. As these

\footnotetext{
445 Arquilla \& Ronfeldt, "Looking Ahead: Preparing For Information-Age Conflict" in Arquilla \& David Ronfeldt (eds.), In Atbena's Camp, pp.442-446

446 Arquilla \& Ronfeldt, "Looking Ahead" in Arquilla \& Ronfeldt (eds.), In Atbena's Camp, pp.444-445
} 
systems exemplify, a historical progression has occurred in the amount of information that can be hurled by weapons. ${ }^{447}$

Boyd's other major ontological statement pertained to the inevitable uncertainty which permeates the activity of warfare, rejecting the drive for predictability of cybernetic warfare. This stance also echoes the discoveries of the non-linear sciences and has crucial implications for the type of control that armies should strive for. In the next section, I will look at this new understanding of chaos and uncertainty, particularly through a rereading of Clausewitz, and the lessons which the new military theorists draw from it.

\section{Uncertainty in War: the Non-Linear Clausewitz and the Future of Military \\ Organisation}

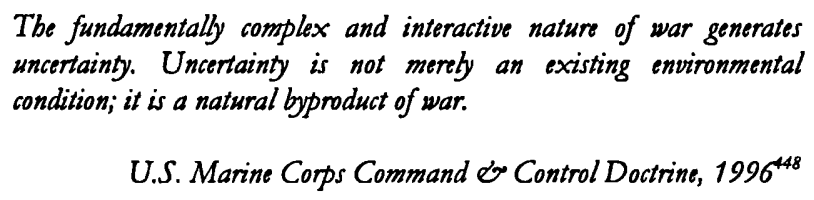

In 1992, Alan Beyerchen published an influential article reading Clausewitz's writings through the lens of developments in the non-linear sciences of chaos and complexity. Indeed, Clausewitz's insistence on unpredictability and the imperfection of knowledge in the practice of war appears to echo similar claims made by the new sciences. Beyerchen finds in the strategist's writings three considerations of unpredictability in war: from interaction, from friction, and from chance. Interaction is inherent in war as it "is not an exercise of the will directed at inanimate matter, as is the case with the mechanical arts" but rather is "directed at an animate object that reacts," effectively an opposing will $^{499}$ (this is the crux of Clausewitz's disagreement with mechanistic theorists of war like Jomini and von Bulow). This reaction locks both wills and forces into feedback loops whereby positive feedback loops can cause run-away processes -

\footnotetext{
${ }^{447}$ Arquilla \& Ronfeldt, "Information, Power, and Grand Strategy" in Schwartzstein (ed.), The Information Revolution and National Security, p.147

448 MCDP 6: Command and Control, United States Marine Corps, 1996, p.55

http://www.dtic.mil/doctrine/jel/service pubs/mcdp6.pdf

${ }^{440}$ Beyerchen, "Clausewitz, Nonlinearity and the Unpredictability of War"
} 
Clausewitz's tendency for war to become absolute - and make specific prediction impossible:

[Military action] must expect positive reactions, and the process of interaction that results. Here we are not concerned with the problem of calculating such reactions [...] but tather with the fact that the very nature of interaction is bound to make it unpredictable. 450

Friction is quintessentially nonlinear as with it Clausewitz concerns himself with the disproportionate effect small events can have on a battle or campaign:

Success is not due simply to general causes. Particular factors can often be decisive - details only known to those who were on the spot [...] while issues can be decided by chances and incidents so minute as to figure in histories simply as anecdotes. ${ }^{451}$

Non-linear phenomena, characterised by positive feedback loops and sensitivity to initial conditions, are precisely those that allow for such an amplification of 'minute incidents.' Another way of stating this in the phraseology of complexity theory is to say that "local causes can have global effects."

As well as relating friction to the thermodynamic theories that were emerging at Clausewitz's time and notably the concept of entropy, ${ }^{452}$ Beyerchen also connects friction to information theory:

\begin{abstract}
The second meaning of 'friction' is the information theory sense of what we have recently come to call 'noise' in the system. Entropy and information have some interesting formal similarities, because both can be thought of as measuring the possibilities for the behaviour of systems. According to information theory, the more possibilities a system embodies, the more 'information' it contains. Constraints on those possibilities are needed to extract signals from the noise. Clausewitz understands that plans and commands are signals that inevitably get garbled amid noise in the process of communicating them down and through the ranks even in peacetime, much less under the effects of physical exertion and danger in combat. His well-known discussion of the difficulty in obtaining accurate intelligence presents the problem from the inverse perspective, as noise permeates the generation and transmission of information rising upward through the ranks. From this perspective, his famous metaphor of the 'fog' of war is not so much about a dearth of information as how distortion and overload of information produce uncertainty as to the actual state of affairs. ${ }^{453}$
\end{abstract}

As we saw in the earlier section on the Vietnam War, misperceptions and uncertainties in military affairs are fuelled by an inability to distinguish relevant from false

\footnotetext{
450 Beyerchen, "Clausewitz, Nonlinearity and the Unpredictability of War"

451 Clausewitz, On War, translation by Michael Howard and Peter Paret (Princeton, NJ: Princeton

University Press, 1984), p.595

452 See chapter 4

453 Beyerchen, "Clausewitz, Nonlinearity and the Unpredictability of War"
} 
information (signal from noise) and excess volumes of data can hinder more than assist in this.

Chance is Clausewitz's blanket term for the uncertainty inherent to war and constitutes one part of his famous trinity, standing between the poles of irrationality (the natural force of violence, hatred and enmity among the people) and rationality (the instrumental subordination of war to government policy). The very metaphor Clausewitz employs to describe the complex interplay of the three components of the trinity is markedly nonlinear: "our task therefore is to develop a theory that maintains a balance between these three tendencies, like an object suspended between three magnets. ${ }^{3454}$ The Prussian officer is referring to a popular scientific experiment in which a metal object oscillates erratically between competing points of attraction in such a way that the pattern in unpredictable and for all practical purpose irreproducible - due to high sensitivity to initial conditions, minute differences in the location of the object as it starts its motions result in wildly different patterns.

Returning to the question of chance, Beyerchen calls on French nineteenth century mathematician Henri Poincaré to distinguish between three ways in which chance manifests itself to us and which can be all found in Clausewitz:

- as a statistically random phenomenon (the traditional understanding of stochastic chaos, best analysed through the use of probabilities - Clausewitz's references to war as the play of probabilities and analogies to gambling);

- as the amplification of a micro-cause (deterministic forms of chaos in systems showing sensitivity to initial conditions, as seen in friction);

- as a function of our analytical blindness. ${ }^{455}$

The difference between the first two forms of chance is crucial since the former is truly random and unpredictable while the latter is actually a highly ordered form of disorder as considered by chaos theorists. If sensitivity to initial conditions and irreducible constraints on the precision of measurements impose limits on the long term predictability of systems characterised by this form of chaos, the discovery of

454 Beyerchen, "Clausewitz, Nonlinearity and the Unpredictability of War" 455 Beyerchen, "Clausewitz, Nonlinearity and the Unpredictability of War" 
deterministic processes behind certain phenomena has shifted our understanding of them away from the first category of stochastic chance. This is the central paradox of chaos theory and the non-linear sciences in general: linear, Newtonian concepts and methodologies are found to be inapplicable to a vast range of phenomena which have to be tackled by approaches which cannot apprehend them in a similarly precise and predictive manner but, at the same time, the discovery has been made that phenomena which previously appeared entirely random have in fact a complex and identifiable structure. On one hand, the original promise of absolute control and omniscience of the Newtonian or cybernetic paradigms have to be abandoned. On the other, a new form of less direct and precise control and knowledge seems within reach to replace the former. In the words of Katherine Hayles, chaos has been bound. ${ }^{1456}$ This implies new ways of directing armies on the battlefield, as will be discussed below.

The last manifestation of chance - as a function of our analytical blindness - is a result of our tendency to partition the world into discrete pieces amenable to analysis. When two such pieces interact, we are faced with phenomena that are unexplainable to us and appear as the product of chance. What is required is a holistic approach that does not seek to isolate open systems from their environment but apprehends their profound interconnectedness. On the issue of critical analysis and proof, Clausewitz asserts the following:

It is bound to be easy if one restricts oneself to the most immediate aims and effects. This may be done quite arbitrarily if one isolates the matter from its setting and studies it only under those conditions. But in war, as in life generally, all parts of the whole are interconnected and thus the effects produced, however small their cause, must influence all subsequent military operations and modify their final outcome to some degree, however slight. ${ }^{457}$

This Clausewitzian understanding of war and reality as read through the non-linear sciences in which uncertainty, unpredictability and change are central implies a particular approach to the conduct of warfare and the organisation of armies. An understanding of war through the lens the complexity naturally calls for a direction of the military systems fighting it that draws on the insights of the new sciences. As Bar-Yam puts it:

In recent years it has become widely recognized in the military that war is a complex encounter between complex systems in complex environments. Complex systems are formed of multiple interacting elements whose collective actions are difficult to infer from

456 Hayles, Chaos Bound

${ }^{457}$ Beyerchen, "Clausewitz, Nonlinearity and the Unpredictability of War" 
those of the individual parts, predictability is severely limited, and response to external forces does not scale linearly with the applied force. It is reasonable to postulate that warfare can be better executed by those who understand complex systems than those who focus on simple linear, transparent, classically logical, Newtonian constructs. ${ }^{458}$

If, as the U.S. Marine Corps's 1989 warfighting manual postulates, "the occurrences of war will not unfold like clockwork," it is futile to attempt to "impose precise, positive control over events" ${ }^{359}$ and "it is unreasonable to expect command and control to provide precise, predictable, and mechanistic order to a complex undertaking like war. ${ }^{2460}$ As opposed to a process obeying eternal laws which can be uncovered and exploited to design infallible tactics, war is here an amorphous and constantly renewed phenomenon. Or to put it in Clausewitz's words, "war is a chameleon" - its forms fluctuates and mutates, only its basic nature is invariant. The successful army must internalise this lesson and constitute itself accordingly:

\begin{abstract}
Like friction and uncertainty, fluidity is an integral attribute of the nature of war. Each episode in war is the temporary result of a unique combination of circumstances, requiring an original solution. But no episode can be viewed in isolation. Rather, each merges with those that precede and follow it - shaped by the former and shaping the conditions of the latter - creating a continuous, fluctuating fabric of activity replete with fleeting opportunities and unforeseen events. Success depends in large part on the ability to adapt to a constantly changing situation. 461
\end{abstract}

The ability to adapt in such fluid situations is dependent on being able to discern patterns from the seemingly random and here chaos theory provides new tools and insights. For Andrew Ilachinski, "implicit in any application of the 'new sciences' to land combat $[\ldots]$ is the idea that there is some latent order underlying what appears on the surface to be irregular and chaotic." 462 Ilachinski dubs 'intuition' "the ability to perceive patterns in an otherwise patternless process," ${ }^{\text {,463 }}$ echoing Clausewitz's notions of 'genius' and 'coup d'oeil' that constitute "that superb display of divination" in the successful commander:

Circumstances vary so enormously in war, and are so indefinable, that a vast array of factors has to be appreciated - mostly in light of probabilities alone. The man responsible for evaluating the whole must bring to his task the quality of intuition that perceives the

458 Yaneer Bar-Yam, "Complexity of Military Conflict: Multiscale Complex Systems Analysis of Littoral Warfare", New England Complex Systems Institute, 2003, p.1

http://necsiorg/projects/yaneer/SSG NECSI 3 Litt.pdf

459 FMFM1: Warfighting, United States Marine Corps, 1989

http://wrww.clausewitz.com/CWZHOMIE/Warfit 1.htm

460 MCDP 6: Command and Control, United States Marine Corps, pp.46-47

461 Warfigting, FMFM1, United States Marine Corps

462 Andrew Ilachinski, Land Warfare and Complexity - Part I: Mathematical Background and Technical Sourcebook (Alexandria, VA: Center for Naval Analyses, July 1996), p.27 http://www.cna.org/isaac/lwpart2.pdf

${ }^{463}$ Ilachinski, Land Warfare and Complexity, p.27 
truth at every point. Otherwise a chaos of opinions and considerations would arise, and fatally entangle judgment. 464

The recognition of truth (or pattern) is what allows for a fleeting discernment of order from the chaos of the battlefield (reflected in a conceptual chaos in the mind) and appropriate responsiveness to the ever-fluctuating conditions of war. We are reminded here of Boyd's frameworks of orientation and Gell-Mann's schemata.

Not only are closed and rigid systems unable to respond to the eruption of novelty and unexpected challenges but attempts to increase their performance exposes them to catastrophic breakdown. John Urry discusses this point generally in the context of complexity theory but it bear clear parallels with military organization and Boyd's own statements about the self-defeating nature of efforts to perfect the internal coherence of closed systems:

\begin{abstract}
Up to a point, tightening the connections between elements in the system will increase efficiency when everything works smoothly. But, if one small item goes wrong, then that can have a catastrophic knock-on effect throughout the system. The system literally switches over, from smooth functioning to interactively complex disaster. ${ }^{465}$
\end{abstract}

The implication is that the components within a system should be loosely connected together with a built-in redundancy and ability to reconfigure their positions within the network when necessary, allowing for the emergence of new behaviour and organizational arrangements. In other words, the military must be a complex adaptive system operating at the edge of chaos:

This view sees the military organization as an open system, interacting with its surroundings (especially the enemy), rather than as a closed system focused on internal efficiency. An effective command and control system provides the means to adapt to changing conditions. We can thus look at command and control as a process of continuous adaptation. [...] Like a living organism, a military organization is never in a state of stable equilibrium but is instead in a continuous state of flux - continuously adjusting to its surroundings. 466

In these conditions of perpetual flux, traditional conceptualisations of control have to be abandoned or redefined in favour of a more modest channelling - "the best we can hope for is to impose a general framework of order on the disorder, to prescribe the general flow of action rather than to try to control each event." ${ }^{467}$ A new military

\footnotetext{
${ }^{464}$ Clausewitz, On War, p.112

465 Urry, Global Complexity, p.35

${ }^{466}$ MCDP 6: Command and Control, United States Marine Corps, p.46

${ }^{467}$ FMFM1: Warfighting, United States Marine Corps, 1989
} 
doctrine and practice can only emerge by breaking with the command and control principles that governed cybernetic warfare during the Cold War:

Control Theory requires both prediction and the existence of an adequate set of levers of control. [...] [But] having effective, centrally managed levers that can control or even predictably influence a complex, adaptive system is far from guaranteed. [...] In the Information Age, control needs to be thought about and approached differently. Control is not something that can be imposed on a complex adaptive system, particularly when there are many independent actors. Control, that is, ensuring that behavior stays within or moving to within acceptable bounds, can only be achieved indirectly. The most promising approach involves establishing, to the extent possible, a set of initial conditions that will result in the desired behavior. In other words, control is not achieved by imposing a parallel process, but rather emerges from influencing the behaviors of independent agents. ${ }^{468}$

If centralised control is no longer desirable and must give way to decentralised means for the coordination of 'independent agents', a new organisational form is necessary to overcome the limitations of hierarchical structures. This form is that of the network.

\section{The Age of the Network}

The future may belong to whoever masters the network form.

Jobn Arquilla and David Ronfeldt ${ }^{49}$

Possibly the single most transforming thing in our force will not be a weapons system, but a set of interconnections.

Donald Rumsfeld ${ }^{770}$

The network form can be seen to have presently truly come of age, at least in terms of featuring heavily in both public and academic consciousness. Manuel Castells's highly influential opus on network society argues that networks constitute no less than "the new social morphology of our societies and the diffusion of networking logic substantially modifies the operation and outcomes in the processes of production,

\footnotetext{
${ }^{468}$ David S. Alberts \& Richard E. Hayes, Power to the Edge - Command... Control... in the Information Age (Department of Defense CCRP, 2003), pp.206-208

${ }^{469}$ Arquilla \& Ronfeldt, "Cyberwar is Coming!" in Arquilla \& Ronfeldt (eds.), In Athena's Camp, p.40

470 Tim Weiner, “A ‘God's-Eye View' of the Battlefield”, The New York Times, November 20, 2004
} 
experience, power and culture." ${ }^{471}$ The network is hence taken to be the new predominant form of social organisation in a world perceived as globalised and interconnected through time- and space-defying technologies of transport and telecommunications.

Unsurprisingly, much of the literature on the network form therefore connects its rise with the development of information and communication technologies (ICTs), pointing to the diffusion of computers, mobile telecommunications and the Internet. The Internet famously finds its roots in a military program of the 1960s and 1970s under the U.S. Department of Defense's ARPA (the Advanced Research Project Agency, now known as DARPA). ${ }^{42}$ In 1962, ARPA created the Information Processing Technology Office (IPTO), led by J.C.R. Licklider, a veteran of the Macy Conferences on cybernetics, for the purpose of furthering research from the Semi Automatic Ground Environment (SAGE) program, the radar and air defence system discussed in chapter 6 . The resulting ARPANET became the first operational packet-switching network. ${ }^{473}$ After the military spun off the ARPANET to the civilian sector, what was to become the Internet took on a life of its own, eventually reaching broader public awareness in the 1990s and transforming business and social interaction in a process that is still ongoing today. Along with the diffusion of other telecommunication systems, the Internet became a central piece of an emerging network culture which has promoted decentralised forms of organisation and non-hierarchical channels of communication.

Castells sums up an increasingly commonly held belief with the idea that "networks are proliferating in all domains of the economy and society, outcompeting and

471 For Castells, the network is intimately connected to the development of capitalism and late modernity in the last decades of the twentieth century. "Networks are appropriate instruments for a capitalist economy based on innovation, globalisation, and decentralised concentration; for work, workers and firms based on flexibility; for a culture of endless deconstruction and reconstruction; for a polity geared towards the instant processing of new values and public moods; and for a social organisation aiming at the supersession of space and the annihilation of time."

Manuel Castells, The Rise of the Network Society - $2^{\text {nd }}$ ed. (Cambridge, MA; Oxford, UK: Blackwell, 2000), p. 500

472 (D)ARPA was created in 1958 in response to the Soviet launch of Sputnik and was designed to act as a technological 'engine' for the DoD, carrying out long term projects with potential military applications.

${ }^{473}$ An enduring myth is that the rationale behind ARPANET was to build a telecommunications network able to survive a nuclear attack. While a RAND report did consider this eventuality, the aims of the ARPANET program were more general in simply seeking to improve the resilience and cost-effectiveness of existing telecommunications based on circuit switching. Resistance to network losses was certainly part of the project but was not initially conceived for the specific context of a nuclear war.

See Barry M. Leiner, Vinton G. Cerf, David D. Clark, Robert E. Kahn, Leonard Kleinrock, Daniel C. Lynch, Jon Postel, Larry G. Roberts \& Stephen Wolff, "A Brief History of the Internet" (The Internet Society, 2003) http://www.isoc.org/internet/histor/brief.shtml 
outperforming vertically organised corporations and centralised bureaucracies. ${ }^{3474}$ While of course the network form of social organisation existed long before the development and widespread diffusion of twentieth century ICTs, they have certainly acted as enablers for the formation and increased efficiency of social networks, thereby challenging the previously dominant hierarchical form. ${ }^{475}$ For Arquilla and Ronfeldt:

\begin{abstract}
The information revolution is strengthening the importance of all forms of networks social networks, communications networks, etc. The network form is very different from the institutional form. While institutions (large ones in particular) are traditionally built around hierarchies and aim to act on their own, multi-organizational networks consist of (often small) organizations or parts of institutions that have linked together to act jointly. The information revolution favors the growth of such networks by making it possible for diverse, dispersed actors to communicate, consult, coordinate, and operate together across greater distances and on the basis of more and better information than ever before. ${ }^{476}$
\end{abstract}

While the technological infrastructure of the network is important, even more crucial are the actual dynamics of networks and here we find ourselves firmly within the conceptual frameworks of chaos and complexity theory. Indeed, the network form implies a decentralized, open, and adaptable form of organization, naturally best suited to adjust to a rapidly changing environment through the self-organising and emergent properties of the network. As Ian King puts it, "networking [is] a way of maintaining a low-level chaotic substrate so that - as in the brain - the chaos will from time to time give birth to an intellectual self-organising structure." ${ }^{477}$ Similarly, for Castells, "a network-based social structure is a highly dynamic, open system, susceptible to innovating without threatening its balance. ${ }^{.048}$ In the context of military operations, the art of war becomes the harnessing of similarly fluid structures through informational exchanges between its interacting parts, a process in which information and communication technologies naturally play a crucial role.

Although much of this technology had been developed by the military, the latter only became aware of these social transformations belatedly, triggering animated discussion of the implications for military doctrine and practice. U.S. practitioners looked particularly to business for inspiration, invoking Alvin and Heidi Toffler's mantra - "the

\footnotetext{
${ }^{474}$ Manuel Castells, The Internet Galaxy (Oxford, New York: Oxford University Press, 2001), p.1

475 "While the networking form of social organization has existed in other times and spaces, the new information technology paradigm provides the basis for its pervasive expansion throughout the entire social structure."

Castells, The Rise of the Network Society, p.500

${ }^{476}$ Arquilla \& Ronfeldt, "Cyberwar is Coming!" in Arquilla \& Ronfeldt (eds.), In Atbena's Camp, pp.26-27

$477 \mathrm{King}$, Social Science and Complexity, p.55

${ }^{478}$ Castells, The Rise of the Network Society, pp.501-502
} 
way we make war reflects the way we make wealth"479 - and emphasising the role of information superiority, adaptability, the flattening of management structures, increases in speed, and, above all, networks.

Arquilla and Ronfeldt have been among the most vocal proponents of networked organisation, arguing that new related forms of conflict are emerging. Although they distinguish between cyberwar - the conduct of organized violence according to information-related principles - and netwar - the use of information and media for propaganda and exertion of influence - both are characterized by the predominance of networked actors (even though their leadership may be itself quite hierarchical). These emerging actors pose serious challenges to their more rigidly hierarchical rivals, particularly states and armies (which the authors dub 'institutions'). Arquilla and Ronfeldt see cyberwar "in the realms of low-intensity conflict - international terrorists, guerrilla insurgents, drug smuggling cartels, ethnic factions, as well as racial and tribal gangs." ${ }^{280}$

Since September 11, the focus has naturally been on al-Qaeda and the wider movement of radical Islamic militancy and terrorism. The nebulous and dispersed nature of these organizations has invited their analysis in terms of decentralized networks and complex adaptive systems. "Organizationally, al-Qaeda is intentionally decentralized with recursive operational and financial interrelationships dispersed geographically across numerous associated terrorist organizations that adapt, couple and aggregate in pursuit of common interests." ${ }^{481}$ For Marion and Uhl-Bien, interactive non-linear bottom-up dynamics are behind the self-organisation of al-Qaeda in which bin Laden and the alQaeda leadership are an emergent phenomenon: "leaders do not create the system but rather are created by it, through a process of aggregation and emergence. ${ }^{\text {ग482 }}$ While a diffuse movement of Islamic radicalism coalesced to create terrorist networks from

\footnotetext{
${ }^{479}$ Alvin \& Heidi Toffler, War and Anti-War: Survival at the Dawn of the 21st Century (Boston, MA \& London: Little, Brown \& Company, 1993)

${ }^{480}$ Arquilla \& Ronfeldt, "Cyberwar is Coming!" in Arquilla \& Ronfeldt (eds.), In Athena's Camp, p.40

${ }^{481}$ Michael F. Beech, "Observing Al Qaeda Through the Lens of Complexity Theory: Recommendations for the National Strategy to Defeat Terrorism", Center for Strategic Leadership, U.S. Army War College, July 2004

http://www.carlisle.arms.mil/usacsl/Publications/S04-01.pdf

482 Russ Marion \& Mary Uhl-Bien, "Complexity Theory and Al-Qaeda: Examining Complex Leadership", Presentation given at Managing the Complex IV: A Conference on Complex Systems and the

Management of Organizations, Fort Meyers, FL, December, 2002

http://isce.edu/ISCE Group Site/web-

content/ISCE\%20Events/Naples 2002/Naples 2002 Papers/Marion Uhl-Bien.pdf p.5
} 
which the leadership could spring, the latter has also assisted the continued development of a decentralised movement by maintaining and fostering "a moderately coupled network, but one possessing internal structures that were loosely and tightly organized as appropriate." ${ }^{\text {483 }}$ The authors distinguish between loosely coupled networks in which the parts have functional independence, thus granting the system great resilience to large-scale perturbations, and tightly coupled networks in which the leadership imposes control mechanisms that enable it to direct activities and receive regular reports. In between these two poles, we find moderately coupled networks which allow some degree of directing by leadership but retain great resiliency. If the wider radical Islamic movement is only loosely coupled and individual terrorist cells are tightly coupled, the pre-9/11 al-Qaeda leadership network sat somewhere in between, performing the function of a galvanising interface.

Even in the case of single operation such as September 11, it has become increasingly clear that its planning and execution were far more decentralised than initially supposed. The different cells in the plot, although tightly coupled internally, functioned quasiautonomously, and although they received some financial, logistical and training support from other parts of the organisation, were not exclusively dependent on them. Sheik Mohammed, said to be the operational 'mastermind' behind September 11 (a designation which, although commonly used in the media, is problematic as it suggests highly centralised planning and control) and now in American military custody, is alleged to have claimed that "the final decisions to hit which target with which plane was entirely in the hands of the pilots." 484 Sheikh Mohammed was only then subsequently informed of their decision in July 2001. According to this same testimony, bin Laden and the high ranks of the al-Qaeda organisation were also only very loosely informed of specific details and had a very limited directing role. Many of bin Laden's close associates were never even made aware of the plot. This form of organisational and operational structure is one that is particularly alien to Western states and their hierarchical military and security apparatuses, as Mohammed himself recognises: "I know that the materialistic western mind cannot grasp the idea, and it is difficult for

${ }^{483}$ Marion \& Uhl-Bien, "Complexity Theory and Al-Qaeda", p.27

${ }^{484}$ Substitution for the Testimony of Sheik Khaled Mohammed

http://news.bbc.co.uk/1/shared/bsp/hi/pdfs/06 0406 testimony.pdf p.28 
them to believe that the high officials in al-Qaeda do not know about operations carried out by its operatives, but this is how it works. ${ }^{2485}$

The resilience and adaptability of the network has been further demonstrated by events following September 11 and the American response. Despite the loss of its host state of Afghanistan, a global crackdown on the organisation and its financial sources, and the military intervention of the sole superpower, it cannot be said that al-Qaeda, or at least its ideology and methods, have been defeated. If its original leadership has been mostly arrested, killed, or so severely restricted in its movements and communications as to render it operationally impotent, ${ }^{486}$ it remains a powerful symbol for the Jihadist movement at wide. Endowed with an authority and prestige which enables it to claim responsibility for attacks in Madrid and London despite scant evidence of logistical or organisational connections to the responsible cells, ${ }^{487}$ al-Qaeda's leadership has in a sense blended back into the loosely connected radical Islamic movement while giving a name and a face to the fluid and amorphous networks that compose it and crystallize at certain points to carry out violent actions - both for the West which tends to see alQaeda at every turn and for aspiring militants which see it as a model to follow.

Existing state structures are ill-equipped to deal with these new forms of threats since "it will take networks to fight networks." ${ }^{488}$ For Arquilla and Ronfeldt, the emerging conflicts will:

\begin{abstract}
require major innovations in organisational design, in particular a shift from hierarchies to networks. The traditional reliance on hierarchical design may have to be adapted to network-oriented models to allow greater flexibility, lateral connectivity, and teamwork across institutional boundaries. The traditional emphasis on command and control, a key strength of hierarchy, may have to give way to an emphasis on consultation and coordination, the crucial blocks of network designs. ${ }^{489}$
\end{abstract}

\footnotetext{
485 Substitution for the Testimony of Sheik Khaled Mohammed http://news.bbc.co.uk/1/shared/bsp/hi/pdfs/06 0406 testimony.pdf p.55

${ }^{486}$ President Bush declared in his State of the Union address in January 2004 that "We are tracking alQaeda around the world, and nearly two-thirds of their known leaders have now been captured or killed." George W. Bush, State of the Union Address, January 20, 2004 http://wrww.whitehouse.gov/news/releases/2004/01/20040120-7.html

487 "Madrid bombing probe finds no al-Qaida link", MSNBC, March 9, 2006 htp://wrw.msnbc.msn.com/id/11753547/from/RL.1/ Mark Townsend, "Leak reveals official story of London bombings", Observer, April 9, 2006 http://politics.guardian.co.uk/labour/story/0.1750264,00.htm 488 Arquilla \& Ronfeldt, "Looking Ahead" in Arquilla \& Ronfeldt (eds.), In Atbena's Camp, p.456

489 Arquilla \& Ronfeldt, "Cyberwar is Coming!" in Arquilla \& Ronfeldt (eds.), In Athena's Camp, p.45
} 
However, the authors recognise that it is not possible or even desirable for state actors to completely abandon hierarchies (states have an irreducibly hierarchical core). The challenge is therefore for these actors to exploit the flexibility and adaptability of networks while preserving some hierarchical features - hybridisation is the goal. For Ronfeldt and Arquilla, the ability of the state to meet the challenges of the twenty-first century will hinge on its ability to appropriate the network form, whether in the political, administrative, policing, or military sphere. In the latter, networks have the potential not only for new organisational forms but also for new tactics, in particular that of swarming.

\section{Swarming: Of Ants and Men}

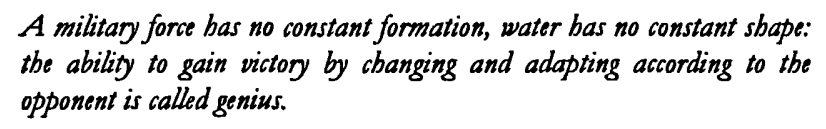
Sun Tzu, The Art of War

According to the new emerging military paradigm, operating as a networked force allows troops to act in ways which are impossible to their hierarchical counterparts. Drawing further from the writings of complexity theorists and deploying biological and zoological metaphors, military theories appeal to the 'swarm', the networks of distributed intelligence which enable bees, ants, and termites to evolve complex forms of collective behaviour on the basis of the simple rules of interaction of their individual members. Of particular interest is the resiliency and flexibility of these swarms as amorphous ensembles in which no single individual is critical to their continued existence and successful operation. Military swarms promise not only more adaptable and survivable forces but also new offensive and defensive tactics better suited to the contemporary battlespace.

Kevin Kelly contrasts the clock model whereby "you construct a system as a long string of sequential operations" with the swarm model, "systems ordered as a patchwork of parallel operations" where, in the absence of a chain of command "what emerges from the collective is not a series of critical individual actions but a multitude of simultaneous 
actions whose collective pattern is more important. ${ }^{3400}$ These two models constitute for Kelly the two theoretical poles of organisation and offer a trade-off between control and predictability on one hand and adaptability and resilience on the other. Real-life systems most often lie somewhere in between these two poles and if the military is not attempting to completely dispense with hierarchy, it is now feeling the pull of the swarm pole most.

The fluidity of swarms allows these forms of social organization to adapt more rapidly and effectively to the unforeseen. When discussing ant colonies, Nicolis and Prigogine argue that:

\begin{abstract}
[a] permanent structure in an unpredictable environment may well compromise the adaptability of the colony and bring it to a suboptimal regime. A possible reaction toward such an environment is to maintain a high rate of exploration and the ability to rapidly develop temporary structures suitable for taking advantage of any favorable occasion that might arise. In other words, it would seem that randomness presents an adaptive value in the organization of society. ${ }^{491}$
\end{abstract}

What enables ants to identify the optimal state of fitness in a given environment is the process of distributed computing they can be thought of as embodying. For'example, despite the limited perceptive apparatus and intelligence of the single ant, a colony can identify rapidly the shortest route across a rugged landscape. This is achieved by the secretion of pheromones which serves to communicate between its members "pheromones can be thought of as information broadcasted or communicated within the ant system. ${ }^{3492}$ In this manner, tiny pieces of local knowledge acquired by individual ants combine to constitute the emergent global knowledge that characterises the colony as a whole. The sheer number of ants allows for a process of computational trial and error which enables the colony to evolve the optimal solution to any problem. As Kelly puts it, "this calculation perfectly mirrors the evolutionary search: dumb, blind agent, simultaneous agents trying to optimise a path on a computationally rugged landscape. Ants are a parallel processing machine. ${ }^{293}$ This distributed form of computing is what grants complex adaptive systems their ability to change and produce creative solutions to new problems.

\footnotetext{
${ }^{490}$ Kevin Kelly, Out of Control: The New Biology of Macbines (Reading, Berks, UK: Cox \& Wyman, 1994), p.27

${ }^{491}$ Gregoire Nicolis \& Ilya Prigogine, Exploring Complexity (New York: W.H Freeman, 1989), p.233

492 Kelly, Out of Control, p.395

${ }^{493}$ Kelly, Out of Control, p.395
} 
For Marion and Uhl-Bien, al-Qaeda successfully constituted a distributed intelligence network which "enabled creativity and innovation on a large scale (such as that needed to pull off the $9 / 11$ events), and helped assure the broadly based viability of the system. ${ }^{.494}$ Sageman's own account of the manner in which jihadist networks carry out operations fits this picture:

\begin{abstract}
When a terrorist network embarks on a major new operation, the people involved do not know exactly how they are going to do it. No role is specified in advance. Each mujaheed starts with a general notion of what is required of him and improvises with other mujaheed as he goes along. Terrotist operations are not so frequent that they become routine, for law enforcement forces would then catch on and be able to prevent them. These operations involve much uncertainty and many unanticipated obstacles. The state of affairs requires communication among mutually dependent mujahedin, in the sense that each possesses information and resources relevant to the other and none has enough to act in isolation. At this local level, the mujahedin form a network of information processors, where the network handles large volumes of information efficiently without overloading any individual processor [...] Communications are possible horizontally among multiple nodes, allowing them to solve their problems locally without having to refer up to Central Staff and overwhelming the vertical links of communication. ${ }^{45^{\circ}}$
\end{abstract}

It is therefore through a form of parallel processing that jihadists find their way towards a solution to the organisational challenges of fulfilling a designated mission and that collective behaviour emerges without the direction from a hierarchy.

Translated to the military field, swarms are the natural corollary of the constitution of the networked forces, emergent phenomena produced by decentralisation and information-sharing:

\begin{abstract}
in the future, platforms will evolve from being networked entities to being nodes in the network, to organizing efforts resembling 'packs' and 'swarms.' This transformation will be so complete that the packs and swarms that evolve from existing platforms will bear no resemblance to their distant (in generations, not time) predecessors. Hence, in the process, the very notion of a platform will evaporate; their raison d'être will be satisfied by a new approach as a result of a series of transformations consisting of ever-larger numbers of smaller, dumber, and cheaper components. These collections of entities will ultimately become dynamically reconfigurable packs, swarms, or other organizations of highly specialized components that work together like the cells of our bodies. As such, they will be able to be far more discriminating and precise in the effects they cause. They will become less mechanical and more organic, less engineered and more 'grown. ${ }^{496}$
\end{abstract}

The language employed suggests that these constituent 'entities' may not necessarily be human. Indeed, Glenn James predicts the battlespace of the future may see what he dubs "'fire ant' warfare - combat of the small and numerous" in which swarms

${ }^{494}$ Marion \& Uhl-Bien, "Complexity Theory and Al-Qaeda", p.27

495 Mark Sageman, Understanding Terror Networks (Philadelphia, PA: University of Pennsylvania Press, 2004), p. 165

496 Alberts \& Hayes, Power to the Edge, p.169 
composed of millions of sensors, emitters, microbots, and micro-missiles and deployed via pre-positioning, burial, air drops, artillery rounds, or missiles, saturate the terrain of conflict. $^{497}$

Beyond the flexibility and evolutionary capability that is attributed to military swarms, it is also claimed that they will also be able to bring force to bear in a new manner: "in netwar, attacks will come in 'swarms' rather than in more traditional 'waves." ${ }^{3498}$ Rather than throwing themselves onto the enemy, forces will be able converge on all directions for offensive bursts thereby maximizing the shock effect:

\begin{abstract}
swarming is achieved when the dispersed nodes of a network of small (and also perhaps some large) forces can converge on an enemy from multiple directions, through either fire or maneuver. The overall aim should be sustainable pulsing - swarm networks must be able to coalesce rapidly and stealthily on a target, then dissever and redisperse, immediately ready to recombine for a new pulse. A swarm network should have little to no mass as a rule (except perhaps during a pulse), but it should have a high energy potential - like a swarm of bees that can fell a mighty beast, or a network of antibodies that can attack a spreading virus. ${ }^{499}$
\end{abstract}

Dispersing after an attack also renders troops less vulnerable to enemy attacks, particularly in the context of the high lethality and precision of contemporary and future battlefields.

Arquilla and Ronfeldt do not merely see swarming as a military tactic to come but as one that has been already successfully employed many times in the past, from the Mongol hordes of Genghis Khan to the German U-Boat tactics in World War II. They also observe that similar tactics have been employed in non-military context by diverse activists during the civil rights, anti-Vietnam war, and Seattle anti-globalisation protests. ${ }^{500}$ While Linda Beckerman does not employ the term of swarming, her description of the tactics of "mass and disperse oscillation" deployed by Somali fighters during the infamous Battle of Mogadishu in October 1993 (most commonly known as the Black Hawk Down incident) is also relevant. ${ }^{501}$ This broad range of examples underlines again that such networked tactics are primarily organisationally driven rather than by technology, although developments in ICTs have certainly made them more widely applicable.

${ }^{497}$ James, "Chaos Theory: The Essentials for Military Applications", p.79

498 Arquilla \& Ronfeldt, "The Advent Of Netwar" in Arquilla \& Ronfeldt (eds.), In Athena's Camp, p.282

499 Arquilla \& Ronfeldt, "Looking Ahead" in Arquilla \& Ronfeldt (eds.), In Atbena's Camp, p.465

500 Arquilla \& Ronfeldt, "Looking Ahead" in Arquilla \& Ronfeldt (eds.), In Athena's Camp, p.465

${ }^{501}$ Beckerman, "The Non-Linear Dynamics of War" 
Arquilla and Rondfeldt propose a new doctrine of BattleSwarm that the U.S. military should adopt along with a greater networking of its forces. This would entail a shift towards light networked semi-autonomous forces supported by the latest ICTs and directed by a command authority with informational topsight (a scheme that resembles very much that of network-centric warfare, discussed in the following section). While the authors draw inspiration from complexity theory and studies of the behaviour of swarms, packs and flocks in the natural world, they recognize that the networked behaviour they are advocating is distinct in significant ways. Swarming networks in the natural world are more fluid and distributed than their military counterparts, while at the same time lacking in topsight. The swarming models created by complexity theorists and which provided the original insights into animal behaviour naturally share these features:

This theoretical and experimental work usually depicts swarming as a system in which autonomous agents interact and move around according to a set of rules and a schedule, often seeking an optimal outcome vis-à-vis another agent, set of agents, or environmental feature. The modeling allows for continual interactions among the agents, as they form and reform in fluid, shifting networks (and maybe hierarchies as well). These networks may persist for some time, or may break down and recombine into others opportunistically. Information may flow quite freely from one agent to the next about conditions near them in the model, but, in the examples we have seen, there is rarely an identifiable distribution of, or hub for distributing, topsight among all the agents. Some of the models and applications seem to be more about follow-the-leader or follow-your-neighbor 'flocking' behavior than swarming conjointly to attack an adversary or other target. ${ }^{502}$

The behaviour these models describe does indeed seem to resemble more that of international jihadist terrorism and insurgency than the ideals of BattleSwarm in which 'autonomous' agents are constrained within more formalised structures of hierarchical authority and operate on the basis of centralised information. Once again, Arquilla and Ronfeldt strive for a hybrid model in-between the poles of rigid centralisation and radical decentralisation.

The above sections have reviewed the connections between chaos theory and complexity science and new military thinking on warfare through the themes of decision cycles, uncertainty, networks, and swarming. The discussion of all these elements will come to bear on the following section in which the now official Pentagon doctrine of network-centric warfare will be critically examined in order to determine how

${ }^{502}$ John Arquilla \& David Ronfeldt, Swarming and the Future of Conflict (RAND Corporation, 2000), pp.48-49

http://www rand.org/pubs/documented briefings/2005/RAND DB311.pdf 
significantly it breaks with cybernetic warfare and whether it truly heralds the emergence of a new regime of chaoplexic warfare.

\section{Complexity Goes To War? The Rise of Network-Centric Warfare}

\section{One of the things that has emerged out of the study of war is that to beat} an enemy's complex system, you require a system that's more complex.

Navy Vice Admiral Artbur Cebrowskes 503

The debacle in Vietnam delivered a strong blow to cybernetic warfare and its ambitions for informational omniscience and total predictability. Uncertainty and chaos had not been banished from the battlefield - on the contrary, the North Vietnamese had exploited it consummately to derail the American war machine and its reliance on technology. While the defeat in Vietnam prompted some soul-searching, most of the armed forces refused to view it as a military defeat and blamed the political leadership for its inability to overcome an inferiorly equipped peasant guerrilla. Hence the lesson to be learnt was not how to win such wars but to avoid such conflicts in the first place. The military could thus return to focusing on preparing for war against an opponent similar to itself, namely the Soviet Union and the Warsaw Pact, and in which it could still place hope in the principles that had been so patently ineffective in Vietnam.

The ideals of cybernetic warfare experienced a resurgence in the 1980s and then 1990s with the SDI project and debate over the forever imminent Revolution in Military Affairs (RMA). A key discursive reference for RMA proponents are the texts by futurists Alvin and Heidi Toffler, The Third Wave (1980) and War and Anti-War (1995) - to the extent that critics frequently refer to RMA advocates as Tofflerians. The Tofflers famously argued that human civilisation was entering a third wave in its history; after the first agtarian and second industrial societies, comes the informational age. Each new wave supersedes the other and brings with it new techniques of production and destruction since "nations make war the same way they make wealth." Among the

\footnotetext{
503 Matthew French, "Cebrowski sees Transformation Change", FCW.com, January 23, 2004 http://www.fcw.com/fcw/articles/2004/0119/web-cebrowski-01-23-04.asp

504 Alvin Toffler, The Third Wave (London: Collins, 1980); Alvin \& Heidi Toffler, War and Anti-War
} 
criticisms levelled at the Tofflers is an excessively deterministic and technocentric outlook. Nonetheless, the Tofflers' ideas proved to be immensely popular within the U.S. military and it became one of the core texts of RMA advocates.

In the hands of those evangelists, the Third Wave translated into an RMA vision in which the future was computers, information networks, and precision-guided munitions. Dreams of automated, centralised and even casualty-free wars were revived, fuelled in no small part by the spectacular success of the Gulf War. As Atkinson and Moffat put it:

[The information age] brought with it an illusion or panacea that it might be possible to exercise control from the centre after all, that new information systems, and ever greater bandwidth and computing power would enable command to be controlled, and that, somehow, technology could, in itself, create the necessary interaction across the layers to enable automated control. that processes could be controlled through automation and it was only a matter of devising yet more capable computers and information systems. ${ }^{505}$

Under this worldview, uncertainty and disorder are merely temporary obstacles soon to be banished, a limitation of existing technology. "What was often referred to as the 'fog of war' is in reality disorder - the inability to maintain unity of action due to shortcomings in the C3I systems. ${ }^{3506} \mathrm{~A}$ 'system of systems' which would allow for the interoperability and synergy of Command, Control, Computers, Communications, and Information (C4I) and Intelligence, Surveillance and Reconnaissance (ISR) systems was recurrently touted as the key to 'information superiority' and the eradication of the 'fog of war.'

The discourse of RMA proponents has followed a regular pattern over the years: new technology is within reach that will revolutionise warfare and will finally render it to a state of full control and predictability. Admiral William Owens, one of the keenest advocates in recent years, provides us here with a typical specimen:

There is profound information technology available in America. This technology would allow our country the capability for the first time in history of man, to be able to 'see' a very large strategic battlefield with great definition. That means that 24 hours a day, in realtime, all weather, we could have the ability in a 'strategic' battlefield, the size of a country 250 miles on a side, to see every activity and facility which might be of interest to our warfighting, peacemaking or peacekeeping effort. Every command centre, every vehicle

505 Simon Ray Atkinson \& James Moffat, The Agile Organization: From Informal Networks to Complex Effects and Agility (Department of Defense CCRP, 2005), pp.170-171

http://www. dodecrp.org/publications/pdf/Atkinson_Agile.pdf

506 Norman C. Davis, "An Information-Based Revolution in Military Affairs" in Arquilla \& Ronfeldt

(eds.), In Athena's Camp, p.86 
moving down a road or in a battlefield, every radar and radio, and every critical facility could be identified and located to great accuracy, probably about $10 \mathrm{~cm}$. And what is important is that if we are able to view a strategic battlefield this way and prevent an enemy from doing so, we have dominant battlefield awareness, and we are certain to prevail in a conflict. ${ }^{507}$

Although separated by thirty years, Owens has not departed in any way from the vision of Westmoreland's 1969 speech on the automated battlefield who at the time had foreseen its arrival in "no more than 10 years." ${ }^{\text {508 }}$ In the post-Cold War environment in which military budgets were cut as part of the 'peace dividend', the promises of the RMA were particularly appealing as they became a way of doing more with less and substituting manpower for technology. Owens again:

\begin{abstract}
We have too much functional redundancy across our military services and agencies, particularly in support and force enhancers like intelligence, medical, logistics, and communications, and perhaps in combat areas such as air defense and long range strike. In the past, redundancy was compelling because the 'fog of war' demanded it to compensate for the unexpected. Today, as a nation's information edge becomes more prominent, the extent to which we need the same level of redundancy is questionable..$^{509}$
\end{abstract}

This view of warfare is in complete contradiction with the teachings of chaos and complexity theory. Warfare cannot be completely predicted or controlled, knowledge is imperfect, and redundancy allows for great adaptability and resilience in the face of contingency. It would therefore appear that the RMA is a mere extension of the principles of cybernetic warfare and allied with a scientific worldview that has not taken on board the most significant recent developments in the field, despite a non-negligible military literature that has attempted to draw valuable lessons from them (as seen above).

However, the most recent, and now dominant, strand of the RMA literature has drawn in particular from complexity theory and sought to combine past claims from RMA prophets with an organisational doctrine inspired by the language and concepts of the non-linear sciences. According to its most vocal advocate and subsequent founding director of the Office of Force Transformation, Vice Admiral Arthur Cebrowski, "network-centric warfare looks at war as a complex, adaptive system where nonlinear

\footnotetext{
${ }^{507}$ Statement of Admiral William A. Owens, USN (Ret) To The US Senate, February 12, 2001 http://budget.Senate.gov/democraric/testimony/2001/owens defhrngr021201.pdf 508 William Westmoreland, Address to the Association of the U.S. Army, October 14, 1969 http://216.239.59.104/search? q=cache:Kw2tmkrW5lgJ:www.stanford.edu/group/mmdd/SiliconValley/ Westmoreland/westmoreland.rtf

${ }^{509}$ Statement of Admiral William A. Owens, USN (Ret) To The US Senate, February 12, 2001
} 
variables continuously interact. ${ }^{3510}$ Through the establishment of information networks, it is claimed that military organisation can be radically decentralised, allowing for processes of self-organisation and emergence. Although still in its infancy, the doctrine's ultimate ambition is nothing less than a "new theory of war." 511

The rest of the section will seek to critically assess the claims of network-centric warfare, identify the elements it draws from complexity theory, and attempt to establish the extent to which the doctrine truly constitutes a break with cybernetic warfare. It is my claim here that although network-centric warfare has indeed appropriated the language and ideas of complexity, it has done so selectively and still rests on many of the presumptions of earlier RMA theories. Furthermore, while decentralisation - or rather self-synchronisation - appears to have become the new watchword, many of the information systems that network-centric warfare advocates also allow for greater centralisation and micro-management.

The doctrine of network-centric warfare (NCW) first appeared on the scene in the late 1990s, rapidly rising to prominence to become the new official Pentagon gospel under the agenda of "Transformation." NCW now has its counterparts in most major Western militaries with Network Enabled Capabilities (NEC) in the U.K., NATO Network Enabled Capabilities (NNEC), and Network Enabled Operations (NEOps) in Canada. At first sight, network-centric warfare may appear to constitute a decisive break with established thinking, drawing explicitly from complexity theory and announcing a reversal of the dominant centralising approach. While in some respects, this is a legitimate claim, the following analysis will seek to demonstrate that its practical implications are for more ambiguous and that in many ways it displays significant continuity with previous RMA theories.

Originating in the U.S. Navy, the ideas of network-centric warfare started gaining wider attention with the evangelism of Arthur Cebrowski. In 1998, Cebrowski published with John Garstka an influential article entitled Network-Centric Warfare: Its Origin and Future in

510 Gray, Strategy for Chaos, p.105

511 "When you rack and stack all of that what we are really talking about is a new theory of war because we are talking about new sources of power."

Navy Vice Adm. Arthur Cebrowski, Speech to Network-Centric Warfare Conference, January 22, 2003

http://www.oft.osd.mil/library/library files/speech 143 CEBROWSKI\%20SPEECH $\% 20$ TO\%20NET WORK\%20CENTRIC\%20WARFARE\%20CONFERENCE.dOC 
which he announced a decisive shift in the theory and practice of warfare. In order to bolster his claims for this RMA, Cebrowski pointed to changes in the economy and business management, a very Tofflerian move and in line with an understanding of warfare as an activity that can be reduced to production. In the midst of the Internet boom of the late nineties, the Vice Admiral waxed lyrical about a new economy that had turned the laws of supply and demand "on their heads" and was "characterised by extraordinary growth and wealth generation." 512 For Cebrowski, the source of this revolution was clear and available to all in the military which were willing to listen:

\begin{abstract}
Central to these developments is the shift to network-centric operations, which are characterized by information-intensive interactions between computational nodes on the network. Whether these interactions are focused on commerce, education, or military operations, there is 'value' that is derived from the content, quality, and timeliness of information moving between nodes on the network. This value increases as information moves toward $100 \%$ relevant content, $100 \%$ accuracy, and zero time delay - toward information superiority. [emphasis added] ${ }^{513}$
\end{abstract}

'Information superiority - which sounds a lot like Owen's dominant battlefield awareness - is the key concept to NCW since this is the element from which increased combat power is believed to originate. Thus NCW defines itself as "an information superiority-enabled concept of operations that generates increased combat power by networking sensors, decision makers, and shooters to achieve shared awareness, increased speed of command, higher tempo of operations, greater lethality, increased survivability, and a degree of self-synchronization.",514

While NCW authors differ in the extent to which they believe the fog of war can be irrevocably lifted, they all share a common understanding of uncertainty as generated by a lack of information. The response is therefore consistently the same: deploy technology to acquire, process and distribute more information and ensure certain victory through information superiority. While improving the reliability of information can certainly be beneficial, the non-linear sciences point to the profound limitations of such an approach and there are three fundamental criticisms that can be levelled at the conception of information in NCW literature.

\footnotetext{
512 Arthur K. Cebrowski \& John J. Garstka, "Network-Centric Warfare: Its Origin and Future", Proceedings, U.S. Naval Institute, January 1998 http://www.usni.org/Proceedings/Articles98/PROcebrowski.htm 513 Cebrowski \& Garstka, "Network-Centric Warfare"

514 David S. Alberts, John J. Garstka \& Frederick P. Stein, Network-Centric Warfare: Developing and Leveraging Information Superiority, $2^{\text {nd }}$ ed. (Department of Defense CCRP, 2000), p.2 http://rww dodccrp.org/publications/pdf/Alberts NCW.pdf
} 
Firstly, as chaos theory has demonstrated, the sensitivity to initial conditions of nonlinear systems implies that no matter how precise our information about a system's operation and its state at any given instant, our long term predictability is severely limited, if not completely inexistent. Such a conclusion applies to a perfectly transparent set of non-linear functions run through a computer, let alone to a real-world phenomenon like war in which the system's borders are uncertain, variables are undoubtedly far more numerous, and successfully identifying and measuring them is nigh impossible. On its own this might not necessarily be a fatal criticism since shortterm predictability may still be possible and an approximate long term predictability may also be achievable if system attractors are identified.

Secondly, if we take Boyd's OODA loop' seriously, we must accept that any fixed model of reality is destined to experience entropic decay - information cannot merely traverse the system, it must also be the basis on which the latter can be reshaped and reorganised. However, in appropriating the OODA loop', NCW has merely reduced it to a greatly simplified decision cycle which acts more like a cybernetic negative feedback loop than a complex adaptive system - more on this later.

Finally, NCW proponents seem to discount completely one of Clausewitz's most famous pronouncements - "a great part of the information obtained in war is contradictory, a still greater part is false, and by far the greatest part is of doubtful character" ${ }^{515}$ - or at least presume that it only applies to times bygone and is now rendered irrelevant by advances in ICTs. Indeed, NCW puts complete faith in sensor technology and the ability of computer systems to synthesise their input into a coherent and unambiguous shared operational picture of the battlespace on the basis of which military units will be able to develop new levels of collaboration and coordination. Such a view rests on several crucial assumptions such as the infallibility of sensors and computer systems, discounting the ability of adversaries to fool sensors and create a misleading picture, and presuming that common data will necessarily be interpreted in the same manner by all units. Furthermore, NCW seems to assume that greater quantities of sensor information will result in a higher quality of information - an assumption which again rests on the belief that ambiguity and uncertainty only results from a lack of information, not from confusion produced by potentially conflicting

515 Clausewitz, On War 
pieces of information or failures in their interpretation. As Milan Vego points out in referring back to Clausewitz, "uncertainty is not the result of gaps in information but largely is caused by lack of comprehension or false interpretation of the information acquired." ${ }^{\text {516 }}$ By ignoring all these insights, the U.S. military runs the risk of designing an organisation which relies on reliable high-quality information rather than granting it the ability to adapt to uncertain conditions where information may be scarce, incomplete, or untrustworthy.

Therefore the most likely road to success does not lie in attempting the attain the illusory goal of " $100 \%$ relevant content, $100 \%$ accuracy, and zero time delay" which would allow the perfect operation of a frictionless cybernetic war machine, but in embracing uncertainty and designing a resilient and flexible military that is capable of adapting to the unforeseen and contingent. Conversely, an advantage over the adversary can be acquired not merely through targeting his information systems or accelerating the tempo of operations but by varying the tactics and offensive moves deployed against him. This would constitute a far more faithful application of chaos and complexity theory than most of the principles of NCW, despite their regular references to the aforementioned sciences.

However, it is important to note that NCW does seem to break with previous conceptions of the RMA in its goal of self-synchronisation and draws here its inspiration and terminology directly from complexity theory. Self-synchronisation implies a radical decentralisation of the command structure by increasing the freedom of low-level forces to operate nearly autonomously and coordinate themselves on the basis of shared awareness, common doctrine and rules of engagement, and the commander's general intent (i.e. the overall objectives of the mission) - a set-up reminiscent, at least on paper, of the German Auftragstaktik. The underlying principle is that forces will selforganise and emergent properties denied to top-down command will emerge. For Cebrowski and others, complexity theory is the key to unlocking increased combat power:

Military operations are enormously complex, and complexity theory tells us that such enterprises organize best from the bottom-up. Traditionally, however, military commanders work to obtain top-down command-directed synchronization to achieve the required level

516 Milan Vego, "Net-Centric Is Not Decisive", Proceedings, U.S. Naval Institute, January 2003 http://www.usni.org/proceedings/articles $03 /$ provego01.htm 
of mass and fires at the point of contact with the enemy. Because each element of the force has a unique operating rhythm, and because errors in force movement needlessly consume combat power, combat at the operational level is reduced to a step function, which takes time and provides opportunity to the enemy. After the initial engagement, there is an operational pause, and the cycle repeats. In contrast, bottom-up organization yields selfsynchronization, where the step function becomes a smooth curve, and combat moves to a high-speed continuum. The "Observe-Orient-Decide-Act (OODA) Loop" appears to disappear, and the enemy is denied the operational pause. ${ }^{517}$

Self-synchronised forces can therefore 'mass effects', increasing the combat tempo and raining blows on an adversary that is denied the time to respond and go through his own decision cycle, thus leading to his collapse (the phenomenon of 'shock and awe').

For the proponents of NCW, this new emerging form of warfare marks a momentous shift from 'platform-centric' organisations which privilege independent platforms (weapon systems) with their own sensors and weapons to 'network-centric' organizations that link together sensors, decision makers, and shooters into a single network. The network therefore constitutes the warfighting system in NCW with all nodes (platforms) on it ultimately substitutable. The principle is to create a form of distributed intelligence by sharing total information among all participants. According to the theory, this pooling of information creates a state of shared awareness among all actors which leads to self-synchronisation an emergent behaviour (see Figure 18).

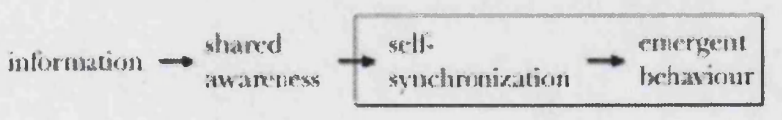

Figure 18: From information to emergence ${ }^{518}$

For NCW theorists, the communications network and the information superiority it provides constitute the substrate from which bottom-up self-organisation can emerge. "NCW works because it has identified, in general terms, the initial conditions that need to exist in order to achieve effective self-synchronization." 519

While self-synchronisation sounds a lot like self-organisation and that NCW advocates frequently speak of it as if it was a straightforward lesson from complexity theory, the

${ }^{517}$ Cebrowski \& Garstka, "Network-Centric Warfare"

518 Moffat, Complexity and Network-Centric Warfare, p.50

519 Alberts \& Hayes, Power to the Edge, pp.208-209 
practices it covers are in fact much more ambiguous and decentralisation does not necessarily flow from it. Self-synchronisation is presented as the coordination of units through the creation and distribution of a common operational picture by networking sensors, shooters, and decision-makers. This theoretically overcomes the limitations of platform-centric warfare in which information is 'stove-piped' in each individual platform and can only be communicated in a highly inefficient manner (traditionally using voice communication). However, this does not automatically mean greater autonomy and initiative for subordinate units since it in fact also allows for a tightening of the degree of control of the C\&C hierarchy over them. Indeed, some have argued that "the seductiveness of information technology stimulates military organisational orientation towards greater centralised control and more rigid hierarchical organisations instead of the desired orientation of decentralised control and more flexible organisations." 520

NCW talks of decoupling sensors, actors, and decision-makers for the benefit of connecting them all to a common infostructure. However this also paves the way for an even greater differentiation between those units that command and those that merely carry out the orders. As Kolanda argues, a quite opposite argument to selfsynchronisation can be made on the basis of the same technological arrangements: "the core assumptions of this argument are that shared information leads to shared understanding, that decisions are made most effectively at higher echelons of organization, that organisations consist of 'decision entities' controlling 'actor entities' and that networks permit fewer of the former to control more of the latter." ${ }^{.521}$ As some of the most prominent theorists of NCW recognise themselves, "in general, greater capability to acquire, integrate, move, and process larger amounts of information rapidly makes more centralised decisionmaking possible." ${ }^{3522}$ Thus, when NCW advocates speak of "flattening hierarchies" in order to increase the "span of control", 523 this may entail removing layers of middle management that came with industrial age bureaucracies (here the inspiration is again similar changes in business organisations) but does not necessarily lead to an emancipation of lower-level forces from hierarchical control.

${ }^{520}$ Gregory A. Roman, "The Command or Control Dilemma", p.3

${ }^{521}$ Christopher D. Kolenda, "Transforming How We Fight - A Conceptual Approach", Naval War

College Review, Spring 2003, Vol. LVI, No. 2

http://www.nwc.navy.mil/press/Review/2003/Spring/art6-sp3.htm

522 David S. Alberts, John J. Garstka, Richard E. Hayes \& David A. Signorip, Understanding Information Age

Warfare (CCRP Publications, 2001), p.177 http://www.dodccrp.org/publications/pdf/Alberts ULAW.pdf

${ }^{523}$ Alberts, Garstka \& Stein, Network-Centric Warfare, p.81 
For one, the full operational picture constituted through the infostructure is not available to all levels of the hierarchy but only to the senior levels of command \& control which can subsequently decide what picture is made available to different units. While "shared awareness" is referred to as "a type of collective consciousness", 524 in practice it implies total omniscience at the top which can then choose which parts of the picture are made available to subordinates. NCW theorists concede that "current discussion of the need for new C2 approaches in an era of Information Age Warfare explicitly considers situations where the best (most current, accurate, and complete) information may no longer be located at the subordinate command engaged in the field, but rather may be located at senior headquarters." ${ }^{2525}$ This is in marked contrast with previous cases of decentralised military organisation as employed by the German army in World War II with Blitzkrieg - the assumption was that subordinate units possessed more accurate local knowledge than headquarters and would therefore be better able to adapt to changing circumstances and demonstrate appropriate creativity and initiative.

Thomas Barnett expresses some serious reservations about the idea of the 'common operating picture', the shared awareness which is supposed to be the catalyser for bottom-up self-synchronisation:

\begin{abstract}
The common operating picture cannot really be shared in the sense that ownership will remain a top-down affair [...] NCW promises to flatten hierarchies, but the grave nature of military operations may push too many commanders into becoming control freaks, fed by an almost unlimited data flow [...] The infusion of information technology into hierarchical organisations typically reduces the traditional asymmetries of information that define superior-subordinate relationships. Taken in this light, the common operating picture is an attempt by military leaders to retain the high ground of command prerogative - a sort of non-stop internal spin control by commanders on what is necessarily a constantly breaking story among all participants, given their access to information that previously remained under the near-exclusive purview of superior officers. That gets me to the question of the common operating picture's 'realness', for it suggests that the picture will be less a raw representation of operational reality than a command-manipulated virtual reality. ${ }^{526}$
\end{abstract}

Units whose operational picture consists merely of a simplified version of that available to their superiors are effectively deprived of any ground upon which to make recommendations and exert influence on their commanding officers, particularly when local and situated knowledge not represented in the networked infosphere is devalued.

\footnotetext{
${ }^{524}$ Alberts, Garstka \& Stein, Network-Centric Warfare, p.135

525 Alberts, Garstka, Hayes \& Signorip, Understanding Information Age Warfare, p.178

526 Thomas P.M. Barnett, "The Seven Deadly Sins of Network-Centric Warfare", Proceedings, U.S. Naval

Institute, January 1999, pp.36-39 http://www thomaspmbarnett.com/published/7d.htm
} 
In other words, it negates the possibility of realising command and control as theorised by the Marine Corps:

Command and control is not so much a matter of one part of the organisation 'getting control over' another as something that connects all the elements together in a cooperative effort. All parts of the organisation contribute action and feedback - 'command' and 'control' - in overall cooperation. Command and control is thus fundamentally an activity of reciprocal influence. 527

The use of the Predator aircraft drone in Afghanistan is a case in point. Beaming images from the battlefield straight to U.S. Central Command headquarters in Tampa and at the Pentagon, the sensor provided soldiers on the ground "little useful information and were sometimes a distraction, encouraging higher-level military staffs to try to micromanage the fighting." 528 As Vego argues, "having a common operating picture will lead operational commanders to be increasingly involved in purely tactical decisions, instead of focusing on the operational and strategic aspects of the situation within their respective areas of responsibility. ${ }^{.529}$

Bar-Yam recognises that there are two fundamentally distinct approaches to networked operations:

\begin{abstract}
The first involves networked action agents capable of individual action but coordinated for effective collective function through self-organized patterns. Analogous behaviors can be identified in swarming insects and the immune system. The second involves networked decision makers receiving information from a set of sensors and controlling coherent large scale effectors. Analogous organizational structures can be identified in the physiological neuro-muscular system. Each of these important models of networks deserves consideration for the development of networked military forces. The two paradigms are also not restrictive in the sense that there are many intermediate cases that can be considered. 530
\end{abstract}

We see here two conceptions of warfare each with its respective scientific corpus and biological metaphors. While the former is a decentralised, self-organised network of autonomous units, the latter is a centralised army in which the network serves only to strengthen the distinction between decision-makers and those that carry the actions out (the effectors). In the second case, there is no sense in which a true network has replaced a hierarchical structure.

${ }^{527}$ MCDP 6: Command and Control, United States Marine Corps, pp.46-47

528 Thomas E. Ricks, "Beaming the Battlefield Home: Live Video of Afghan Fighting Had Questionable Effect", Washington Post, 26 March 2002

529 Vego, "Net-Centric Is Not Decisive"

${ }^{530}$ Bar-Yam, "Complexity of Military Conflict", p.23-4 
Arquilla and Ronfeld also recognise that networking does not simply entail decentralisation of command and control but also greater 'topsight' for the hierarchy:

\begin{abstract}
Moving to networked structures may require some decentralisation of command and control, which may well be resisted in light of earlier views that the new technology would provide greater central control of military operations. But decentralisation is only part of the picture; the new technology may also provide greater 'topsight' - a central understanding of the big picture that enhances the management of complexity. Many treatments of organisational redesign laud decentralisation; yet decentralisation alone is not the key issue. The pairing of decentralisation with topsight brings the real gains..$^{531}$
\end{abstract}

Both Bar-Yam and Arquilla and Ronfeldt posit two poles to military organisation of hierarchies and networks within which the U.S. military can fluctuate according to its needs and opportunities. Official NCW literature goes in the same direction: "NCW gives us the opportunity to explore the vast middle ground between the Industrial Age top-down hierarchical command and control approach and the highly decentralised model of small units assigned pieces of the problem with only their organic capabilities." ${ }^{\text {532 }}$

For Bar-Yam, the merits of networks over hierarchies are to be found in the superiority of the formers' distributed information processing; while hierarchical structures can be effective at ordering large scale operations, they are far less efficient in conditions of high complexity:

\footnotetext{
Hierarchical command systems are designed for the largest scale impacts and thus relatively simple warfare. Indeed, traditional military forces and related command control and planning, were designed for conventional large scale conflicts. Distributed control systems, when properly designed, can enhance the ability to meet complex challenges. ${ }^{533}$
}

The real benefits of the network are to be found in its capacity for distributed computing and overcoming the limitations of hierarchical command in complex environments (Bar-Yam contrasts the simplicity of maritime combat to littoral warfare, and the simple environments of the desert and the plain to the complexity of the jungle, mountains, and urban areas):

\begin{abstract}
The key to this understanding is that each individual has a limited complexity. In particular, an individual is limited in ability to process information and to communicate with others (bandwidth). In an idealised hierarchy, only the single leader of the organisation can coordinate the largest organisational units whose commanders are directly under his/her command. The coordination between these units cannot be of greater complexity than the
\end{abstract}

\footnotetext{
531 Arquilla \& Ronfeldt, “Cyberwar is Coming!" in Arquilla \& Ronfeldt (eds.), In Athena's Camp, pp.30-31

532 Alberts, Garstka \& Stein, Network-Centric Warfare, p.162

${ }^{533}$ Bar-Yam, "Complexity of Military Conflict", p.1
} 
leader. More generally, we can state that to the extent that any single human being is responsible for coordinating parts of an organisation, the coordinated behaviours of the organisation will be limited to the complexity of a single individual. Since coordinated behaviours are relatively large scale behaviours, this implies that there is a limit to the complexity of larger scale behaviours of the organization. Thus, using a command hierarchy is effective at amplifying the scale of behaviour, but not its complexity. By contrast, a network structure (like the human brain) can have a complexity greater than that of an individual element (neuron). ${ }^{534}$

While the logic of this argument is sound and that different organisational arrangements may indeed suit different types of war environments and situations, much will depend on the ability of the U.S. military hierarchy to show appropriate judgement and resist the temptations of centralisation and micro-management when it is counter-productive. The historical record in this respect should not inspire much confidence.

It is also necessary to point out that to present claims that shared awareness leads to bottom-up self-organisation as a straightforward application of the principles of complexity is to fundamentally misinterpret the scientific theory. As we saw in our discussion on swarming, complexity in natural or simulated systems does not emerge from a global shared situational awareness that would be available to all or any of the components of a system. This assumes a centralisation of information that precedes any decentralized action by the parts of the system Rather, it is on the basis of localised information, calculation and action that highly complex behaviour can emerge without any single entity possessing an overall knowledge of the system and environment. No single ant has a complete knowledge of the state of its colony or environment at any given moment - it acts on the basis of only partial knowledge of its immediate vicinity as provided by its senses and of information that has been passed to it by neighbouring ants or pheromone deposits - even if the colony as a whole appears to behave as if it did. This is how complex systems can develop emergent behaviour on the basis of localised action. Or as the Marine Corps command and control doctrine puts it in discussing military organisation, "a complex system is any system composed of multiple parts, each of which must act individually according to its own circumstances and which, by so acting, changes the circumstances affecting all the other parts." ${ }^{.535}$

This is not to discount the benefits of shared informational awareness but to signal crucial divergences with the complexity sciences which $\mathrm{NCW}$ claims its authority from.

534 Bar-Yam, "Complexity of Military Conflict", p.8

${ }^{535}$ MCDP 6 Command and Control, United States Marine Corps, 1996, p.41 
Rather than constituting a decentralised organisation which can operate on the basis of limited and dispersed information, as in the case of al-Qaeda, the US military is developing armed forces which are dependent on large volumes of accurate information to take their decisions and act in unison.

This information is to be acquired, processed and distributed through an overarching "system of systems" that has been an ambition of the U.S. military since General Westmoreland. For NCW advocates, this is the "entry fee" to the brave new military world they promise and that has prompted the Pentagon to earmark $\$ 200$ billion or more in expenditure for the acquisition of network hardware and software over the next decade. ${ }^{536}$ However, the very systems the whole edifice of NCW is built on may in fact never perform as their proponents and manufacturers claim.

For critics like Chuck Spinney, the RMA and NCW are only further iterations of the concepts that underlay Robert McNamara's failed Igloo White project, the cybernetic system designed to create an impassable electronic line in Vietnam. ${ }^{537}$ In every iteration the resulting "system of systems" relies on four components:

(1) observation systems to identify enemy forces and targets;

(2) orientation processes that filter observations through computerised target recognition templates based on the predicted 'signatures' we expect our adversary to exhibit on the battlefield;

(3) centralised command and control systems to orchestrate the mix of attack options on the selected set of enemy signatures (the array targets);

(4) a mix of hi-tech precision-guided weapons to execute the desired attack options. ${ }^{538}$

Spinney finds three crucial assumptions underpinning such a project. The first is the ability to predict the signature pattern of the adversary. The second is the assumption that surveillance and reconnaissance systems will be able to distinguish enemy forces from background noise constituted by friendly forces, non-combatants, and the environment. Finally, and perhaps most importantly, the OODA loop' which proponents of these systems refer to is:

based on a simplistic cybernetic model that assumes the conduct of war can be methodically monitored and minutely regulated by a system of sensors and negative feedback control signals, much like the temperature of a room is monitored and regulated by the predicted target temperature (or template) and negative feedback signals of a thermostat. One consequence of these assumptions is that the exclusive reliance on a

\footnotetext{
536 Weiner, “A 'God's-Eye View' of the Battlefield”

537 See chapter 6

538 Spinney, "Asleep at the Switch in Versailles"
} 
negative feedback control architecture eliminates the possibility of adapting to unforeseen circumstances. This limitation can turn Boyd's conception of a dialectical non-linear OODA loop' based on the idea of co-evolution into a one way non-adaptive road to confusion and disorder if the enemy chooses to act unpredictably. ${ }^{539}$

Indeed, while advocates of NCW refer to Boyd and the OODA Toop', their main concern seems to be to defeat the enemy through an acceleration of the decision cycle, as opposed to the ability to act unpredictably and creatively adapt in response to contingencies. Boyd did talk of cycling through the OODA 'loop' quicker but in the sense of adapting to the battle situation faster, not merely by executing the same commands at a faster pace. By emphasising speed above everything else, NCW seeks merely to act faster by cutting down the time dedicated to all the phases in the decision cycle, including analysis and synthesis. General Myers's pronouncement is symptomatic: "improved joint C4ISR will allow U.S. forces to exploit a decision cycle - to observe, decide, and act - faster than an adversary. History is pretty clear: The side that does this faster wins." ${ }^{540}$ The omission of the orientation phase from the decision cycle in Myers's statement is revealing of the impoverished understanding of the OODA 'loop' that is prevalent among NCW evangelists. Rather than utilising gains in the speed of information processing and distribution to increase the time available for orientation and thereby the ability to adapt to changing circumstances and surprise adversaries, NCW persists with a rigid cybernetic understanding of warfare that risks rendering U.S. military operations utterly predictable to a competent opponent.

Spinney points to the ease with which the Serbs were able to fool NATO sensors with relatively low-tech countermeasures (decoys, camouflage, fleeting emissions) during the Kosovo War. When the smoke from the campaign had cleared, the ineffectiveness of the 78 day aerial bombardment became obvious, along with the extent to which NATO had been operating under a completely false sense of success. Newsweek reported in 2000 that an Air Force investigation discovered on the ground the remains of only 14 tanks (out of 120 initially 'confirmed' strikes), 18 armoured personnel carriers (as opposed to 220), and 20 artillery pieces (out of the previously claimed 450 ). ${ }^{541}$ Despite such failures by electronic sensors and the systems designed to accumulate and process the information they receive, U.S. military gluttony for ever more information has

${ }^{539}$ Spinney, "Asleep at the Switch in Versailles"

${ }^{540}$ Richard B. Myers, "Understanding Transformation" Proceedings, U.S. Naval Institute, February 2003, pp. $39-40$

541 John Barry \& Evan Thomas, "The Kosovo Cover-Up”, Newsweek, May 15, 2000

http://www.medill.northwestern.edu/whca/2001poe2.html 
continued unabated. The new watchword is "persistent surveillance", "the ability to place intelligence assets on a target continuously or near continuously, ${ }^{, 542}$ with which a new raft of hardware and software procurement is being justified and still premised on the notion that greater volumes of information will deliver greater understanding and certainty.

Perhaps the hubristic quality of the faith in the omniscient powers of ICTs - if only enough information can be gathered - was never more flagrant than in DARPA's now defunct Information Awareness Office (IAO). Created in January 2002, the IAO's purpose was to combine several DARPA projects for the application of information technology to counter transnational threats to national security. According to the IAO:

\begin{abstract}
The key to fighting terrorism is information. Elements of the solution include gathering a much broader array of data than we do currently, discovering information from elements of the data, creating models of hypotheses, and analyzing these models in a collaborative environment to determine the most probable current or future scenario. ${ }^{543}$
\end{abstract}

The most important and controversial program was the Total Information Awareness (TIA) project - later renamed Terrorism Information Awareness in response to criticism by privacy groups - a systems-level program which would integrate the technology from all the other IAO programs to create a "counterterrorism information architecture." This architecture would then apply data-mining techniques imported from the business world to vast quantities of information pooled from personal records, financial and commercial transactions, media content, private conversations, and existing intelligence in order to uncover suspicious correlations and patterns and thus pre-empt future terrorist attacks. The program would effectively create a virtual database of "an unprecedented scale," "a new kind of extremely large, omni-media, virtually-centralized and semantically rich information repository. ${ }^{25+4}$ Related projects of IAO included automated text and speech translation and summarisation, facial recognition, identification and classification of human activities in surveillance environments (including crowds) using video and a range of sensors, automatic

\footnotetext{
${ }^{542}$ Tamara E. McFarren, "Persistent Surveillance", Military Geospatial Technology, Volume 2, Issue 3, September 28, 2004 http:/ www.military-geospatial-technology.com/article.cfm?DocID=6.31 $5+3$ Information Awareness Office, DARPA http://web.archive.org/web/20021017111910/http://waw.datpa.mil/iao/ $5+4$ "BAA 02-08 - Information Awareness Proposer Information Pamphlet" (Information Awareness Office) http://infowar.net/tia/www.darpa mil/iao/BAA02-08.pdf
} 
extraction of intelligence from broadcasts, newswires and conversations, and assisted decision-making and predictive software.

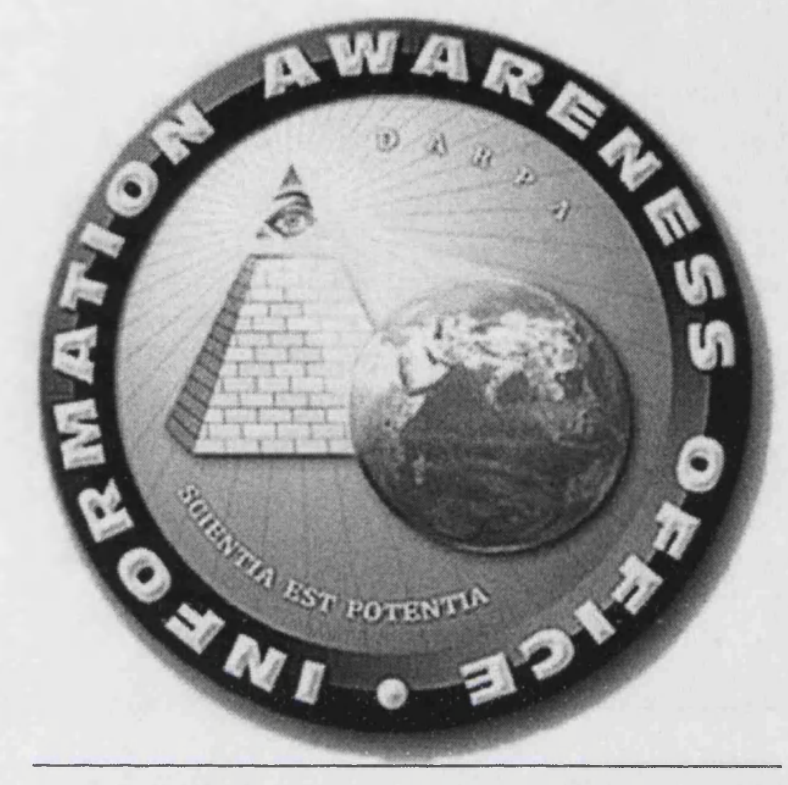

Figure 19: The Information Awareness Office logo $0^{545}$

The original name of the project pointed to its ambition as an all-encompassing program of data processing and analysis through which an omniscient ability to 'join the dots' and filter valuable information from noise would be granted. The office's chosen logo was revealing in itself, showing an all-seeing eye scanning the globe and bearing the Latin motto scientia est potentia - 'knowledge is power' (Figure 19). However, serious scepticism was expressed about the faith put in the system's ability to foil terrorist attacks by identifying the 'information signature' of plotters and critics pointed to the high risk of false positives. According to the CEO of a data-mining software company that worked with DARPA on TIA-related technologies in the late 1990s, when it comes to terrorism, "there is no pattern." ${ }^{346}$ Although the IAO was eventually defunded by Congress in September 2003 after mounting criticisms that it threatened domestic civil liberties, it has been claimed that many elements of its projects continue under different guises in different agencies (and with no supervision by Congress).

\footnotetext{
545 http://web.archive org/weh/20021017111910/http://www darpa mil/iao/

${ }^{5+6}$ Shane Harris, "Total Information Awareness Official responds to Criticism", GoExec.com, January 31, $2003 \mathrm{http://www} \mathrm{govexec.com/dailyfed/0103/013103h1.htm}$
} 
The IAO was symptomatic of the military's approach to information and its drive for centralising ever greater quantities of data to be processed and filtered by ICTs. According to network-centric warfare, these huge volumes of information and the resulting superior battlefield knowledge are supposed to be the basis on which forcemultiplying decentralisation and self-synchronisation can be achieved. However, such a scheme jars with all the historical evidence on the successful practices pertaining to the organisation of armies.

\section{Conclusion}

In his seminal text Command in War, van Creveld provides a masterly overview of command systems across the ages with particular attention to the manner in which they tackle the problem of uncertainty. Van Creveld concludes that when faced with a task for which insufficient information is available for its completion, a military organisation must choose from one of two approaches: "one is to increase its information-processing capacity, the other to design the organisation, and indeed the task itself, in such a way as to enable it to operate on the basis of less information.. ${ }^{547}$ The first approach results in a multiplication of communication channels (not necessarily vertically but also eventually horizontally) and results in an increase in the size and complexity of the "central directing organ." The second approach offers two further alternatives: either to radically simplify the organisation by planning everything ahead and drilling troops into a sequential number of moves to be repeated on the battlefield (such as was practiced by Frederick the Great) or to establish a force composed of semi-autonomous units that can deal with parts of the task separately. Van Creveld claims that the latter approach has proven itself consistently superior to the other two throughout history. The peculiarity of NCW is that it appears to seek to chart a fourth approach by, on one hand increasing the information-processing capacity and multiplying the number of communication channels, and on the other calling for a decentralisation of military organisation.

547 Van Creveld, Command in War, p.269 
The central purpose of decentralisation is to distribute uncertainty throughout the organisation yet NCW remains attached to the notion that a technologically-driven centralisation and fusion of information can overcome uncertainty and impose order on chaos. We are far from van Creveld's exhortation to recognise that "a certain amount of confusion and waste are, owing to the great uncertainty involved, inevitable in war; and that such confusion is not inconsistent with, and may indeed be a prerequisite for, results." ${ }^{548}$ In designing a military that relies on historically unprecedented volumes of information, NCW makes the ICT infrastructure it depends on into a critical vulnerability and negates precisely the key advantage of decentralised organisations, namely their ability to operate in conditions where only limited and uncertain information is available. NCW advocates may retort that their doctrine being nothing less than a 'new theory of war', we should not be surprised to see it break established moulds and that NCW will in fact achieve the synthesis of seemingly contradictory approaches. Only time will tell if this is indeed the case but for now it seems that, while appropriating some of the notions of complexity, NCW will not break decisively with the principles of cybernetic warfare. Nonetheless, the growing influence of chaos theory and complexity science on military theory and practice is clearly visible today and the current contradictions of network-centric warfare are perhaps only the birth pangs of a future truly chaoplexic regime in the scientific way of warfare.

${ }^{548}$ Van Creveld, Command in War, pp. 270-271 


\section{Chapter 9: Conclusions}

While the history of warfare in the Western world has been shaped by a variety of sociocultural factors, I have chosen in this thesis to focus on the role of science and technology. What such an enquiry reveals is the formation of a scientific approach to warfare in which prevalent technologies and scientific ideas and practices combine to resonate with other social and cultural developments underpinning the profound transformations of warfare in the modern era. The influence of this scientific way of warfare is neither consistent nor the object of a linear rise to prominence, but one can nevertheless chart an overall ascendancy of this discourse alongside the increasing industrialisation and technological dependency of Western warfare throughout the studied period.

However we cannot satisfy ourselves with a monolithic treatment of this discourse since, if the appeals to scientific method and prestige do endure, the ideas and principles embodied by the scientific way of warfare have been subject to considerable variation, both as a result of changes internal to science and to broader socio-cultural (including military) transformations. This has led me to establish a speculative periodisation according to the dominant scientific ideas in different eras since the onset of the Scientific Revolution and of the historical epoch generally known as modernity. While the different scientific and military regimes I have thus described and analysed cannot be circumscribed by clearly delineated dates marking their beginning and end, it is nonetheless possible to point to historical intervals in which the ideas and practices characterised by a particular regime are seen to be dominant.

\section{A Genealogy of Control}

The mechanistic era can be broadly situated within the seventeenth and eighteenth centuries, present at the very foundation of modern scientific method. Organised 
around the clockwork metaphor, it vehicled a conception of the world as perfectly ordered and intricately linked together in a divine mechanism set in motion by the Creator. This worldview found its echo in the absolutist monarchical regimes which emerged in Europe at this time. Mechanistic warfare itself peaked in the second half of the eighteenth century, with Frederick the Great's army as its paradigmatic embodiment. Geometry and the newly discovered laws of motion had been already widely applied to improve fortifications and ballistics, but the Prussians did the most to turn the army itself into a giant clockwork mechanism. Via a process of intense drilling which disciplined the bodies and minds of soldiers, Frederick could not only ensure unprecedented speed and reliability in the execution of repeated firearm volleys but could also experiment with complex tactical deployments on the field. However, tactics had to be almost entirely decided on before engagement since all initiative had been removed from individual soldiers and contemporary communication technologies did not allow the commander much input once battle had begun. Only by meticulously planning ahead the course of the battle and dictating the series of manoeuvres to be carried out could the mechanistic commander chart a path to victory.

The industrialisation and motorisation of society marked the advent of the thermodynamic age, a period of great political and social upheaval. Science turned to the study of energy, articulating a new understanding of the world and of the irreversibility of certain transformational processes within it. With the formulation of entropy in particular, came a probabilistic approach to scientific problems, undermining the tidy linearity and precise predictability of mechanistic models. Thermodynamic warfare saw the channelling of ever greater flows of energy into war, whether of a ballistic, motorised, industrial or moral nature, as nation-states clashed in ever-wider conflicts which drew on all the resources at their disposal. Beginning with the feverish élan of the French Revolution and Napoleonic wars of conquest, it culminated in the ultimate paroxysm of the Second World War and the detonation of the atom bomb. Although it was not consistently applied, a number of armies in this era experimented with tactical decentralisation to manage the uncertainty caused by the friction and fog of war which Clausewitz had theorised.

If the Second World War was the apotheosis of thermodynamic warfare, it also marked the threshold of a new regime of the scientific way of warfare. Cybernetics offered a 
science of control and communications organised around the concept of information and embodied in advances in electromagnetic telecommunication and calculation devices made during the war, most notably the computer. Information became conceptualised as the inverse of entropy and thus the source of all order. Vast command-and-control architectures were established in the context of a Cold War liable to escalate into a full-blown nuclear conflict, promising centralised control and stabilising self-regulation through negative information feedback. In the elusive quest for predictability, scientific methodology was applied more systematically than ever to warfare with the comprehensive treatment by operations research and systems analysis of military and strategic questions.

With the Vietnam War, cybernetic warfare experienced its first serious reversal, exposing the limitations of its conceptual framework and socio-technical arrangements, particularly when engaged in a low-intensity conflict. Simultaneously, scientists were developing their informational theories, outgrowing some of the limitations of early cybernetics. From a focus on stability and self-regulation, they turned their interest to processes of dynamic change such as those of decentralised self-organisation. Nonlinear mathematics uncovered ordered processes behind seemingly random phenomena, giving birth to chaos theory. The figure of the network allowed for the formalisation of the patterns of relations between autonomous agents which give rise to the emergence of complex entities. Contemporary to these developments are the diffusion of decentralised telecommunication networks such as the Internet and the forms of social organisation that have accompanied them. Postulating that we may be in the midst of the emergence of a new regime of chaoplexic warfare, this thesis has found a growing influence of the ideas of chaos theory and complexity science in military theory and practice. On the face of it, the new doctrine of network-centric warfare would appear to mark its coming of age in the United States military with its emphasis on networked organisation, swarming and self-synchronisation. However, this study has found that there are serious question marks over whether network-centric warfare truly constitutes the arrival of chaoplexic warfare or whether it is a mere repackaging of cybernetic warfare since many of the latter's centralising impulses appear alive and well in current practices. Nevertheless, it is clear that the scientific discourse of chaos and complexity is in the ascendancy and that both jihadist networks and the Iraqi insurgency are currently 
demonstrating the advantages of warfare based on decentralisation and selforganisation.

It is important to note that the rise of one regime of the scientific way of warfare has not necessarily signified the disappearance of all the ideas and practices of previous regimes. Some elements of past regimes remain relevant and even complementary under a new regime, albeit sometimes in a modified form. For example, the practice of intensive drilling of recruits which was so central to Frederick the Great's clockwork army has been pursued ever since to enhance discipline and reliability in the execution of orders, even if the robotic slavishness of the Prussian soldier has been generally abandoned in favour of a greater degree of autonomy and initiative of the individual in uniform. Similarly, if the drive for ever greater mobilisations and releases of energy is no longer the central focus of Western militaries, developments in the motorisation and destructive power of military force have not been cast away but rather integrated into the set of cybernetic technologies and principles which in the following era sought to bring more precise and targeted applications of this energy. And if we are to see a new era of warfare in which self-organising dynamics and decentralised tactics will be privileged, these will in all likelihood be complemented by self-regulating processes of stabilisation and a degree of top-down oversight.

One way of understanding these developments is as a process of evolution in the forms of control adopted for the purpose of handling the uncertainty inherent in the practice of warfare. I have sought in this thesis to relate the socio-technical assemblages embodying these forms of control to their contemporary scientific worldviews. If successive worldviews shift the focus of scientific analysis and formulate distinct ontological claims, thereby rejecting or limiting some of the methods and assertions of previous worldviews, acquired means of control do not thereupon vanish but instead remain part of the ensemble of control assemblages liable to be deployed in the social field.

Katherine Hayles echoes the story told here in her own account of James Beniger's The Control Revolution:

In broad outline, the forms of control moved from mechanical (a cam directing a mechanical tod to follow a certain path) to thermodynamic (a governor directing the action of a heat engine) to informational (including cybernetic mechanisms of all kinds, from 


\section{Chapter 9: Conclusions}

While the history of warfare in the Western world has been shaped by a variety of sociocultural factors, I have chosen in this thesis to focus on the role of science and technology. What such an enquiry reveals is the formation of a scientific approach to warfare in which prevalent technologies and scientific ideas and practices combine to resonate with other social and cultural developments underpinning the profound transformations of warfare in the modern era. The influence of this scientific way of warfare is neither consistent nor the object of a linear rise to prominence, but one can nevertheless chart an overall ascendancy of this discourse alongside the increasing industrialisation and technological dependency of Western warfare throughout the studied period.

However we cannot satisfy ourselves with a monolithic treatment of this discourse since, if the appeals to scientific method and prestige do endure, the ideas and principles embodied by the scientific way of warfare have been subject to considerable variation, both as a result of changes internal to science and to broader socio-cultural (including military) transformations. This has led me to establish a speculative periodisation according to the dominant scientific ideas in different eras since the onset of the Scientific Revolution and of the historical epoch generally known as modernity. While the different scientific and military regimes I have thus described and analysed cannot be circumscribed by clearly delineated dates marking their beginning and end, it is nonetheless possible to point to historical intervals in which the ideas and practices characterised by a particular regime are seen to be dominant.

\section{A Genealogy of Control}

The mechanistic era can be broadly situated within the seventeenth and eighteenth centuries, present at the very foundation of modern scientific method. Organised 
these technologies on the world has been their material imprint but this should not obscure their profound cultural impact, enmeshed as they are in the discourses contemporary to them, whether they be scientific, philosophical, or other. Hence the present work shares Edwards's ambition to write a history "neither of ideas alone nor of machines and their effects, but of ideas, experiences, and metaphors in their interaction with machines and material change.",551

\section{Some Final Thoughts}

While this study has primarily sought to chart the development and evolution of a scientific way of warfare throughout the modern era rather than to offer any prescriptions as to the most effective means of waging warfare, it is nonetheless possible to draw from this thesis a few conclusions about the respective merits of the different approaches that have been distinguished.

We have seen that underpinning each of the worldviews articulated under the scientific way of warfare is a distinct approach to control and to the problem of order and chaos. As was argued in the theoretical chapter and hopefully substantiated by the following chapters, the practice of warfare, and in particular its instrumental use by the state, requires the establishment of an intellectual and organisational framework which provides a degree of predictability and control over its outcome. Therefore in this sense, warfare can be seen as part of the quest for order, that is the search for regularity and reliability of behaviour which can be observed at work in other forms of social activity. However, war is a specific field of human endeavour in that the nature of combat, namely the fact of two opposing wills pitted against each other and both seeking to outwit and undermine each other, entails an irreducible uncertainty and unpredictability in its pursuit and hence the permanent threat of chaos erupting among even the most ordered of arrangements. Indeed, victory in war generally requires the imposition of chaos on the adversary.

Here, warfare is to be distinguished in at least one regard from both science itself and from processes of economic production which have also developed in accordance with

${ }^{551}$ Edwards, The Closed World, p.xv 
technoscientific evolutions. ${ }^{552}$ In contrast with warfare, both science and production are not pitted against a sentient foe consciously trying to disrupt their efforts to impose order. The chaos or resistance to order they seek to dispel is not the work of a trickster liable to change his ways from one moment to the next, rather it is a fixed and consistent obstacle to be overcome. Thus the scientist seeking to uncover nature's laws through the discovery of patterns of regularities takes these laws to be universal and unchanging, waiting to be discovered and not susceptible to sudden change. Likewise, production is the exertion of work on generally inanimate matter according to a general and abstract plan which divides and distributes labour. While manufacturing processes are almost always susceptible to further improvement and that occasional breakdowns will occur through mechanical or operator error, the actual matter being worked upon does not wilfully vary the nature of its resistance. ${ }^{553}$

Clausewitz was making very much the same point when he warned against those approaches to war that treated it as another science or art:

\begin{abstract}
War is no activity of the will, which exerts itself upon inanimate matter like the mechanical arts; or upon the living but still passive and yielding subject, like the human mind and the human feelings in the ideal arts, but against a living and reacting force. How little the categories or the arts and sciences are applicable to such an activity strikes us at once; and we can understand at the same time how that constant seeking and striving after laws like those which may be developed out of the dead material world could not but lead to constant errors. ${ }^{554}$
\end{abstract}

Clausewitz is insisting here on precisely the distinction I have drawn between science and production on one hand and warfare on the other in relation to the respective passivity and reactivity of their subject matter.

This is not to say that some aspects of the requirements of modern warfare cannot benefit from the application of a productivist framework, notably for the purpose of the

352 It is quite feasible to provide an account of the history of economic production according to a similar narrative of technoscientific change as is provided here for warfare. Clockwork and mechanism can be related to the principle of rationalised division of labour, the engine and thermodynamics to the motorisation and industrialisation of production, and the computer and cybernetics to automation and numerical control.

553 This observation no longer holds if we shift analysis from production per se to competition between different enterprises in the marketplace. Here we see sentient opposition of a similar nature to that found in war. This may account for the widespread use of military metaphors in the language of business and the current popularity of Sun Tzu in management and business strategy literature.

Mark R. McNeilly, Sun Tzu and the Art of Business: Six Strategic Principles for Managers (Oxford University Press Inc, 2000); Gerald A. Michaelson, Sun Tzu: The Art of War for Managers - 50 Strategic Rules (Adams Media Corporation, 2001)

554 Clausewitz, On War, p.103 
mobilisation of a war economy or in the realm of logistics (although a higher degree of redundancy will most likely need to be built into military logistics than in business). However, attempts to bring the entire spectrum of activity of war under such a framework can only be self-defeating. James Gibson's analysis of the specific failing of 'technowar' as "a production system that can be rationally managed" in Vietnam can thus be extended to a wider observation about the general unsuitability of this approach to warfare. ${ }^{555}$

For Daniel Pick, we find "two interlocking projects in the history of European culture and political thought: the one tracing the quest for a pure science of war; the other charting the dissolution of the belief that war can be reduced to laws or predictable patterns." ${ }^{556}$ While I generally agree with this account of two conflicting stances in Western thought towards the question of the possibility of making warfare into a fully predictable and ordered affair, I would not so firmly oppose scientific thought to a nonscientific outside opposed to the former's totalising drive. While science has indeed most often been recruited in the attempt to bring warfare under the complete control of its practitioners, this thesis suggests that within science itself are present currents of thought which posit intrinsic limits to predictability and ordering. In particular, we have seen how Clausewitz's ideas about friction can be related to ideas articulated in the sciences of thermodynamics, chaos theory and complexity.

The historical record does seem to substantiate the idea that attempts to render war fully predictable have been largely counter-productive and that "in armed conflict no success is possible - or even conceivable - which is not grounded in an ability to tolerate uncertainty, cope with it, and make use of it." ${ }^{~} 557$ The successful pursuit of warfare therefore requires a recognition of the inherent unpredictability that accompanies the use of military force and to build into military organisation a tolerance to uncertainty and even a capacity to profit from it.

There is great danger in adopting a misguided faith in the efficacy and predictability of military force. Such a belief tends to make war into a more attractive option among the instruments of policy because of its presumed decisiveness and unambiguity, thereby

555 Gibson, The Perfect War, p.156

556 Pick, War Macbine, p.1

557 Van Creveld, Technology and War, p.316 
resulting in the conceptual teduction of complex strategic problems requiring a multipronged approach into ones liable to be fully resolved through military intervention, and frequently leading to disastrous consequences when acted upon on this basis. Arguably, it was a misplaced confidence in the capabilities of the U.S. military (buoyed by the perceived early success in Afghanistan) and a grave underestimation of the difficulties that would arise in the phase following the toppling of the Baathist regime which have led to the current dire situation in Iraq. ${ }^{558}$

Related to the drive for order in military affairs is the age-old tension in the conduct of military affairs between centralisation and decentralisation of armed forces and in which the scientific approaches to warfare have fully played into. This tension has always presented an acute organisational dilemma for the military with the need to conciliate the tight control of a hierarchy over its subordinates and the operational need to provide autonomy and flexibility to its constituent units. Of course, instrumentalist military thinking is above all concerned with efficiency, namely the perceived successes and failures of respective approaches. As such, the security environment and challenges presented in any era play a crucial role in determining the direction these debates take. There is no doubt that centralised and hierarchical mechanisms were largely successful in the conduct of the large-scale conflicts that characterised the major wars of the twentieth century and in the management of the perpetual state of nuclear readiness of the Cold War. However, this approach has demonstrated severe limitations in the context of counter-insurgency operations or guerrilla warfare, the Vietnam War or second Iraq conflict potently illustrating the inadequacy of the American war machine when confronted with a decentralised and diffuse enemy operating in a complex environment. The redefinition of the security environment and the new tasks given the military following the end of the Cold War have provided a powerful impetus for new military thinking arguing for the benefits of decentralisation.

\footnotetext{
558 It is notable that Donald Rumsfeld's successor as Secretary of Defense has articulated a much more cautious view of the effects of the application of military force than his predecessor. When questioned by the Senate panel which approved his nomination about his views on possible military intervention against Iran, Robert Gates replied that "I think that we have seen in Irag that once war is unleashed, it becomes unpredictable. And I think that the consequences of a military conflict with Iran could be quite dramatic." David S. Cloud \& Mark Mazzetti, "Senate Panel Approves Defense Nominee", New York Times, December 5, 2006 http: / www.nytimes.com/2006/12/05/washington/06gatescnd.html?ex $=1322974800 \& \mathrm{en}=7 \mathrm{fce} 77 \mathrm{a} 91 \mathrm{bd}$ c.c4e0\&ei $=5088$ partnet $=r$ ssnyt\&emc $=r s s$
} 
While broad historical trends can be observed, we should resist the temptation of following an evolutionist line of thinking according to which centralisation would be irrevocably giving way to decentralisation. Centralisation and decentralisation are not so much antithetical as distinct poles within which organisational reality fluctuates. A pure state of decentralisation is impossible since hierarchies are always being formed (a state's armed forces are inconceivable without them) and likewise spheres of autonomy and self-organisation necessarily emerge within a hierarchical structure, particularly in the context of the chaos of the battlefield. Furthermore, even if network forms of organisation are being increasingly promoted, they are still institutionally contested and hierarchical command-and-control remains the dominant mindset in many branches of the military (and is likely to remain so for the foreseeable feature).

Since chaoplexic warfare has not itself fully arrived yet and that military theorists are still grappling with the full implications of the non-linear sciences, it is far too early to speculate on what regime of the scientific way of warfare may follow it. It does however seem probable that scientific discourse will continue to exert a powerful influence on theories and practices of warfare as technological developments and their incorporation into military activity continue apace. And regardless of the particulars of future sciences and technologies, perhaps the only certainty we may have is that any future regime of warfare will necessarily mark another chapter in the continually renewed yet never settled quest for order on the battlefield. 


\section{Bibliography}

Alberts, David S. \& Czerwinski, Thomas J. (eds.), Complexity, Global Politics, and National Security (Washington, DC: National Defense University, 1997).

http://www.dodccrp.org/publications/pdf/Alberts_Complexity_Global.pdf

Alberts, David S., Garstka, John J. \& Stein, Frederick P., Network-Centric Warfare:

Developing and Leveraging Information Superiority, 2nd ed. (Department of Defense CCRP, 2000). http://www.dodccrp.org/publications/pdf/Alberts_NCW.pdf

Alberts, David S., Garstka, John J., Hayes, Richard E. \& Signorip, David A.,

Understanding Information Age Warfare (CCRP Publications, 2001).

http://www.dodccrp.org/publications/pdf/Alberts_ULAW.pdf

Alberts, David S. \& Hayes, Richard E., Power to the Edge - Command... Control... in the

Information Age (Department of Defense CCRP, 2003).

Arquilla, John \& Ronfeldt, David, "Information, Pówer, and Grand Strategy: In

Athena's Camp" in Stuart J.D. Schwartzstein (ed.), The Information Revolution and

National Security (Washington, DC: The Center for Strategic and International

Studies, 1996).

-- (eds.), In Athena's Camp: Preparing for Conflict in the Information Age (RAND, 1997).

--, Swarming and the Future of Conflict (RAND Corporation, 2000).

http://www.rand.org/pubs/documented_briefings/2005/RAND_DB311.pdf

Atkinson, Simon Ray \& Moffat, James, The Agile Organization: From Informal Networks to

Complex Effects and Agility (Department of Defense CCRP, 2005).

http://www.dodccrp.org/publications/pdf/Atkinson_Agile.pdf

Atlan, Henri, L'Organisation Biologique et la Théorie de l'Information (Paris: Editions du Seuil, 2006).

Baeyer, Hans Christian von, Information: The New Language of Science (London: Weidenfeld \& Nicolson, 2003).

Barnett, Thomas P.M., "The Seven Deadly Sins of Network-Centric Warfare",

Proceedings, U.S. Naval Institute, January 1999, pp.36-39.

http://www.thomaspmbarnett.com/published/7d.htm

Bar-Yam, Yaneer, "Complexity of Military Conflict: Multiscale Complex Systems

Analysis of Littoral Warfare”, New England Complex Systems Institute, 2003.

http://necsi.org/projects/yaneer/SSG_NECSI_3_Litt.pdf

Bauman, Zygmunt, Liquid Modernity (Cambridge Polity, 2000). 
Beck, Ulrich, Risk Society: Towards a New Modernity (London: Sage Publications, 1992). Beckerman, Linda P., "The Non-Linear Dynamics of War", Science Applications International Corporation, 1999.

http://www.belisarius.com/modern_business_strategy/beckerman/non_linear. htm

Beech, Michael F., “Observing Al Qaeda Through the Lens of Complexity Theory: Recommendations for the National Strategy to Defeat Terrorism", Center for Strategic Leadership, U.S. Army War College, July 2004.

http://www.carlisle.army.mil/usacsl/Publications/S04-01.pdf

Beer, Stafford, "What Has Cybernetics to Do with Operational Research?", Operational Research Quarterly, Vol. 10, No. 1, 1959.

--, Cybernetics and Management - 2nd edition (London: English Universities Press, 1967).

Beniger, James, The Control Revolution: Technological and Economic Origins of the Information Society (Cambridge, MA: Harvard University Press, 1986).

Beyerchen, Alan D. "Clausewitz, Nonlinearity and the Unpredictability of War", International Security, 17:3 Winter, 1992.

http://www.clausewitz.com/CWZHOME/Beyerchen/

CWZandNonlinearity.htm

--, "Clausewitz, Nonlinearity, and the Importance of Imagery" in David S. Alberts and Thomas J. Czerwinski (eds.), Complexity, Global Politics, and National Security (Washington, DC: National Defense University, 1997). http://www.dodccrp.org/publications/pdf/Alberts_Complexity_Global.pdf Bien, David D., "Military Education in 18th Century France; Technical and NonTechnical Determinants" in Monte D. Wright \& Lawrence J. Paszek (eds.), Science, Tecbnology and Warfare: The Proceedings of the Third Military History Symposium - United Air Force Academy 8-9 May 1969.

Black, Jeremy, War. Past, Present, and Future (Stroud: Sutton, 2000).

--, Retbinking Military History (London: Routledge, 2004).

Black, Max, Models and Metaphors: Studies in Language and Philosopby (Ithaca, NY: Cornell University Press, 1962).

Bolter, David, Turing's Man: Western Culture in the Computer Age (London: Duckworth, 1984).

Boorstin, Daniel J., The Discoverers: A History of Man's Search to Know his World and Himself 
(Hamondsworth, Middlesex: Penguin, 1986).

Booss-Bavnbek, Bernhelm, "Mathematics and War" (Draft Essay for Hutchinson

Companion Encyclopedia of Mathematics, 2001).

http://mmf.ruc.dk/ booss/mathwar/bb_mathwar.htm

Bourke, Joanna, An Intimate History of Killing: Face-to-Face Killing in Twentieth-Century

Warfare (London: Granta, 2000).

Boyd, John R., "Destruction and Creation" (1976).

http://www.belisarius.com/modern_business_strategy/boyd/destruction/destr uction_and_creation.htm

--, "Patterns of Conflict" (Presentation, December 1986).

http://www.d-n-i.net/boyd/patterns.ppt

--, "Organic Design for Command and Control" (Briefing - May 1987).

http://www.d-n-i.net/boyd/pdf/c\&c.pdf

--, "The Essence of Winning and Losing" (Briefing, January 1996).

--, "The Conceptual Spiral" (unpublished briefing).

http://www.d-n-i.net/boyd/pdf/intro.pdf

Brey, Philip, "Theorising Modernity and Technology" in Thomas J. Misa, Philip Brey \& Andrew Feenberg (eds.), Modernity and Technology (Cambridge, MA: MIT Press, 2003).

Bryen, Stephen David, The Application of Cybernetic Analysis to the Study of International

Politics (The Hague: Martinus Nijhoff, 1971).

Bull, Hedley, The Anarchical Society: A Study of Order in World Politics (London: Macmillan, 1977).

Campbell, David, Crutchfield, Jim, Farmer, Doyne \& Jen, Erica, "Experimental

Mathematics: The Role of Computation in Nonlinear Studies", Communications of $A C M$ 28(4), 1.985, pp.374-384.

http://www.santafe.edu/ jdf/papers/experimentalmathematics.pdf

Campen, Alan D. \& Dearth, Douglas H., Cyberwar 3.0: Human Factors in Information

Operations and Future Conflicts (Fairfax, VA: AFCEA International Press, 2000).

Capra, Fritjof, The Web of Life: $A$ New Synthesis of Mind and Matter (London: Flamingo, 1997).

Capurro, Rafael, The Concept of Information (2003).

http://www.capurro.de/infoconcept.html

Cardwell, D.S.L., Turming Points in Western Technology: A Study of Technology, Science and 
History (New York: Neale Watson Academic Publications, 1974).

Carnot, Lazare, Essai sur les Machines en Général (1786).

http://math-doc.ujf-grenoble.fr/cgi-bin/oeitem?id=OE_CARNOT_1_R5_0

Carnot, Sadi, Reflections on the Motive Power of Fire and on Machines Fitted to Develop that Power

(1824). http://www.history.rochester.edu/steam/carnot/1943/

Castells, Manuel, The Internet Galaxy (Oxford, New York: Oxford University Press, 2001).

Castells, Manuel, The Rise of the Network Society - 2nd ed. (Cambridge, MA; Oxford, UK: Blackwell, 2000).

Cebrowski, Arthur K. \& Garstka, John J., "Network-Centric Warfare: Its Origin and Future", Proceedings, U.S. Naval Institute, January 1998.

http://www.usni.org/Proceedings/Articles98/PROcebrowski.htm

Clausewitz, Carl von, On War, trans. Michael Howard and Peter Paret (Princeton, NJ: Princeton University Press, 1984).

--, On War, trans. J.J Graham (Hertfordshire: Wordsworth, 1997).

Coker, Christopher, The Future of War. The Re-Enchantment of War in the Twenty-First

Century (Oxford: Blackwell Publishing., 2004).

Colburn, Timothy R., Pbilosophy and Computer Science (Armont, NY \& London: M.E.

Sharpe, 2000).

Creveld, Martin van, Command in War (Cambridge, MA \& London: Harvard University Press, 2003).

Creveld, Martin van, Technology and War. From 2000 B.C. to the Present (New York: Free Press, 1989).

Cummings, Nigel, "How the World of OR Societies Began" (The OR Society). http://www.orsoc.org.uk/orshop/(awaqdrfkrmznlwneegwigdqi)/orcontent.asp $\mathbf{x}$ ?inc $=$ article_news_orclub.htm

Dale, Rodney, Timekeeping (London: The British Library, 1992).

Davis, Norman C., "An Information-Based Revolution in Military Affairs" in John Arquilla \& David Ronfeldt (eds.), In Athena's Camp: Preparing for Conflict in the Information Age (RAND, 1997).

De Landa, Manuel, War in the Age of Intelligent Machines (New York: Swerve Editions, 1991).

--, A Thousand Years of Non-Linear History (New York: Swerve Editions, 2003).

De Pauw, Linda Grant, Battle Cries and Lullabies: Women in War from Prehistory to the Present 
(Norman: University of Oklahoma Press, 1998).

Dechert, Charles R., The Social Impact of Cybernetics (Notre Dame, ID: University of Notre Dame, 1966).

Deleuze, Gilles \& Guattari, Felix, $A$ Thousand Plateaus (London \& New York:

Continuum, 2003).

Deleuze, Gilles, Foucault (Paris: Les Editions de Minuit, 1986).

Demenÿ, Georges, Les Bases Scientifiques de l'Education Pbysique (Paris: Alcan, 1902).

Deutsch, Karl, The Nerves of Government (New York, NY: The Free Press, 1963)

Duffy, Christopher, The Army of Frederick the Great (Vancouver: David \& Charles, 1974).

Easton, David, A Systems Analysis of Political Life (New York, NY: John Wiley \& Sons, 1965).

--, A Framework for Political Analysis (Chicago, IL \& London: University of Chicago Press, 1979)

Edwards, Paul N., "The Closed World: Systems Discourse, Military Policy and PostWorld War II US Historical Consciousness" in Les Levidow \& Kevin Robins (eds.), Cyborg Worlds: The Military Information Society (London: Free Association Books, 1989).

-, "From 'Impact' to Social Process: Computers in Society and Culture" in Sheila Jasanoff et al. (eds.), Handbook of Science and Technology Studies (Beverly Hills, CA: Sage Publications, 1994). http://www.si.umich.edu/ pne/PDF/impact.pdf --, "Cyberpunks in Cyberspace: The Politics of Subjectivity in the Computer Age" in Susan Leigh Star, ed., Cultures of Computing (Keele, UK: Sociological Review and Monograph Series, 1995), pp. 69-84.

http://www.si.umich.edu/ pne/cyberpunks.htm

--, The Closed World: Computers and the Politics of Discourse in Cold War America (Cambridge, MA: MTT Press, 1996).

--, "Why Build Computers?" in Merritt Roe Smith \& Gregory K. Clancey (eds.), Major Problems in the History of American Technology: Documents and Essays (Boston: Houghton Mifflin, 1998).

Ellis, John, The Social History of the Machine Gun (Baltimore, MD: Johns Hopkins University Press, 1986).

Fortun, M. \& Schweber, SS., "Scientists and the Legacy of World War II: The Case of Operations Research (OR)", Social Studies of Science, Vol. 23, 1993.

Foucault, Michel, Surveiller et Punir (Paris: Editions Gallimard, 1975). 
--, Power/Knowledge (Hemel Hampstead, Herfordshire: Harvester Press, 1980).

--, Discipline and Punish (London: Penguin Books, 1991).

--, Foucault Live - Interviens 1961-1984 (edited by Sylvère Lotringer) (New York, NY:

Semiotext(e), 1996).

Franchi, Stefano, Güzeldere, Güven \& Minch, Eric, "Interview with.Heinz von

Foerster", Stanford Humanities Review, Volume 4, Issue 2, 1995.

http://www.stanford.edu/group/SHR/4-2/text/interviewvonf.html

Franklin, H. Bruce, War Stars: The Superweapon and the American Imagination (Oxford

University Press: New York, 1988).

French, David, The British Way in Warfare 1688-2000 (London: Unwin Hayman, 1990).

Freud, Sigmund, Civilisation and its Discontents (London: Penguin, 2004).

Fuller, J. F. C., The Foundations of the Science of War (1926).

http://cgsc.leavenworth.army.mil/carl/resources/csi/fuller2/fuller2.asp

Gaddis, John Lewis, Strategies of Containment: A Critical Appraisal of Postwar American

National Security Poligy (Oxford: Oxford University Press, 1982).

Gat, Azar. A History of Military Thought: From the Enlightenment to the Cold War (Oxford:

Oxford University Press, 2001).

Gell-Mann, Murray, The Quark and the Jaguar. Adventures in the Simple and the Complex

(London: Little Brown \& Company, 1994).

--, "Let's Call It Plectics", Complexity Joumal, Vol. 1/ No. 5 (1995/96).

http://www.santafe.edu/ mgm/plectics.pdf

Gerovitch, Slava, From Newspeak to Cyberspeak: $A$ History of Soviet Cybernetics (Cambridge,

MA \& London: MIT Press, 2002).

Ghamari-Tabrizi, Sharon, "U.S. Wargaming Grows Up: A Short History of the

Diffusion of Wargaming in the Armed Forces and Industry in the Postwar

Period up to 1964", StrategyPage.Com.

http://www.strategypage.com/articles/default.asp?target=Wgappen.htm

--, The Worlds of Herman Kabn: The Intuitive Science of Thermonuclear War (Cambridge,

MA: Harvard University Press, 2005).

Gibson, James, The Perfect War. Technowar in Vietnam (Boston, MA: Atlantic Monthly

Press, 1986).

Giddens, Anthony, The Consequences of Modernity (Cambridge: Polity in association with

Blackwell, 1990).

Gleick, James, Chaos: Making a New Science (London: Vintage, 1987). 
Gleyse, Jacques \& al., "Physical Education as a Subject in France (Shool Curriculum, Policies and Discourse): The Body and the Metaphors of the Engine - Elements Used in the Analysis of a Power and Control System during the Second Industrial Revolution", Sport, Education and Society 1, vol. 7 (2002), p.5-23. http://recherche.univ-montp3.fr/cerfee/article.php3?id_article=191

Goldstein, Joshua S., War and Gender. How Gender Shapes the War System and Vice Versa (Cambridge: Cambridge University Press, 2001).

Gray, Chris Hables (ed.), The Cyborg Handbook (New York: Routledge, 1995).

--, Postmodern War. The New Politics of Conflict (New York: The Guilford Press, 1997).

--, Peace, War, and Computers (New York: Routledge, 2005).

Gray, Colin S., Strategy for Chaos: Revolutions in Military Affairs and the Evidence of History (London: Frank Cass, 2002).

Hacker, Barton C., "Military Institutions, Weapons, and Social Change: Toward a New History of Military Technology", Technology and Culture, Vol. 35, No. 4. (Oct., 1994), pp. 768-834.

Hambling, David, Weapons Grade (London: Constable \& Robinson, 2005).

Hammond, Grant T., "The Essential Boyd" http://www.belisarius.com/modern_business_strategy/hammond/essential_bo yd.htm

Hanson, Victor Davis, Why the West Has Won: Nine Landmark Battles in the Brutal History of Western Victory (London: Faber, 2002).

Harris, Carl \& Gass, Saul (eds.), Encyclopaedia of Operations Research and Management Science (Kluwer Academic Publishers, 2000).

Harvey, David, The Condition of Postmodernity: An Enquiry into the Origins of Cultural Change (Oxford: Basil Blackwell, 1990).

Hayles, N. Katherine, Chaos Bound: Orderly Disorder in Contemporary Literature and Science (Ithaca \& London: Cornell University Press, 1990).

--, How We Became Posthuman: Virtual Bodies in Cybernetics, Literature, and Informatics

(Chicago \& London: University of Chicago Press, 1999).

--, "Liberal Subjectivity Imperilled: Norbert Wiener and Cybernetic Anxiety"

http://www.english.ucla.edu/faculty/hayles/wiener.htm

Heidegger, Martin, The Question Concerning Technology and Other Essays (Harper

Torchbooks, 1977).

Heim, Michael, The Metaphysics of Virtual Reality (New York : Oxford University Press, 
1993).

Heims, Steve J., John Von Neumann and Norbert Wiener. From Mathematics to the Technologies of Life and Death (Cambridge, MA \& London: MIT Press, 1980).

--, The Cybernetics Group (Cambridge, MA: MIT Press, 1991).

Herken, Gregg, Counsels of War (New York, NY: Alfred A. Knopf, 1985).

Heuser, Beatrice, Reading Clausewritz (London: Pimlico, 2002).

Heylighen, Francis, “Complex Adaptive Systems” (Principia Cybernetica Web, 1996). http://pespmc1.vub.ac.be/CAS.html

Heylighen, Francis \& Joslyn, Cliff, "Cybernetics and Second-Order Cybernetics" in R.A. Meyers (ed.), Encyclopedia of Physical Science \& Technology - 3rd ed. (New York: Academic Press, 2001) http://pespmc1.vub.ac.be/Papers/Cybernetics-EPST.pdf

Hobbes, Thomas, Leviathan (1651). http://www.gutenberg.org/dirs/etext02/lvthn10.txt Holland, John H., Adaptation in Natural and Artificial Systems (Cambridge, MA: MIT Press, 1995).

Holley Jr., I.B., "The Evolution of Operations Research and the Impact on the Military Establishment; The Air Force Experience" in Monte D. Wright \& Lawrence J. Paszek (eds.), Science, Technology and Warfare: The Proceedings of the Third Military History Symposium - United Air Force Academy 8-9 May 1969.

Horgan, John, The End of Science: Facing the Limits of Knowledge in the Twilight of the Scientific Age (London: Abacus, 2002).

Ilachinski, Andrew, Land Warfare and Complexity - Part I: Mathematical Background and Tecbnical Sourcebook (Alexandria, VA: Center for Naval Analyses, July 1996) http://www.cna.org/isaac/lwpart2.pdf

James, Glenn E., "Chaos Theory: The Essentials for Military Applications" (Naval War College, Newport, Rhode Island, Center for Naval Warfare Studies, Newport Paper Number Ten, October 1996).

http://www.nwc.navy.mil/press/npapers/np10/np10.pdf

Jameson, Frederic, Postmodernism or The Cultural Logic of Late Capitalism (London: Verso, 1991).

Jenner, R A., "Dissipative Enterprises, Chaos, and the Principles of Lean Organizations", Omega: The International Journal of Management Science, Vol. 26, No. 4, December, 1998.

Jünger, Ernst, Der Kampf als Inneres Erlebnis (1922). 
http://mitglied.lycos.de/nordolf/Ernst $\% 200 \%$ fcnger $\% 20$ -

$\% 20$ Der $\% 20$ Kampf $\% 20$ als $\% 20$ inneres $\% 20$ Erlebnis.doc

--, Feuer und Bewegung (1930).

--, Sämtliche Werke, vol. I-IX (Stuttgart, 1980).

Kaplan, Fred, The Wizards of Armageddon (New York: Simon \& Schuster, 1984).

Katch, Frank, “Antoine Laurent Lavoisier (1743-1794)” (Sportscience, 1998).

http://www.sportsci.org/news/history/lavoisier/lavoisier.html

Kay, Lily E., Who Wrote the Book of Life? A History of the Genetic Code (Stanford, CA:

Stanford University Press, 2000)

Keegan, John, The Face of Battle (London: Cape, 1976).

--, A History of Warfare (London: Pimlico, 2004).

Kelly, Kevin, Out of Control: The New Biology of Machines (Reading, Berks, UK: Cox \&

Wyman, 1994).

King, Ian T., Social Science and Complexity: The Scientific Foundations (Huntington, NY: Nova Science Publishers, 2000).

King, James, Science and Rationalism in the Government of Louis XIV (Baltimore, MD: John

Hopkins Press, 1949).

Kissinger, Henry, Agenda for a Nation (Washington, DC: The Brookings Institution, 1968).

Klein, Gary, Sources of Power. How People Make Decisions (Cambridge, MA: MIT Press, 1998).

Koestler, Arthur, The Sleepwalkers (London: Arkana Books, 1989).

Kolenda, Christopher D., "Transforming How We Fight - A Conceptual Approach", Naval War College Review, Spring 2003, Vol. LVI, No. 2.

http://www.nwc.navy.mil/press/Review/2003/Spring/art6-sp3.htm

Kranzberg, Melvin, "Science-Technology and Warfare: Action, Reaction, and

Interaction in the Post-World War II Era" in Monte D. Wright \& Lawrence J.

Paszek (eds.), Science, Technology and Warfare: The Proceedings of the Third Military

History Symposium - United Air Force Academy 8-9 May 1969.

Kuhn, Thomas S., The Structure of Scientific Revolutions - 3rd ed. (Chicago, IL: University of Chicago Press, 1996).

La Mettrie, Julien Offray de, L'Homme Machine (1748). .

http://cscs.umich.edu/ crshalizi/LaMettrie/Machine

Lafontaine, Céline, L'Empire Cybernétique - Des Machines à Penser à la Pensée Macbine (Paris: 
Editions du Seuil, 2004).

Lakoff, George \& Johnson, Mark, Metaphors We Live By (Chicago, IL: University of

Chicago Press, 1990).

Landes, David, Revolution in Time: Clocks and the Making of the Modern World (Cambridge,

MA: Harvard University Press, 1983).

Laplace, Pierre Simon de, "Theorie. Analytique des Probabilités", Oeuvres Completes de

Laplace, Volume VII (Paris: Gauthier-Villars, 1820).

Laudan, Rachel (ed.), The Nature of Technological Knowledge: Are Models of Scientific Change

Relevant? (Dordrecht, Holland: D. Reidiel Publishing, 1984).

Lawrence, Philip K., Modernity and War. The Creed of Absolute Violence (Houndmills,

Basingstoke: Macmillan, 1997)

Lechte, John, Key Contemporary Concepts: From Abjection to Zeno's Paradox (London: Sage, 2003).

Leiner, Barry M., Cerf, Vinton G., Clark, David D., Kahn, Robert E., Kleinrock, Leonard, Lynch, Daniel C., Postel, Jon, Roberts, Larry G. \& Wolff, Stephen, “A

Brief History of the Internet" (The Internet Society, 2003).

http://www.isoc.org/internet/history/brief.shtml

Levidow, Les \& Robins, Kevin (eds.), Cyborg Worlds: The Military Information Society

(London: Free Association Books, 1989).

Light, Jennifer S., From Warfare to Welfare: Defense Intellectuals and Urban Problems in Cold

War America (Baltimore, MD \& London: John Hopkins University Press, 2003).

Lynn, John A., "The Treatment of Military Subjects in Diderot's Encyclopédie", The

Journal of Military History, Vol. 65, No. 1. Jan., 2001), pp. 131-165.

Lynn, John A., Battle: A History of Combat and Culture (Boulder, CO: Westview Press, 2003).

Macy, Samuel, Clocks and the Cosmos: Time in Western Life and Thought (Hamden, CT:

Archon Books, 1980).

Mandelbrot, Benoit B. \& Hudson, Richard L, The (Mis)Behaviour of Markets: A Fractal

View of Risk, Ruin and Reward (London: Profile Books, 2004).

Marion, Russ \& Uhl-Bien, Mary, "Complexity Theory and Al-Qaeda: Examining

Complex Leadership", Presentation given at Managing the Complex IV: A

Conference on Complex Systems and the Management of Organizations, Fort

Meyers, FL, December, 2002. http://isce.edu/ISCE_Group_Site/web- 
content/ISCE\%20Events/Naples_2002/Naples_2002_Papers/Marion_UhlBien.pdf

Martin, James \& Norman, Adrian R.D., The Computerised Society (Harmondsworth, Middlesex: Penguin Books, 1973).

Maturana, Humberto \& Varela, Francisco, "Autopoiesis and Cognition: the Realization of the Living" in Robert S. Cohen and Marx W. Wartofsky (eds.), Boston Studies in the Philosopby of Science 42 (Dordecht: D. Reidel Publishing Co, 1980)

Mayr, Otto, Authority, Liberty of Automatic Machinery in Early Modern Europe (Baltimore, MD \& London: John Hopkins University Press, 1986).

McFarren, Tamara E., "Persistent Surveillance", Military Geospatial Technology, Volume 2, Issue 3, September 28, 2004.

http://www.military-geospatial-technology.com/article.cfm?DocID $=631$

McNeill, William H., The Pursuit of Power. Technology, Armed Force, and Society since A.D. 1000 (Chicago: University of Chicago Press, 1982).

--, "The Structure of Military-Technical Transformation" (USAFA Harmon Memorial Lecture \#37, 1994). http://www.usafa.af.mil/df/dfh/docs/Harmon37.doc

McNeilly, Mark R., Sun Tzu and the Art of Business: Six Strategic Principles for Managers (Oxford University Press Inc, 2000).

Mershon, Sherie \& Schlossman, Steven, Foxholes and Color Lines: Desegregating the U.S. Armed Forces (Baltimore, MD: Johns Hopkins University Press, 1998).

Michaelson, Gerald A., Sun Tzu: The Art of War for Managers - 50 Strategic Rules (Adams Media Corporation, 2001).

Misa, Thomas J., Brey, Philip \& Feenberg, Andrew (eds.), Modernity and Technology (Cambridge, MA: MIT Press, 2003).

Moffat, James, Complexity and Network-Centric Warfare (CCRP Publications, 2003). http://www.dodccrp.org/publications/pdf/Moffat_Complexity.pdf

Mustin, Jeff, "Flesh and Blood: The Call for the Pilot in the Cockpit", Air \& Space Power Journal - Chronicles Online Journal, July 2001.

http://www.airpower.maxwell.af.mil/airchronicles/cc/mustin.html

Myers, Richard B., "Understanding Transformation”, Proceedings, U.S. Naval Institute, February 2003.

Nicholls, David \& Tagarev, Todor, "What Does Chaos Theory Mean for Warfare?”, 
Aerospace Power Journal, Fall 1994.

http://www.airpower.maxwell.af.mil/airchronicles/apj/apj94/nichols.html

Nicolis, Gregoire \& Prigogine, Ilya, Exploring Complexity (New York: W.H Freeman, 1989).

Nietzsche, Friedrich, The Genealogy of Moral, II 12 (Dover Publications, 2003).

O'Hanlon, Michael, Technological Change and the Future of Warfare (Washington, DC:

Brookings Institution Press, 2000).

Ott, Edward, Grebogi, Celso \& Yorke, James A., "Controlling Chaos", Physical Review Letters 64, 1990, pp.1196-1199.

Owens, William A. \& Offley, Edward, Lifting the Fog of War (Baltimore, MD: John Hopkins University Press, 2000).

Pacey, Arnold, Technology in World Civilization (Oxford: Basil Blackwell, 1990).

Panel on Mathematics (Nonlinear Science and the Navy), Naval Studies Board, Commission on Physical Sciences, Mathematics, and Applications, National Research Council, "Nonlinear Science" (Washington DC: National Academy Press, 1997).

Pick, Daniel. War Macbine: The Rationalisation of Slaughter in the Modern Age (New Haven, CT: Yale University Press, 1993).

Price, Derek J. De Solla, 'Notes Towards a Philosophy of the Science/Technology Interaction" in Rachel Laudan (ed.), The Nature of Technological Knowledge: Are Models of Scientific Change Relevant? (Dordrecht, Holland: D. Reidiel Publishing, 1984).

Prigogine, Ilya \& Stengers, Isabelle, Order out of Chaos: Man's New Dialogue with Nature

(Fontana: London, 1985).

RAND Corporation, "A Brief History of RAND"

http://www.rand.org/about/history/

--, "Preliminary Design of an Experimental World-Circling Spaceship" (1946).

http://www.rand.org/pubs/special_memoranda/2006/SM11827part1.pdf

Robbins, Richard H., The Belief Machine (1985).

http://faculty.plattsburgh.edu/richard.robbins/Belief/belief-machine.htm

Rochlin, ,Gene I., Trapped in the Net. The Unanticipated Consequences of Computerization

(Princeton, NJ: Princeton University Press, 1997).

Rogers, John, The Matter of Revolution: Science, Poetry, and Politics in the Age of Milton (Ithaca,

NY \& London: Cornell University Press, 1996). 
Roland, Alex, "Science, Technology, and War", Technology and Culture, Vol. 36, No. 2, Supplement: Snapshots of a Discipline: Selected Proceedings from the Conference on Critical Problems and Research Frontiers in the History of Technology, Madison, Wisconsin, October 30-November 3, 1991 (Apr. 1995). Roman, Gregory A., "The Command or Control Dilemma: When Technology and Organizational Orientation Collide" (Maxwell AFB, Alabama: Air University Press, February 1997). http://csat.au.af.mil/2025/volume1/vol1ch04.pdf Sageman, Mark, Understanding Terror Networks (Philadelphia, PA: University of Pennsylvania Press, 2004).

Schon, Donald A., Displacement of Concepts (London: Tavistock Publications, 1963).

Schrödinger, Erwin, What is Life? And Other Scientific Essays (Garden City, NY:

Doubleday Anchor, 1956).

Schwartzstein, Stuart J.D. (ed.), The Information Revolution and National Security

(Washington, DC: The Center for Strategic and International Studies, 1996).

Serres, Michel, Hermes III: La Traduction (Paris: Les Editions de Minuit, 1974).

Serres, Michel, Hermes: Literature, Science, and Philosophy (Baltimore, MD: John Hopkins

University, 1983).

Shannon, Claude E., "A Mathematical Theory of Communication", Bell System Technical Journal, Vol. 27, 1948.

http://cm.bell-labs.com/cm/ms/what/shannonday/shannon1948.pdf

Showalter, Dennis, The Wars of the Frederick the Great (London \& New York:

Addison Wesley Longman, 1997).

Shy, John, "Commentary on Western Military Education 1700-1850" in Monte D.

Wright \& Lawrence J. Paszek (eds.), Science, Technology and Warfare: The Proceedings of the Third Military History Symposium - United Air Force Academy 8-9 May 1969. Siegfried, Tom, The Bit and the Pendulum: From Quantum Computing to M Theory - The New Physics of Information (New York: John Wiley \& Sons).

Smith, Crosbie, The Science of Energy: A Cultural History of Energy Physics in Victorian Britain (London: Athlone, 1998).

Smith, Merritt Roe \& Clancey, Gregory K. (eds.), Major Problems in the History of American Technology: Documents and Essays (Boston: Houghton Mifflin, 1998).

Spinney, Chuck, “Genghis John”, Proceedings, U. S. Naval Institute, July 1997.

http://www.d-n-i.net/fcs/comments/c199.htm

--, “Asleep at the Switch in Versailles... or ... Why Nonlinear Realities Overwhelm 
Linear Visions ... or ... Why did Slobo Cave?" (Defense and the National

Interest, September 6, 1999). http://www.d-n-i.net/fcs/comments/c317.htm

--, “Is America Inside Its Own OODA Loop?” (Defense and the National Interest,

January 26, 2005). http://www.d-n-i.net/fcs/comments/c536.htm

Steele, Brett D., "Muskets and Pendulums: Benjamin Robins, Leonhard Euler, and the

Ballistics Revolution", Technology and Culture, Vol. 35, No. 2. (Apr. 1994), pp. 348382.

Taylor, Mark C., The Moment of Complexity - Emerging Network Culture (Chicago, IL:

University of Chicago Press, 2001).

Thurston, Robert, $A$ History of the Growth of the Steam-Engine (New York: Appleton, 1878).

http://www.history.rochester.edu/steam/thurston/1878/

Toffler, Alvin, The Third Wave (London: Collins, 1980).

Toffler, Alvin \& Heidi, War and Anti-War. Survival at the Dawn of the 21st Century (Boston,

MA \& London: Little, Brown \& Company, 1993).

Urry, John, Global Complexity (Cambridge: Polity, 2003).

Vego, Milan, "Net-Centric Is Not Decisive”, Proceedings, U.S. Naval Institute, January

2003. http://www.usni.org/proceedings/articles03/provego01.htm

Virilio, Paul, Speed and Politics: An Essay on Dromology (New York: Semiotext(e), 1986).

--, The Lost Dimension (NewYork: Semiotext(e), 1991).

Waldrop, M. Mitchell, Complexity: The Emerging Science at the Edge of Order and Chaos

(London: Viking, 1992).

Watts, Barry D., "Clausewitzian Friction and Future War" (McNair Paper Number 52,

October 1996). http://www.ndu.edu/inss/McNair/mcnair52/m52c11.html

Weber, Eugen J., Peasants into Frenchmen: The Modernisation of Rural France, 1870-1914

(Stanford, CA: Stanford University Press, 1976).

Weigley, Russell F., The American Way of War: A History of the United States Military Strategy

and Policy (Bloomington, IN: Indiana University Press, 1973).

Wertheim, Margaret, The Pearly Gates of Cyberspace: $A$ History of Space from Dante to the Internet (New York: W.W. Norton, 1999).

Wiener, Norbert, Cybernetics or Control and Communications in the Animal and the Macbine

(New York: Wiley, 1949).

--, The Human Use of Human Beings: Cybernetics and Society (London: Eyre and

Spottiswoode, 1954).

--, God and Golem, Inc: A Comment on Certain Points Where Cybernetics Impinges on Religion 
(Cambridge, MA: MTT Press, 1964).

Wiener, Norbert \& Rosenbluth, Arturo, "Purposeful and Non-Purposeful Behaviour", Philosopby of Science 17, Oct 1950.

Winner, Langdon, The Whale and the Reactor. A Search for Limits in an Age of High Technology

(Chicago, IL \& London: University of Chicago Press, 1986).

Winter, Jay M., Sites of Memory, Sites of Mourning: The Great War in European Cultural History (Cambridge: Cambridge University Press, 1995).

Wohlstetter, Albert, “The Delicate Balance of Terror" (1958).

http://www.rand.org/publications/classics/wohlstetter/P1472/P1472.html

Wright, Monte D. \& Paszek, Lawrence J. (eds.), Science, Technology and Warfare: The

Proceedings of the Third Military History Symposium - United Air Force Academy 8-9 May 1969. 


\section{Speeches/Press Releases/Policy \& Doctrinal Documents}

Bush, George W., State of the Union Address, January 20, 2004.

http://www.whitehouse.gov/news/releases/2004/01/20040120-7.html

Cebrowski, Arthur, Speech to Network-Centric Warfare Conference, January 22, 2003. http://www.oft.osd.mil/library/library_files/speech_143_CEBROWSKI\%20S PEECH\%20TO\%20NETWORK\%20CENTRIC\%20WARFARE\%20CONFE RENCE.doc

Department of the Army Pamphlet 600-3-49, "Operations Research/Systems Analysis" (Washington, DC: Department of the Army, 1987) http://www.army.mil/usapa/epubs/pdf/p600_3_49.pdf

Eisenhower, Dwight, Farewell Address to the People, January 17, 1961.

Information Awareness Office, "BAA 02-08 - Information Awareness Proposer Information Pamphlet." http://infowar.net/tia/www.darpa.mil/iao/BAA02-08.pdf

Owens, William A., Statement to the U.S. Senate, February 12, 2001. http://budget.senate.gov/democratic/testimony/2001/owens_defhrng021201. pdf

Substitution for the Testimony of Sheik Khaled Mohammed. http://news.bbc.co.uk/1/shared/bsp/hi/pdfs/06_04_06_testimony.pdf

United States Marine Corps, FMFM1: Warfighting, 1989.

http://www.clausewitz.com/CWZHOME/Warfit1.htm --, MCDP 6: Command and Control, 1996.

http://www.dtic.mil/doctrine/jel/service_pubs/mcdp6.pdf

Westmoreland, William, Address to the Association of the U.S. Army, October 14, 1969.

http://216.239.59.104/search?q=cache:Kw2tmkrW5lgJ:www.stanford.edu/grou $\mathrm{p} / \mathrm{mmdd} /$ SiliconValley/Westmoreland/westmoreland.rtf

\section{News Stories}

Barry, John \& Thomas, Evan, "The Kosovo Cover-Up”, Newsweek, May 15, 2000. http://www.medill.northwestern.edu/whca/2001poe2.html 
Cloud, David S. \& Mazzetti, Mark, “Senate Panel Approves Defense Nominee”, Nen York Times, December 5, 2006.

http://www.nytimes.com/2006/12/05/washington/06gatescnd.html?ex=13229 74800\&en $=7$ fce77a91 bdcc4e $0 \&$ ei $=5088$ partner $=$ rssnyt\&emc $=$ rss

French, Matthew, "Cebrowski sees Transformation Change”, FCW.com, January 23, 2004.

http://www.fcw.com/fcw/articles/2004/0119/web-cebrowski-01-23-04.asp

Harris, Shane, "Total Information Awareness Official responds to Criticism",

GoExec.com, January 31, 2003.

http://www.govexec.com/dailyfed/0103/013103h1.htm

MSNBC, "Madrid bombing probe finds no al-Qaida link", March 9, 2006.

http://www.msnbc.msn.com/id/11753547/from/RL.1/

Ricks, Thomas E., "Beaming the Battlefield Home: Live Video of Afghan Fighting Had

Questionable Effect", Washington Post, 26 March 2002.

Strassman, Paul A., "Taking a Bite Out of Overhead", Baseline Magazine, May 2005.

http://www.strassmann.com/pubs/baseline/2005-05-a.pdf

Townsend, Mark, "Leak reveals official story of London bombings", Observer, April 9, 2006. http://politics.guardian.co.uk/labour/story/0,1750264,00.html

Weiner, Tim, "A 'God's-Eye View' of the Battlefield”, The New York Times, November $20,2004$.

\section{Websites}

American Society for Cybernetics: $\underline{\text { http: } / / w w w . a s c-c y b e r n e t i c s . o r g / ~}$

Defense and the National Interest: $\underline{h t p}: / /$ www.d-n-i.net/

Federation of American Scientists: http://www. fas.org/

Information Awareness Office, DARPA: http://web.archive.org/web/20021017111910/http://www.darpa.mil/iao/

Information Warfare Site: http://www.iwar.org.uk/

Principia Cybernetica Web: http://pespmc1.vub.ac.be/

U.S. Department of Defense: http://www.defenselink.mil/ 